Márcio Borges Ferreira

\title{
Caracterização da Água Modal Subtropical na região da Confluência Brasil-Malvinas
}

Tese apresentada ao Instituto Oceanográfico da Universidade de São Paulo, como parte dos requisitos para obtenção do título de Doutor em Ciências, área de Oceanografia Física.

Orientadora:

Profa. Dra. Olga Tiemi Sato

São Paulo

2016 


\title{
UNIVERSIDADE DE SÃO PAULO INSTITUTO OCEANOGRÁFICO
}

\section{Caracterização da Água Modal Subtropical na região da Confluência Brasil-Malvinas}

\author{
Márcio Borges Ferreira
}

Tese apresentada ao Instituto Oceanográfico da Universidade de São Paulo, como parte dos requisitos para obtenção do título de Doutor em Ciências, área de Oceanografia Física.

Julgada em

Profa. Dra.

Conceito

Prof. Dr.

Conceito

Prof. Dr.

Conceito

Prof. Dr.

Conceito

Prof. Dr.

Conceito 
"Concedei-me Senhor a serenidade para que eu possa aceitar as coisas que não posso modificar, coragem para modificar as que posso, e sabedoria para distinguir umas das outras."

Reinhold Niebuhr 


\section{Sumário}

Agradecimentos $\quad$ iii

Resumo vii

\begin{tabular}{ll}
\hline Abstract & ix
\end{tabular}

Lista de Siglas e Acrônimos $\quad$ xi

Lista de Figuras $\quad$ xiv

\begin{tabular}{ll}
\hline Lista de Tabelas & xx \\
\hline
\end{tabular}

\begin{tabular}{lll}
\hline & Introdução & 1
\end{tabular}

1.1 Preâmbulo . . . . . . . . . . . . . . . . . . . . . 1

1.2 Síntese da Literatura $\ldots \ldots \ldots$. . . . . . . . . . . . . . . . 3

1.2.1 Confluência Brasil-Malvinas (CBM) . . . . . . . . . . . . . 3

1.2.2 Água Modal Subtropical . . . . . . . . . . . . . . . . . . . . 9

1.2.3 Água Modal Subtropical do Atlântico Sul (AMSTAS) . . . . . . . 23

1.3 Objetivos . . . . . . . . . . . . . . . . . . . . 28

1.3 .1 Hipótese . . . . . . . . . . . . . . . . . . . . . 28

1.3 .2 Objetivos Específicos . . . . . . . . . . . . . . . . 28

2 Conjunto de Dados 31

2.1 Preâmbulo . . . . . . . . . . . . . . . . . . . . . . . . . 31

2.2 Dados Hidrográficos In Situ . . . . . . . . . . . . . . . . . . 32

2.3 Dados de Modelos Numéricos . . . . . . . . . . . . . . . . . . . . 34

2.4 Dados Altimétricos $\ldots \ldots \ldots$. . . . . . . . . . . . . . . . 39 
\begin{tabular}{lll}
\hline & Metodologia & 41
\end{tabular}

3.1 Preâmbulo . . . . . . . . . . . . . . . . . . . . . . . . 41

3.2 Dados de Hidrografia . . . . . . . . . . . . . . . . . . . 42

3.2.1 Tratamento Básico dos Dados de Hidrografia . . . . . . . . . . . . 42

3.2 .2 Interpolação dos Dados Hidrográficos . . . . . . . . . . . . . . 43

3.2.3 Cálculo da Velocidade Geostrófica para Dados In Situ . . . . . . . 43

3.2 .4 Função de Corrente Geostrófica . . . . . . . . . . . . . . . . . . . . 45

3.3 Cálculo da Vorticidade Potencial . . . . . . . . . . . . . . . . . . 47

3.4 Deteç̧ão da AMSTAS . . . . . . . . . . . . . . . . . 50

3.4 .1 Dados In Situ . . . . . . . . . . . . . . . . . . . . . 50

3.4 .2 Dados de Modelo Numérico . . . . . . . . . . . . . . . . 50

3.5 Cálculo de Volume . . . . . . . . . . . . . . . . . . . . . . . 51

3.6 Cálculo do Calor Armazenado . . . . . . . . . . . . . . . . . 52

\begin{tabular}{|lll}
\hline 4 & Resultados e Discussão & 55
\end{tabular}

4.1 Preâmbulo . . . . . . . . . . . . . . . . . . . . . . . . . 55

4.2 Estudo da AMSTAS por meio de Dados In Situ . . . . . . . . . . . . 56

4.2 .1 Dados de CTD . . . . . . . . . . . . . . . . 56

4.2 .2 Dinâmica na área da OCSUL . . . . . . . . . . . . . . . 63

4.2 .3 Dados de perfiladores Argo . . . . . . . . . . . . . . . 65

4.3 Estudo dos Dados de Modelos Numéricos . . . . . . . . . . . . . . . 68

4.3 .1 HYCOM-SAMOC . . . . . . . . . . . . . . . . . . . . . 69

4.3 .2 HYCOM $1 \ldots \ldots \ldots \ldots \ldots$

$4.3 .3 \quad \mathrm{HYCOM} 2 \ldots \ldots \ldots \ldots \ldots \ldots$

4.3 .4 Calor Armazenado . . . . . . . . . . . . . . . . . . . 83

4.4 Estudo dos Dados de Altímetro . . . . . . . . . . . . . . . . . . . . . 92

\begin{tabular}{|lll}
5 & Considerações Finais & 98
\end{tabular}

5.1 Síntese e Conclusões . . . . . . . . . . . . . . . . . . . . . . . 98

5.2 Sugestões para Trabalhos Futuros . . . . . . . . . . . . . . . . . . 101

\begin{tabular}{ll}
\hline Referências Bibliográficas & 103
\end{tabular} 


\section{Agradecimentos}

"Ó Senhor dos Exércitos, feliz o homem que em ti confia."

Desde minha formatura na Escola Naval, quando recebi das carinhosas mãos de minha mãe uma placa de metal contendo estes dizeres como homenagem pela grande conquista, o Salmo 84:12 se tornou o norte da minha vida profissional. Após esse árduo período de luta, quando mais do que nunca confiei em ti, agradeço Senhor Deus por me manter firme e perseverante. E também por todas as amizades eternas que angariei ao longo desse curso.

À Marinha do Brasil (MB) pela confiança em mim depositada e pela oportunidade de realizar um curso de tão alto nível de conhecimento, agradeço.

Não posso me furtar de agradecer ao Exmo. Sr. Vice-Almirante Glauco Castilho Dall'Antonia, Comandante do $8^{\circ}$ Distrito Naval, que em meio à tormenta particular que me assombrava fez os tempos de embarque retornarem a minha vida. Não obstante o mar encapelado e a borrasca, como líder e grande Comandante do Navio, indicou o rumo correto a seguir com serenidade e demonstrou extrema confiança no seu tripulante, asseverando o êxito desse trabalho mesmo com as incertezas provocadas pelo tempo exíguo que me restava.

Ao Exmo. Sr. Contra-Almirante Newton Calvoso Pinto Homem, agradeço por ser favorável à minha inscrição e pelo apoio constante e fraterna amizade desde as singraduras antárticas.

Aos senhores CMG (EN) Ricardo Santana Soares e CMG (EN) Jorge Luís da Cunha, Diretores do Centro de Coordenação de Estudos da Marinha em São Paulo, agradeço pela cordialidade e apoio irrestrito durante todo o curso. A presença de um órgão da MB no interior da USP constitui apoio logístico essencial ao andamento dos cursos de pós-graduação realizados por oficiais-alunos. 
Ao Sr. CMG Carlos Augusto Chaves Leal Silva, Diretor do Centro de Hidrografia da Marinha (CHM), agradeço pelo auxílio e compreensão principalmente ao final do curso, concedendo o período de férias que viabilizou a conclusão da Tese apesar da necessidade imediata de pessoal para guarnecer a Divisão de Oceanografia Operacional do CHM.

A minha orientadora, Profa. Dra. Olga Tiemi Sato, por me aceitar como aluno e por todo o conhecimento e experiência transmitidos, paciência e compreensão, sem os quais eu seria incapaz de chegar ao fim dessa longa jornada. Serei eternamente grato pelos momentos em que a senhora e o Prof. Polito, meu eterno Mestre, me ampararam quando a saudade da minha família me assolava.

A minha mãe Vera, agradeço por seu silencioso exemplo de resiliência: Missão cumprida!! A senhora sempre acreditou nesse sonho muito mais do que o sonhador. Seu soldado conseguiu, minha mãe!! Dedico essa conquista à senhora!

A meu pai Aloisio, agradeço por seu exemplo, sua nobreza, bondade e apoio constante em mais essa empreitada. Seu desprendimento me faz acreditar que sempre podemos ser bondosos, não importa a situação ou pessoas que estão a nossa volta.

A minha irmã Aline pelos constantes exemplos de perseverança e apoio inconteste. Obrigado por ter sempre acreditado que eu chegaria até aqui, quando eu mesmo duvidava que seria possível. Obrigado também ao meu cunhado Márcio Castellões e ao pequeno João Pedro por trazerem mais alegria e carinho para nossa família.

A minha Amandinha agradeço pelo amor, paciência e compreensão durante todos os momentos difíceis. Sei o quanto foi difícil para você estar sempre distante da família, dos amigos e, ao final, de mim mesmo. Sua abnegação foi fundamental para que eu pudesse prosseguir lutando. Farei sempre o impossível para torná-la cada vez mais feliz. A partir de agora, estaremos sempre juntos e felizes. Com nosso "molequito" grudado, é claro!

Arthurzinho, meu "amigãozão": você é dono do sorriso do papai! Obrigado por me ensinar a todo instante que existe amanhã.

Queridos sogros Iza e Alziro, agradeço por todo amor e carinho que dedicam aos meus tesouros durante meus longos períodos de ausência. Que Deus os conserve plenos de saúde sempre. 
Aos amigos CF Felipe Santos e CF Toledo pela confiança e amizade irretocáveis e por envidarem todos os esforços para que o cruzeiro oceanográfico fosse realizado por completo. Aos amigos da REMO: CMG Alvarenga, Dra. Raquel Mello, Victor Daher e CF Reinert por todo sacrifício e prontidão para que o modelo HYCOM 1 funcionasse mesmo com escassos recursos computacionais e pelos dados de altímetro do Projeto ATOBA. Aos CMG Santos (NHo "Cruzeiro do Sul") e CMG Vinícius (NOc "Antares") pela condução segura, dedicação para a conclusão das comissões e amizade no comando dos Navios que participaram da coleta de dados aqui apresentados. Enfim, às tripulações dos Navios e aos amigos da nossa valorosa DHN que trabalharam de forma profícua para o sucesso desse projeto, apresento meus sinceros agradecimentos.

Ao amigo CF Barroso agradeço pela fraterna amizade desde os conveses do bravo NHi "Sírius"e por sua imensa contribuição para o artigo que descreveu a influência da água modal na acústica submarina. Desejo muito sucesso no restante do seu doutorado e que em breve possamos trabalhar juntos novamente.

Aos amigos Dr. Marouan Bouali, Piero Bernardo, Dante Campagnoli, Iury Simões, Márcio Yamashita e Dr. Wandrey Watanabe, agradeço pela ajuda com o processamento dos dados, orientações científicas e amizade. Serei eternamente grato pelo fraterno companheirismo de vocês sem o qual não seria possível concluir esse trabalho. Em especial ao "marujo" Piero agradeço pelos longos debates sobre água modal e pela lealdade em todos os momentos difíceis. Aguardo sua apresentação às fileiras da briosa MB em breve!!!

À amiga Hebe Queiroz pelos ensinamentos, conselhos e atenção em todos os momentos difíceis deste doutorado, mesmo a distância.

Aos membros da banca examinadora pela fidalguia ao aceitar o convite. Sintome honrado com vossa presença.

Aos professores, Prof. Dr. Ilson Carlos Almeida da Silveira, Prof. Dr. Edmo José Dias Campos, Prof. Dr. Frederico Pereira Brandini e Prof. Dr. Tércio Ambrizzi pelos preciosos conhecimentos transmitidos durante as aulas e exame de qualificação. Em especial ao Prof. Ilson agradeço pelo respeito, amizade e apoio espiritual nos momentos de angústia que vivi no último ano. Ao Prof. Edmo agradeço pela atenção e fidalguia em ceder os dados do modelo HYCOM-SAMOC para este estudo. 
Aos amigos: Patola, Gilberto, Bia, Guilherme, Pedrão Morais, Thiago Parente, Rafinha, Leandro Machado, Carol Miyoshi, Tiago Biló, Mestre, Paulo Victor, Fábio Leke, Nancy, Isabel, Carol Ernani, Mariana, Paulinha, Hélio e Mateus Chuqui sou grato pelo ambiente de cooperação, amizade e momentos de descontração.

Ao Prof. Dr. Paulo Simionatto Polito agradeço a cordialidade, apoio e orientação segura em todos os momentos, desde o Mestrado.

Aos funcionários da biblioteca, da seção de informática, da secretaria, cantina, enfim, a todos os funcionários do Instituto Oceanográfico que, direta ou indiretamente, contribuíram para a minha jornada do doutorado. 


\section{Resumo}

A Confluência Brasil-Malvinas (CBM) é formada pelo encontro da Corrente do Brasil (CB) com a Corrente das Malvinas (CM) no Atlântico Sul e, por constituir o encontro de correntes de contorno oeste (CCO), é demarcada por um intenso gradiente horizontal de temperatura. A inclinação das isopicnais na porção mais quente de regiões de encontro de duas CCO favorece a formação de águas modais ao final do inverno. O estudo de águas modais subtropicais ainda é incipiente no Atlântico Sul, quando comparado com os diversos trabalhos versando sobre o fenômeno em outras regiões do mundo.

A realização do primeiro cruzeiro oceanográfico especificamente planejado para o estudo de águas modais na região da CBM e de retroflexão da CB permitiu verificar a anisotropia desse extenso corpo d'água, cuja espessura e profundidades máxima e mínima variam mormente com a latitude em que o fenômeno ocorre. Os dados fornecidos pelos perfiladores Argo lançados durante o cruzeiro, e ainda em operação na região da $\mathrm{CBM}$, corroboraram tal observação e revelaram o limite norte da região de formação da água modal subtropical do sudoeste do Atlântico Sul (AMSTAS) em torno da latitude de $34^{\circ} \mathrm{S}$.

A comparação dos resultados obtidos in situ com os dados do modelo oceânico HYCOM, numa simulação de 4 anos, permitiu observar a mesma anisotropia e limite norte da área de formação. Embora relativamente curta, a série temporal viabilizou a primeira estimativa de volume da AMSTAS e uma avaliação preliminar dos processos envolvidos na dissipação da AMSTAS recém formada.

O emprego de dados de satélites altímetros para o cálculo do calor armazenado $\left(C_{A}\right)$ na região de estudo permitiu verificar que a instabilidade apresentada na série temporal de dados do modelo HYCOM se deve sobretudo à dinâmica de mesoescala 
na região mais próxima do encontro das duas $\mathrm{CCO}$. A análise do $C_{A}$ na região onde foi realizado o cruzeiro oceanográfico do estudo, permitiu identificar mais claramente a existência de diferentes padrões de calor armazenado coincidentes com áreas típicas de formação, os quais não ocorreram em áreas que continham AMSTAS apenas afundada.

Descritores: Água Modal Subtropical do Atlântico Sul, perfiladores Argo, HYCOM, ATOBA, vorticidade potencial, calor armazenado. 


\section{Abstract}

The Brazil-Malvinas confluence zone (BMCZ) is an energetic region of the South Atlantic Ocean where the Brazilian Current (BC) and the Malvinas Current (MC) meet. As a convergence area of Western Boundary Currents (WBC), it is marked by intense horizontal temperature gradients. The inclination of isopycnals in the warm side of WBC convergence zone enables the formation of mode water at the end of winter. The study of subtropical mode waters in the South Atlantic is still incipient compared to similar investigations conducted in other regions of the world.

The first oceanographic cruise specifically dedicated to the study of mode waters in the $\mathrm{BMCZ}$ and the $\mathrm{BC}$ retroflection helped verify the anisotropy of such extensive water masses, whose maximum and minimum thickness and depth vary mainly with the latitude where these phenomenon occur. Data derived from Argo profilers released during the cruise and currently still operating in the BMCZ, support this observation and indicate the northern limit of the formation region of the Southwestern Atlantic subtropical mode water (SASTMW) near latitude $34^{\circ} \mathrm{S}$.

Comparison of in situ results with those obtained from a 4-years simulation with the HYCOM ocean model, indicates similar anisotropy and northern limit of the formation area. Despite its relatively small length, this time series enabled the first estimation of the SASTMW volume, and a preliminary validation of the processes involved in the dissipation of newly formed SASTMW.

The use of satellite altimetry data for the computation of heat content in the study area helped conclude that the instability observed in the time series of the HYCOM model output is due to mesoscale dynamics near the convergence zone of the $\mathrm{BC}$ and the MC. Analysis of heat content in the region where the oceanographic cruise was conducted helped identify the existence of different patterns in heat content, that 
coincide with typical formation areas but not with areas where SASTMW is already submerged.

Keywords: South Atlantic subtropical mode water, Argo profilers, HYCOM, ATOBA, potential vorticity, heat content. 


\section{Lista de Siglas e Acrônimos}

ASM Altura da Superfície do Mar

AASM Anomalia da Altura da Superfície do Mar

ACAS Água Central do Atlântico Sul

CP Água Circumpolar Profunda

ACS Água Circumpolar Superior

AIA Água Intermediária Antártica

ADCP Acoustic Doppler Current Profiler

AOML Atlantic Oceanographic and Meteorological Laboratory

APAN Água Profunda do Atlântico Norte

APMW Água Profunda do Mar de Weddel

ASA Água Subantártica de Superfície

ASM Altura da Superfície do Mar

AT Água Tropical

ATG Along Track Gridded

ATOBA Altimetry Tailored and Optimized for Brazilian Applications

AVGS Anomalia da Velocidade Geostrófica de Superfície cross-track

AVHRR Advanced Very High Resolution Radiometer

AVISO Archiving, Validation and Interpretation of Satellite Oceanographic data

CA Corrente das Agulhas

CAS Corrente do Atlântico Sul

CB Corrente do Brasil

CBg Corrente de Benguela

CBM Confluência Brasil-Malvinas

CCA Corrente Circumpolar Antártica

CCI Corrente de Contorno Intermediária

CCO Corrente de Contorno Oeste

CCSE Contracorrente Sul Equatorial

CHM Centro de Hidrografia da Marinha

CLS Collecte Localisation Satellites 


$\begin{array}{ll}\text { CM } & \text { Corrente das Malvinas } \\ \text { CMDT } & \text { Combined Mean Dynamic Topography } \\ \text { CNB } & \text { Corrente Norte do Brasil } \\ \text { CNES } & \text { Centre National d'Etudes Spatiales } \\ \text { CSE } & \text { Corrente Sul Equatorial } \\ \text { CSEc } & \text { Ramo Central da Corrente Sul Equatorial } \\ \text { CSEe } & \text { Ramo Equatorial da Corrente Sul Equatorial } \\ \text { CSEn } & \text { Ramo Norte da Corrente Sul Equatorial } \\ \text { CSEs } & \text { Ramo Sul da Corrente Sul Equatorial } \\ \text { CTD } & \text { Conductivity, Temperature, and Depth } \\ \text { DAC } & \text { Drifter Data Assembly Center } \\ \text { DHN } & \text { Diretoria de Hidrografia e Navegação } \\ \text { DUACS } & \text { Data Unification and Altimeter Combination System } \\ \text { EnOI } & \text { Ensemble Optimal Interpolation } \\ \text { FBM } & \text { Frente Brasil-Malvinas } \\ \text { FST } & \text { Frente Subtropical } \\ \text { GFS } & \text { Global Forecast System } \\ \text { HYCOM } & \text { HYbrid Coordinate Ocean Model } \\ \text { Ifremer } & \text { Institut Français de Recherche pour L'exploitation de La Mer } \\ \text { IGY } & \text { International Geophysical Year } \\ \text { ISAS } & \text { In Situ Analysis System } \\ \text { LANL } & \text { Los Alamos National Laboratory } \\ \text { LPO } & \text { Laboratoire de Physique dês Océans } \\ \text { MICOM } & \text { Miami Isopycnic Coordinate Ocean Model } \\ \text { MOC } & \text { Meridional Overturning Circulation } \\ \text { MODIS } & \text { Moderate-Resolution Imaging Spectroradiometer } \\ \text { NASA } & \text { National Aeronautics and Space Administration } \\ \text { NCODA } & \text { Navy Coupled Ocean Data Assimilation } \\ \text { NHo } & \text { Navio Hidroceanográfico } \\ \text { NOAA } & \text { National Oceanic and Atmospheric Administration } \\ \text { NOPP } & \text { National Ocean Partnership Program } \\ \text { NRL } & \text { Naval Research Laboratoty } \\ \text { OCSUL } & \text { Comissão Hidroceanográfica OCEANO SUL } \\ \text { OSTIA } & \text { Operational Sea Surface Temperature and Sea Ice Analysis } \\ \text { PO.DAAC } & \text { Physical Oceanography Distributed Active Archive Center } \\ \text { POP } & \text { Paralel Ocean Program } \\ \text { REMO } & \text { Rede de Modelagem e Observação Oceanográfica } \\ & \end{array}$




$\begin{array}{ll}\text { SAMOC } & \text { South Atlantic Meridional Overturning Circulation } \\ \text { SCE } & \text { Subcorrente Equatorial } \\ \text { SCSE } & \text { Subcorrente Sul Equatorial } \\ \text { SNB } & \text { Subcorrente Norte do Brasil } \\ \text { SNE } & \text { Subcorrente Norte Equatorial } \\ \text { SSALTO } & \text { Segment Sol multimissions d'ALTimétrie, d'Orbitographie et de localisation précise } \\ \text { TDM } & \text { Topografia Dinâmica Média } \\ \text { TSM } & \text { Temperatura da Superfície do Mar } \\ V_{g e o} & \text { Velocidade Geostrófica } \\ \text { XBT } & \text { eXpendable BathyThermograph } \\ \text { UNESCO } & \text { United Nations Educational, Scientific and Cultural Organization }\end{array}$




\section{Lista de Figuras}

1.1 Esquema da circulação de larga escala para as correntes geostróficas no Atlântico

\begin{tabular}{l}
\hline Sul, entre 0 e 100 m. São mostradas: Subcorrente Equatorial (SCE); Corrente \\
\hline Norte do Brasil (CNB); Subcorrente Sul Equatorial (SCSE), Contracorrente Sul \\
\hline Equatorial (CCSE); Ramos central (CSEc), sul (CSEs) e equatorial (CSEe) da \\
\hline Corrente Sul Equatorial (CSE); Corrente do Brasil (CB); Corrente do Atlântico \\
\hline Sul(CAS); Corrente Circumpolar Antártica (CCA); Corrente das Malvinas (CM); \\
\hline Corrente das Agulhas (CA); Corrente de Benguela (CBg). As correntes estão \\
\hline sobrepostas a um mapa de temperatura da superfície do mar (TSM em ${ }^{\circ}$ C) ori- \\
\hline undo do World Ocean Atlas 2005 (WOA05). Modificado de Stramma E England \\
\hline [1999]. . . . . . . . . . . . . . . . . . . . . . . . . . . . . . . . . . . . . . . \\
\hline
\end{tabular}

1.2 Diagrama da circulação de superfície no Atlântico Sudoeste. Modificado de LPiola \& Matano[2001]. . . . . . . . . . . . . . . . . . 5 5

1.3 Imagem AVHRR da Confluência Brasil-Malvinas editada a partir de Olson et al.

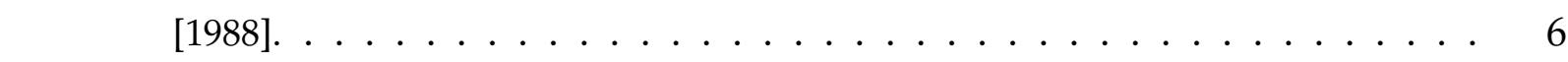

1.4 Localização das estações hidrográficas do cruzeiro Confluence 3. As radiais são referenciadas por A, B, C, D, E, F. Modificado de Provost et al.[1995]. . . . . . . 9

1.5 Média anual global da contribuição do fluxo de empuxo para o fluxo de PVP total. As áreas destacadas correspondem à região de formação de águas modais subtropicais no Atlântico Norte e no Atlântico Sul. Modificado de Olsina et al. [2013]. . . . . . . . . . . . . . . . . . . . 13 
2.1 Número de ocorrências da AMSTAS nos meses de abril e maio ao longo de treze anos a partir de médias mensais obtidas de observações por dados hidrográficos in situ. As 45 estações planejadas para a OCSUL estão assinaladas pelos círculos verdes. As áreas em azul indicam que não houve ocorrência de água modal durante os referidos meses em todos os anos da série temporal de 2002 a 2014 . . . 33

2.2 Área de ocorrência da água modal subtropical na região da Confluência BrasilMalvinas. Os triângulos indicam a localização das estações CTD realizadas durante o cruzeiro. As trajetórias A e B foram realizadas pelos perfiladores Argo lançados, respectivamente, em 28/04/2015 e 10/05/2015. As cores ao fundo representam a temperatura da superfície do mar (TSM) média para o mês de abril de 2015 obtida a partir do sensor MODIS Terra. Os contornos, oriundos dos dados da climatologia do In Situ Analysis System (ISAS), representam a profundidade da isoterma de $16^{\circ} \mathrm{C}$ para o mês de abril. . . . . . . . . . . . . . . . 34

2.3 Energia cinética média do modelo HYCOM 1 por unidade de área (em Joules $/ \mathrm{m}^{2}$ ) a partir do início da simulação $(01 / 01$ do ano hipotético 1993). . . . . . . . . . . 38

2.4 Limites da Metarea V (em amarelo). . . . . . . . . . . . . . . . . . . . . . 39

4.1 Diagramas TS (pares coletados até a profundidade de $1000 \mathrm{~m}$ ) das estações de CTD realizadas na OCSUL (painel da esquerda), dos perfis realizados pelo perfilador Argo A (painel central) e pelo perfilador Argo B (painel da direita). Os pares TS assinalados em cinza destacam os pontos com temperatura, salinidade e vorticidade potencial típicos da AMSTAS. . . . . . . . . . . . . 57

4.2 Profundidades mínima (a), máxima (b) e espessura (c) da camada de AMSTAS identificada por meio dos dados de CTD, em metros. Os triângulos em (c) indicam a posição das estações de CTD realizadas. . . . . . . . . . . . . . 58

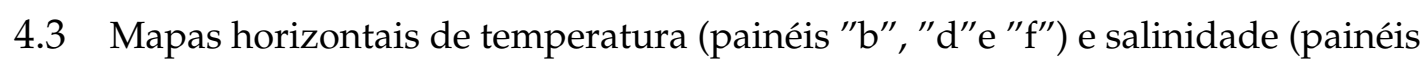
"a", "c"e "e $\mathrm{e}^{\prime \prime}$ com os vetores de velocidade geostrófica baroclínica relativa a $500 \mathrm{~m}\left(\vec{V}_{g}\right)$ para as profundidades de $100 \mathrm{~m}$ (painéis "a"e "b"), $150 \mathrm{~m}$ (painéis "c $\mathrm{c}^{\prime \prime} \mathrm{e}^{\prime \prime} \mathrm{d}$ ) e $200 \mathrm{~m}$ (painéis " $\mathrm{e}^{\prime \prime} \mathrm{e}$ " $\mathrm{f}$ "). Linhas contínuas vermelhas indicam os limites superiores de T e S para detecção da AMSTAS $\left(15,9^{\circ} \mathrm{C}\right.$ e 35,8 , respectivamente) e as linhas tracejadas vermelhas os limites inferiores $\left(14,1^{\circ} \mathrm{C}\right.$ e 35,4 , respectivamente). . . . . . . . . . . . . . . . . . 59 
4.4 Similar à Figura 4.3 para as profundidades de $250 \mathrm{~m}$ (painéis "a"e "b"), $300 \mathrm{~m}$ (painéis "c"e "d") e $350 \mathrm{~m}$ (painéis " $\mathrm{e}^{\prime \prime} \mathrm{e}$ " $\mathrm{f}^{\prime \prime}$ ). . . . . . . . . . . . . . . . . 60

4.5 Posição das isotermas de $14,1^{\circ} \mathrm{C}$ (painel " $\mathrm{a}^{\prime \prime}$ ) e $15,9^{\circ} \mathrm{C}$ (painel " $\mathrm{b}^{\prime \prime}$ ) na área de estudo com anotação da profundidade (em metros) de ocorrência sobre as mesmas. 61

4.6 Temperatura (painéis superiores) e salinidade (inferiores) das seções meridionais realizadas em $40^{\circ} \mathrm{W}, 35^{\circ} \mathrm{W}, 30^{\circ} \mathrm{W}$, e das seções zonais em $38^{\circ} \mathrm{S}, 35^{\circ} \mathrm{S}$ e $30^{\circ} \mathrm{S}$ a partir dos dados de CTD. Os pontos azuis indicam as posições do perfil onde foi detectada AMSTAS. . . . . . . . . . . . . . . . . . . . . . . 62

4.7 Mapa horizontal de função de corrente geostrófica baroclínica $(\Psi)$ com sobreposição dos vetores de velocidade geostrófica baroclínica $\left(\vec{V}_{g}\right.$ em $\left.\mathrm{cm} \mathrm{s}^{-1}\right)$, ambos referentes a $500 \mathrm{~m}$, para as profundidades de $50 \mathrm{~m}, 100 \mathrm{~m}, 150 \mathrm{~m}, 200 \mathrm{~m}$ (painéis "a", "b", "c"e "d", respectivamente). . . . . . . . . . . . . . . 63

4.8 Similar à Figura 4.7 para as profundidades de $300 \mathrm{~m}$ (painel "a") e $350 \mathrm{~m}$ (painel

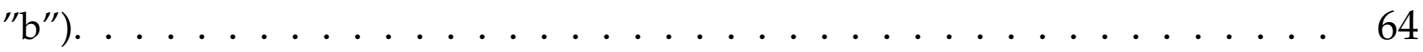

4.9 Mapa horizontal de temperatura na superfície com sobreposição dos vetores de velocidade geostrófica baroclínica relativa a $500 \mathrm{~m}\left(\vec{V}_{g} \mathrm{em} \mathrm{cm} \mathrm{s}^{-1}\right)$. A linha contínua azul indica a isoterma de $21,0^{\circ} \mathrm{C}$, característica da FCB. . . . . . . . . 65

4.10 Diagrama profundidade-tempo da temperatura (em ${ }^{\circ} \mathrm{C}$ no painel superior), \begin{tabular}{|c|}
\hline salinidade (intermediário) e vorticidade potencial $\left(Q \mathrm{em} \mathrm{m}^{-1} \mathrm{~s}^{-1}\right.$, inferior) do \\
\hline perfilador Argo A. Os contornos destacados indicam as isotermas e isohalinas \\
\hline dentro da camada de AMSTAS. As barras verticais em cinza no painel inferior \\
\hline são formadas pela união dos pontos que contém as posições do perfil onde foi \\
\hline
\end{tabular} detectada AMSTAS. . . . . . . . . . . . . . . 66

4.11 Similar à Figura 4.10 para o perfilador Argo B. . . . . . . . . . . . . . 67

4.12 Profundidade média (em metros) das isotermas de $14,1^{\circ} \mathrm{C}$ (painel "a") e $15,9^{\circ} \mathrm{C}$ (painel " $\mathrm{b}^{\prime \prime}$ ) para o período da OCSUL nos pontos de grade do modelo HYCOMSAMOC em que a vorticidade potencial $(Q)$ foi inferior a $2,0 \times 10^{-10} \mathrm{~m}^{-1} \mathrm{~s}^{-1} . \quad 70$

4.13 Série temporal do volume $\left(\mathrm{em} \mathrm{m}^{3}\right)$ de AMSTAS detectado a partir dos dados \begin{tabular}{|c|}
\hline do modelo HYCOM 1. Em vermelho estão marcados os volumes de AMSTAS \\
\hline recém formados $\left(Q<2,0 \times 10^{-11} \mathrm{~m}^{-1} \mathrm{~s}^{-1}\right)$ e em azul os volumes de AMSTAS \\
\hline consolidada e afundada $\left(2,0 \times 10^{-11} \mathrm{~m}^{-1} \mathrm{~s}^{-1}<=Q<=2,0 \times 10^{-10} \mathrm{~m}^{-1} \mathrm{~s}^{-1}\right) . \quad$ \\
\hline
\end{tabular} 
4.14 Taxa de variação mensal (em \%) do volume de AMSTAS afundado detectado a

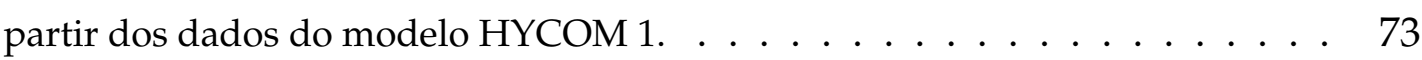

4.15 Mapa horizontal de espessura em metros da camada de AMSTAS formada, durante os quatro meses típicos do período de formação (JUL a OUT), no primeiro ano da simulação, detectada a partir dos dados do modelo HYCOM 1 em cada ponto da área de estudo. O retângulo vermelho indica os limites da área onde foi realizada a OCSUL. . . . . . . . . . . . . . . . . . . . . . . . . . . . 74

4.16 Semelhante à Figura $4.15 \mid$ para o segundo ano da simulação. . . . . . . . . . . 74

4.17 Semelhante à Figura 4.15 para o terceiro ano da simulação. . . . . . . . . . . . 75

4.18 Semelhante à Figura 4.15 para o quarto ano da simulação. . . . . . . . . . . . 75

4.19 Mapa horizontal de espessura em metros da camada de AMSTAS afundada no

\begin{tabular}{|c|}
\hline mês de novembro do primeiro ano (painel superior esquerdo) e do segundo \\
\hline ano (painel inferior esquerdo) da simulação, e no mês de abril do segundo ano \\
\hline (painel superior direito) e do terceiro ano (painel inferior direito) da simulação, \\
\hline
\end{tabular}
detectada a partir dos dados do modelo HYCOM 1. O retângulo vermelho indica os limites da área onde foi realizada a OCSUL. . . . . . . . . . . . . . 76

\begin{tabular}{|l|l|l|l|l}
4.20 & Similar à Figura & para os meses de novembro do terceiro (painel superior
\end{tabular} esquerdo) e do quarto ano (painel inferior esquerdo) da simulação, de abril do quarto ano (painel superior direito) e de março do quinto ano da simulação (painel inferior direito). . . . . . . . . . . . . . . . . . . 77

4.21 Mapa horizontal de incidência de AMSTAS afundada (azul), em formação na superfície (vermelho) e afundada concomitante com recém formada (verde) durante os meses de formação do segundo ano da simulação em cada ponto da área de estudo. O retângulo vermelho indica os limites da área onde foi realizada a OCSUL . . . . . . . . . . . . . . . . . . . . . 78

4.22 Similar à Figura 4.21 para o terceiro ano da simulação. . . . . . . . . . . . . 79

4.23 Similar à Figura 4.21 para o quarto ano da simulação. . . . . . . . . . . . . . 79

4.24 Série temporal do volume $\left(\mathrm{em}^{3}\right)$ de AMSTAS detectado a partir dos dados do modelo HYCOM 2. Em vermelho estão marcados os volumes de AMSTAS recém formados $\left(Q<2,0 \times 10^{-11} \mathrm{~m}^{-1} \mathrm{~s}^{-1}\right)$ e em azul os volumes de AMSTAS consolidada e afundada $\left(2,0 \times 10^{-11} \mathrm{~m}^{-1} \mathrm{~s}^{-1}<=Q<=2,0 \times 10^{-10} \mathrm{~m}^{-1} \mathrm{~s}^{-1}\right)$. 
4.25 Série temporal do volume $\left(\mathrm{em} \mathrm{m}^{3}\right)$ de parcelas de água com vorticidade potencial $(Q)$ inferior a $2,0 \times 10^{-10} \mathrm{~m}^{-1} \mathrm{~s}^{-1}$ detectado a partir dos dados do modelo HYCOM 2, e temperaturas típicas da AMSTAS. Em vermelho estão marcados os volumes com $Q<2,0 \times 10^{-11} \mathrm{~m}^{-1} \mathrm{~s}^{-1}$ e em azul os volumes $\operatorname{com} Q>=2,0$ $\times 10^{-11} \mathrm{~m}^{-1} \mathrm{~s}^{-1} \ldots \ldots \ldots \ldots \ldots \ldots 2$

4.26 Mapa da temperatura média na superfície $\left(\mathrm{em}^{\circ} \mathrm{C}\right)$ dos quatro anos da simulação. As isotermas de $21^{\circ} \mathrm{C}$ (característica da Frente da Corrente do Brasil - FCB) e de $16^{\circ} \mathrm{C}$ (limite máximo da AMSTAS detectada nos dados in situ) são destacadas nas cores branca e preta, respectivamente. A subarea retangular demarcada pela linha sólida indica os limites da área do cruzeiro oceanográfico (OCSUL) e a identificada pela linha tracejada delimita a região de encontro da Corrente

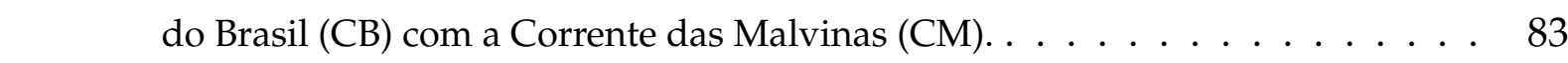

4.27 Série temporal do calor armazenado $\left(C_{A}\right)$ para toda a área de estudo, apresentada em $\mathrm{J} \mathrm{m}^{-2}$ integrado até $500 \mathrm{~m}$ de profundidade (cor azul) e apenas no interior da camada de AMSTAS (cor vermelha). . . . . . . . . . . . . . . 84

4.28 Série temporal do calor armazenado $\left(C_{A}\right)$, apresentada em $\mathrm{J} \mathrm{m}^{-2}$, na região da OCSUL, integrado até $500 \mathrm{~m}$ (cor vermelha) e integrado somente na camada de AMSTAS (cor azul). . . . . . . . . . . . . . . . . . 85

4.29 Similar à Figura 4.28 para a subarea referente à CBM. . . . . . . . . . . . . . 86

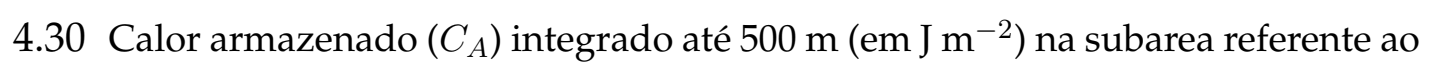
\begin{tabular}{|c|}
\hline cruzeiro nos meses do período de pré-formação (março a junho) do terceiro ano \\
\hline da simulação do HYCOM 1. Os contornos das isotermas de $21^{\circ} \mathrm{C}$ (característica \\
\hline
\end{tabular}

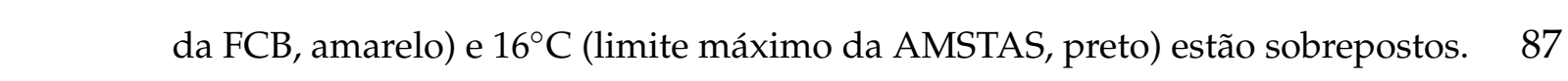

4.31 Similar à Figura 4.30 para os meses do período de pós-formação (novembro -

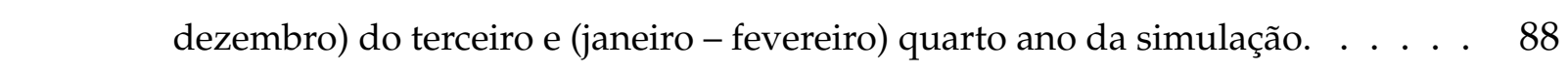

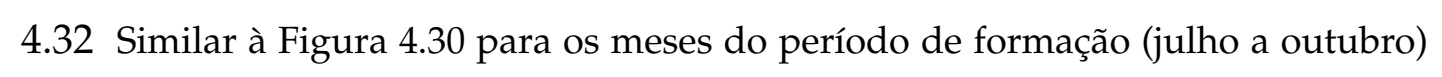
do terceiro ano da simulação. . . . . . . . . . . . . . . . . . 89

4.33 Altura da superfície do mar (ASM) média do período de 1993 a 2013 obtida \begin{tabular}{|c|}
\hline da AVISO (painel da esquerda) e energia cinética turbulenta (ECT - painel da \\
\hline
\end{tabular} \begin{tabular}{|l|}
\hline direita) indicando a reduzida dinâmica de meso escala da área da OCSUL (con- \\
\hline torno sólido) quando comparada à região da CBM (contorno tracejado). . . . . 9 90
\end{tabular} 
4.34 Calor armazenado $\left(C_{A}\right)$ integrado até $500 \mathrm{~m}\left(\mathrm{em} \mathrm{J} \mathrm{m}^{-2}\right)$ na subarea referente à CBM nos meses do período de pré-formação (março a junho) do terceiro ano da simulação. Os contornos das isotermas de $21^{\circ} \mathrm{C}$ (característica da FCB, amarelo) e $16^{\circ} \mathrm{C}$ (limite máximo da AMSTAS, preto) estão sobrepostos. . . . . . . . . . . . 90

4.35 Similar à Figura 4.34 para os meses do período de pós-formação (novembro dezembro) do terceiro e (janeiro - fevereiro) quarto ano da simulação. . . . . . . 91

4.36 Similar à Figura 4.34 para os meses do período de formação (julho a outubro) do terceiro ano da simulação. . . . . . . . . . . . . . . . . . . . . . 9 92

4.37 Calor armazenado $\left(C_{A}-\mathrm{J} \mathrm{m}^{-2}\right)$ dos dados de altímetro na subarea referente à CBM (azul) e para a região da OCSUL (vermelha). . . . . . . . . . . . . . . . 93

4.38 Calor armazenado $\left(C_{A}\right)$ em $\mathrm{J} \mathrm{m}^{-2}$, oriundo dos dados do Projeto ATOBA, para subarea referente ao cruzeiro oceanográfico nos meses do período de pré-formação (março a junho) de $2014 . \ldots \ldots$. . . . . . . . . . . . . . . 94

4.39 Similar à Figura 4.38 nos meses do período de pós-formação (novembro - dezem-

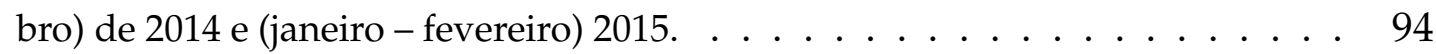

\begin{tabular}{|l|l|l|l|l}
4.40 & Similar à Figura & 4.38 & nos meses do período de formação (julho a outubro) de
\end{tabular}

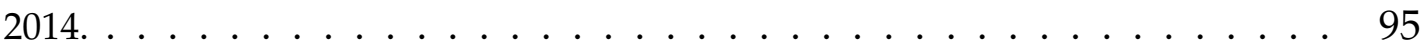

4.41 Calor armazenado $\left(C_{A}\right)$ em $\mathrm{J} \mathrm{m}^{-2}$, oriundo dos dados do Projeto ATOBA, para subarea referente à CBM nos meses do período de pré-formação (março a junho) de $2014 . \ldots \ldots \ldots \ldots$. . . . . . . . . . . . . . . . . 96

4.42 Similar à Figura 4.41 nos meses do período de pós-formação (novembro - dezembro) de 2014 e (janeiro - fevereiro) 2015 . . . . . . . . . . . . . . . . . . . 97

\begin{tabular}{|l|l|l|l|l}
4.43 & Similar à Figura & nos meses do período de formação (julho a outubro) de
\end{tabular}

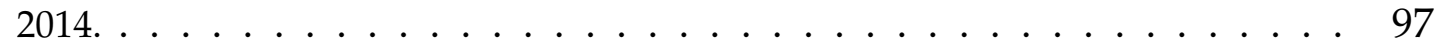




\section{Lista de Tabelas}

4.1 Valores do volume médio mensal $\left(\times 10^{14} \mathrm{~m}^{3}\right)$ total de AMSTAS detectado nos 


\section{Capítulo 1}

\section{Introdução}

\subsection{Preâmbulo}

A circulação oceânica de larga escala forçada pelo vento forma células praticamente fechadas ou giros oceânicos que se distribuem zonalmente acompanhando a linha de rotacional nulo do vento [Sverdrup, 1947]. Observam-se correntes bem mais intensas no lado oeste dos giros oceânicos que suas correspondentes do lado leste. Através de um estudo sobre a circulação dirigida pelo vento, considerando um oceano retangular e homogêneo, Stommel [1948] explicou o fato das correntes oceânicas serem mais intensas no lado oeste, demonstrando que a assimetria dos giros oceânicos é devida à variação do parâmetro de Coriolis com a latitude. Essas correntes mais intensas no lado oeste dos giros oceânicos são denominadas de Correntes de Contorno Oeste (CCO). As CCO são fluxos intensos, estreitos e bem definidos que representam o escoamento de retorno do giro oceânico devido ao transporte de Sverdrup. Anderson $\mathcal{E}$ Gill [1975] sugeriram que o processo de intensificação das CCO está associado à propagação de energia do interior oceânico para a borda oeste por meio de ondas planetárias.

Por conservação de vorticidade potencial as CCO tem direção predominantemente meridional ajustando sua posição com a variação da vorticidade planetária a fim de compensar a vorticidade relativa fornecida pelo vento. Ao atingirem a linha de rotacional nulo do vento, as CCO fluem para o interior da bacia oceânica onde conservam sua vorticidade planetária numa determinada latitude em balanço com a 
vorticidade relativa adquirida.

O afastamento das CCO da costa ocorre de duas formas bastante distintas. Pode ocorrer suavemente, auxiliado pela inclinação da costa em direção ao interior da bacia oceânica como, por exemplo, na Corrente do Golfo [Campos E Olson, 1991]. Pode também ocorrer de forma abrupta, devido ao encontro de massas de água de estrutura termohalina muito distintas em regiões onde a inclinação da costa forma um ângulo obtuso em relação ao norte geográfico [Silveira et al., 1999]. A forma abrupta de afastamento das CCO recebe o nome de retroflexão e tem como exemplo no Atlântico Sul a separação da Corrente do Brasil (CB) em sua região de encontro com a Corrente das Malvinas (CM), conhecida como Confluência Brasil-Malvinas (CBM). As regiões de encontro de Correntes de Contorno Oeste (CCO), no limite mais próximo dos polos nos giros subtropicais, favorecem particularmente a formação de águas modais subtropicais devido as suas características termohalinas [Hanawa E Talley, 2001].

O foco do presente estudo é o entendimento dos mecanismos que causam a variabilidade do volume de água modal existente na região da CBM. Para tal são analisados: i) dados coletados in situ por meio de uma comissão oceanográfica embarcada planejada exclusivamente para o estudo de águas modais; ii) dados de modelos numéricos oceânicos; e iii) dados da anomalia da altura da superfície do mar obtidos por satélites altimétricos para o cálculo do calor armazenado. Para a consecução deste estudo é essencial a descrição dos resultados obtidos previamente a fim de estabelecer valores comparativos como referência para a avaliação da variabilidade.

Neste capítulo será apresentada uma síntese da literatura acerca da região da CBM, da estimativa de volume de águas modais subtropicais e de sua variabilidade em outras regiões do oceano global e acerca de estudos pregressos conduzidos para investigação de águas modais subtropicais no Atlântico Sul. Serão também expostos os objetivos que nortearam os procedimentos e resultados analisados na presente tese. 


\subsection{Síntese da Literatura}

\subsubsection{Confluência Brasil-Malvinas (CBM)}

A Figura 1.1 apresenta um esquema da circulação de larga escala para as correntes geostróficas no Atlântico Sul, na camada superior do oceano entre 0 e $100 \mathrm{~m}$. Nela, a Corrente Sul Equatorial (CSE) flui de leste para oeste e se bifurca ao se aproximar da costa brasileira aproximadamente em $15^{\circ} \mathrm{S}$. Os estudos de Molinari [1982] e Stramma [1991] descreveram a CSE como um fluxo para oeste com três ramos distintos: sul (CSEs), central (CSEc) e equatorial (CSEe), onde os ramos CSEe e CSEc estariam separados pela Subcorrente Sul Equatorial (SCSE), e os ramos CSEc e CSEs pela Contracorrente Sul Equatorial (CCSE).

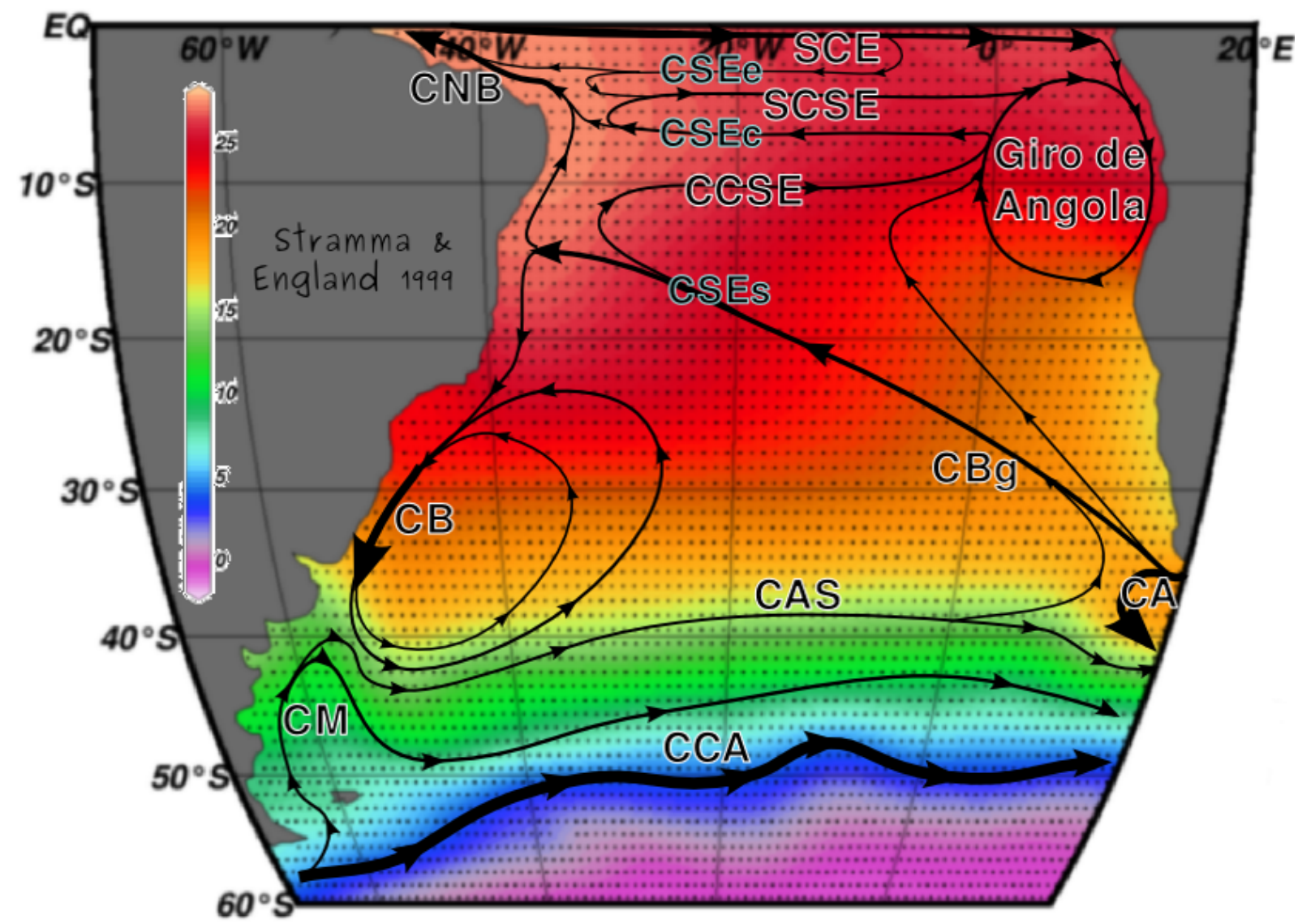

Figura 1.1: Esquema da circulação de larga escala para as correntes geostróficas no Atlântico Sul, entre 0 e 100 m. São mostradas: Subcorrente Equatorial (SCE); Corrente Norte do Brasil (CNB); Subcorrente Sul Equatorial (SCSE), Contracorrente Sul Equatorial (CCSE); Ramos central (CSEc), sul (CSEs) e equatorial (CSEe) da Corrente Sul Equatorial (CSE); Corrente do Brasil (CB); Corrente do Atlântico Sul (CAS); Corrente Circumpolar Antártica (CCA); Corrente das Malvinas (CM); Corrente das Agulhas (CA); Corrente de Benguela (CBg). As correntes estão sobrepostas a um mapa de temperatura da superfície do mar (TSM em ${ }^{\circ} \mathrm{C}$ ) oriundo do World Ocean Atlas 2005 (WOA05). Modificado de Stramma E England][1999]. 
Ao sul da bifurcação da CSE, a CB flui para sul até aproximadamente $36^{\circ} \mathrm{S}$, iniciando seu afastamento da costa até $38^{\circ} \mathrm{S}$ devido ao encontro de suas águas quentes e salinas com as águas de origem subpolar da CM [Garzoli \& Garrafo, 1989]. A diferença na estrutura vertical de densidade das duas correntes aliada às velocidades relativamente grandes propicia a ocorrência de instabilidades que se manifestam sob a forma de meandros e vórtices intensos [Chelton et al., 1990].

$\mathrm{Na} C B M$, a CB divide-se em dois ramos: um que retorna para norte aproximadamente ao longo de $53^{\circ} \mathrm{W}$ (lóbulo de retroflexão) e forma uma célula de recirculação anticiclônica quase-estacionária, centrada na latitude $\sim 34^{\circ}$ S [Stramma E Peterson, 1990]; o outro flui para sul até a latitude aproximada de $45^{\circ} \mathrm{S}$, onde desvia para nordeste formando a Corrente do Atlântico Sul (CAS) [Böebel et al., 1999]. Essa corrente localiza-se no limite sul do giro subtropical do Atlântico Sul e está associada às grandes velocidades zonais observadas na frente subtropical. A Figura 1.2 apresenta um diagrama da circulação de superfície no Atlântico Sudoeste, evidenciando a presença da bifurcação supracitada.

A região da CBM corresponde a uma das áreas mais energéticas do oceano global, demarcada por um intenso gradiente meridional de temperatura [Gordon, 1981. Chelton et al., 1990]. Portanto, o estudo mais acurado dos mecanismos responsáveis pela variabilidade do volume de águas modais nessa região requer um levantamento detalhado da dinâmica de meso e larga escala da CBM.

A variabilidade temporal dos fenômenos de meso e larga escala na CBM ocorre em várias bandas do espectro. Goni \& Wainer [2001], empregando dados altimétricos, indicaram que a frente na região da CBM apresenta intensa variabilidade interanual, com amplitudes médias anuais de $1^{\circ}$ a $6^{\circ}$ de latitude, o que corresponde à aproximadamente $650 \mathrm{~km}$ de distância meridional. Segundo os autores, essa variação está fortemente relacionada às flutuações do transporte baroclínico da CB. Assireu et al. [2003] observaram grande influência de anomalias meteorológicas na região frontal da CBM e oscilação da posição desta com período sazonal.

O estudo da variabilidade de mesoescala da CBM por meio de observações de derivadores e imagens satélites por sensor infra-vermelho Advanced Very High Resolution Radiometer (AVHRR) efetuado por Olson et al. [1988] indicou que o lóbulo prin- 


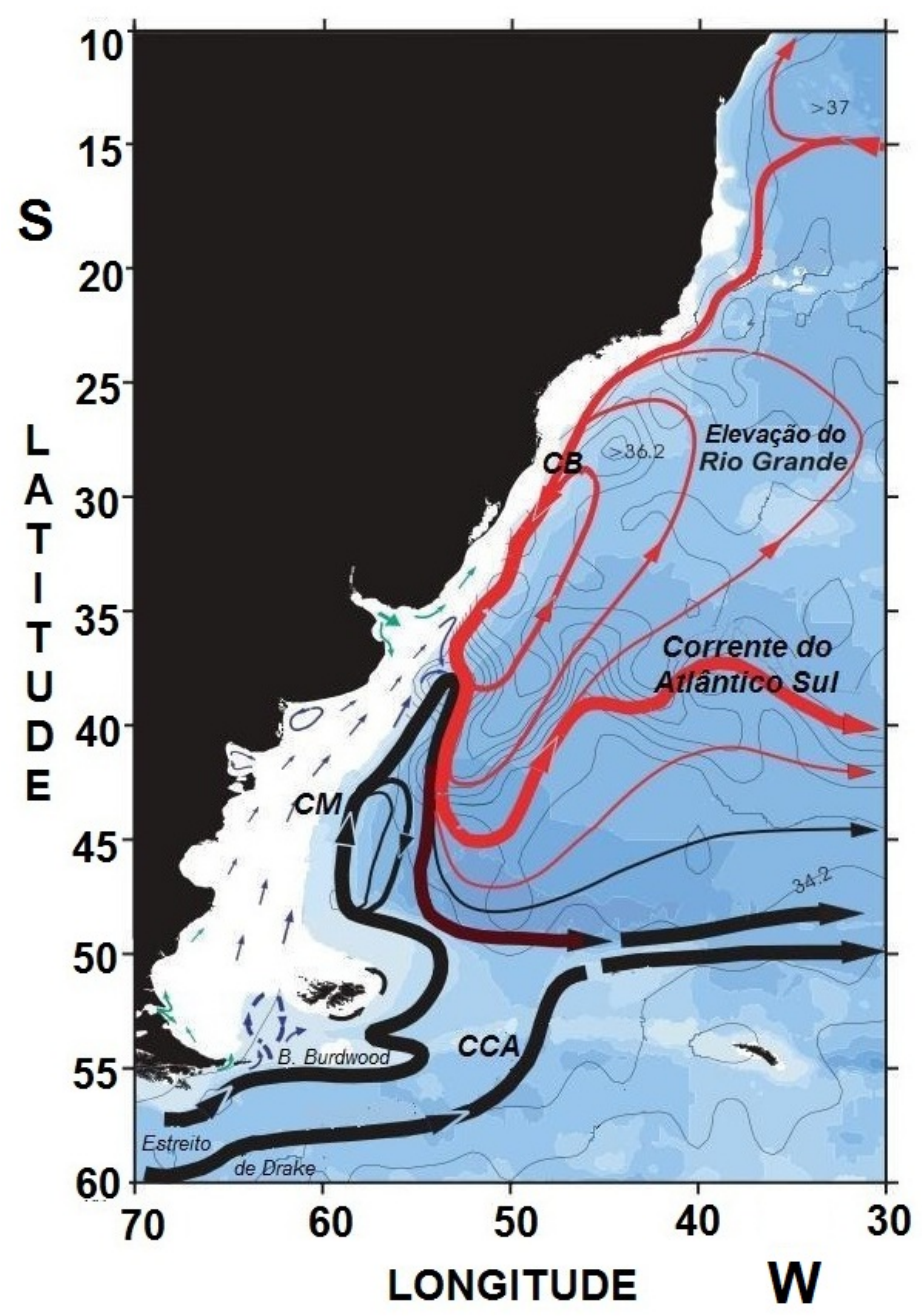

Figura 1.2: Diagrama da circulação de superfície no Atlântico Sudoeste. Modificado de Piola E Matano [2001].

cipal de retroflexão da $C B$ frequentemente se alonga para sul, emitindo vórtices anticiclônicos dentro do giro subpolar. Lentini et al. [2006] detectaram 40 vórtices anticiclônicos de núcleo quente, emitidos pela CB após essas incursões austrais, no período de janeiro de 1993 a outubro de 1998 com o emprego de dados do satélite altímetro TOPEX/Poseidon e campos de temperatura e salinidade climatológica para a região da CBM. A Figura 1.3 apresenta um vórtice com essas características e o lóbulo principal de retroflexão da CB por meio de uma imagem AVHRR da Confluência BrasilMalvinas. 


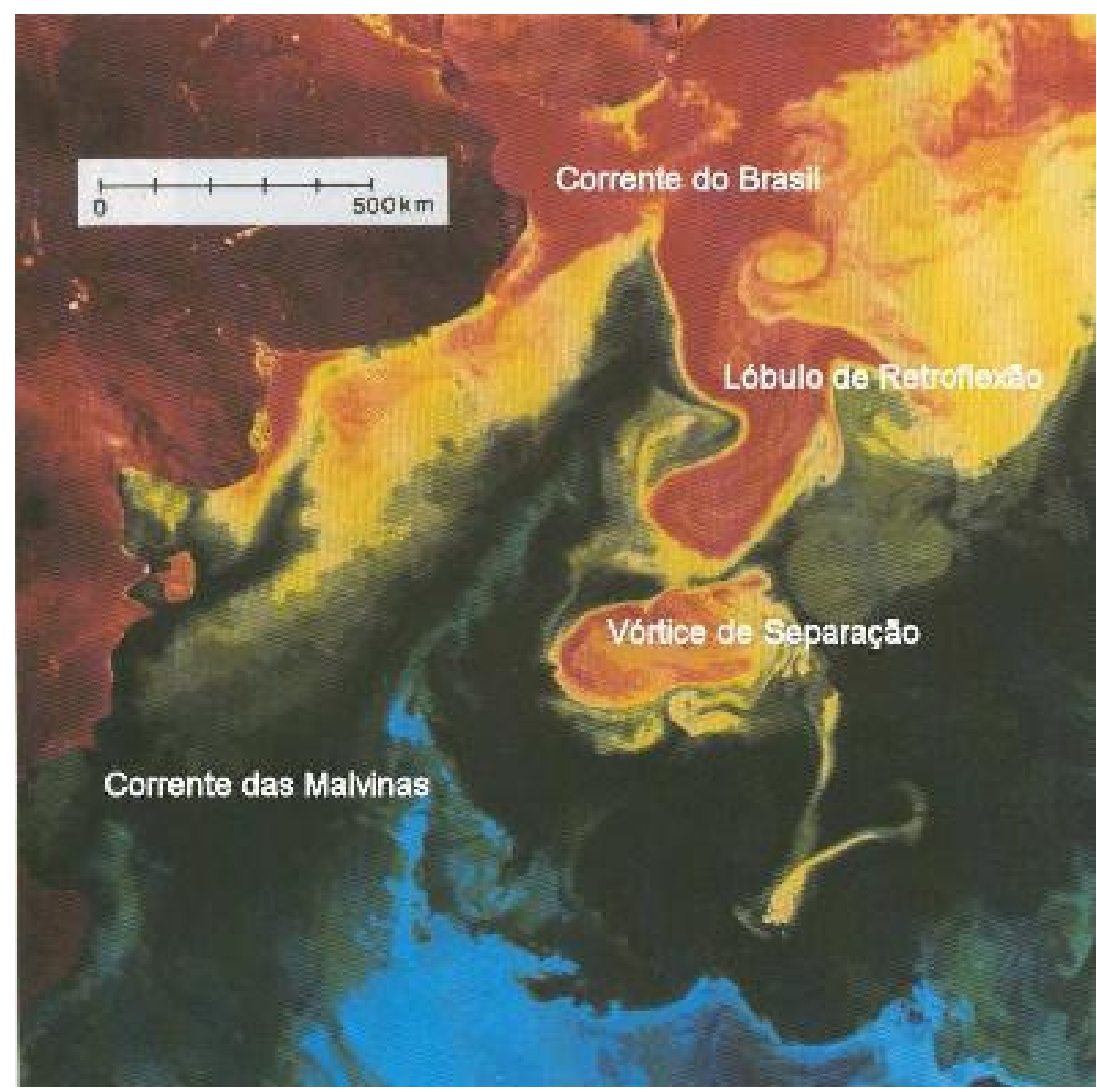

Figura 1.3: Imagem AVHRR da Confluência Brasil-Malvinas editada a partir de Olson et al. [1988].

Vivier E Provost [1999] empregaram uma radial composta por 17 correntômetros distribuídos em quatro fundeios lançados entre $40^{\circ} \mathrm{S}$ e $41^{\circ} \mathrm{S}$, nas profundidades de 450 , 1507, 2200 e 3043 m, de modo a amostrar toda a extensão transversal da CM. A radial permaneceu fundeada por 18 meses, de dezembro de 1993 a junho de 1995. A partir de uma série inicial de 254 dias os autores estimaram o valor de $(41,5 \pm 12,2)$ Sv para o transporte de volume da CM através de toda a seção transversal da radial. Uma parte significante deste desvio padrão é devido à atividade de mesoescala da Confluência Brasil-Malvinas, pois retirando-se os sinais com período inferior a 2 meses o desvio padrão reduz-se aproximadamente à metade. A disponibilidade simultânea de medidas de subsuperfície por correntômetros, anomalias da velocidade geostrófica de superfície cross-track oriundas do satélite altímetro TOPEX/Poseidon e dados hidrográficos in situ propiciaram aos autores a oportunidade de estimar a velocidade média de superfície. Vivier \& Provost [1999] demonstraram que pode-se inferir a velocidade média 
geostrófica na superfície a partir do cálculo da velocidade cross-track numa determinada profundidade de referência para cada dado de satélite altímetro. A velocidade cross-track é calculada conhecendo-se o cisalhamento geostrófico entre a profundidade de referência e a superfície para uma passagem específica do satélite altímetro.

Empregando essa metodologia Vivier \& Provost [1999] observaram que com os dados altimétricos do satélite TOPEX/Poseidon, em conjunto com informações estatísticas da estrutura vertical da corrente, é possível monitorar o fluxo de volume. Uma série de 3 anos do transporte foi derivada a partir desse estudo e apresentou uma correlação de 0,8 com as estimativas obtidas a partir dos dados oriundos dos correntômetros na $\mathrm{CM}\left(40^{\circ}-41^{\circ} \mathrm{S}\right)$. Cerca de $60 \%$ da variância dos dados foi explicada por períodos superiores a 20 dias. Dois períodos dominaram a variação de posição da frente na CBM: 50 - 80 dias e 180 dias. As oscilações interanuais observadas tiveram mais energia que as de período anual. Foi sugerido pelos autores que a $\mathrm{CM}$ tem pouco impacto sobre as migrações anuais da confluência. A predominância do ciclo semianual da migração da frente é compatível com forçantes remotas como sugerido por estudos observacionais de Goni et al. [1996] e de Provost et al. [1992], e numéricos de Smith et al. [1994.

Smith et al. [1994] empregando um modelo isopicnal forçado por ventos realísticos no Atlântico Sul relacionaram o ciclo semianual de variação da posição da Frente Brasil-Malvinas (FBM) com o transporte no Estreito de Drake. Eles observaram que enquanto existiu uma alta correlação entre o transporte no Estreito de Drake, o transporte na $\mathrm{CM}$ e os movimentos meridionais sazonais da CBM, o ciclo do transporte na $\mathrm{CB}$ exibiu um pico significativo de energia somente no período anual. Tal fato denotou que o sinal semianual local forçado pelo vento ao sul da CBM é extremamente atenuado antes de alcançar a região da CB por diversos fatores: atrito, o próprio fluxo oposto da corrente e a incapacidade das densas massas de água que compõe a $\mathrm{CM}$ de penetrar a circulação subtropical que é confinada às camadas superiores do modelo. Goni et al. [1996] observaram aproximadamente o mesmo ciclo semianual em $37,5^{\circ} \mathrm{S}$, assim como o estudo de Provost et al. [1992] por meio de 3 anos de dados de TSM.

Goni et al. [2011] observaram por meio do emprego de uma série de 15 anos de dados de altura da superfície do mar (ASM) e TSM que a FBM migrou 1,5 graus de 
latitude (cerca de $100 \mathrm{~km}$ ) para sul no período de 1993 a 2008. A ausência de mudanças de longo termo na série do transporte de volume calculado pelos autores para a CB e para a CM não permitiu a correlação da variação desses transportes com a migração da FBM observada. Goni et al. [2011] verificaram ainda a existência de tendência positiva tanto nos dados de TSM quanto nos dados de AASM, sugerindo um aumento do calor armazenado nas camadas superiores na região da CBM.

Observa-se que as isopicnais se aprofundam rapidamente em direção ao norte na região da CBM, através da frente encontrada no limite sul do giro subtropical do Atlântico Sul [Hanawa E Talley, 2001]. Desta forma, a região compreendida entre o fluxo principal da Corrente do Brasil (CB) e o seu lóbulo de retroflexão, ou seja no interior da célula de recirculação supracitada, apresenta aspectos propícios para a formação de uma espessa massa de água modal ao norte da frente e no lado mais quente desta, onde encontra-se a CB. Tal região tem ainda potencializada sua capacidade de formação dessa água modal devido à processos de interação oceano-atmosfera, associada à perda de calor latente ocorrida durante o inverno [Piola \& Matano, 2001].

O primeiro cruzeiro oceanográfico com coleta de dados ao longo do talude continental na região da CBM, desde a profundidade de $100 \mathrm{~m}$ até profundidades superiores a $4000 \mathrm{~m}$, com perfis contínuos de oxigênio dissolvido, foi o Confluence 3 realizado entre 7 e 27 de fevereiro de 1990 a bordo do Navio de Pesquisa "Le Suroit". Provost et al. [1995] analisaram os dados dessa pioneira comissão oceanográfica, apresentando as condições hidrográficas encontradas no verão austral de 1990.

Os autores observaram a presença da água modal subtropical nas radiais B e C do cruzeiro (Figura 1.4), nas profundidades entre $200 \mathrm{~m}$ e $400 \mathrm{~m}$. Essa água modal foi caracterizada por vorticidade potencial menor que $1,0 \times 10^{-10} \mathrm{~m}^{-1} \mathrm{~s}^{-1}$, temperatura de $14,5^{\circ} \mathrm{C}$ a $16,0^{\circ} \mathrm{C}$ e salinidade de 35,5 a 36,0 . Foi possível observar ainda máximos locais na concentração de oxigênio dissolvido de $4,85 \mathrm{~mL} \mathrm{~L}^{-1}$ a $5,05 \mathrm{~mL} \mathrm{~L}^{-1}$ e densidade potencial variando de $26,3 \mathrm{~kg} \mathrm{~m}^{-3}$ a $26,5 \mathrm{~kg} \mathrm{~m}^{-3}$ referentes a essa água modal. Os autores não foram capazes de calcular o volume de água modal subtropical existente na região e a idade da mesma devido à indisponibilidade de dados para tal. 


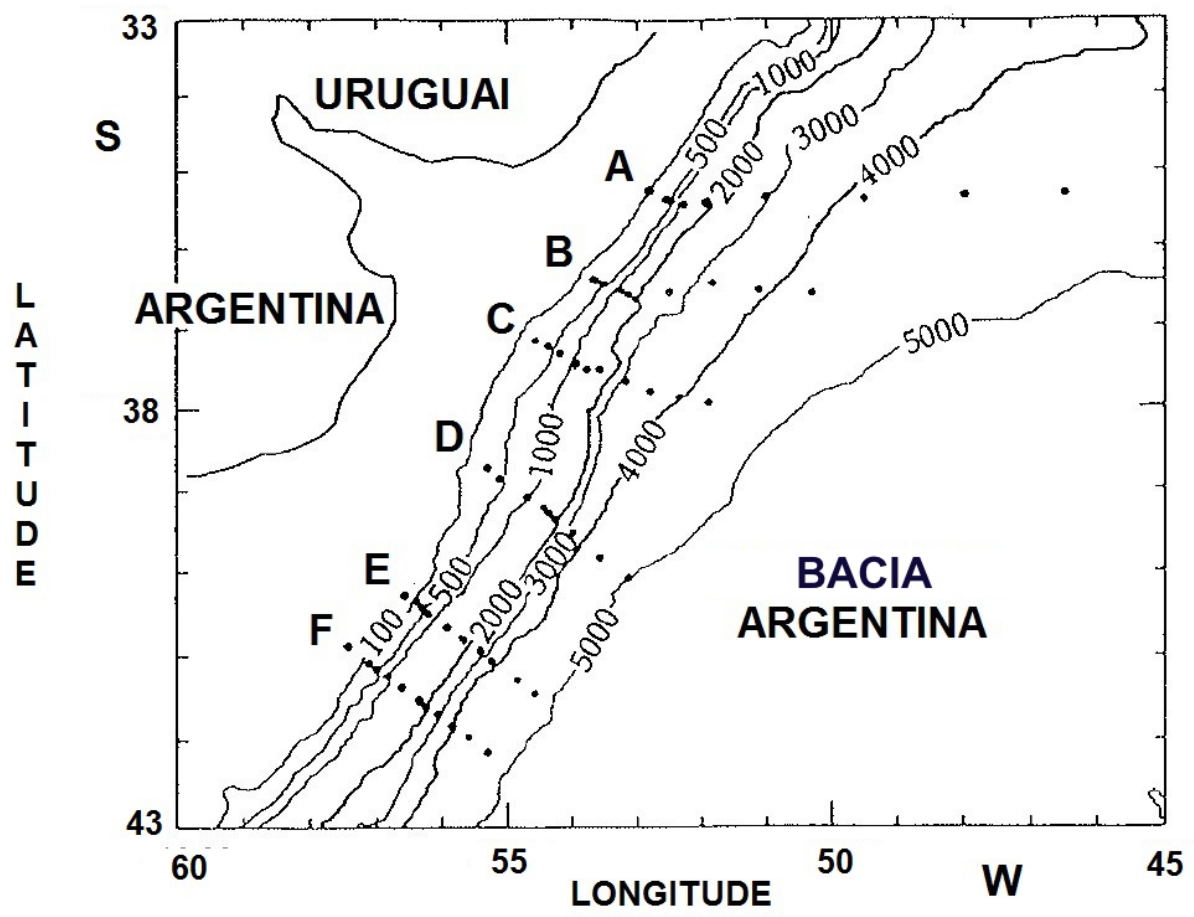

Figura 1.4: Localização das estações hidrográficas do cruzeiro Confluence 3. As radiais são referenciadas por A, B, C, D, E, F. Modificado de Provost et al. [1995].

\subsection{2 Água Modal Subtropical}

Amplamente estudadas no Hemisfério Norte, as águas modais constituem uma espécie de corpo d'água com o potencial de diagnosticar alterações climáticas ocorridas na atmosfera devido à mudanças nos processos de troca de calor entre o oceano e a atmosfera [Hanawa E Talley, 2001]. Sua formação ocorre geralmente desde o inverno até a primavera, quando condições atmosféricas severas com ventos de maior intensidade associadas à massas de ar com baixas temperaturas e menores índices de umidade relativa, junto da superfície do oceano, provocam o aumento do fluxo de calor latente do oceano para a atmosfera [Yu et al., 2008]. Essa perda de calor do oceano redunda no decréscimo do empuxo desse corpo d'água propiciando sua subsidência para camadas inferiores do oceano. O movimento convectivo que é gerado incrementa a mistura vertical das camadas da superfície até abaixo da camada de mistura, podendo chegar até a profundidade da termoclina permanente dependendo das condições na superfície.

Com o desenvolvimento da termoclina sazonal durante a primavera e o verão, ocorre o isolamento dessa camada de mistura profunda gerada no inverno. Com isso, 
têm-se a água modal formada e confinada abaixo da termoclina sazonal e acima da termoclina permanente, com suas temperatura, salinidade e vorticidade potencial características bem definidas Provost et al. [1999]. No decorrer do ano, esse volume de água modal sofrerá advecção lateral ao longo de sua isopicnal de equilíbrio por meio de processos de reestratificação e dissipação, provocando sua migração para regiões afastadas de seu local de formação [Douglass et al., 2013].

A interação oceano-atmosfera é em grande parte responsabilizada por mecanismos pelos quais a vorticidade potencial (VP) é extraída do oceano. A parcela da VP devido ao estiramento do tubo de vórtice está diretamente relacionada com o gradiente vertical de densidade [McCartney, 1982]. Águas verticalmente homogêneas, como as modais, apresentam pequena variação da densidade na vertical e, por conseguinte, baixos valores de VP. Desta forma, o estudo da interação oceano-atmosfera é de grande relevância para a compreensão da formação das águas modais subtropicais, já que estas são caracterizadas por baixa VP.

O estudo realizado por Worthington [1972] evidenciou a importância do fluxo de calor do oceano para a atmosfera como mecanismo responsável pela formação de massas de água no hemisfério norte. O autor observou que no limite oeste dos giros subtropicais do Atlântico e Pacífico Norte a perda de calor do oceano para a atmosfera ocorrida ao final do inverno provoca o afundamento de grandes porções de águas superficiais nessas regiões dos oceanos. O cálculo do calor armazenado, e a variação desse ao longo do tempo, pode indiretamente indicar a importância do fluxo de calor do oceano para a atmosfera nas regiões de formação de águas modais subtropicais, tipicamente no limite oeste dos giros oceânicos nessa faixa de latitude.

Estimativas do calor armazenado $\left(C_{A}\right)$ na coluna d'água são tradicionalmente baseadas em medidas in situ ou em conjuntos de dados climatológicos. Yan et al. [1995], por exemplo, realizaram um estudo de variabilidade do calor armazenado por meio de dados de XBT (eXpendable BathyTermograph) lançados de 1976 a 1989 em diversas posições entre as latitudes de $30^{\circ} \mathrm{N}$ e $40^{\circ} \mathrm{N}$ no Oceano Pacífico. Os autores observaram que a variação temporal da taxa de armazenamento de calor para a isoterma característica da camada de mistura correspondeu ao fluxo de calor tanto nos locais escolhidos quanto atravessando a bacia inteira. Além disso, verificaram que o cálculo da taxa 
de calor armazenado é afetado pela isoterma escolhida e escala espacial envolvida.

O estudo da circulação e da variabilidade temporal da água modal subtropical do Atlântico Sul, na região da CBM, ainda é incipiente. Em outras regiões do globo, onde os estudos de massas d'água deste tipo são muito mais frequentes, foram observadas diferentes escalas temporais governando a ocorrência e intensidade da formação dessas águas modais regionalmente.

\section{Água Modal Subtropical do Atlântico Norte}

O Atlântico Norte é a região do globo que detém, até o momento, a maior quantidade de estudos de água modal subtropical. A água modal subtropical do Atlântico Norte ou água de 18 graus (AM18) é estudada desde os trabalhos de Worthington [1959]. O autor descreveu a AM18 como uma camada de água isotérmica e isohalina, formada durante o inverno no Mar do Sargasso, com espessura superior a $250 \mathrm{~m}$, temperatura típica $(17,9 \pm 0,3)^{\circ} \mathrm{C}$ e salinidade $36,5 \pm 0,1$. O volume de AM18 apresenta variação interanual e interdecadal. Estudos voltados à investigação de processos de baixa frequência apontaram que invernos intensos, capazes de produzir mistura convectiva de mais de $500 \mathrm{~m}$ e portanto maiores volumes de água modal, ocorreram em intervalos de vários anos (1964, 1975, 1982 e 1988) [Talley E Raymet, 1982; Jenkins, 1987, 1998; Klein \& Hogg, 1996].

Kwon $\mathcal{E}$ Riser [2004] observaram que a água modal de $18^{\circ} \mathrm{C}$ apresentou um tempo médio de residência de $(3,57 \pm 0,54)$ anos, usando a série de dados de 1961 - 2000 do World Ocean Database 2001 (WOD2001), de perfiladores dos projetos World Ocean Circulation Experiment (WOCE) e Argo. O cálculo do tempo médio de residência consistiu da divisão do volume médio anual de AM18 pelo volume médio anual de água modal recém-formada em contato com a superfície, ou seja, representa a quantidade de períodos de formação necessários para recompor todo o volume médio de AM18 detectado na série temporal. Nesse estudo, o volume de água anualmente gerada foi de $(1,10 \pm 0,16) \times 10^{14} \mathrm{~m}^{3}$ para um volume médio total de água modal no inverno de $(3,93 \pm 0,20) \times 10^{14} \mathrm{~m}^{3}$. Os autores observaram ainda uma variabilidade interanual superior a 6 anos, onde invernos mais rigorosos provocaram maior formação de água modal e o contrário ocorrendo durante invernos menos intensos. 
Maze et al. [2013] estudaram os mecanismos de extração da VP do oceano por meio da comparação de padrões espaciais e de magnitude dos fluxos de VP na superfície, por origem diabática e do atrito, em uma simulação numérica de alta resolução do Atlântico Norte. O modelo representou satisfatoriamente vórtices de mesoescala e apresentou realismo no volume e na distribuição regional da água modal de $18^{\circ} \mathrm{C}$, tanto para a média anual quanto para o ciclo sazonal, quando comparados com outros estudos [Maze et al., 2009; Forget et al., 2011].

Maze et al. [2013] determinaram o valor de $26,34 \mathrm{~kg} \mathrm{~m}^{-3}$ para a densidade potencial do núcleo da água modal de $18^{\circ} \mathrm{C}$ no Atlântico Norte, com variação $( \pm 0,2) \mathrm{kg} \mathrm{m}^{-3}$, em consonância com estimativas anteriores [Forget et al., 2011; Kwon E Riser, 2004]. Nessa camada de densidade potencial ocorre uma convergência de fluxos de volume, da camada menos densa para a mais densa, muito maior na porção mais quente da frente no limite norte da Corrente do Golfo quando comparada à porção mais fria. Esta convergência foi responsável pela formação de aproximadamente $4 \mathrm{~Sv}$ de água modal subtropical por ano em média, durante o período de 2003 - 2006. A água modal de $18^{\circ} \mathrm{C}$ apresentou uma média anual de $350 \mathrm{~m}$ para a máxima espessura da camada entre $50^{\circ} \mathrm{W}$ e $55^{\circ} \mathrm{W}$, na latitude de $36^{\circ} \mathrm{N}$. Esse corpo d'água estava armazenado em dois reservatórios principais ao sul da Corrente do Golfo: um centrado em $52^{\circ} \mathrm{W}$ e o outro, coerente com as observações de Kwon E Riser [2004], em cerca de $70^{\circ} \mathrm{W}$.

Foi observado por Maze et al. [2013] um volume médio anual da AM18 de 57 Svy, onde 1 Svy $\simeq 3,15 \times 10^{13} \mathrm{~m}^{3}$ correspondentes a um fluxo de $1 \mathrm{~Sv}\left(=10^{6} \mathrm{~m}^{3} \mathrm{~s}^{-1}\right)$ mantido por um ano. A amplitude do ciclo sazonal do volume de AM18 foi cerca de 11 Svy com máximo ocorrendo ao final do mês de março (término do inverno boreal). Não foram observadas pelos autores significativa acumulação ou destruição da AM18 ao longo do período analisado por meio dos dados empregados.

Já Marshall et al. [2009] foram capazes de observar que, durante o inverno, a formação de água modal foi dominada por fluxos oceano-atmosfera enquanto a destruição da AM18 se deu primordialmente por fluxos não advectivos (mistura) no interior do oceano. Os autores verificaram a formação de $(9,3 \pm 1,8)$ Svy de AM18 no inverno, sendo $(4,9 \pm 1,8)$ Svy destes formados devido ao fluxo de calor oceano-atmosfera e $(3,7 \pm 1,8)$ Svy destruídos pela mistura vertical ocorrida no interior do oceano. 
Ainda sob a ótica dos mecanismos responsáveis pela extração de VP do oceano, Olsina et al. [2013] utilizaram a metodologia conhecida como pseudo vorticidade potencial (PVP) para estimar a VP aplicada sobre o oceano a partir de dados observados e gerar mapas climatológicos que indicassem a variabilidade interanual das forçantes. A PVP é uma grandeza obtida com a substituição da densidade potencial pela temperatura potencial no cálculo da vorticidade potencial. Segundo os autores, devido à correspondência entre a temperatura potencial e a densidade potencial dos afloramentos de AM18 durante o inverno, os resultados do estudo utilizando a PVP são equivalentes ao comportamento da VP observado nas áreas de formação de águas modais subtropicais.

O mapa global construído por Olsina et al. [2013] (Figura 1.5] evidencia a importância do fluxo de empuxo em relação ao fluxo total de pseudo vorticidade potencial (PVP) nas regiões subtropicais onde ocorre o encontro de CCO. No Atlântico Norte os autores observaram que o fluxo de empuxo tem contribuição dominante para a PVP atuando como forçante da formação de AM18. Tal prevalência não foi observada pelos autores no Atlântico Sul, onde os maiores gradientes verificados na região da CBM denotaram maior influência do vento nos processos de extração de VP do oceano, e por conseguinte, atuando como forçante principal da formação de água modal nessa região.

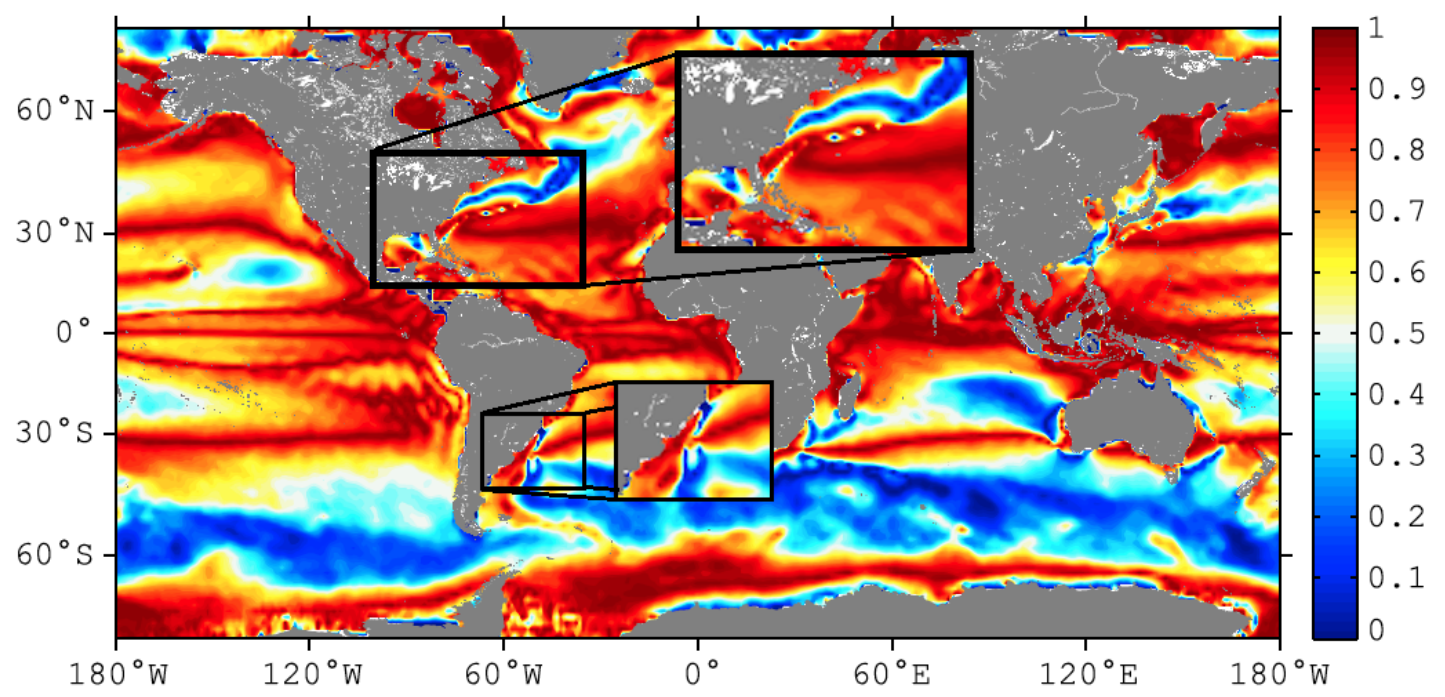

Figura 1.5: Média anual global da contribuição do fluxo de empuxo para o fluxo de PVP total. As áreas destacadas correspondem à região de formação de águas modais subtropicais no Atlântico Norte e no Atlântico Sul. Modificado de Olsina et al. [2013]. 
Embora a perda de calor do oceano para a atmosfera seja responsável por grande parcela de água modal formada na região subtropical do Atlântico Norte, Davis et al. [2013] observaram por meio de dados oriundos de dois fundeios posicionados ao sul da Corrente do Golfo e próximos da mesma, numa região típica de formação da AM18, que a advecção lateral exerce importante papel na consolidação das propriedades típicas dessa água modal, particularmente de sua temperatura, salinidade e na determinação do ínicio do processo de formação. Segundo os autores, tal influência ocorre pela manutenção da estratificação, retardando o início do processo de formação de AM18, por meio de um suprimento direto de calor e sal oriundo da Corrente do Golfo para as camadas superficiais. Desta forma foi observada a maior relevância desses processos laterais no fundeio mais próximo dessa CCO.

Silverthorne \& Toole [2013] empregaram perfiladores lagrangeanos na região da Corrente do Golfo com o objetivo de analisar mudanças no calor armazenado nas camadas superiores do oceano. Os autores observaram que a variabilidade do calor armazenado na camada de mistura nessa área típica de formação da AM18 é controlada primordialmente por processos advectivos e pelo intenso cisalhamento vertical provocado pela Corrente do Golfo. Entretanto, durante o inverno as variações do calor armazenado na camada de mistura foram dominadas pela forçante associada à passagem de intensas tempestades sobre a região do estudo.

O estudo dos processos envolvidos na dissipação e subducção da água modal recém formada foi realizado por Kelly E Dong [2013]. As regiões de formação de água modal foram caracterizadas pelas autoras como aquelas em que houve ocorrência de temperaturas da superfície do mar entre $17^{\circ} \mathrm{C}$ e $19^{\circ} \mathrm{C}$ coincidentes com camadas de AM18 com espessuras superiores a 100m durante o inverno. As autoras observaram um volume médio de AM18 de 3,9 $\times 10^{14} \mathrm{~m}^{3}$ ao final do inverno e 2,8 $\times 10^{14} \mathrm{~m}^{3}$ ao término do outono. Kelly \& Dong [2013] estimaram a formação de $2,4 \times 10^{14} \mathrm{~m}^{3}$ de volume de água modal nova a cada inverno em média, entretanto apenas $35 \%$ desse volume recém formado é advectado e alcança maiores profundidades na região de subducção, onde a AM18 não atinge a superfície durante o inverno. As autoras atribuíram uma perda de $65 \%$ do volume de AM18 recém formado à mistura causada pelo meandramento nas proximidades da Corrente do Golfo. 
O uso de perfiladores lagrangeanos por Fratantoni et al. [2013] permitiu que os autores realizassem observações diretas da circulação e estratificação da AM18 ao longo de 4 anos de observações. O estudo revelou que a circulação no interior da AM18 indicou significativa presença de vórtices, tanto próximo da Corrente do Golfo quanto ao longo do giro subtropical, associada com alterações na espessura da camada de AM18. Isso denota que os vórtices podem desempenhar importante papel na dispersão da AM18 dentro do giro subtropical. Além disso, os autores observaram que a maior parte da água modal afundada detectada pelos perfiladores do estudo estava isolada da atmosfera a menos de 24 meses.

\section{Interações Físico-Biológicas da AM18}

Palter et al. [2005] observaram que a participação da água modal na produtividade primária no oceano não se dá apenas pelo aporte de nutrientes trazidos para a zona eufótica pela convecção gerada durante seu processo de formação. Os autores verificaram que após invernos intensos, quando ocorreu maior formação de AM18, houve elevada depleção de nutrientes. Isso significa que camadas espessas de água modal com baixa concentração de nutrientes ao serem advectadas a partir da região de formação podem diminuir a produtividade primária nessas regiões remotas de onde ocorreu a formação, alterando a disponibilidade de nutrientes em subsuperfície. Como exemplo, citaram a concentração de nitrato em uma estação realizada próximo do arquipélago de Bermuda, ao sul da região de formação da AM18. Em julho de 1960, foi observada nesse ponto uma camada de AM18 com cerca de $400 \mathrm{~m}$ de espessura e concentração de nitrato de $2,5 \mathrm{mmol} \mathrm{m}^{-3}$ na profundidade de $500 \mathrm{~m}$. Na mesma profundidade, em julho de 1989, a concentração de nitrato observada foi de 7,1 $\mathrm{mmol} \mathrm{m}^{-3}$ para uma camada de AM18 inferior a 200 m. A camada de água modal ao ser advectada, provocou o movimento vertical da nutriclina para baixo, afastando a mesma do limite da zona eufótica e reduzindo a produtividade primária por escassez de nutrientes.

Uma possível explicação para a baixa concentração de nutrientes característica da AM18 foi apresentada por Lévy [2005]. A autora sugeriu que o crescimento do fitoplâncton na água modal subtropical durante o inverno provoca o consumo dos nu- 
trientes em larga escala e, em seguida, o início do processo de afundamento da água modal e sua advecção ao longo da porção subsuperficial do oceano reduz a eficiência do processo de remineralização, responsável pela reposição dos nutrientes consumidos, provocando a escassez de nutrientes e de dióxido de carbono $\left(\mathrm{CO}_{2}\right)$ na $\mathrm{AM} 18$. Por conseguinte, a baixa concentração de dióxido de carbono nas águas superficiais do oceano provocada pela formação de água modal subtropical permite a passagem de $\mathrm{CO}_{2}$ da atmosfera para a água do mar.

Andersson et al. [2013] estudaram a influência do processo de formação de AM18 no fluxo de $\mathrm{CO}_{2}$ no giro subtropical do Atlântico Norte. Os autores observaram que o carbono inorgânico dissolvido (CID) médio existente na AM18 recém formada durante o inverno de 2007 foi ligeiramente menor do que o CID observado em AM18 antigas cobertas pela picnoclina sazonal a montante da Corrente do Golfo. Tal resultado foi atribuído à mistura vertical de águas de superfície com baixa concentração de CID com a AM18 antiga, na região de formação. Estudos de Levine et al. [2011] também creditaram a essa mistura o movimento vertical para cima de $\mathrm{CO}_{2}$ antropogênico por meio de trocas gasosas e entranhamento de massas de água com elevada assinatura antropogênica.

Embora tenham verificado um aumento do CID de apenas $(4,1 \pm 2,7) \mu \mathrm{mol} \mathrm{kg}^{-1}$ entre fevereiro e março de 2007, ou seja ao final do inverno, Andersson et al. [2013] estimaram por meio da integração vertical desse aumento até a base da camada de mistura

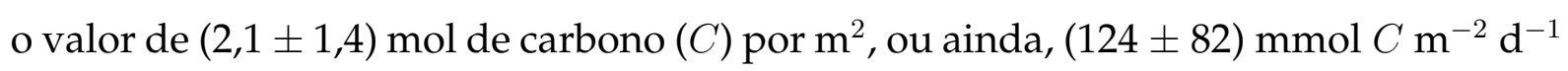
de aumento vertical para toda a camada de AM18. O valor total é considerável pois os autores trataram de uma camada de mistura de $\sim 500 \mathrm{~m}$ de espessura. Os autores calcularam o valor de $0,007 \mathrm{Pg} C y^{-1}$ a $0,015 \mathrm{Pg} \mathrm{Cy}^{-1}$ para o total de $\mathrm{CO}_{2}$ trazido à superfície anualmente pela formação de nova AM18. Para tanto, utilizaram o volume de AM18 total formado de 9,3 Svy obtido por Marshall et al. [2009], a espessura média da camada de mistura de 400 m durante a formação e o período de 30 a 60 dias para a AM18 em contato com a atmosfera. Entretanto, os autores avaliaram que a remoção efetiva de $\mathrm{CO}_{2}$ atmosférico e o tempo em que o gás permanece armazenado dependem da velocidade de destruição e renovação da AM18 e da quantidade de AM18 destruída e renovada. A variabilidade desses parâmetros está ligada a modos climáticos tais como 
a Oscilação do Atlântico Norte e o El Niño conforme estudos de Bates et al. [2002]; Gruber et al. [2002]; Levine et al. [2011].

Fenômenos de mesoescala, tais como vórtices, estão diretamente associados com a ocorrência de episódios de maior produtividade primária em regiões subtropicais predominantemente oligotróficas. Todavia, McGillicuddy et al. [2007] observaram que os vórtices anticiclônicos apresentam um padrão diferente da média quando propagando-se sobre um volume de água modal. Os vórtices anticiclônicos sem água modal aprofundam tanto a picnoclina sazonal quanto a principal enquanto vórtices de água modal, cujo nome foi associado pelos autores à existência de espessa camada de água modal, provocaram o afundamento da picnoclina principal e a elevação da picnoclina sazonal. Nos vórtices de água modal os autores verificaram que as velocidades geostróficas são governadas pelo afundamento da picnoclina principal, provocando o mesmo sentido de rotação dos vórtices anticiclônicos. Durante a formação e intensificação dos vórtices de água modal a ressurgência no interior dos mesmos é favorecida, assim como nos vórtices anticiclônicos sem água modal. Entretanto, a partir da redução de velocidade de rotação dos vórtices de água modal, a subsidência é favorecida, assumindo padrões semelhantes aos vórtices ciclônicos sem água modal.

Os vórtices de água modal observados por McGillicuddy et al. [2007] foram associados a máximos de Clorofila a (Chl-a) dominados por algas diatomáceas, detentoras de alta taxa de crescimento em condições de pouca luminosidade. Os máximos de Chl-a associados aos vórtices ciclônicos observados pelos autores tiveram predominância de Prochlorococcus spp. e prymnesiofitos, sendo inexistentes as algas diatomáceas. Os autores observaram que as concentrações de diferentes espécies se devem à interação da tensão de cisalhamento do vento com os vórtices de água modal propiciar o aumento do fluxo de nutrientes no interior dos mesmos. Em contraste, a interação com os vórtices ciclônicos provoca a redução do fluxo de nutrientes e a presença de espécies de menor tamanho e maior dependência da incidência de luz.

\section{Água Modal Subtropical do Pacífico Norte}

Os primeiros relatos da água modal subtropical do Pacífico Norte (AMSPN) foram realizados por Masuzawa [1969]. O autor descreveu a AMSPN como um grande 
volume de água com homogeneidade vertical semelhante a AM18, distribuído zonalmente por uma extensa área delimitada pelas correntes de Kuroshio, do Pacífico Norte, da Califórnia e corrente Norte Equatorial. Esse volume ocupava profundidades entre 100 e $300 \mathrm{~m}$ na latitude aproximada de $30^{\circ} \mathrm{N}$, e era caracterizado por uma temperatura média de $16,5^{\circ} \mathrm{C}$ e salinidade média de 34,75 .

Talley [1988] verificou a existência de regiões com vorticidade potencial menor que $2 \times 10^{-12} \mathrm{~m}^{-1} \mathrm{~s}^{-1}$ na parte oeste do giro subtropical do Pacífico Norte coincidentes com as áreas de ocorrência da AMSPN relatadas por Masuzawa [1969]. A autora observou ainda que o mínimo vertical na vorticidade potencial ocorrido aproximadamente na longitude $140^{\circ} \mathrm{E}$ coincidiu com a densidade potencial de $25,2 \mathrm{~kg} \mathrm{~m}^{-3}$. A região que o continha se estendia na direção leste, com acréscimo de densidade, até a longitude de $170^{\circ} \mathrm{W}$ onde alcançava o máximo de $26,0 \mathrm{~kg} \mathrm{~m}^{-3}$.

Suga et al. [1989] observaram por meio de uma radial de estações oceanográficas com emprego de equipamento CTD (Condutivity, Temperature and Depth) realizada ao longo da longitude $137^{\circ} \mathrm{E}$, diferentes valores característicos da AMSPN para o verão e o inverno. Foram analisados pelos autores dados de temperatura, salinidade, pressão e oxigênio dissolvido, coletados durante todos os meses de inverno desde 1967 e durante todos os meses de verão desde 1972 pela Agência Meteorológica do Japão. Adicionalmente à vorticidade potencial os autores empregaram a Utilização Aparente de Oxigênio (UAO), que corresponde à diferença entre a concentração de oxigênio numa parcela de água e o valor de saturação do oxigênio desta mesma parcela, como ferramenta para a caracterização da AMSPN.

A UAO tem tendência a aumentar devido ao consumo de oxigênio por processos orgânicos ao longo do tempo decorrido após a parcela de água estar isolada da atmosfera. Suga et al. [1989] observaram valores de UAO entre 0,55 e 0,65mL L ${ }^{-1}$ para o verão e de $0,85-0,95 \mathrm{~mL} \mathrm{~L}^{-1}$ para o inverno. Adicionalmente, verificaram por meio do emprego de correlação com atraso de seis meses aplicada aos valores característicos de temperatura potencial, salinidade e densidade potencial dos pontos com AMSPN, que as regiões que continham AMSPN no verão e no inverno subsequente aparentemente tiveram essa parcela de AMSPN formada no inverno imediatamente anterior. Os autores sugeriram que a AMSPN observada no verão tinha idade de 6 meses enquanto a 
AMSPN observada no inverno tinha 1 ano de idade, indicando que a AMSPN formada em um determinado inverno pode ter sido advectada a partir do local de formação na direção sul. Os valores típicos de temperatura potencial, salinidade e densidade potencial observados pelos autores para o verão foram $17,5^{\circ}-19,1^{\circ} \mathrm{C} ; 34,77$ - 34,89 e 24,75 $25,35 \mathrm{~kg} \mathrm{~m}^{-3}$. Para o inverno, os valores típicos observados para a AMSPN foram 15,9 $-17,7^{\circ} \mathrm{C} ; 34,71-34,83$ e $25,05-25,55 \mathrm{~kg} \mathrm{~m}^{-3}$.

De acordo com os estudos de Suga et al. [1989] a variação sazonal da posição da frente subtropical pode interferir na advecção e formação de AMSPN, tendo em vista o menor volume de AMSPN observado durante o período de grande meandramento do Kuroshio, particularmente no verão de 1977 e nos invernos de 1978 e 1979. Suga E Hanawa [1995] empregaram os dados disponíveis de temperatura, salinidade e oxigênio coletados no oeste do Pacífico Norte de 1945 a 1987 e localizados entre as latitudes de $10^{\circ}-40^{\circ} \mathrm{N}$ e entre as longitudes de $120^{\circ}-170^{\circ} \mathrm{E}$, compilados pelo Centro de Dados Oceanográficos do Japão, em seu estudo de circulação da AMSPN. Os autores confirmaram a advecção da AMSPN na direção sul sugerida por Suga et al. [1989], observando que a contracorrente de Kuroshio, que é parte da recirculação anticiclônica de Kuroshio, advecta a AMSPN formada no inverno a leste de $140^{\circ} \mathrm{E}$ na direção sudoeste de Honshu nos períodos em que não ocorre um grande meandramento do Kuroshio. Já na ocorrência desse meandramento, o sistema de recirculação foi dividido em dois giros anticiclônicos separados geograficamente pelo meridiano de $140^{\circ} \mathrm{E}$ e nenhuma advecção substancial da AMSPN na direção sudoeste foi observada.

O padrão de circulação da AMSPN na direção sudoeste a partir da região de formação observado em estudos pregressos foi correlacionado com o acúmulo de volumes de água com baixa vorticidade potencial (VP) ao sul do Japão por Qiu E Miao [2000]. Esse estudo foi baseado em um modelo numérico de duas camadas com equações primitivas para o Pacífico Norte. O acúmulo de volume de baixa VP seria responsável por iniciar o ciclo autossustentável de seleção do padrão de circulação da Corrente de Kuroshio ao sul do Japão, retilíneo ou meandrante, conforme explicado abaixo. De acordo com Qiu \& Miao [2000] esse acúmulo de baixa VP fortalece o giro de recirculação ao sul da Corrente de Kuroshio e pressiona a mesma a fluir paralelamente à costa (padrão retilíneo). Posteriormente, o fortalecimento do giro de recirculação au- 
menta o cisalhamento de velocidades do padrão retilíneo e provoca o surgimento de instabilidades baroclínica e barotrópica do sistema, conduzindo ao desenvolvimento do padrão meandrante (grande meandro de Kuroshio). Com o crescimento do meandro, ocorre a liberação de vórtices ciclônicos transportando água com alta VP a partir da costa, enfraquecendo o giro de recirculação. Ao longo do tempo, o acúmulo de volume de água com baixa VP é restabelecido ao sul do Japão e o ciclo é reiniciado.

Qiu et al. [2006] realizaram um estudo sinótico da AMSPN por meio de estações oceanográficas com emprego de CTD e de 20 perfiladores Argo, lançados na região da recirculação e na extensão da Corrente de Kuroshio. Os autores constataram que no período do estudo o jato da extensão de Kuroshio estava estável, com o giro de recirculação bem desenvolvido e com baixa incidência de vórtices de mesoescala regionais. Essas condições são favoráveis à formação de uma intensa AMSPN na região geograficamente confinada no giro de recirculação ao norte de $30^{\circ} \mathrm{N}$. A AMSPN foi caracterizada por temperaturas de $16,0-18,0^{\circ} \mathrm{C}$; salinidade de $34,70-34,85$ e densidade de $25,2-25,5 \mathrm{~kg} \mathrm{~m}^{-3}$. Entretanto, ao sul de $30^{\circ} \mathrm{N}$ Qiu et al. [2006] observaram que a camada de mistura do inverno anterior atingiu profundidades menores $(150 \mathrm{~m})$ em comparação com as observadas no giro de recirculação e que a maioria dos núcleos de baixa vorticidade potencial foram dissipados com o desenvolvimento da termoclina sazonal após o inverno. Assim sendo, os autores sugeriram que a AMSPN remanescente ao sul de $30^{\circ} \mathrm{N}$ se deve mormente à indução lateral a partir do giro de recirculação e não à formação local por convecção na camada de mistura.

A variabilidade decadal da AMSPN foi analisada por Qiu E Chen [2006] utilizando dados de CTD e XBT contidos no World Ocean Atlas 2001 (WOA01) [Conkright et al., 2002], dados de perfiladores Argo e dados de temperatura obtidos pelo Centro de Dados Oceanográficos do Japão. Além disso, os autores empregaram dados de anomalia da altura da superfície do mar (AASM) obtidos por meio de satélites altimétricos e fornecidos pelo Centre National d'Etudes Spatiales (CNES) [Ducet et al., 2000] para detectar a variabilidade temporal da superfície dinâmica nas proximidades da região do giro de recirculação e extensão da Corrente de Kuroshio. Para quantificar as forçantes devido aos processos de interação oceano-atmosfera sobre a região de formação de AMSPN foram utilizados dados de fluxo de calor pela superfície de reanálise oriundos 
do National Center for Environmental Prediction-National Center for Atmospheric Research (NCEP-NCAR) [Kistler et al., 2001].

Os autores observaram a presença de sinal decadal na variabilidade da AMSPN caracterizado pela progressiva redução da profundidade atingida pela camada de mistura no inverno anterior à formação da AMSPN no período de 1993 a 1999. Adicionalmente, ocorreu um subsequente espessamento dessa camada a partir do ano 2000, tanto na região central de formação no giro de recirculação da Corrente de Kuroshio (localizada entre as latitudes $31^{\circ}-36^{\circ} \mathrm{N}$ e entre as longitudes $141^{\circ}-150^{\circ} \mathrm{E}$ ) quanto ao sul do giro de recirculação $\left(26^{\circ}-30^{\circ} \mathrm{N}, 140^{\circ}-144^{\circ} \mathrm{E}\right)$. No primeiro período a camada de mistura no inverno sofreu redução até 200 m na região de formação. Entretanto, nos anos de 1995/96 e 2003/04, quando ocorreu maior formação de AMSPN, foi verificada uma camada de mistura no inverno de $\sim 320 \mathrm{~m}$. A forçante associada às trocas de calor entre o oceano e a atmosfera foi responsável por $80 \%$ da variância da camada de mistura no inverno anterior à formação da AMSPN.

Suga et al. [2008] analisaram o processo de ventilação da picnoclina permanente na região subtropical do Pacífico Norte a partir da contribuição proveniente das águas modais subtropicais. Os autores calcularam a vorticidade potencial (VP) da água afundada originada no limite inferior da camada de mistura de inverno com base na estimativa de taxa de subducção. Assim, observaram que a alta taxa de subducção foi a principal responsável pela manutenção dos volumes de água com baixa vorticidade potencial da AMSPN. Para as demais águas modais do Pacífico Norte, não relacionadas com a região de encontro de duas CCO, a baixa taxa de advecção de densidade (fluxo transversal às isopicnais) foi determinante para a baixa VP das mesmas. Verificaram também que o tempo de renovação para AMSPN menos densa $\left(25,0-25,3 \mathrm{~kg} \mathrm{~m}^{-3}\right)$ foi de 2 anos enquanto que a AMSPN mais densa $\left(25,3-25,6 \mathrm{~kg} \mathrm{~m}^{-3}\right)$ preservou seus valores típicos de formação por um período de 5 - 9 anos.

O emprego do modelo númerico de alta resolução do Parallel Ocean Program (POP), aplicado para a região da extensão da Corrente de Kuroshio, viabilizou as estimativas de volume da AMSPN realizadas por Rainville et al. [2007]. O referido modelo foi inicializado a partir da climatologia do Modular Ocean Data Assimilation System (MODAS) da Marinha Americana com resolução espacial de 1/8 [Fox et al., 2002]. Os 
autores registraram o valor médio de $1,0 \times 10^{14} \mathrm{~m}^{3}$ de volume formado ao término do inverno, sendo mantidos em média $3,5 \times 10^{14} \mathrm{~m}^{3}$ ao longo do ano, para os três anos de simulação (1998 a 2000) do estudo.

Douglass et al. [2012] empregaram o modelo POP supracitado com rodada global e condições atmosféricas de superfície repetidas anualmente, conhecidas como forçantes anuais normais do NCEP-NCAR [Large E Yeager, 2009]. Significativa variabilidade interanual e decadal do volume de AMSPN na região de formação foi observada pelos autores. Essa variabilidade temporal de larga escala foi atribuída à características intrínsecas do oceano, previamente observadas por Qiu \& Miao [2000]. O volume médio observado pelos autores foi de $1,15 \times 10^{15} \mathrm{~m}^{3}$ ao longo de 120 anos de simulação.

Douglass et al. [2012] verificaram ainda a presença de um ciclo sazonal bem definido e de diferenças nos parâmetros físicos da AMSPN de acordo com a região onde foi detectada. Próximo da costa do Japão a AMSPN foi encontrada em maiores profundidades, mais quente e menos densa do que os valores típicos observados pelos autores ao sul da extensão da Corrente de Kuroshio para leste. Essa variabilidade foi confirmada pela idade da AMSPN obtida pelos autores a partir de dados de traçadores de clorofluorcarbonos (CFC) que indicaram a média de 4,1 anos, com variação desde 3,0 anos na porção mais a leste até 4,9 anos no extremo oeste da área onde ocorreu AMSPN. Dessa forma, Douglass et al. [2012] identificaram que a formação da AMSPN se dá, ao sul da extensão da Corrente de Kuroshio $\left(\sim 36^{\circ} \mathrm{N}\right)$, sendo em média formada mais de $40 \%$ de água modal nova entre as longitudes $150^{\circ}-165^{\circ} \mathrm{E}$ e $30 \%$ entre as longitudes $165^{\circ}-180^{\circ} \mathrm{E}$. Apenas $5 \%$ do volume total formado por ano ocorre a oeste da longitude $140^{\circ} \mathrm{E}$ e os autores observaram a influência do grande meandro de Kuroshio na variabilidade do volume formado.

O estudo comparativo entre as águas modais subtropicais do Atlântico Norte (AM18) e do Pacífico Norte (AMSPN) desenvolvido por Douglass et al. [2013] apresentou aproximadamente o mesmo volume de água modal para os dois oceanos $(1,0$ $\times 10^{15} \mathrm{~m}^{3}$ ). Eles evidenciaram que mudanças no volume médio são apenas da ordem de $5 \%$, sendo o desvio padrão do volume médio de $4,9 \times 10^{13} \mathrm{~m}^{3}$ para a AM18 e $5,2 \times 10^{13} \mathrm{~m}^{3}$ para a AMSPN. Em ambas as bacias foi observada a dominância do ciclo sazonal com magnitude muito superior a da variabilidade interanual, com máximo ao 
final do inverno e mínimo ao término do outono.

\subsection{3 Água Modal Subtropical do Atlântico Sul (AMSTAS)}

Um número de observações consideravelmente menor orienta o conhecimento em relação à água modal no Atlântico Sul. Gordon [1981] em seu estudo sobre a ventilação da termoclina no Atlântico Sul, por meio de estações hidrográficas realizadas entre 8 de dezembro de 1979 e 10 de janeiro de 1980, descreveu pela primeira vez o que seria conhecido posteriormente por Água Modal Subtropical do Atlântico Sul (AMSTAS). $\mathrm{O}$ autor caracterizou essa massa d'água, obtida na sua estação número 37 $\left(53,5^{\circ} \mathrm{W} / 42,5^{\circ} \mathrm{S}\right)$, como uma espessa camada aproximadamente homogênea de 200 $\mathrm{m}$, coberta por uma fina camada de $50 \mathrm{~m}$ de água de superfície de baixa salinidade. Os parâmetros físicos da camada observados pelo autor foram temperaturas de 13 a $14^{\circ} \mathrm{C}$, salinidade 35,7 e densidade potencial $\left(\sigma_{\theta}\right)$ de $26,65 \mathrm{~kg} \mathrm{~m}^{-3}$. Gordon [1981] sugeriu que a camada relativamente quente e salina abaixo da superfície era remanescente da camada de mistura de inverno e que a camada fina de baixa salinidade existente na superfície seria proveniente de fenômeno pós-inverno. A origem dessa água modal atribuída pelo autor foi a extensão da Água Central do Atlântico Sul (ACAS) transportada em direção ao pólo sul pela CB, entretanto Gordon [1981] a denominou primeiramente como Água Modal Subantártica.

Estudos posteriores de McCartney [1982] e Roden [1989] observaram dois tipos de água modal no Atlântico Sul. Uma delas, formada na zona Subantártica, com $\sigma_{\theta}=27,2 \mathrm{~kg} \mathrm{~m}^{-3}$ classificada como Água Modal Subantártica. A outra menos densa, apresentou $\sigma_{\theta} \approx 26,5 \mathrm{~kg} \mathrm{~m}^{-3}$ e está relacionada com a Água Modal Subantártica descrita por Gordon [1981], constituindo de fato um tipo de AMSTAS devido sua região de formação estar contida no interior do giro subtropical. A ocorrência dessa água modal com densidade de 26,5 $\mathrm{kg} \mathrm{m}^{-3}$ foi observada por McCartney [1982] na extensão para leste até $20^{\circ} \mathrm{W}$ da radial zonal do International Geophysical Year (IGY) realizada em $32^{\circ} \mathrm{S}$. A presença de água modal semelhante foi também notada por Tsuchiya et al. [1994] por meio de uma longa radial meridional realizada de fevereiro a abril de 1989 ao longo de $25^{\circ} \mathrm{W}$, desde o Equador até $54^{\circ} \mathrm{S}$ (Ilha Georgia do Sul). Os autores observaram a ocorrência de dois tipos de água modal sendo uma com densidade de $26,7 \mathrm{~kg} \mathrm{~m}^{-3}$ en- 
tre a Frente Subtropical em $42^{\circ} \mathrm{S}$ e a Frente da Corrente do Brasil em $34^{\circ} \mathrm{S}$, e a outra com densidade de $26,6 \mathrm{~kg} \mathrm{~m}^{-3}$ ocorrendo ao norte da Frente da Corrente do Brasil. Ambas foram assumidas pelos autores como sendo geradas por forçantes convectivas no inverno.

A variabilidade das águas modais contidas no giro subtropical do Atlântico Sul permaneceram sem estudo até o trabalho de Provost et al. [1999]. Os autores realizaram uma classificação das águas modais por meio de dados hidrográficos e dados de batitermógrafos descartáveis (XBT) coletados no período de 1983 a 1996. A análise da variabilidade dessas águas foi relacionada com flutuações das forçantes atmosféricas na região.

Provost et al. [1999] identificaram três tipos de água modal por meio da detecção de baixos gradientes verticais de temperatura associados com mínimos valores de vorticidade potencial. Essa análise foi baseada em dados de radiais hidrográficas realizadas em: i) janeiro de 1995 na região da CBM $\left(37^{\circ} \mathrm{S}\right)$, ii) em outubro e novembro de 1983 a leste da bacia do Atlântico Sul e junto da costa da África e iii) duas radiais meridionais realizadas entre fevereiro e abril de 1989 ao longo de $25^{\circ} \mathrm{W}$ e de outubro a novembro de 1983 ao longo de $2^{\circ}$ E. Particularmente na região da CBM, os autores observaram a presença de todos os três tipos de água modal mapeados pelo estudo, com $\sigma_{\theta}$ de 26,2; 26,45 e 26,6 $\mathrm{kg} \mathrm{m}^{-3}$, sendo então classificadas como Água Modal Subtropical dos tipos 1, 2 e 3, respectivamente. A mais quente foi a água modal do tipo 1, com valores de temperatura potencial $(\theta)$ de $(17 \pm 1)^{\circ} \mathrm{C}$, densidade de $26,2 \mathrm{~kg} \mathrm{~m}^{-3}$, salinidade $(S)$ de $(36,0 \pm 0,1)$ e vorticidade potencial menor que $1,2 \times 10^{-12} \mathrm{~m}^{-1} \mathrm{~s}^{-1}$, correspondente a um máximo de salinidade subsuperficial centrado em cerca de $100 \mathrm{~m}$ de profundidade com $150 \mathrm{~m}$ de espessura da camada. A água modal do tipo 2 foi encontrada entre $150 \mathrm{~m}$ e $400 \mathrm{~m}$ de profundidade e tinha como características $\theta=(15 \pm 1)^{\circ} \mathrm{C}$, $\sigma_{\theta}=(26,45 \pm 0,05) \mathrm{kg} \mathrm{m}^{-3}, S=35,6 \pm 0,15$ e vorticidade potencial inferior a $0,5 \times 10^{-12}$ $\mathrm{m}^{-1} \mathrm{~s}^{-1}$. O terceiro tipo tinha vorticidade potencial maior que $0,8 \times 10^{-12} \mathrm{~m}^{-1} \mathrm{~s}^{-1} \mathrm{e}$ menor que $1,2 \times 10^{-12} \mathrm{~m}^{-1} \mathrm{~s}^{-1}$ associada aos menores valores de temperatura e salinidade $\left(\theta=(13,0 \pm 1)^{\circ} \mathrm{C}\right.$ e $\left.S=35,3 \pm 0,25\right)$ e às maiores densidades $\left(26,65 \pm 0,05 \mathrm{~kg} \mathrm{~m}^{-3}\right)$, posicionados entre $400 \mathrm{~m}$ e $600 \mathrm{~m}$. Estes três mínimos de vorticidade potencial foram observados pelos autores também na região de recirculação do giro subtropical, a oeste 
de $40^{\circ} \mathrm{W}$ e ao sul de $30^{\circ} \mathrm{S}$.

Estudo recente de Sato E Polito [2014] apresentou um critério robusto para qualificar os diferentes tipos de água modal observados nos dados obtidos por meio de perfiladores lagrangeanos do Projeto Argo. Os autores selecionaram perfis de temperatura potencial $(\theta)$ e salinidade $(S)$ realizados pelos perfiladores Argo no período de 2000 a 2013 em toda a bacia do Atlântico Sul, limitada ao norte pelo Equador e ao sul pela latitude $50^{\circ} \mathrm{S}$. Em seguida, identificaram amostras com vorticidade potencial inferior a $1,5 \times 10^{-10} \mathrm{~m}^{-1} \mathrm{~s}^{-1}$, gradiente vertical de temperatura menor que $0,01{ }^{\circ} \mathrm{C}$ $\mathrm{m}^{-1}$ acima da termoclina principal, temperaturas variando de $11,5^{\circ} \mathrm{C}$ a $18,5^{\circ} \mathrm{C}$ e salinidade variando de 34,7 a 36,5, como possíveis candidatos à água modal subtropical. Devido aos fatores estabelecidos pelos autores, os valores de densidade atribuídos às amostras que seriam avaliadas como possíveis águas modais no estudo foram limitados a $\sigma_{\theta}=25,6 \mathrm{~kg} \mathrm{~m}^{-3}$ a $26,8 \mathrm{~kg} \mathrm{~m}^{-3}$.

Após esta seleção, os autores realizaram uma análise de clusters não hierárquica K means [Gong E Richman, 1995] com o objetivo de agrupar as amostras selecionadas de forma quantitativa de acordo com valores semelhantes de temperatura potencial, salinidade, densidade potencial, posição geográfica e tempo. A distribuição dos pontos semelhantes se dá em torno de um centróide de referência, sob a condição de que as distâncias relativas a ele são minimizadas. A partir deste critério estatístico que primou pela preservação da continuidade dos volumes de água modal, tendo considerado a distribuição horizontal das amostras como um dos fatores de qualificação dos seus diferentes tipos, Sato E Polito [2014] observaram a existência de três tipos de Água Modal Subtropical do Atlântico Sul (AMSTAS), cuja ocorrência se dá em regiões distintas:

1. A AMSTAS 1 apresentou-se mais concentrada a oeste de $25^{\circ} \mathrm{W}$ na região da retroflexão da CB e na região afetada por incursões da CB alongando-se para o sul [Stramma E England, 1999]. A localização do centróide de referência para este cluster foi $36,8^{\circ} \mathrm{W}$ e $36,2^{\circ} \mathrm{S}$, com temperatura e salinidade médias associadas de $(15,0 \pm 0,9)^{\circ} \mathrm{C}$ e $(35,6 \pm 0,2)$. A densidade potencial média que caracterizou esta água modal foi de $(26,4 \pm 0,1) \mathrm{kg} \mathrm{m}^{-3}$ e sua espessura média da camada foi de $(159 \pm 53) \mathrm{m}$. 
2. A AMSTAS 2 ocupou uma ampla área desde a África até $55^{\circ} \mathrm{W}$ e apresentouse como a menos densa das AMSTAS $\left(\sigma_{\theta}=(26,1 \pm 0,1) \mathrm{kg} \mathrm{m}^{-3}\right)$. Com centróide localizado em $2,8^{\circ} \mathrm{W}$ e $32,4^{\circ} \mathrm{S}$, este cluster apresentou salinidade média de $(35,7$ $\pm 0,2)$ e temperatura média de $(16,7 \pm 0,9)^{\circ} \mathrm{C}$. A espessura média da camada da AMSTAS 2 foi de $(152 \pm 42) \mathrm{m}$.

3. A AMSTAS 3 formou-se ao longo da Frente Subtropical (FST), na fronteira sul do giro subtropical. O centróide obtido na análise de clusters localizou-se em $14,3^{\circ} \mathrm{W}$ e $38,0^{\circ} \mathrm{S}$. Com temperatura e salinidade médias de $(13,2 \pm 0,9)^{\circ} \mathrm{C}$ e $(35,2 \pm 0,2)$, foi o mais frio e menos salino dos três tipos observados no estudo. A densidade potencial média foi de $(26,5 \pm 0,1) \mathrm{kg} \mathrm{m}^{-3}$ e sua espessura média da camada foi de $(164 \pm 61) \mathrm{m}$.

Devido à distribuição temporal irregular dos perfiladores Argo, Sato \& Polito [2014] estudaram o ciclo sazonal de formação das AMSTAS por meio da média, durante o verão e o inverno em separado, da densidade potencial de cada perfilador na profundidade da vorticidade potencial média. Foi possível observar que a formação ocorreu principalmente entre os meses de julho e outubro. Nas demais estações do ano, as AMSTAS apresentaram-se submersas e com densidades ligeiramente superiores durante todo o ano, exceto para a AMSTAS 2 que apresentou-se agrupada em torno do período de formação apenas, sendo menos evidente durante o verão. Devido a AMSTAS 2 ser a de menor densidade dentre as AMSTAS, é esperado que isto ocorra já que o aquecimento das camadas de superfície seria suficiente para restabelecer a estratificação no interior da camada deste tipo de água modal. Não foi observada pelos autores tendência significativa de alteração da densidade potencial destas águas modais ao longo do período estudado.

Os autores realizaram ainda o estudo comparativo da energia cinética turbulenta (ECT) associada às espessuras da camada de AMSTAS. Foi observado por meio do espectro cruzado que a AMSTAS 1 foi a única das três águas modais do estudo claramente correlacionada no período anual. A máxima espessura da camada de AMSTAS 1 ocorre 80 dias antes da máxima ECT. Com isso, um aumento da ECT poderia redundar na redução do volume de AMSTAS 1. Os autores observaram ainda que, apenas $22,4 \%$ dos perfis ARGO que foram selecionados por conter AMSTAS encontravam- 
se no interior de um dos vórtices identificados e catalogados por Chelton et al. [2011]. $80 \%$ dos vórtices que continham AMSTAS eram anticiclônicos. Sato E Polito [2014] não foram capazes de afirmar por meio do estudo que mecanismo pode causar a maior incidência de AMSTAS no interior de vórtices anticiclônicos, entretanto, foi possível observar que não há uma clara ligação dos processos de formação, transporte e destruição das AMSTAS com a formação e propagação de vórtices.

É digno de nota que todos os estudos realizados para a investigação de águas modais subtropicais no Atlântico Sul, até então, empregaram dados hidrográficos coletados por projetos que tinham por objetivo principal a observação de outros fenômenos de meso e larga escala na região, sendo o estudo das águas modais aplicado a conjuntos de dados inespecíficos para esse fim, por aproveitamento.

\section{Interações Acústicas da AMSTAS}

O conhecimento da distribuição espacial da AMSTAS é fundamental para o entendimento da propagação acústica na área de ocorrência desse grande volume de águas homogêneas. Ferreira et al. [2015] observaram que a estrutura vertical aproximadamente homogênea da camada de AMSTAS apresentou um aspecto refratário em termos acústicos, em todas as simulações realizadas por meio do modelo de propagação acústica TRACEO [Rodríguez, 2011].

Os autores observaram grandes variações nas trajetórias dos raios sonoros e, consecutivamente, na propagação da energia acústica em função de pequenos deslocamentos na profundidade da fonte. Ferreira et al. [2015] verificaram ainda que nas proximidades da Elevação do Rio Grande os efeitos decorrentes do posicionamento horizontal da fonte acústica no interior da camada de AMSTAS são mais perceptíveis. Isso se deve às alterações no relevo submarino em regiões mais próximas das encostas da Elevação do Rio Grande e à maior interação com o fundo bom refletor característico das mesmas. 


\subsection{Objetivos}

Por se tratar de um estudo específico da Água Modal Subtropical do Atlântico Sul do tipo 1 (AMSTAS 1) classificada por Sato E Polito [2014], na região sudoeste do referido oceano, esse volume d'água será doravante mencionado apenas por AMSTAS.

\subsubsection{Hipótese}

Sabemos que a água modal subtropical do Atlântico Sul ocupa uma região contínua próximo à Confluência Brasil-Malvinas e da retroflexão da Corrente do Brasil e que sua formação está associada à perda de calor pela superfície. Dessa forma, o espessamento da camada de baixa vorticidade potencial associada à AMSTAS, ocorrido durante a formação, tem como resposta oceânica a perda de calor armazenado. Assim, temos por hipótese que:

Na região da Confluência Brasil-Malvinas e retroflexão da Corrente do Brasil a espessura e a profundidade da camada de Água Modal Subtropical do Atlântico Sul (AMSTAS) variam meridionalmente a partir da área de formação, sendo esta associada com a região de perda de calor armazenado.

A confirmação de tal hipótese torna possível a utilização de dados de altímetros para monitorar a formação de água modal subtropical continuamente.

\subsubsection{Objetivos Específicos}

Os objetivos dessa tese consistem em:

- Obter o campo de distribuição horizontal das camadas isopicnais referentes à densidade potencial típica de AMSTAS, a partir de dados in situ, realizando a análise de espessura da camada de água modal subtropical detectada, na região da CBM e retroflexão da CB;

- Obter campos mensais de distribuição horizontal das camadas isopicnais referentes à densidade potencial típica de AMSTAS, a partir de dados de modelo oceânico, na região da $\mathrm{CBM}$ e retroflexão da $\mathrm{CB}$, realizando o cálculo de volume 
de AMSTAS formado e afundado, além de analisar a espessura da camada e sua variabilidade temporal; e

- Obter campos mensais do calor armazenado estimado por meio de dados de modelo oceânico e dados de altímetro, na região da CBM e retroflexão da CB, realizando a análise dos padrões observados associados com a ocorrência da AMSTAS.

A caracterização de águas modais subtropicais por meio de observações in situ confere robustez aos parâmetros físicos identificados, permitindo a validação e concepção de modelos numéricos oceanográficos dedicados à correta identificação e ao estudo das mesmas.

A execução do primeiro cruzeiro oceanográfico planejado exclusivamente para estudo de águas modais no Atlântico Sul, permitiu realizar a caracterização e estimativa inicial de distribuição espacial da AMSTAS em um período intermediário entre dois ciclos de formação. Por meio de dois perfiladores Argo lançados durante o referido cruzeiro foi examinada nos meses subsequentes a evolução da espessura da camada de AMSTAS detectada. A realização de simulações por meio de modelos numéricos oceânicos para a região de estudo, permitiu expandir a estimativa inicial e realizar a detecção da AMSTAS e o cálculo de seu volume médio mensal, a fim de verificar a variabilidade do mesmo na região da CBM ao longo do ano. Além disso, a disponibilidade e a resolução espaço-temporal de dados de satélite altímetro na região de estudo viabilizou o cálculo do calor armazenado e a correlação do mesmo com as áreas de formação de AMSTAS identificadas. No Capítulo 2, serão apresentados os dados que serviram de base para a presente tese.

No Capítulo 3, serão apresentados os procedimentos metodológicos empregados no planejamento da missão, no tratamento e análise dos dados coletados in situ, oriundos das simulações numéricas oceanográficas e da anomalia da altura da superfície do mar (AASM).

As análises realizadas no capítulo supracitado são consolidadas no Capítulo 4. onde serão discutidos os resultados da caracterização e distribuição espacial da AMSTAS obtidos por meio dos dados do cruzeiro oceanográfico, apresentados os mapas horizontais de distribuição da AMSTAS obtidos por meio dos modelos numéricos 
oceanográficos e as estimativas de volume médio mensal de AMSTAS para a região da CBM e será descrita a correlação do calor armazenado estimado com a formação de AMSTAS. E, finalmente, no Capítulo 5, será apresentado um sumário dos resultados, bem como as conclusões e sugestões para trabalhos futuros. 


\section{Capítulo 2}

\section{Conjunto de Dados}

\subsection{Preâmbulo}

São escassas as oportunidades no meio oceanográfico em que se dispõe de dados coletados in situ, particularmente no Atlântico Sul. Tornam-se ainda mais invulgares as comissões oceanográficas conduzidas para a análise de fenômenos de meso e larga escala em regiões distantes da costa, as quais exigem elevado esforço logístico e navios de pesquisa de maior porte, construídos e preparados para longas travessias sob ventos intensos e condições severas de estado do mar. De tal sorte que os poucos dados coletados por navios nessa região até o momento, assim o foram durante o verão austral na plataforma continental, em sua maioria.

A escassez de dados in situ compromete sobremaneira o estudo de fenômenos de meso e larga escala, tais como a formação, afundamento e advecção das águas modais subtropicais. O emprego de modelos numéricos oceanográficos ameniza essa vicissitude típica de estudos no Atlântico Sudoeste, provendo longas e contínuas séries temporais de dados que viabilizam a análise da variabilidade desses processos oceânicos ocorridos em extensas áreas da Terra.

Desde o início da década de 1990, a aquisição quase simultânea de medidas da altura da superfície do mar (ASM) e radiométricas da temperatura da superfície do mar (TSM), têm fornecido informações significativas sobre a circulação oceânica e sobre as interações entre o oceano e a atmosfera. A ASM é uma variável dependente da estrutura termohalina da coluna de água. Nas escalas de tempo e espaço tratadas neste 
estudo os dados altimétricos podem descrever feições que não sejam perceptíveis nas imagens termais devido à cobertura de nuvens ou devido à perda da assinatura termal superficial através de interações oceano-atmosfera.

Graças ao apoio da Marinha do Brasil, por meio de um de seus navios de pesquisa, foi possível congrassar na presente tese o emprego de dados coletados in situ com dados oriundos de modelos oceanográficos gerenciados pelo Centro de Hidrografia da Marinha (CHM). Foram utilizados ainda dados provenientes dos satélites altímetros Jason-2, Cryosat-2 e Saral/AltiKa, disponibilizados pelo Collecte Localisation Satellites (CLS), para cálculo do calor armazenado nas regiões típicas de formação de águas modais subtropicais. A seguir serão apresentados esses dados, bem como algumas características dos sistemas e equipamentos utilizados na coleta dos mesmos. $\mathrm{O}$ processamento dos dados empregados no estudo será apresentado no Capítulo 3.

\subsection{Dados Hidrográficos In Situ}

No intuito de confirmar a presença de AMSTAS na área descrita por Sato $\mathcal{E}$ Polito [2014], entretanto empregando uma observação sistemática e quase-sinótica do fenômeno, foram utilizados no presente estudo dados hidrográficos coletados pelo Navio Hidroceanográfico (NHo) “Cruzeiro do sul” (H-38), da Marinha do Brasil (MB). O cruzeiro ocorreu entre $1^{\circ}$ de abril e 8 de maio de 2015, por meio de 45 estações oceanográficas realizadas, na área compreendida entre as longitudes de $30^{\circ} \mathrm{W}$ e $40^{\circ} \mathrm{W}$ e as latitudes de $30^{\circ} \mathrm{S} \mathrm{e} 38^{\circ} \mathrm{S}$. Essa campanha constituiu o primeiro cruzeiro oceanográfico, denominada Comissão "Oceano Sul"(OCSUL), planejado e conduzido exclusivamente para o estudo de água modal subtropical no Atlântico Sul de que se tem registro.

Para planejamento da OCSUL, foi utilizado um conjunto de dados composto por médias mensais de temperatura e salinidade obtidas a partir de dados hidrográficos in situ, oriundos do sistema In Situ Analysis System (ISAS) [Gaillard et al., 2009]. O ISAS foi desenvolvido e é mantido pelo Laboratoire de Physique dês Océans (LPO) pertencente ao Institut Français de Recherche pour L'exploitation de La Mer (Ifremer). A construção das médias mensais é baseada em dados de perfiladores Argo, CTD e XBT (do inglês eXpendable BathyThermograph). A climatologia do ISAS foi utilizada para a detecção da 


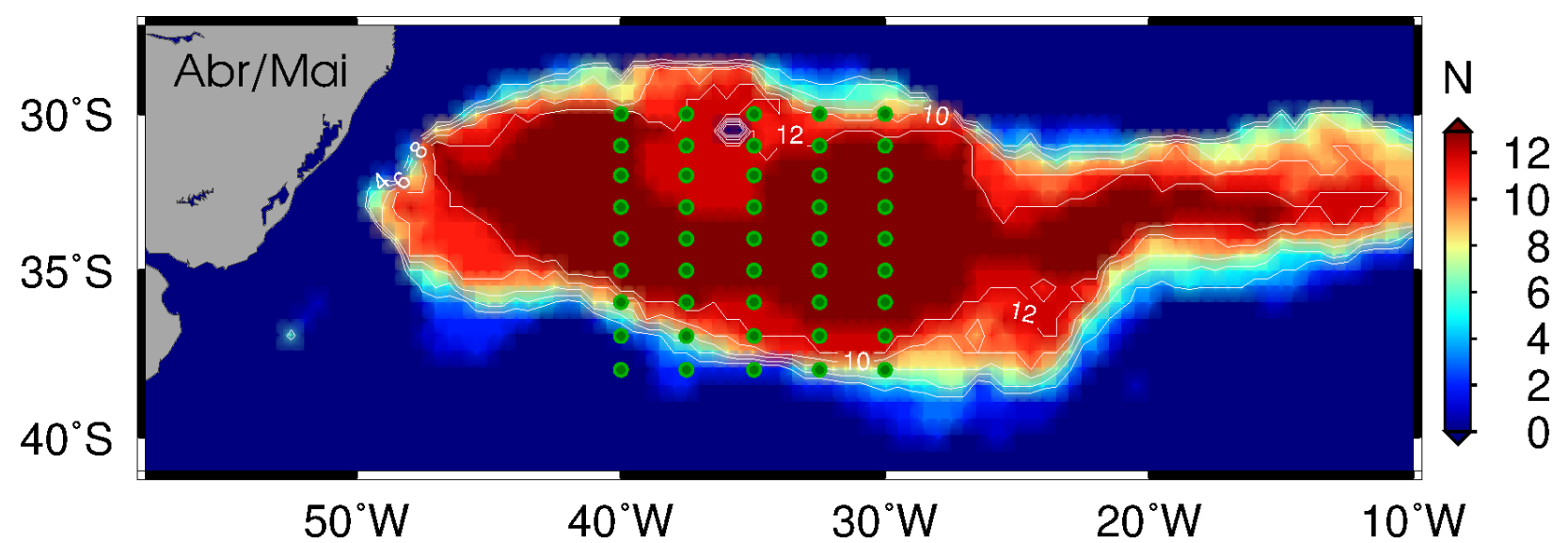

Figura 2.1: Número de ocorrências da AMSTAS nos meses de abril e maio ao longo de treze anos a partir de médias mensais obtidas de observações por dados hidrográficos in situ. As 45 estações planejadas para a OCSUL estão assinaladas pelos círculos verdes. As áreas em azul indicam que não houve ocorrência de água modal durante os referidos meses em todos os anos da série temporal de 2002 a 2014.

AMSTAS no sudoeste do Atlântico Sul no período de 2002 a 2014.

O mapa da frequência de ocorrência da AMSTAS nos meses de abril e maio do período de onze anos supracitado (Figura 2.1) serviu de referência para o planejamento das 45 estações oceanográficas. Nesse cruzeiro foram obtidas medições de salinidade (condutividade), temperatura e pressão (profundidade) por meio de um conjunto CTD-Rosette, equipado ainda com fluorímetro, turbidímetro e sensor de oxigênio dissolvido.

Durante o referido cruzeiro oceanográfico foram também lançados dois perfiladores lagrangeanos Argo, fornecidos pelo Centro de Hidrografia da Marinha (CHM), nas posições $35^{\circ} \mathrm{W} / 35^{\circ} \mathrm{S}$ e $40^{\circ} \mathrm{W} / 30^{\circ} \mathrm{S}$. Ambos foram configurados para realizar sua deriva na profundidade de $1000 \mathrm{~m}$ e medições na subida a cada 5 dias, um período mais curto que os 10 dias convencionais do Projeto Argo [Gould, 2005]. O ciclo de amostragem mais curto foi escolhido a fim de obter maior resolução da água modal subtropical durante seu período de formação. Tal período ocorre entre os meses de julho e outubro no hemisfério sul e apenas em algumas regiões específicas. Além disso, visando discriminar as diferenças de densidade e temperatura nos intervalos típicos de profundidades onde era esperado observar a formação e afundamento das águas modais subtropicais, a configuração dos perfiladores foi alterada para que os mesmos concentrassem a coleta de dados no oceano superior, realizando medições a 


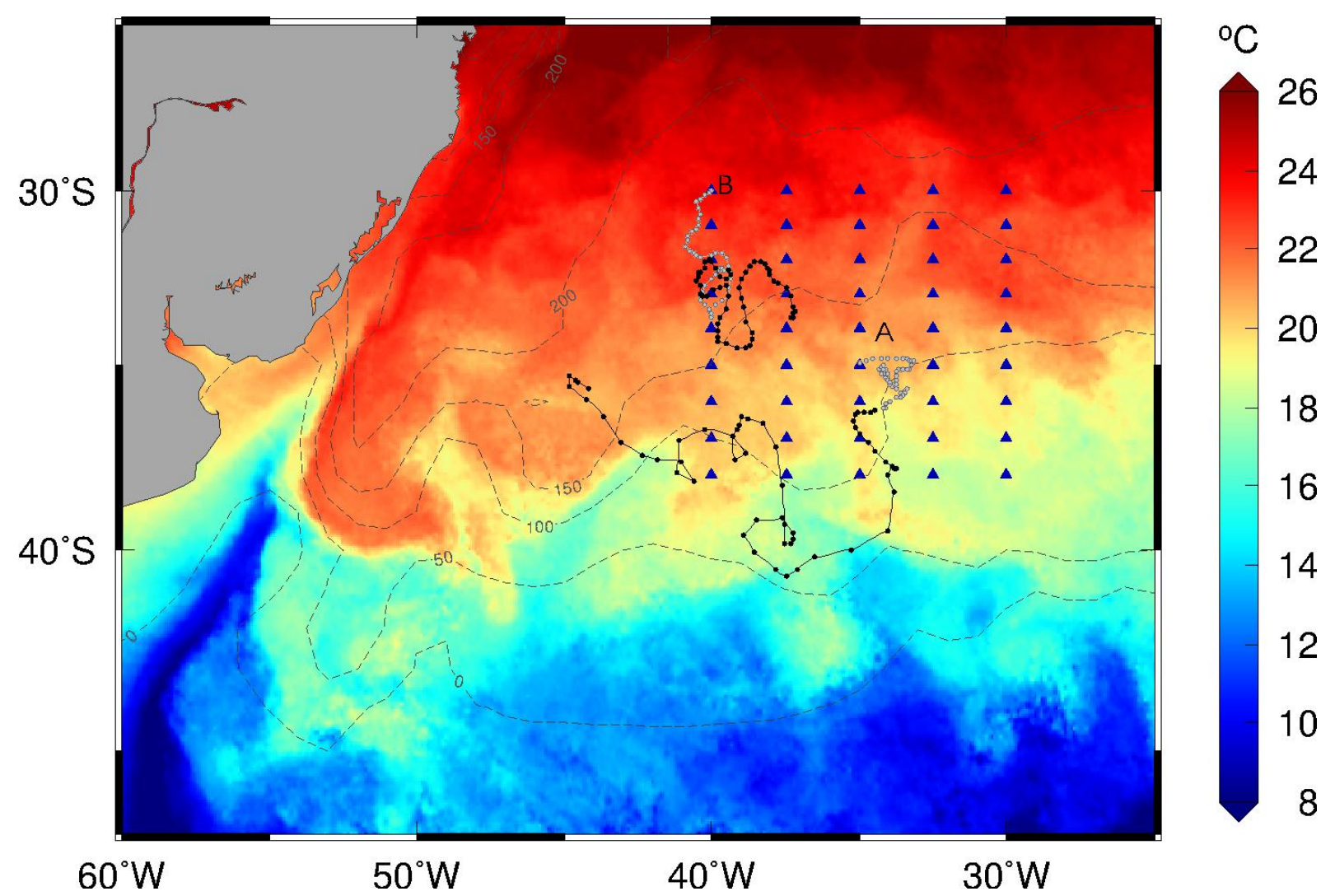

Figura 2.2: Área de ocorrência da água modal subtropical na região da Confluência BrasilMalvinas. Os triângulos indicam a localização das estações CTD realizadas durante o cruzeiro. As trajetórias A e B foram realizadas pelos perfiladores Argo lançados, respectivamente, em 28/04/2015 e 10/05/2015. As cores ao fundo representam a temperatura da superfície do mar (TSM) média para o mês de abril de 2015 obtida a partir do sensor MODIS Terra. Os contornos, oriundos dos dados da climatologia do In Situ Analysis System (ISAS), representam a profundidade da isoterma de $16^{\circ} \mathrm{C}$ para o mês de abril.

cada $5 \mathrm{~m}$ na vertical, desde a superfície até $500 \mathrm{~m}$ de profundidade.

A Figura 2.2 apresenta a trajetória dos perfiladores Argo desde seu lançamento até outubro de 2016 e as estações oceanográficas realizadas durante a OCSUL. Essas posições foram plotadas sobre o mapa de temperatura da superfície do mar (TSM) média para o mês de abril obtido do sensor MODIS Terra.

\subsection{Dados de Modelos Numéricos}

O modelo numérico HYbrid Coordinate Ocean Model (HYCOM) é uma evolução do Miami Isopycnic Coordinate Ocean Model (MICOM). Seu desenvolvimento é resultado dos esforços da colaboração entre a University of Miami, o Naval Research Laboratory 
(NRL) e o Los Alamos National Laboratory (LANL). Essas instituições fazem parte do consórcio multi-institucional HYCOM Consortium for Data Assimilative Ocean Modeling fundado pelo National Ocean Partnership Program (NOPP) em 1999 para desenvolver e avaliar um modelo oceânico de coordenadas híbridas isopicnal-sigma-pressão, com suporte para assimilação de dados [Bleck, 2002, Chassignet et al., 2003; Halliwell, 2004].

Este modelo numérico hidrodinâmico, como o MICOM, é baseado em cinco equações de prognóstico, sendo: uma equação de continuidade de massa ou equação de tendência de espessura de camada; duas equações para as componentes horizontais da velocidade e duas equações conservativas para um par de variáveis termodinâmicas, tais como temperatura e salinidade ou densidade e salinidade [Bleck, 2002]. Com o emprego de coordenadas híbridas, o HYCOM se beneficia das vantagens das três coordenadas tradicionalmente utilizadas: as coordenadas isopicnais, que representam superfícies de densidade constante para modelagem de oceanos profundos e estratificados; os níveis $z$ que representam níveis fixos de profundidade ou de pressão constante, para modelagem próximo à superfície do oceano, ou seja, dentro da camada de mistura, onde é necessário uma maior resolução vertical; e os níveis sigma, utilizados em regiões com expressivos gradientes topográficos como a transição entre a plataforma continental e o talude [Bleck, 2002; Halliwell, 2004; Chassignet et al., 2003, 2007].

O emprego de modelos numéricos em regiões do oceano que possuem considerável escassez de dados in situ é primordial para a avaliação de fenômenos de meso e larga escala. Os modelos podem prover séries temporais longas, incrementando a capacidade de produzir diagnósticos e prognósticos a partir do estudo da variabilidade desses fenômenos. Todavia, é fundamental realizar a verificação dos resultados apresentados pela modelagem, tanto com relação à magnitude dos fenômenos representados quanto a sua periodicidade.

Assim sendo, com o objetivo de reproduzir por meio de modelagem numérica, os resultados obtidos a partir dos dados do cruzeiro oceanográfico OCSUL descrito na Seção 2.2, foi analisado inicialmente o modelo HYCOM na configuração estabelecida para o estudo do impacto do Atlântico Sul na Meridional Overturning Circulation (MOC), conduzido pelo Projeto SAMOC [Campos et al., em fase de elaboração]. Essa circulação é caracterizada por um fluxo de águas relativamente mais quentes, que 
atravessa a linha do Equador na direção norte nas camadas superiores, retornando a partir do polo norte como um fluxo na direção sul de águas mais frias em regiões profundas.

O referido modelo, aqui nominado por HYCOM-SAMOC, tem cobertura global com uma grade de resolução horizontal de aproximadamente $9 \mathrm{~km}\left(1 / 12^{\circ}\right)$, utilizando a projeção de Mercator entre as latitudes de $47^{\circ} \mathrm{N}$ e $78^{\circ} \mathrm{S}$ e bipolar para regiões ao norte de $47^{\circ} \mathrm{N}$. No presente estudo foram analisados os dados dessa configuração para o mesmo período em que foi realizada a OCSUL (meses de abril e maio de 2015).

O HYCOM-SAMOC foi concebido com 33 níveis isopicnais para o domínio, sendo 4 deles (níveis 11 a 14) coerentes com os valores típicos de $\sigma_{\theta}$ observados por Sato $\mathcal{E}$ Polito [2014] para a AMSTAS (de 25,6 a 26,8 $\mathrm{kg} \mathrm{m}^{-3}$ ). Os dados batimétricos empregados nessa configuração do modelo HYCOM foram obtidos da topografia de fundo apresentada por Smith E Sandwell] [1997], com resolução horizontal de 1852 m. O modelo foi forçado de duas formas diferentes durante a integração, aplicando os dados meteorológicos de reanálise do National Centers of Environmental Prediction (NCEP): inicialmente as forçantes empregadas eram provenientes de uma climatologia de 12 meses, iniciando a partir de um estado inicial arbitrário. Em seguida, o último dia de 15 anos de rodada climatológica foi empregado como condição inicial para uma simulação forçada com as médias mensais dos dados meteorológicos datados no período de 1949 a 2015.

No intuito de observar os padrões de variabilidade do mesmo modelo com distribuição de níveis isopicnais específica para detecção da AMSTAS e com capacidade prognóstica, posteriormente foi empregado o HYCOM em duas configurações distintas preparadas pela equipe da Rede de Modelagem e Observação Oceanográfica (REMO) estabelecida no CHM. A primeira, doravante chamada HYCOM 1, com uma grade de resolução horizontal de aproximadamente $9 \mathrm{~km}\left(1 / 12^{\circ}\right)$ para a área compreendida entre as latitudes de $7^{\circ} \mathrm{N}$ a $78^{\circ} \mathrm{S}$ e as longitudes $40^{\circ} \mathrm{E}$ e $70^{\circ} \mathrm{W}$ (bacia do Atlântico Sul). Verticalmente foram adotados 33 níveis para o domínio, sendo 18 destes concentrados entre as camadas isopicnais de 25,70 e $27,40 \mathrm{~kg} \mathrm{~m}^{-3}$, com diferença de $0,10 \mathrm{~kg} \mathrm{~m}^{-3}$ entre eles, a fim de obter melhor detalhamento das águas modais subtropicais. Já a segunda configuração, a qual será tratada por HYCOM 2, com resolução 
horizontal de aproximadamente $27 \mathrm{~km}\left(1 / 4^{\circ}\right)$ para a área compreendida entre as latitudes de $50^{\circ} \mathrm{N}$ a $78^{\circ} \mathrm{S}$ e as longitudes $21,7^{\circ} \mathrm{E}$ e $98^{\circ} \mathrm{W}$. Verticalmente foram adotados 21 níveis para o domínio, sendo 7 destes entre as camadas isopicnais de 25,77 e 27,38 $\mathrm{kg} \mathrm{m}^{-3}$. Ambas configurações tem a grade com a borda sul fechada e imposição do transporte da Corrente Circumpolar Antártica (110,0 Sv para leste; $\left.1 \mathrm{~Sv}=10^{6} \mathrm{~m}^{3} \mathrm{~s}^{-1}\right)$ na borda oeste e da Corrente das Agulhas (30,0 Sv para oeste e 150,0 Sv para leste) na borda leste. A borda norte é aberta com imposicão do transporte de 10,0 Sv para norte no HYCOM 1. Já o HYCOM 2 tem a borda norte fechada.

As forçantes utilizadas para integração dos modelos HYCOM 1 e 2 no presente estudo foram a temperatura do ar a $2 \mathrm{~m}$, precipitação, radiação total, radiação de onda curta, razão de mistura de vapor de água, e velocidade do vento a $10 \mathrm{~m}$, extraídas da climatologia do conjunto de dados meteorológicos globais do Global Forecast System (GFS) do NCEP. A batimetria utilizada foi baseada nos dados topográficos do ETOPO2v2 disponibilizados pela National Oceanic and Atmospheric Administration (NOAA). A representação do relevo para profundidades inferiores a $500 \mathrm{~m}$ foi detalhada a partir da digitalização de cartas náuticas da Diretoria de Hidrografia e Navegação $(\mathrm{DHN})$.

A simulação do modelo HYCOM 1 foi realizada para um período de 4 anos, com a repetição das forçantes atmosféricas do GFS para o ano de 2001. Essas forçantes apresentaram resolução temporal de 6 horas e espacial de $1^{\circ}$. Tal metodologia é semelhante à empregada por Douglass et al. [2012]. O período considerado no presente estudo teve início em 01/04 do primeiro ano da simulação, a partir de quando a energia cinética média por unidade de área do modelo apresentou um padrão estabilizado, conforme demonstrado na Figura 2.3 .

O HYCOM 2 teve a simulação realizada para um período de 5 anos a partir de 01/01/2011, utilizando dados do modelo operacional empregado pela REMO, com condições iniciais ("restart") extraídas de resultado de integração referente ao dia 01/01/2011 do modelo HYCOM/NRL constituído pelo modelo HYCOM + NCODA (Navy Coupled Ocean Data Assimilation Global 1/12 Analysis) pertencente ao Naval Research Laboratoty (NRL).

A assimilação de dados empregada no HYCOM 2 utiliza a técnica de Inter- 


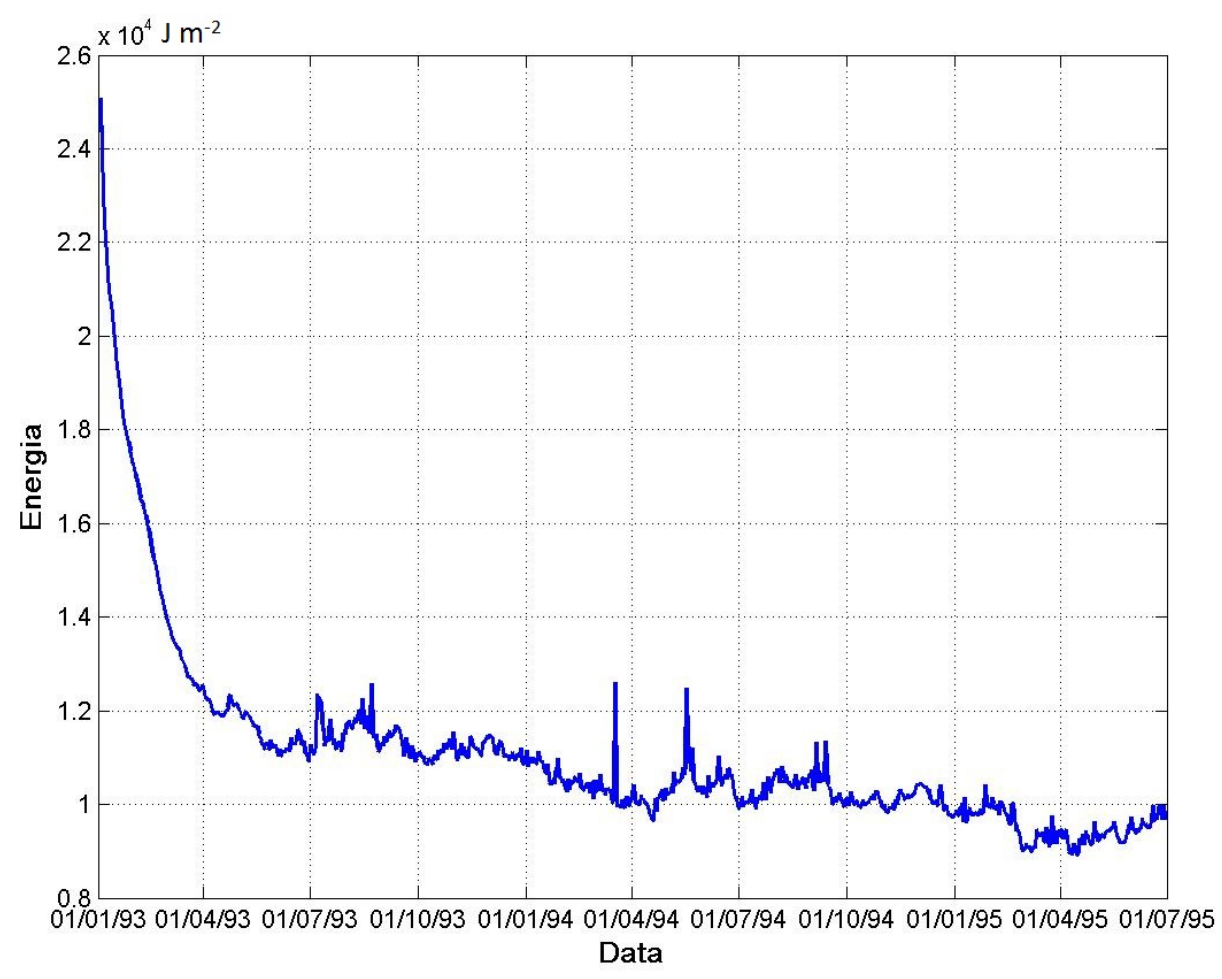

Figura 2.3: Energia cinética média do modelo HYCOM 1 por unidade de área (em Joules $/ \mathrm{m}^{2}$ ) a partir do início da simulação (01/01 do ano hipotético 1993).

polação Ótima por Conjuntos (Ensemble Optimal Interpolation-EnOI), baseada no método desenvolvido por Cooper $\mathcal{E}$ Haines [1996]. Os dados de temperatura da superfície do mar (TSM) e altura da superfície do mar (ASM) assimilados no HYCOM 2 foram extraídos do HYCOM/NRL até 10/05/2014 (TSM) e 03/12/2014 (ASM). A partir dessas datas respectivamente, os dados de TSM assimilados foram obtidos do sistema Operational Sea Surface Temperature and Sea Ice Analysis (OSTIA) e os dados de ASM assimilados foram fornecidos pelo Collecte Localisation Satellites (CLS) por meio do convênio denominado Altimetry Tailored and Optimized for Brazilian Applications (ATOBA) firmado entre o CLS e a REMO em 2012. As forçantes atmosféricas diárias foram obtidas do Global Forecast System (GFS) para o período de simulação supracitado, sendo os dados de TSM e ASM assimilados a cada 5 dias.

No presente estudo foi analisado o desempenho de cada um dos modelos na detecção da AMSTAS. O modelo que apresentou os resultados que mais concordaram com as observações foi empregado para as estimativas de volume e análise dos parâmetros da AMSTAS detectada, além do cálculo do calor armazenado. 


\subsection{Dados Altimétricos}

O Collecte Localisation Satellites (CLS) é um centro de estudos francês que detém o estado da arte no desenvolvimento da tecnologia de altimetria por satélite há mais de 10 anos, tomando parte nos principais programas internacionais multi-missão. Dentre eles destacamos o Segment Sol multimissions d'ALTimétrie, d'Orbitographie et de localisation précise do Data Unification and Altimeter Combination System (SSALTO/DUACS), destinado à unificação do processamento e análise de dados de satélites altímetros de diferentes agências espaciais. O CLS é vinculado à European Space Agency (ESA) e ao Centre National d'Etudes Spatiales (CNES) sendo responsável pelo desenvolvimento de instrumentos altimétricos, processamento e validação de dados coletados, distribuição dos dados para diferentes níveis de usuário e comercialização de dados diferenciados.

Devido à mundialmente reconhecida excelência dos serviços do CLS, foi firmado um convênio em 2012 entre a REMO e o CLS, denominado Altimetry Tailored and Optimized for Brazilian Applications (ATOBA). O propósito deste convênio é obter o desenvolvimento e o refinamento de dados altimétricos diferenciados para as regiões de interesse da REMO, a fim de incrementar a pesquisa oceanográfica observacional e a assimilação de dados em modelos numéricos.

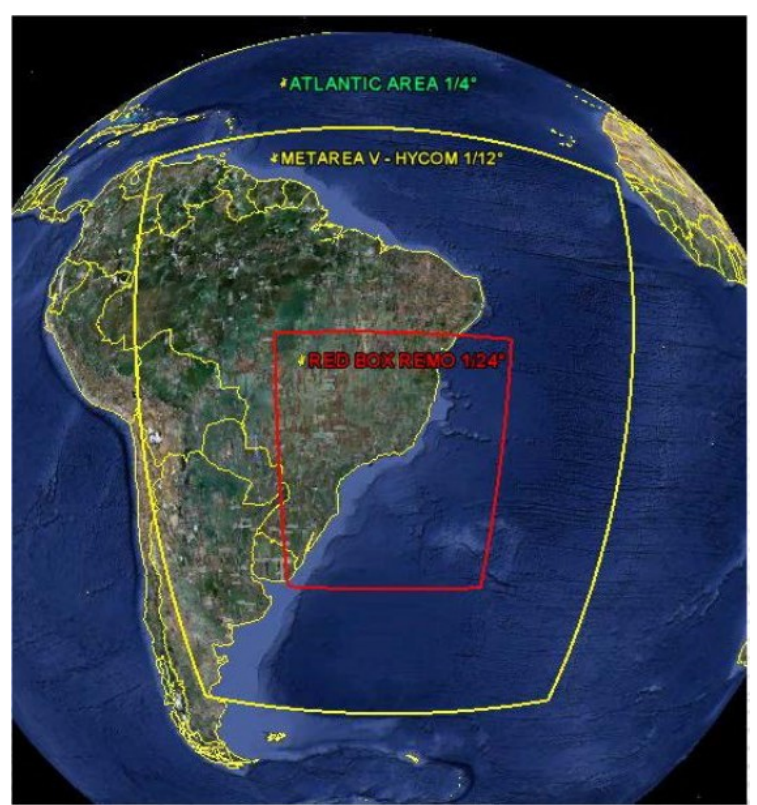

Figura 2.4: Limites da Metarea V (em amarelo).

Foram empregados no presente estudo dados altimétricos do projeto ATOBA obtidos por meio dos satélites Jason-2, Cryosat-2 e Saral/AltiKa. Os dados utilizados são de nível 4, mapas interpolados em grades regularmente espaçadas de $1 / 8^{\circ}$. Tais dados foram preparados pelo CLS para assimilação no modelo HYCOM $1 / 12^{\circ}$ empregado pela REMO na área denominada V1 e coincidente com a METAREA V, delimitada pelas latitudes $11^{\circ} \mathrm{N}-46^{\circ} \mathrm{S}$ e longitudes $68^{\circ} \mathrm{W}-18^{\circ} \mathrm{W}$, conforme a Figura 2.4 . 
Para a área V1 foram aplicadas pelo CLS uma correção de maré oceânica por meio das alturas de maré estimadas pelo modelo FES2012 [Carrère et al., 2012]. Embora a área de estudo compreenda em sua maioria profundidades maiores que $1000 \mathrm{~m}$, em seu interior e próximo do lóbulo de retroflexão da CB está localizada a Elevação do Rio Grande, delimitada por $33,7^{\circ} \mathrm{W}-37,1^{\circ} \mathrm{W}$ e $29,6^{\circ} \mathrm{S}-31,5^{\circ} \mathrm{S}$, onde a redução de maré se torna relevante para a correta medição dos satélites altímetros pois apresenta profundidades menores que $1000 \mathrm{~m}$.

Os dados de nível 4 da AASM do Projeto ATOBA, interpolados e distribuídos numa grade regular com resolução de $1 / 8^{\circ}$, foram empregados no presente estudo para o cálculo do calor armazenado. 


\section{Capítulo 3}

\section{Metodologia}

\subsection{Preâmbulo}

O emprego de perfis verticais de propriedades hidrográficas no oceano requer o tratamento básico dos dados adquiridos. Esse tratamento visa eliminar erros ou registros espúrios e repetições existentes no conjunto de dados coletados e discretizar as observações em um número finito de profundidades, muitas vezes equidistantes, entre a superfície e o fundo [Miranda et al. 2002]. Tais erros são devidos às características intrínsecas dos equipamentos e sensores utilizados, além de peculiaridades típicas dos métodos de lançamento.

A utilização de dados oriundos de modelos oceânicos permite produzir séries temporais longas de dados distribuídos por extensas áreas do oceano, viabilizando o estudo de variabilidade temporal de fenômenos de meso e larga escala. No caso específico das águas modais subtropicais do Atlântico Sul, os resultados gerados por modelos podem resultar na primeira estimativa do volume e da distribuição horizontal da AMSTAS na região da Confluência Brasil-Malvinas.

A maior parte das medidas obtidas por sensores remotos são superficiais e quando muito, revelam valores integrados na camada superior. $O$ altímetro, entretanto, nos permite inferir informações sobre a estrutura interna dos oceanos, uma vez que os fatores que causam a elevação da superfície dos mesmos estão associados ao efeito integrado dos processos na coluna d'água. Portanto, mediante algumas aproximações sobre a estrutura vertical do oceano, podemos estimar o que ocorre abaixo da superfície, 
tal como a velocidade média das correntes geostróficas, o calor armazenado na coluna d'água e variações na profundidade da termoclina a partir de medidas altimétricas [Robinson, 2004].

A fundamentação teórica para emprego dos dados supracitados na detecção de águas modais e os demais processos e cálculos empreendidos para tratamento e interpretação desses dados serão descritos a seguir.

\subsection{Dados de Hidrografia}

Para tratamento dos dados hidrográficos obtidos durante o cruzeiro oceanográfico e por meio dos perfiladores Argo foram empregados os seguintes processos: eliminação de picos, média em caixas e filtragem por janela móvel.

\subsubsection{Tratamento Básico dos Dados de Hidrografia}

\section{Eliminação de Picos}

A eliminação de picos consistiu da remoção de ruídos aleatórios de grande intensidade. Esse procedimento foi realizado por meio da aplicação de um filtro simples nos dados para remover qualquer amostra que tem seu valor maior ou menor que 3 vezes o desvio padrão do trecho de coluna de água que a envolve.

\section{Média em Caixas}

Em seguida foi realizada a média em caixas a fim de estabelecer o equi-espaçamento vertical dos dados, uma vez que a frequência amostral do equipamento é constante, mas sua velocidade de perfilagem varia. No presente estudo, o perfilador CTD foi empregado com freqüência de amostragem de $24 \mathrm{~Hz}$. O conjunto CTD-Rosette foi arriado e içado a uma velocidade média de $1 \mathrm{~m} \mathrm{~s}^{-1}$. Por conseguinte, o conjunto de dados coletados na OCSUL tem, em média, 24 amostras por metro. Dessa forma, foram utilizados os valores médios das variáveis medidas em caixas de $1 \mathrm{~m}$. 


\section{Filtragem por Janela Móvel}

A filtragem por janela móvel encerrou o tratamento básico dos dados de hidrografia e teve a finalidade de eliminar ruídos e gerar perfis suaves das propriedades, que foram submetidas a cálculos dinâmicos envolvendo primeira e segunda derivadas. Com o objetivo de evitar o vazamento espectral, ou seja, mudanças no espectro original provocadas pela convolução periódica do espectro original com o espectro da janela [Emery E Thomson, 1998], foi empregada uma janela do tipo Blackman.

\subsubsection{Interpolação dos Dados Hidrográficos}

Após o tratamento básico dos dados, foram construídos perfis de temperatura $(T)$, salinidade $(S)$, densidade in situ $(\sigma)$ e densidade potencial $\left(\sigma_{\theta}\right)$, bem como seções verticais e mapas horizontais de $T, S$ e $\sigma_{\theta}$. Os valores de densidade foram calculados a partir dos dados termohalinos, através da equação de estado da água do mar.

Os mapas horizontais de $T, S$ e $\sigma_{\theta}$ foram confeccionados por meio da interpolação horizontal 2-D dos dados obtidos, por nível amostrado, com emprego do método de mínima curvatura (spline) suave, de modo a obter a distribuição horizontal dos dados numa grade regular de $1^{\circ} \times 1^{\circ}$, na área compreendida entre as latitudes de $30^{\circ} \mathrm{S}$ e $38^{\circ} \mathrm{S}$ e longitudes de $30^{\circ} \mathrm{W}$ a $40^{\circ} \mathrm{W}$.

Posteriormente foi realizado o cálculo da vorticidade potencial $(Q)$ e a detecção de águas modais subtropicais na área de estudo. Os mesmos cálculos e processo de detecção foram aplicados individualmente aos perfis realizados pelos dois perfiladores Argo lançados durante o cruzeiro oceanográfico.

\subsubsection{Cálculo da Velocidade Geostrófica para Dados In Situ}

O balanço entre a força do gradiente de pressão e a força de Coriolis é possível para fluidos considerados invíscidos, com escala horizontal de movimento muito maior que a escala vertical e onde a aceleração de Coriolis seja mais determinante para o movimento do que as acelerações local e advectiva. Essas características são observadas em movimentos de larga e meso escala espaço-temporal, tornando as equações do movimento simplificadas na forma: 


$$
\begin{gathered}
-f v_{g}=-\frac{1}{\rho_{0}} \frac{\partial p}{\partial x} \\
f u_{g}=-\frac{1}{\rho_{0}} \frac{\partial p}{\partial y}
\end{gathered}
$$

onde $u_{g}$ e $v_{g}$ são, respectivamente, as componentes zonal e meridional do vetor velocidade geostrófica $\vec{V}_{g}$, $f$ é o parâmetro de Coriolis, $\rho_{0}$ é a densidade tomando-se a altura média da interface ar-mar ou geóide marinho $(z=0)$ como referência, $g$ a aceleração da gravidade, $p$ a pressão, $x$ a coordenada cartesiana zonal e $y$ a coordenada cartesiana meridional.

As equações $3.1 \mathrm{e} 3.2$ permitem concluir que o vetor $\vec{V}_{g}$ é perpendicular ao vetor gradiente de pressão horizontal $\nabla_{H} p$ :

$$
\left(u_{g}, v_{g}\right) \perp\left(\frac{\partial p}{\partial x}, \frac{\partial p}{\partial y}\right) \quad \Rightarrow \quad \vec{V}_{g} \perp \nabla_{H} p \quad \Rightarrow \quad \vec{V}_{g}=\frac{1}{\rho_{0} f} \vec{k} \times \nabla_{H} p
$$

onde $\vec{k}$ é o versor na direção vertical.

O fluxo geostrófico é caracterizado por um movimento ao longo das isóbaras [Tomczak E Godfrey, 1994], ou seja, todo fluxo geostrófico é isobárico [Cushman-Roisin, 1994]. Assim, as velocidades geostróficas podem ser calculadas através da relação existente entre os gradientes de profundidade e as diferenças de geopotencial, que estão associadas aos campos de densidade. O geopotencial $(\Phi)$ é uma função escalar que corresponde à energia potencial do campo gravitacional terrestre, referente a uma parcela de massa unitária. A anomalia do geopotencial $\Delta \Phi$ (função de $S, T$ e $p$ ), definida por Pond E Pickard [1991] como:

$$
\Delta \Phi=\int_{p_{0}}^{p} \delta d p
$$

onde $\delta$ é a anomalia do volume específico e $p_{0}$, o nível isobárico de referência, permite calcular a velocidade geostrófica a partir dos dados in situ por meio do método dinâmico clássico. 


\subsubsection{Função de Corrente Geostrófica}

A equação da continuidade tem importância fundamental para o estudo do movimento dos fluidos. Deduzida a partir do princípio da conservação de massa, essa equação relaciona a variação de densidade com o movimento e está associada a uma propriedade intrínseca dos meios contínuos [Miranda et al., 2002].

A equação da continuidade para escoamentos bidimensionais é definida como [Kundu, 1990] :

$$
\frac{\partial u}{\partial x}+\frac{\partial v}{\partial y}=0
$$

Assim, a função de corrente $\psi(x, y, t)$, onde $t$ é o tempo, se relaciona com as componentes zonal $(u)$ e meridional $(v)$ da velocidade por meio das equações

$$
u=-\frac{\partial \psi}{\partial y} \quad \text { e } \quad v=\frac{\partial \psi}{\partial x}
$$

A derivada total da função de corrente é nula ao longo de uma linha de corrente, ou seja, $\psi(x, y, t)=$ constante. As curvas que unem os pontos de $\psi(x, y, t)=$ constante definem as linhas de corrente representativas do escoamento. Combinando as equações 3.1 e 3.2 com as equações definidas em 3.6 é possível obter:

$$
\begin{aligned}
& u_{g}=-\frac{1}{\rho_{0} f} \frac{\partial p}{\partial y}=-\frac{\partial}{\partial y}\left(\frac{p}{\rho_{0} f}\right)=-\frac{\partial \psi_{g}}{\partial y} \mathrm{e} \\
& v_{g}=\frac{1}{\rho_{0} f} \frac{\partial p}{\partial x}=\frac{\partial}{\partial x}\left(\frac{p}{\rho_{0} f}\right)=\frac{\partial \psi_{g}}{\partial x} .
\end{aligned}
$$

Representadas na forma vetorial por:

$$
\vec{V}_{g}=\vec{k} \times \nabla\left(\frac{p}{\rho_{0} f}\right)=\vec{k} \times \nabla \psi_{g}
$$


Considerando $\vec{V}_{g}$ expressa em coordenadas isobáricas:

$$
\vec{V}_{g}=\frac{g}{f} \vec{k} \times(\nabla z)=\frac{\vec{k}}{f} \times \nabla \Phi \Rightarrow\left\{\begin{array}{l}
v_{g}=\frac{1}{f} \frac{\partial \Delta \Phi}{\partial x} \\
u_{g}=-\frac{1}{f} \frac{\partial \Delta \Phi}{\partial y}
\end{array}\right.
$$

ao combinar as equações de $u_{g}$ e $v_{g}$ em 3.10 com as equações 3.7 e 3.8, obtem-se:

$$
\psi_{g}=\frac{p}{\rho_{0} f}=\frac{\Delta \Phi}{f} \equiv \text { função de corrente geostrófica. }
$$

O teorema de Helmholtz permite a separação do campo de velocidades em duas componentes. Uma componente é não-divergente e rotacional, relacionada à função de corrente $\psi$, e outra componente é irrotacional e divergente, relacionada ao potencial de velocidade $\chi$ :

$$
\vec{V}=\vec{k} \times \nabla \psi+\nabla \chi
$$

No presente estudo os escoamentos analisados apresentam escalas com pequena divergência. Dessa forma, é possível considerar como negligenciável a componente irrotacional (divergente) do campo de velocidades, reduzindo a equação 3.12 a:

$$
\vec{V} \approx \vec{k} \times \nabla \psi
$$

A condição de não-divergência permite a utilização da propriedade física $\psi$ como ferramenta importante para análise dos escoamentos. No presente estudo, foram calculados campos de função de corrente geostrófica baroclínica em vários níveis a partir dos dados de CTD da OCSUL, a fim de obter feições representativas dos escoamentos cujas escalas temporal e espacial se aproximam do movimento geostrófico na área do cruzeiro oceanográfico. O nível de referência empregado foi a profundidade de 500 $\mathrm{m}$ por se tratar do nível mais profundo estabelecido para a análise dos dados na área do cruzeiro oceanográfico, conforme mencionado na Seção 2.2 . 


\subsection{Cálculo da Vorticidade Potencial}

As águas modais subtropicais são caracterizadas pela homogeneidade vertical de seus parâmetros físicos e distribuídas por extensas áreas com baixos valores de vorticidade potencial. A identificação destas áreas de baixa vorticidade potencial é essencial para a detecção e caracterização das águas modais, sendo portanto importante descrever os fundamentos teóricos empregados para o cálculo dessa grandeza.

Extremamente relevantes em dinâmica de fluidos geofísicos, os teoremas de vorticidade detalham como a velocidade angular das partículas de fluido varia com o tempo e posição. Dentre eles, o Teorema de Ertel [Schubert et al., 2004] especifica a evolução dinâmica da vorticidade potencial. Sua importância se deve, principalmente, à conservação da vorticidade potencial ser uma característica inerente dos escoamentos geostróficos e quase-geostróficos. Dessa forma, a equação de vorticidade potencial de Ertel se torna a equação de prognóstico exclusiva que determina a evolução temporal desse tipo de fluxo. Todas as demais variáveis podem ser expressas em termos de vorticidade potencial por meio de equações diagnósticas [Müller, 1995].

Isto posto, o cálculo pode ser iniciado a partir da equação de vorticidade potencial por unidade de volume $(q)$ em coordenadas esféricas [Müller, 1995], sendo $\varphi$ a longitude, $\theta$ a latitude, $r$ a distância radial a partir do centro da Terra, $r_{0}$ o raio médio da Terra e $z=r-r_{0}$ :

$$
q=\omega_{\varphi} \frac{1}{r_{0} \cos \theta} \frac{\partial \kappa}{\partial \varphi}+\omega_{\theta} \frac{1}{r_{0}} \frac{\partial \kappa}{\partial \theta}+2 \Omega \cos \theta \frac{1}{r_{0}} \frac{\partial \kappa}{\partial \theta}+\omega_{z} \frac{\partial \kappa}{\partial z}+2 \Omega \sin \theta \frac{\partial \kappa}{\partial z}
$$

onde

$$
\begin{gathered}
\omega_{\varphi}=\frac{1}{r_{0}} \frac{\partial w}{\partial \theta}-\frac{\partial v}{\partial z}, \\
\omega_{\theta}=\frac{\partial u}{\partial z}-\frac{1}{r_{0} \cos \theta} \frac{\partial w}{\partial \varphi} \mathrm{e} \\
\omega_{z}=\frac{1}{r_{0} \cos \theta} \frac{\partial v}{\partial \varphi}-\frac{1}{r_{0} \cos \theta} \frac{\partial(u \cos \theta)}{\partial \theta}
\end{gathered}
$$


são as componentes esféricas do vetor vorticidade relativa; $u, v$ e $w$ são, respectivamente, as componentes zonal, meridional e vertical da velocidade.

O traçador $\kappa$ empregado pode representar variáveis como a densidade potencial $\left(\rho_{p o t}\right)$, densidade $(\rho)$ ou perturbação da densidade $\left(\rho^{\prime}\right)$, a depender de como o oceano é assumido, se não termobárico, aproximadamente incompressível ou incompressível, respectivamente. As aproximações a serem realizadas dependem da escala do movimento considerado. Assim, $L$ denota a escala de comprimento horizontal e $H$ o comprimento vertical. A escala da velocidade horizontal e vertical é dada por $U$ e $W$, respectivamente. Dessa forma, essas escalas definem a razão de aspecto $(\delta)$ :

$$
\delta=\frac{H}{L}
$$

o número de Rossby advectivo $(R o)$ :

$$
R o=\frac{U}{f L} \mathrm{e}
$$

o parâmetro geométrico $(\lambda)$ :

$$
\lambda=\frac{L}{r_{0}},
$$

os quais medem até que ponto os movimentos são suscetíveis à esfericidade da Terra. Considerando que:

$$
f=f_{z}=2 \Omega \sin \theta
$$

é a componente vertical do vetor vorticidade planetária, conhecida como parâmetro de Coriolis, e empregando as escalas determinadas acima na equação da vorticidade potencial 3.14, seu primeiro termo assume a escala de $R o \delta^{2}$ e $R o$; o segundo termo assume a escala de $R o$ e $R o \delta^{2}$; o terceiro termo tem escala de $\delta$; o quarto tem escala de Ro e o quinto tende a 1.

O número de Rossby mede a relação entre as componentes verticais da vorticidade relativa e da vorticidade planetária [Müller, 1995]. As águas modais são fenômenos de meso até larga escala e sua região de formação está associada com o limite do giro subtropical e com locais onde ocorrem o encontro de correntes de contorno oeste, 
tais como a CBM. Nessas regiões o número de Rossby assume valores muito menores que $1(R o \ll 1)$, assim como $\delta \ll 1$ e $\lambda=O(1)$. Valores estes característicos de movimentos em balanço geostrófico [Pedlosky, 1987].

A aproximação geostrófica reduz a equação (3.14) a

$$
q=f \frac{\partial \kappa}{\partial z}
$$

e as componentes zonal, meridional e vertical da velocidade geostrófica assumindo o equilíbrio hidrostático são expressas por:

$$
\begin{gathered}
f v=\frac{1}{\rho r_{0} \cos \theta} \frac{\partial p}{\partial \varphi}, \\
f u=-\frac{1}{\rho r_{0}} \frac{\partial p}{\partial \theta} \mathrm{e} \\
\rho g=-\frac{\partial p}{\partial z} .
\end{gathered}
$$

A vorticidade potencial isentrópica $(Q)$ ou de Ertel é expressa por unidade de massa, e materialmente conservada. Entretanto, a conservação de vorticidade potencial proposta pelo Teorema de Ertel, inerente ao balanço geostrófico, se dá de forma global e, para tanto, tem de estar associada a uma propriedade medida por unidade de volume $(q)$. A conservação material de $Q$ é condição necessária para a conservação global de $q$, mas não o contrário [Müller, 1995]. Assim, a vorticidade potencial de Ertel $(Q)$ inerente a fluidos em balanço geostrófico é dada por:

$$
Q=\frac{f}{\rho} \frac{\partial \kappa}{\partial z}
$$

Aplicando a densidade $\rho$ em substituição ao traçador $\kappa$ na equação 3.26, temos a forma de equação da vorticidade potencial geostrófica $(Q)$ em função da densidade, obtida por McCartney [1982]:

$$
Q=\frac{f}{\rho} \frac{\partial \rho}{\partial z}
$$

Essa equação denota a influencia da variação da espessura da camada para a vorticidade potencial, por meio do gradiente vertical de densidade. Portanto, constitui 
um indicador direto da homogeneidade vertical da camada e de suma importância para a detecção de amostras de água modal subtropical.

\subsection{Detecção da AMSTAS}

\subsubsection{Dados In Situ}

Após a interpolação dos dados hidrográficos para a área de estudo da OCSUL $\left(30-38^{\circ} \mathrm{S}\right.$ e $\left.30-40^{\circ} \mathrm{W}\right)$ foi realizado o cálculo da vorticidade potencial $(Q)$ de acordo com a equação 3.27. Em seguida, o processo de detecção da AMSTAS foi iniciado por meio da seleção dos valores de $Q$ menores que $1,5 \times 10^{-10} \mathrm{~m}^{-1} \mathrm{~s}^{-1}$ associados, no mesmo ponto, à gradientes verticais de temperatura menores que $0,01^{\circ} \mathrm{C} \mathrm{m}^{-1}$. Esses pontos foram classificados como possíveis amostras de água modal subtropical [Sato E Polito, 2014.

Apenas para as camadas classificadas como contendo água modal subtropical, foi aplicado o critério de temperatura e salinidade médias de $(15,0 \pm 0,9)^{\circ} \mathrm{C}$ e $35,6 \pm 0,2$, respectivamente, a fim de detectar aquelas que continham a AMSTAS. Os valores de $Q$, temperatura e salinidade obtidos por meio dos perfis realizados pelos perfiladores Argo lançados durante o cruzeiro oceanográfico foram submetidos ao mesmo processo de detecção.

\subsubsection{Dados de Modelo Numérico}

O processo de detecção da AMSTAS aplicado aos dados de modelo numérico foi realizado segundo o mesmo método descrito anteriormente para os dados in situ. Todavia, foram utilizados valores diferentes para os parâmetros de detecção coerentes com os empregados em estudos semelhantes realizados por meio de dados de modelos oceânicos no Hemisfério Norte [Douglass et al., 2012; Forget et al., 2011].

Os dados de saída do modelo HYCOM para a área que compreende a CBM e retroflexão da $\mathrm{CB}\left(10-50^{\circ} \mathrm{S}\right.$ e $\left.10-60^{\circ} \mathrm{W}\right)$ foram empregados para o cálculo da vorticidade potencial $(Q)$ conforme descrito na subseção 3.3 . Assim sendo, valores de $Q<2,0 \times 10^{-10} \mathrm{~m}^{-1} \mathrm{~s}^{-1}$, associados com perfis que possuíam gradiente vertical de tem- 
peratura $<0,02{ }^{\circ} \mathrm{C} \mathrm{m}^{-1}$, foram classificados como possíveis amostras de água modal subtropical. Esse valor de $Q$ foi determinado seguindo o mesmo limite utilizado por Douglass et al. [2012] em seu estudo da AMSPN por meio do emprego do modelo numérico oceânico de alta resolução pertencente ao Paralel Ocean Program (POP). O valor limite para o gradiente vertical de temperatura visou apenas a exclusão de pontos abaixo da termoclina principal, conforme estudo de de Boyer Montegut et al. [2007]. Apenas para as camadas classificadas como contendo água modal subtropical, foi aplicado o critério preliminar utilizado por Sato E Polito [2014].

Devido as simulações realizadas com o modelo HYCOM no presente estudo abrangerem inclusive períodos típicos de formação da água modal, foi necessário estabelecer um parâmetro para diferenciar as amostras de AMSTAS características desse período daquelas amostras que jaziam afundadas. Por conseguinte, foi empregado o critério utilizado por Forget et al. [2011], segundo o qual se considera a amostra de água modal subtropical recém formada aquela que possui vorticidade potencial $(Q)$ inferior a $2,0 \times 10^{-11} \mathrm{~m}^{-1} \mathrm{~s}^{-1}$, ou seja, uma ordem de grandeza menor que o valor de $Q$ admitido para a detecção de amostras afundadas.

\subsection{Cálculo de Volume}

As camadas selecionadas como portadoras de AMSTAS obtidas por meio dos dados de modelo numérico, tanto afundada como formada, de acordo com os critérios descritos na subseção 3.4 .2 foram representadas em mapas horizontais mensais contendo sua distribuição horizontal e a espessura da camada.

Para o cálculo do volume, entretanto, não são empregadas todas as camadas de AMSTAS supracitadas. Apenas as camadas com espessura superior a profundidade da camada de mistura, obtida do conjunto de dados de Holte E Talley [2009], e as camadas de água modal afundada com espessura superior a $100 \mathrm{~m}$ foram utilizadas para o cálculo de volume. Tais critérios de espessura mínima foram também empregados por Sato E Polito [2014], porém considerando uma espessura ca racterística baseada em climatologia de profundidade máxima de camada de mistura, a fim de excluir finas camadas transientes que surgem sazonalmente associadas à camada de mistura na área 
de estudo. Foram, portanto, mais restritivos do que o valor de $50 \mathrm{~m}$ empregado por Douglass et al. [2013] para a espessura mínima da camada de AM18 detectada por meio de dados de modelo.

O volume de AMSTAS foi então calculado, apenas para as espessas camadas selecionadas, por meio do emprego de metodologia semelhante à utilizada por Douglass et al. [2012], considerando-se a área mapeada e a espessura das camadas de AMSTAS formada e afundada para o referido cálculo. Assim, o volume foi obtido em cada ponto de grade dos modelos multiplicando-se a área quadrada no entorno do ponto (de acordo com a resolução horizontal) pela espessura da camada de AMSTAS detectada no mesmo ponto. O volume total foi calculado por meio do somatório dos volumes em cada ponto de grade do modelo.

Embora curta, a série temporal do volume de AMSTAS detectada permitiu uma avaliação preliminar das áreas de ocorrência da formação, dissipação e advecção dessa água modal em diferentes períodos do ano.

\subsection{Cálculo do Calor Armazenado}

A capacidade de armazenamento de calor de $1 \mathrm{~m}^{3}$ de água do oceano é 4000 vezes maior que a de $1 \mathrm{~m}^{3}$ de ar, o que equivale a afirmar que uma camada de água de 2,5 m de espessura no oceano é capaz de armazenar a mesma quantidade de calor de toda a atmosfera. Dessa forma, pequenas variações do calor armazenado nos oceanos podem ter consequências climáticas significativas e uma melhor compreensão dos fluxos de calor nos oceanos é imprescindível no estudo das interações entre o oceano e a atmosfera [Sato, 2009]. Por se tratar de um fenômeno diretamente ligado com essas interações, a formação de água modal subtropical necessariamente deve ser analisada considerando a variação do calor armazenado pelo oceano e sua influência nas regiões de formação.

Alterações no calor armazenado $\left(C_{A}\right)$ no oceano estão associadas com mudanças de densidade na coluna d'água e, por conseguinte, com a variação da espessura das camadas isopicnais e com a anomalia da altura da superfície do mar (AASM), segundo o princípio da expansão térmica [Gill $\mathcal{E}$ Niiler, 1973]. O cálculo do calor armazenado 
utiliza a diferença entre a temperatura observada em um determinado ponto e a média de todas as medidas de temperatura disponíveis para aquele ponto, oriunda de climatologia ou de dados coletados in situ ao longo de vários anos. Por conseguinte, o calor armazenado é por definição uma anomalia pois em seu cálculo um valor de referência médio sempre é subtraído do valor observado [Levitus et al., 2012]. Assim:

$$
C_{A}=\rho C_{p} \int_{-h}^{0}\left[T(z)-T_{r e f}\right] d z,
$$

onde $\rho$ é a densidade, $C_{p}$ é o calor específico sob pressão constante, $T(z)$ é a temperatura observada no perfil (in situ), $h$ é a profundidade de integração e $T_{r e f}$ é a temperatura de referência que corresponde à temperatura média de longo termo calculada para o mesmo ponto. $C_{A}$ é expresso em $\mathrm{J} \mathrm{m}^{-2}$ [Polito et al. 2000] e os valores de $C_{p}$ são obtidos do corolário das propriedades fundamentais da água do mar descrito por Fofonoff E Millard [1983].

O calor armazenado total na coluna d'água seria obtido pela integração de $T(z)-$ $T_{\text {ref }}$ da superfície até o fundo. No presente estudo, em particular, a profundidade escolhida como limite para a integração dos perfis de temperatura in situ foi $500 \mathrm{~m}$, em consonância com a estratégia amostral empregada na configuração dos perfiladores Argo lançados durante a OCSUL, conforme mencionado na Seção 2.2 .

O mesmo limite de integração na profundidade de $500 \mathrm{~m}$ foi definido para o cálculo de $C_{A}$ aplicado aos dados de modelo. Dessa forma, foi possível realizar a comparação do calor armazenado apenas na camada de AMSTAS detectada, calculado com o emprego das profundidades mínimas e máximas dessa camada em cada ponto da área de estudo como limites de integração, com o calor armazenado total na coluna d'água até a profundidade de $500 \mathrm{~m}$.

A temperatura média de referência empregada no cálculo de $C_{A}$ por meio dos dados in situ do presente estudo foi obtida do World Ocean Atlas 2013 (WOA13) [Locarnini et al. 2013]. Já para os dados de modelo, o calor armazenado $\left(C_{A}\right)$ médio para cada mês da simulação do modelo foi calculado empregando como $T_{\text {ref }}$ os valores de temperatura média para todo o período da simulação do estudo em cada um dos pontos de grade.

O emprego de dados de altímetro permite o cálculo do calor armazenado, tendo 
em vista que $C_{A}$ está diretamente relacionado com a AASM por meio da relação linear derivada por Chambers et al. [1997]:

$$
C_{A}=\frac{\rho C_{p}}{\alpha}\left(\eta_{0}\right)
$$

onde $\alpha$ é o coeficiente de expansão térmica e $\eta_{0}$ corresponde à AASM.

Os valores de $\rho, C_{p}$ e $\alpha$ são obtidos do corolário das propriedades fundamentais da água do mar descrito por Fofonoff E Millard [1983]. Foram empregados a temperatura [Locarnini et al., 2013] e salinidade [Zweng et al., 2013] médias mensais oriundos do World Ocean Atlas 2013 (WOA13) para o cálculo de $\rho, C_{p}$ e $\alpha$ aplicados aos dados de altímetro.

A disponibilidade dos dados de AASM do Projeto ATOBA, interpolados e distribuídos numa grade regular com resolução de $1 / 8^{\circ}$ conforme descrito na Seção 2.4 , permite a aplicação direta desse conjunto de dados na equação 3.29 , sem necessidade da aplicação adicional de processos de filtragem ou interpolação.

Os mapas horizontais mensais do calor armazenado para a área do estudo foram comparados com os mapas horizontais obtidos dos dados de modelo. Posteriormente, os valores mensais de $C_{A}$ foram correlacionados com as áreas de formação identificadas por meio dos dados in situ e de modelo oceanográfico. Os resultados da análise dos mesmos são apresentados no Capítulo 4 . 


\section{Capítulo 4}

\section{Resultados e Discussão}

\subsection{Preâmbulo}

Um dos objetivos específicos do presente trabalho é apresentar o primeiro estudo descritivo da AMSTAS por meio de um cruzeiro oceanográfico (OCSUL) planejado exclusivamente para o estudo da mesma. Para tal, foi estudada a variação da espessura da camada de AMSTAS na área de estudo entre $30^{\circ} \mathrm{S}-38^{\circ} \mathrm{S}$ e $30^{\circ} \mathrm{W}-40^{\circ} \mathrm{W}$. Foi observada a ocorrência de formação de AMSTAS nos invernos subsequentes ao período do cruzeiro, por meio de análises termodinâmicas e dinâmicas dos dados de perfiladores Argo lançados durante a OCSUL.

A variação da espessura da camada de AMSTAS observada por meio dos dados coletados in situ suscitou a curiosidade de confirmar sua interdependência com alterações da posição das áreas típicas de formação de AMSTAS e do volume recém formado, verificando a relação da redução da espessura da camada afundada com a distância entre sua posição e o limite da área de formação. Devido à ausência de coletas sistemáticas de dados in situ na região, o emprego de dados oriundos de modelos oceanográficos apresentou-se como a única alternativa para uma primeira estimativa e avaliação da variabilidade da espessura e do volume da camada de AMSTAS.

O fluxo de calor pela superfície e o calor armazenado no oceano constituem os parâmetros mais sensíveis para a quantificação de alterações na termodinâmica de determinada região e para a avaliação da contribuição da interação entre oceano e a atmosfera na formação de AMSTAS durante o inverno. A fim de avaliar as variações no 
campo de calor armazenado na região da CBM e retroflexão da $C B$, por meio de diferentes conjuntos de dados, e sua associação com a posição típica das áreas de formação de AMSTAS, foram realizadas as análises do calor armazenado do presente estudo.

Neste capítulo são apresentados os resultados e discussões das análises efetuadas no Capítulo 3, assim como a compilação e estudo comparativo dos mesmos.

\subsection{Estudo da AMSTAS por meio de Dados In Situ}

\subsubsection{Dados de CTD}

Como forma de verificar a existência da AMSTAS em extensa área do Atlântico Sudoeste foram analisados os dados de temperatura, salinidade e pressão do cruzeiro OCSUL. O período de realização do cruzeiro (meses de outono) não coincidiu com a presença de AMSTAS recém-formada nos perfis de CTD coletados. A observação dos períodos de formação de AMSTAS só foi possível por meio dos dados coletados nos invernos subsequentes pelos dois perfiladores Argo lançados durante a OCSUL.

A análise das radiais de CTD evidenciou a presença de AMSTAS em 40 estações oceanográficas realizadas, atendendo ao objetivo principal de realizar uma sistemática observação da água modal subtropical por meio de dados in situ. O processo de detecção descrito na subseção 3.4.1 permitiu identificar a presença de uma espessa camada de água modal em subsuperfície, provavelmente formada em anos anteriores, com densidade potencial média de $26,4 \mathrm{~kg} \mathrm{~m}^{-3}$, de acordo com as observações de Sato $\mathcal{E}$ Polito [2014]. O diagrama TS da Figura 4.1 apresenta todos os perfis de temperatura (T) e salinidade (S) analisados na região de estudo. 

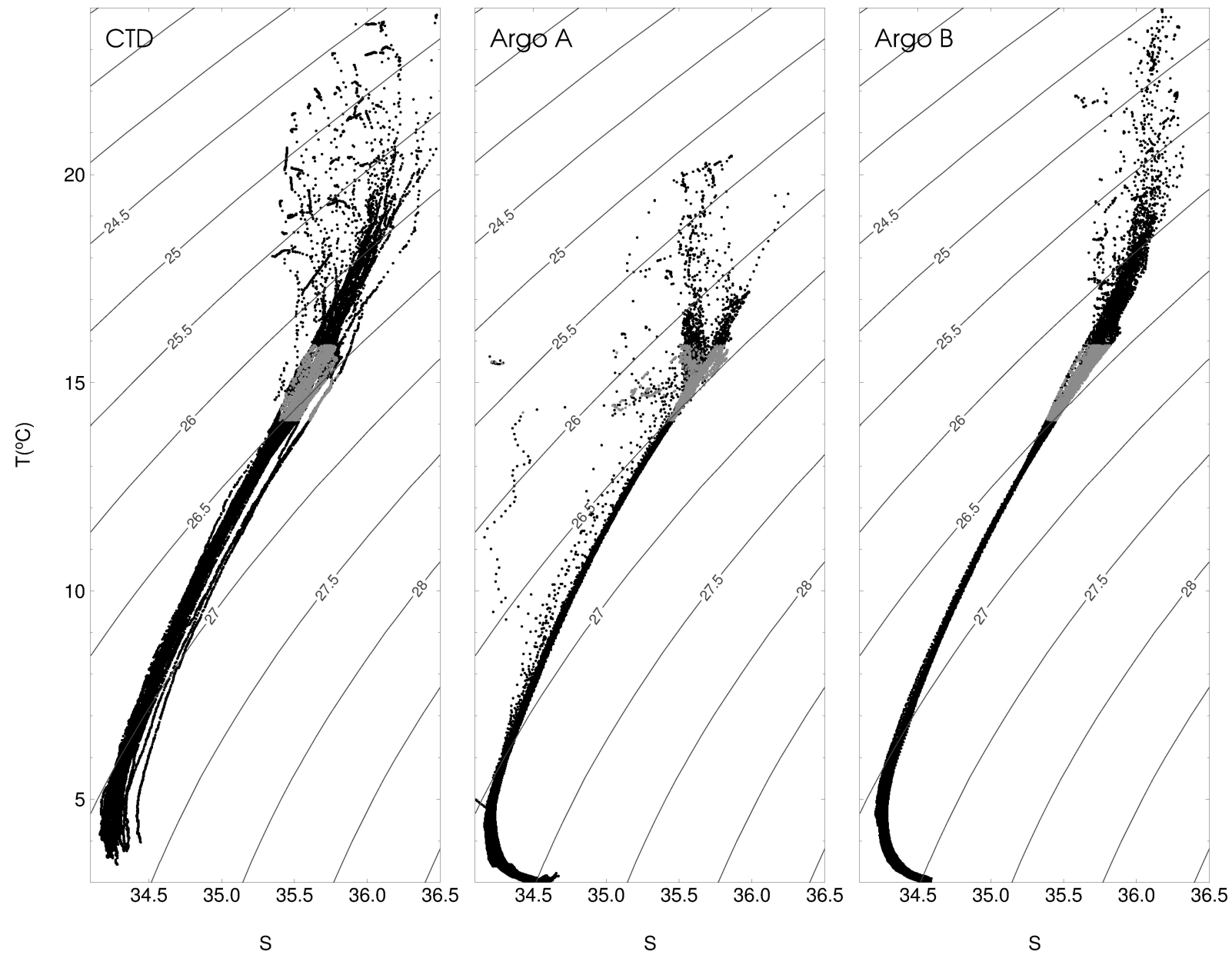

Figura 4.1: Diagramas TS (pares coletados até a profundidade de $1000 \mathrm{~m}$ ) das estações de CTD realizadas na OCSUL (painel da esquerda), dos perfis realizados pelo perfilador Argo A (painel central) e pelo perfilador Argo B (painel da direita). Os pares TS assinalados em cinza destacam os pontos com temperatura, salinidade e vorticidade potencial típicos da AMSTAS.

Foi possível observar a anisotropia em relação à distribuição espacial da AMSTAS, por meio da variação das profundidades mínima, máxima e espessura da camada variando com a latitude da estação oceanográfica, conforme evidenciado nos mapas da Figura 4.2. A espessura média da camada de AMSTAS detectada a partir dos dados de CTD foi de $(120 \pm 30)$ m. A região com a maior espessura observada, superior a $180 \mathrm{~m}$, ocorreu na porção central da área de estudo. O limite superior da camada variou de $77 \mathrm{~m}$ de profundidade na porção sudeste até $272 \mathrm{~m}$ de profundidade no extremo noroeste da área de estudo. Já o limite inferior da camada variou de $166 \mathrm{~m}$ a $394 \mathrm{~m}$ de profundidade nas mesmas posições. Essa inclinação era esperada já que a topografia dinâmica estabelece esse padrão de advecção da água modal em direção ao centro do giro subtropical. 

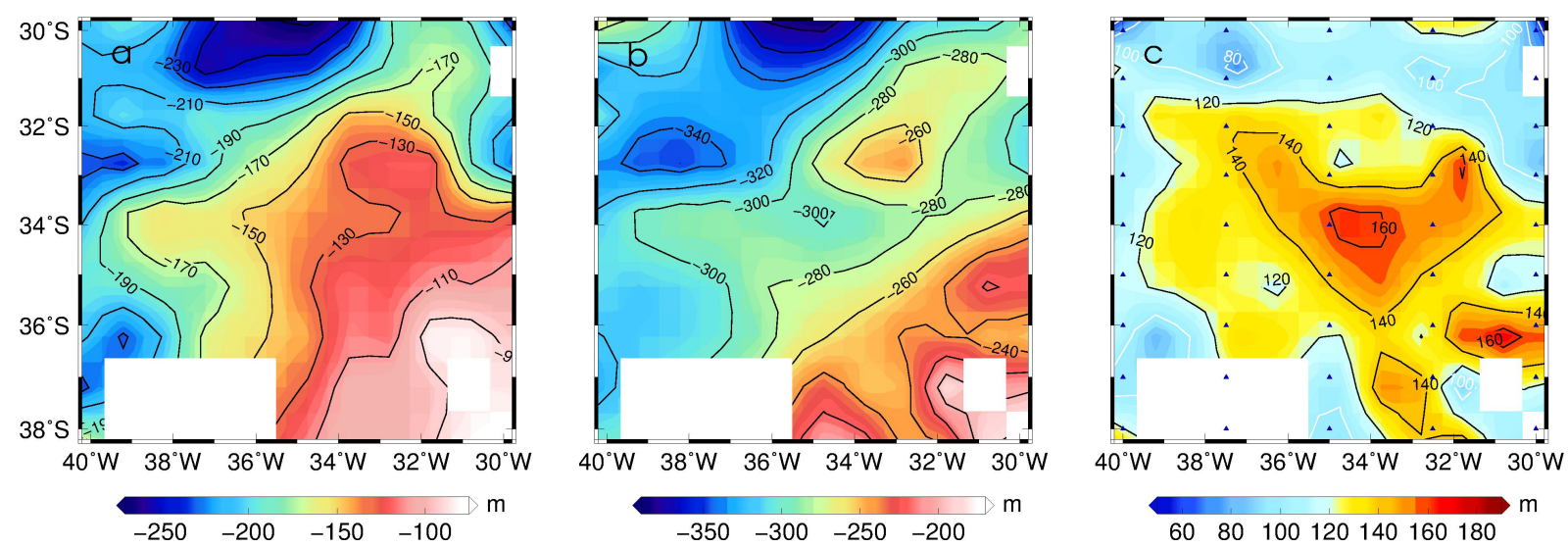

Figura 4.2: Profundidades mínima (a), máxima (b) e espessura (c) da camada de AMSTAS identificada por meio dos dados de CTD, em metros. Os triângulos em (c) indicam a posição das estações de CTD realizadas.

Os mapas horizontais de temperatura e salinidade das Figuras 4.3 e 4.4 permitiram verificar que os limites de temperatura empregados para detecção da AMSTAS nos dados de $\operatorname{CTD}\left(\operatorname{de~} 14,1^{\circ} \mathrm{C}\right.$ a $15,9^{\circ} \mathrm{C}$ ) foram mais determinantes para a definição da área ocupada pela camada de água modal subtropical do que os limites de salinidade $(35,4$ a 35,8$)$. Tal fato se deve ao reduzido gradiente horizontal de salinidade típica da AMSTAS observado em toda área da OCSUL. Dessa forma, as posições e profundidades de ocorrência das isotermas de $14,1^{\circ} \mathrm{C}$ e $15,9^{\circ} \mathrm{C}$, consolidadas na Figura 4.5 , delimitam preliminarmente as regiões de possível ocorrência da AMSTAS por nível de profundidade na área de realização do cruzeiro. O deslocamento das mesmas, com o aumento da profundidade, na direção noroeste a partir do extremo sudeste da área de estudo corrobora a variação de profundidades mínima, máxima e espessura da camada de AMSTAS observada na mesma direção na Figura 4.2 . 


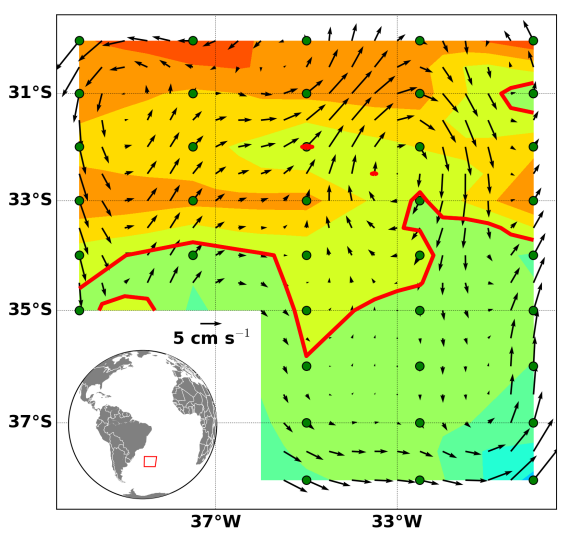

(a)

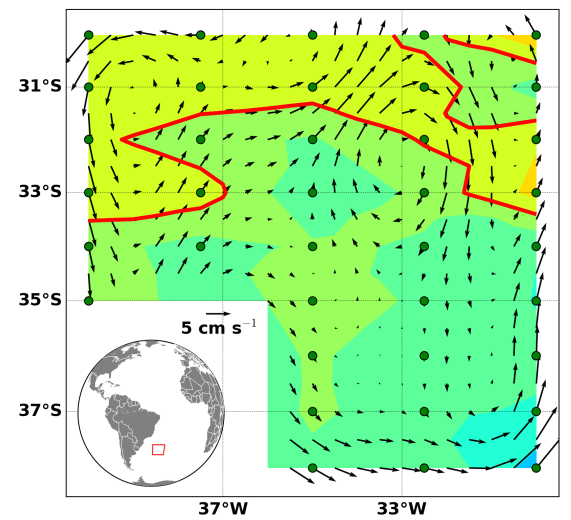

(c)

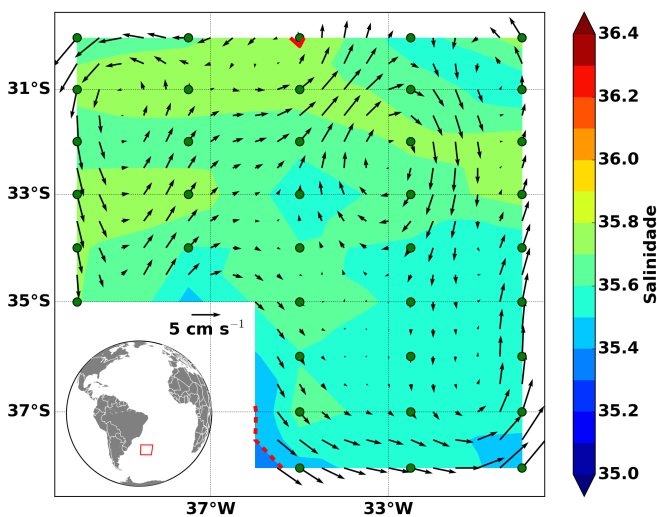

(e)

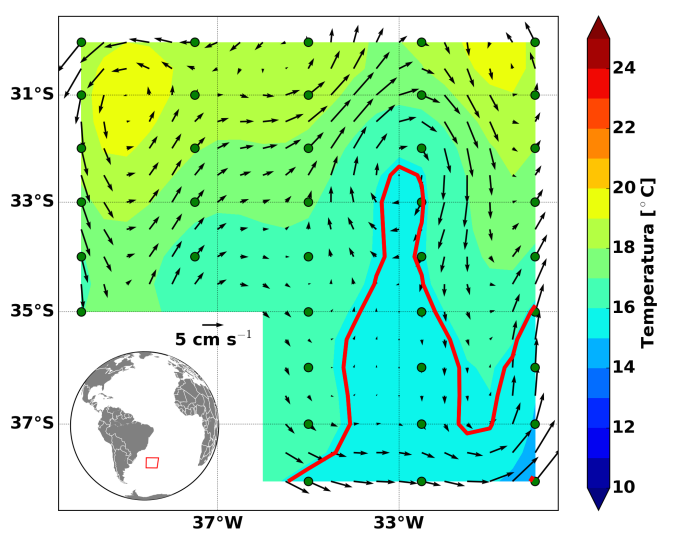

(b)

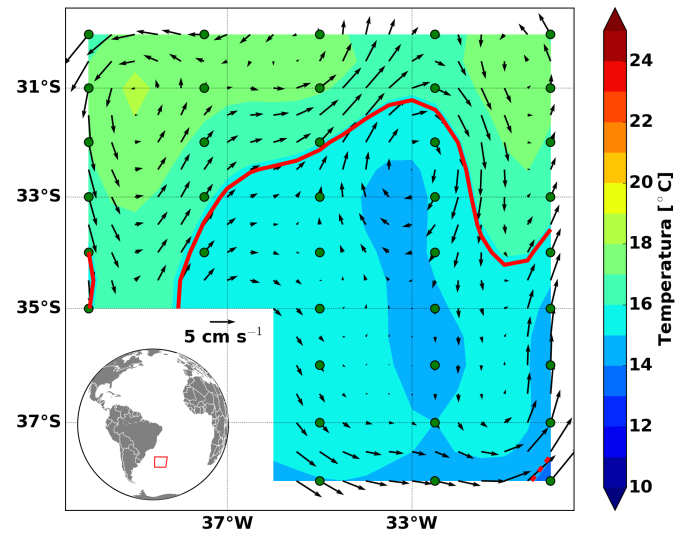

(d)

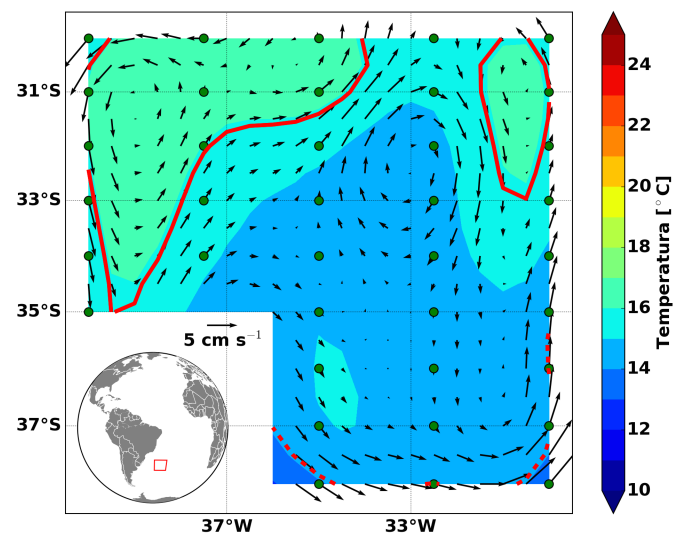

(f)

Figura 4.3: Mapas horizontais de temperatura (painéis " $b$ ", " $d$ "e " $f$ ") e salinidade (painéis "a", "c"e "e") com os vetores de velocidade geostrófica baroclínica relativa a $500 \mathrm{~m}\left(\vec{V}_{g}\right)$ para as profundidades de 100 m (painéis "a"e "b"), 150 m (painéis "c"e "d") e 200 m (painéis "e"e "f"). Linhas contínuas vermelhas indicam os limites superiores de T e S para detecção da AMSTAS $\left(15,9^{\circ} \mathrm{C}\right.$ e 35,8 , respectivamente) e as linhas tracejadas vermelhas os limites inferiores $\left(14,1^{\circ} \mathrm{C}\right.$ e 35,4 , respectivamente). 


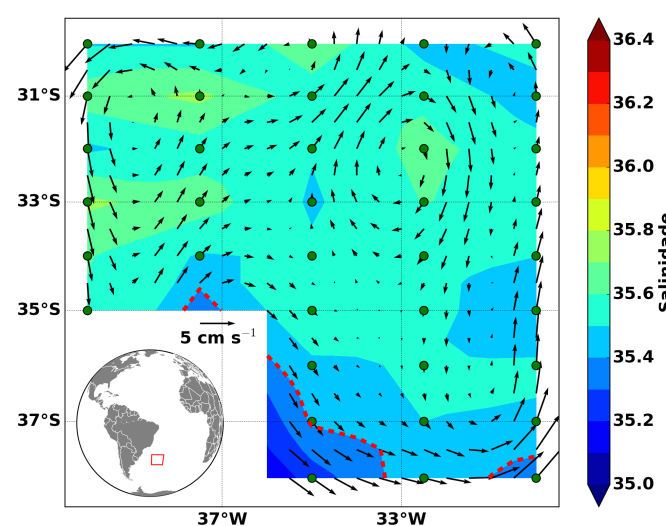

(a)

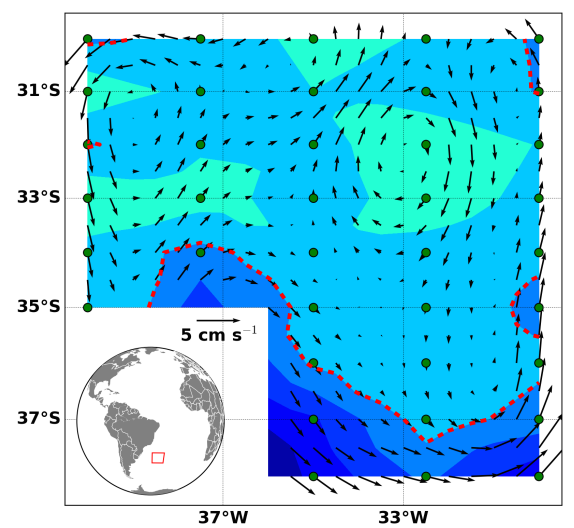

(c)

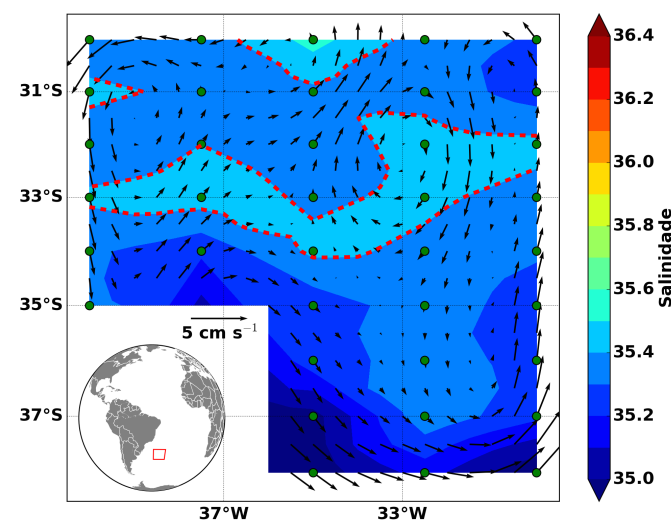

(e)

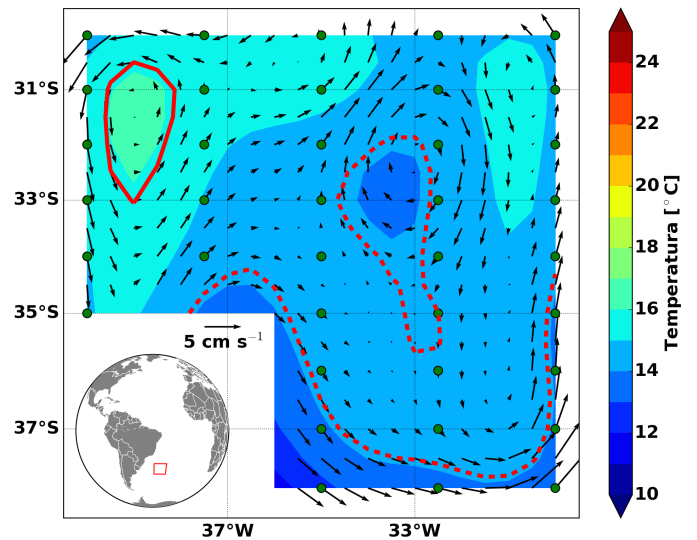

(b)

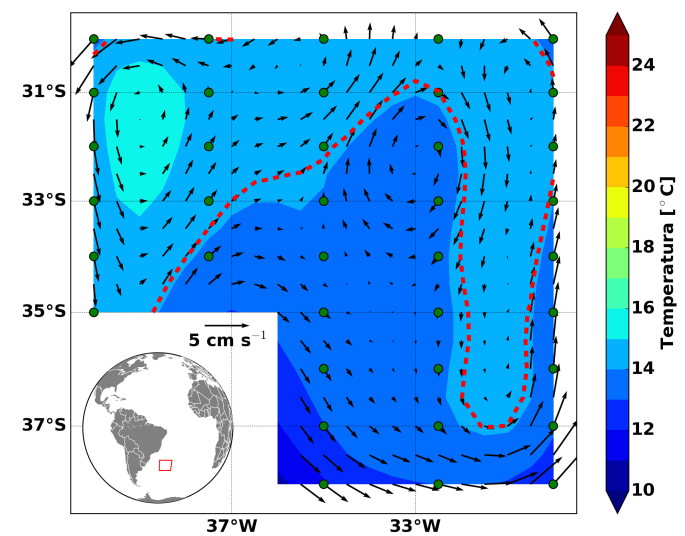

(d)

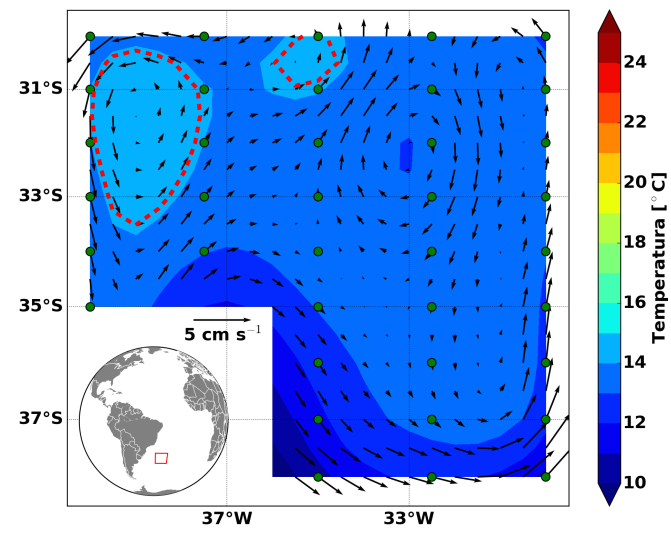

(f)

Figura 4.4: Similar à Figura 4.3 para as profundidades de $250 \mathrm{~m}$ (painéis "a"e "b"), $300 \mathrm{~m}$ (painéis "c"e "d") e 350 m (painéis "e"e "f"). 


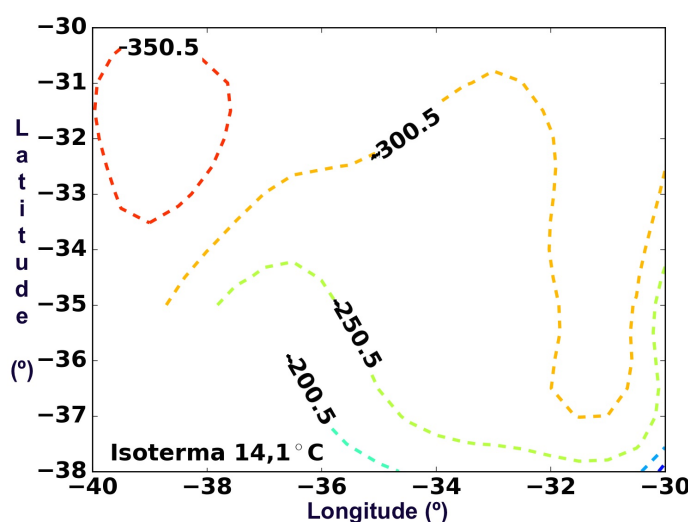

(a)

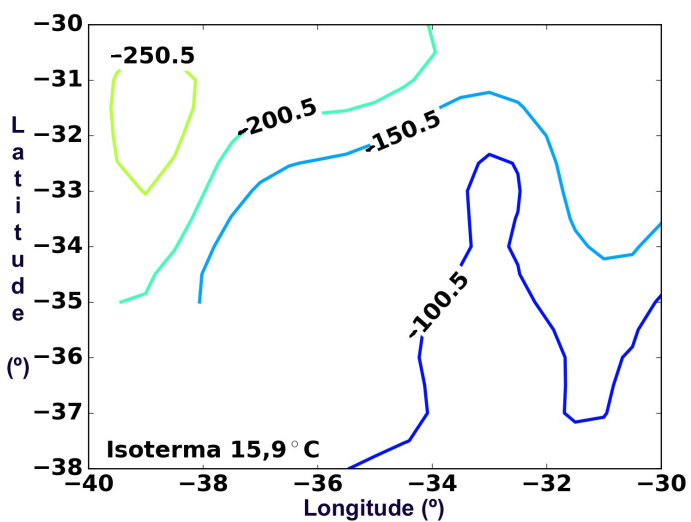

(b)

Figura 4.5: Posição das isotermas de $14,1^{\circ} \mathrm{C}$ (painel "a") e $15,9^{\circ} \mathrm{C}$ (painel "b") na área de estudo com anotação da profundidade (em metros) de ocorrência sobre as mesmas.

As seções zonais e meridionais da área de estudo plotadas na Figura 4.6 indicam o aprofundamento da camada de AMSTAS na direção noroeste. Por tratar-se de um fenômeno diretamente relacionado com a interação oceano-atmosfera, é plausível considerar que as menores profundidades iniciais observadas ao sul da área de estudo se devem à existência de AMSTAS formada recentemente e mais próxima da região de formação, quando comparada às maiores profundidades de ocorrência observadas ao norte da área de estudo, possivelmente associadas à águas modais mais antigas. As espessuras maiores existentes na porção central da área denotam uma zona de transição em que ocorre o acúmulo maior de volumes de AMSTAS formados em diferentes invernos. 

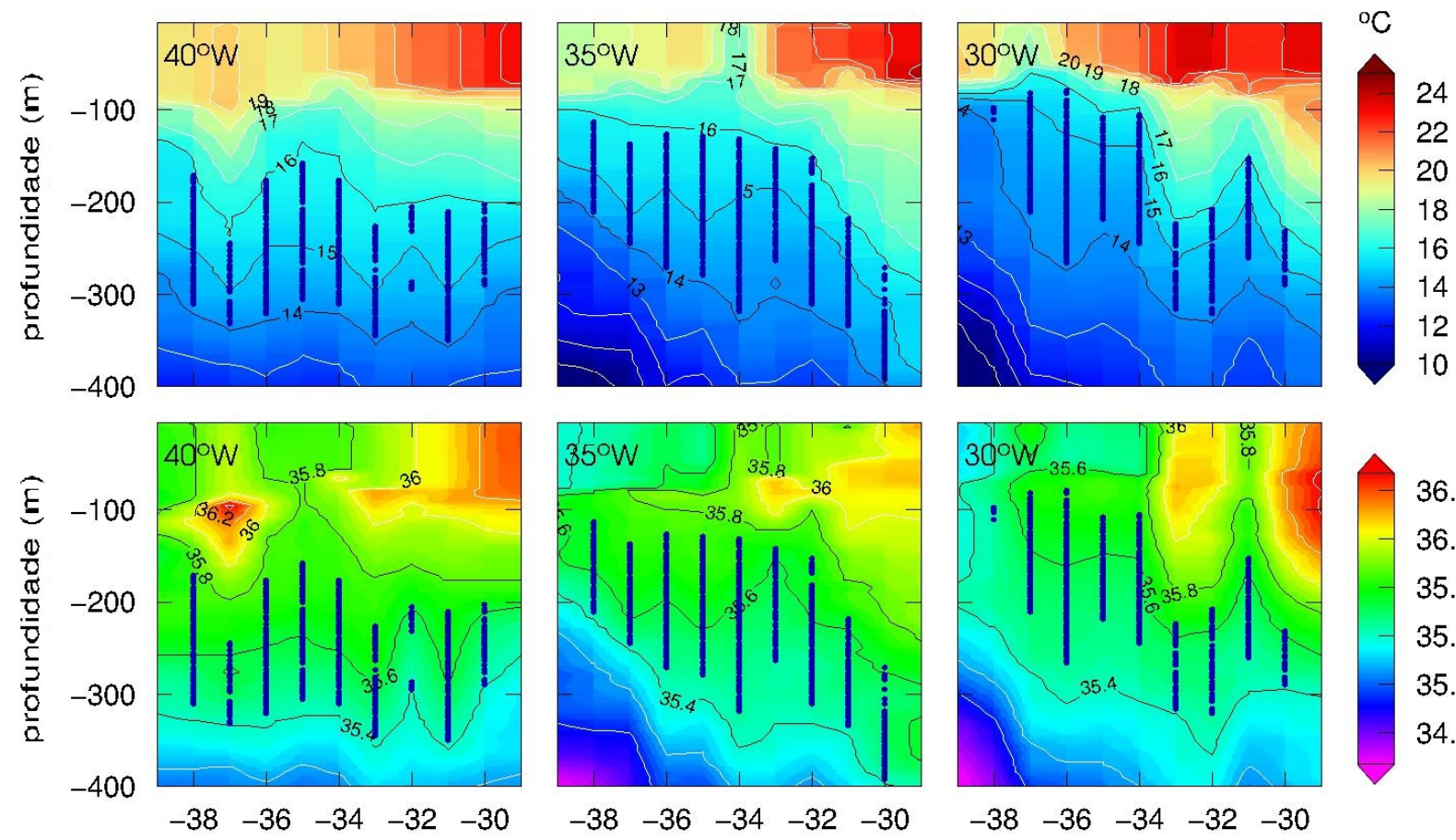

36.3

36.0

35.7

35.4

35.1

34.8
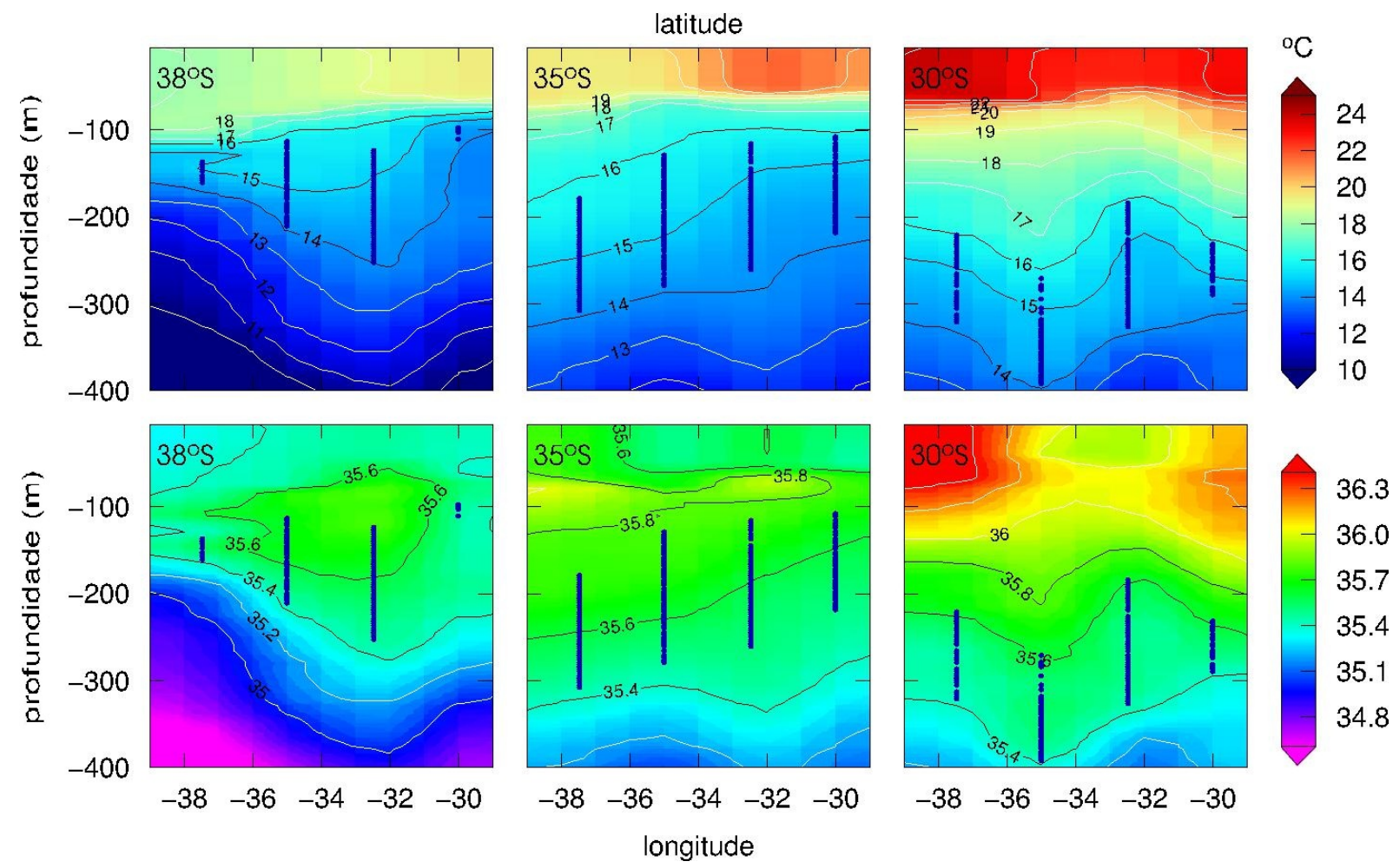

Figura 4.6: Temperatura (painéis superiores) e salinidade (inferiores) das seções meridionais realizadas em $40^{\circ} \mathrm{W}, 35^{\circ} \mathrm{W}, 30^{\circ} \mathrm{W}$, e das seções zonais em $38^{\circ} \mathrm{S}, 35^{\circ} \mathrm{S}$ e $30^{\circ} \mathrm{S}$ a partir dos dados de CTD. Os pontos azuis indicam as posições do perfil onde foi detectada AMSTAS. 


\subsubsection{Dinâmica na área da OCSUL}

As componentes baroclínicas da velocidade geostrófica evidenciaram a ausência de cisalhamento vertical. Isso está demonstrado nos mapas horizontais de função de corrente geostrófica baroclínica relativa a 500 m, Figuras 4.7 e 4.8 . Essa observação denota o caráter eminentemente barotrópico das correntes na área em que foi realizada a OCSUL, em concordância com os estudos de Roden [1986] e Whitworth E Nowlin [1987]. Isso averba a desconsideração da vorticidade relativa no cálculo da vorticidade potencial $(Q)$ proposto por McCartney [1982] e empregado no presente estudo.

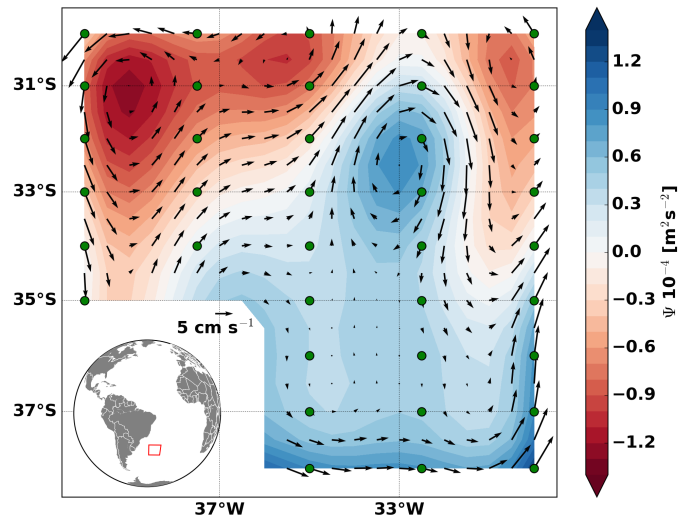

(a)

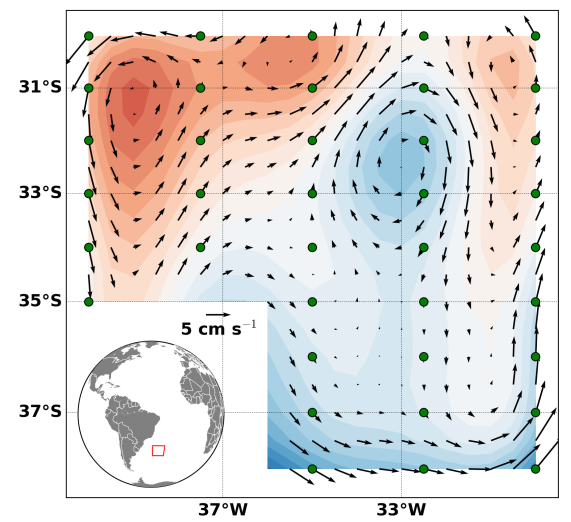

(c)

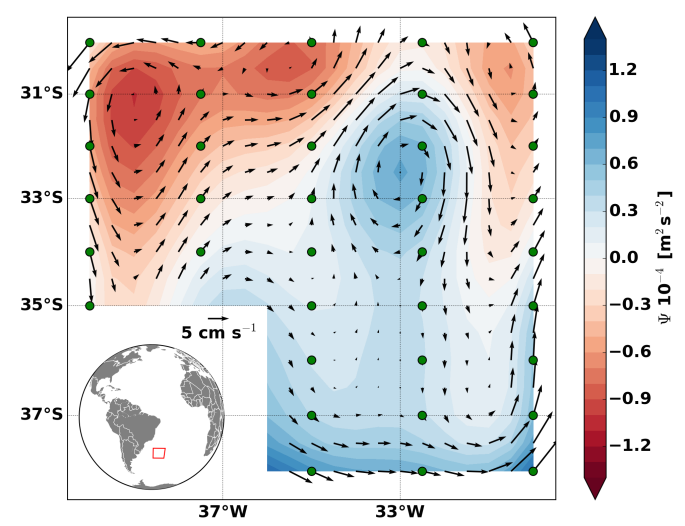

(b)

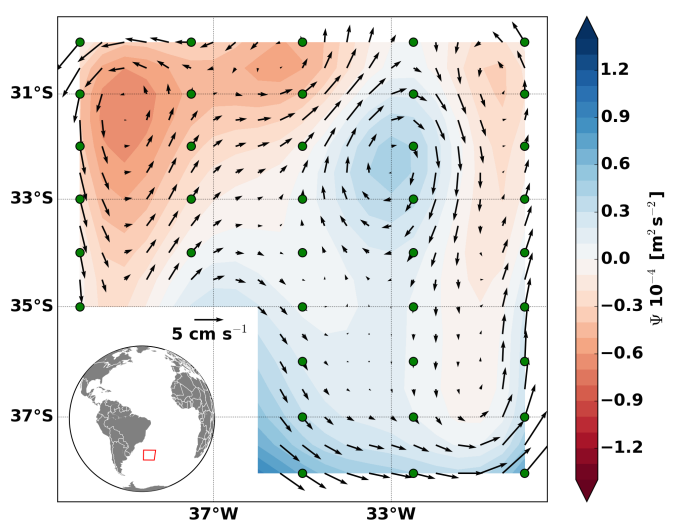

(d)

Figura 4.7: Mapa horizontal de função de corrente geostrófica baroclínica $(\Psi)$ com sobreposição dos vetores de velocidade geostrófica baroclínica $\left(\vec{V}_{g}\right.$ em $\left.\mathrm{cm} \mathrm{s}^{-1}\right)$, ambos referentes a 500 m, para as profundidades de 50 m, 100 m, 150 m, 200 m (painéis "a", " b" , "c"e "d", respectivamente). 


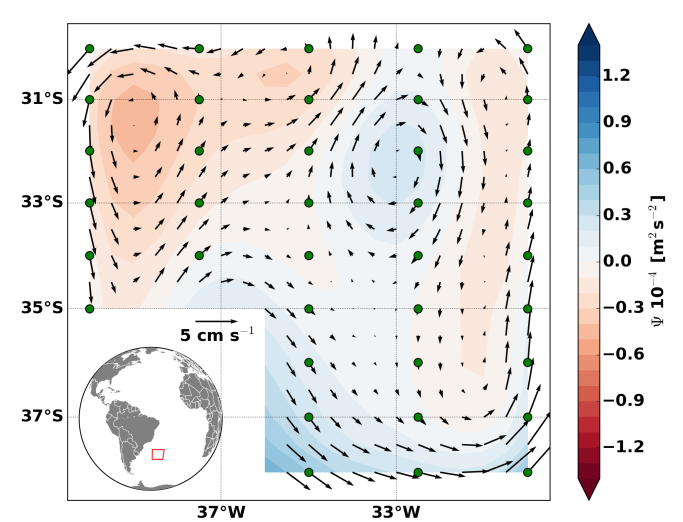

(a)

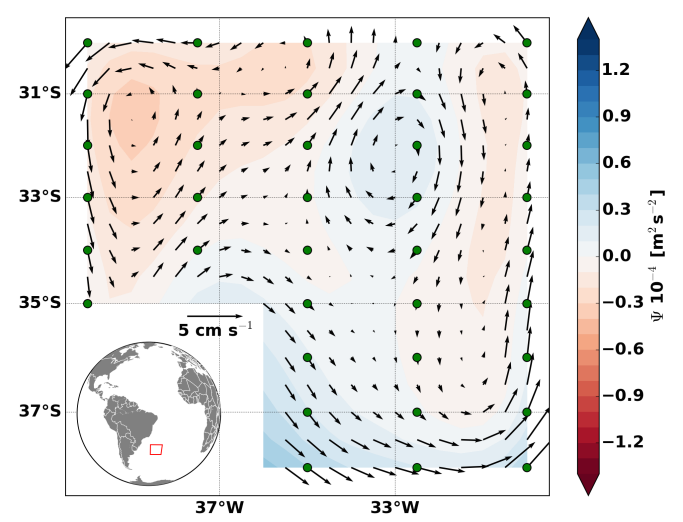

(b)

Figura 4.8: Similar à Figura 4.7 para as profundidades de $300 \mathrm{~m}$ (painel "a") e $350 \mathrm{~m}$ (painel "b").

Foi possível observar a presença da Corrente do Atlântico Sul (CAS) fluindo na direção leste e atravessando a área de estudo ao sul de $37^{\circ} \mathrm{S}$. Da mesma forma, a Frente da Corrente do Brasil (FCB), identificada pela isoterma de $21^{\circ} \mathrm{C}$ [Olson et al., 1988] no mapa de temperatura dos dados de CTD (Figura 4.9), delimita a existência de uma região ao norte da mesma onde ocorrem maiores gradientes horizontais de temperatura na superfície, de acordo com o estudo de Peterson $\mathcal{E}$ Stramma [1991]. Ao sul da FCB ocorreram baixos valores para as componentes zonal $\left(u_{g}\right)$ e meridional $\left(v_{g}\right)$ da velocidade geostrófica baroclínica, no interior da camada onde foi detectada a AMSTAS. Tal fato era esperado e se deve à homogeneidade horizontal da mesma indicar a presença de pequenos valores de gradiente horizontal de densidade. 


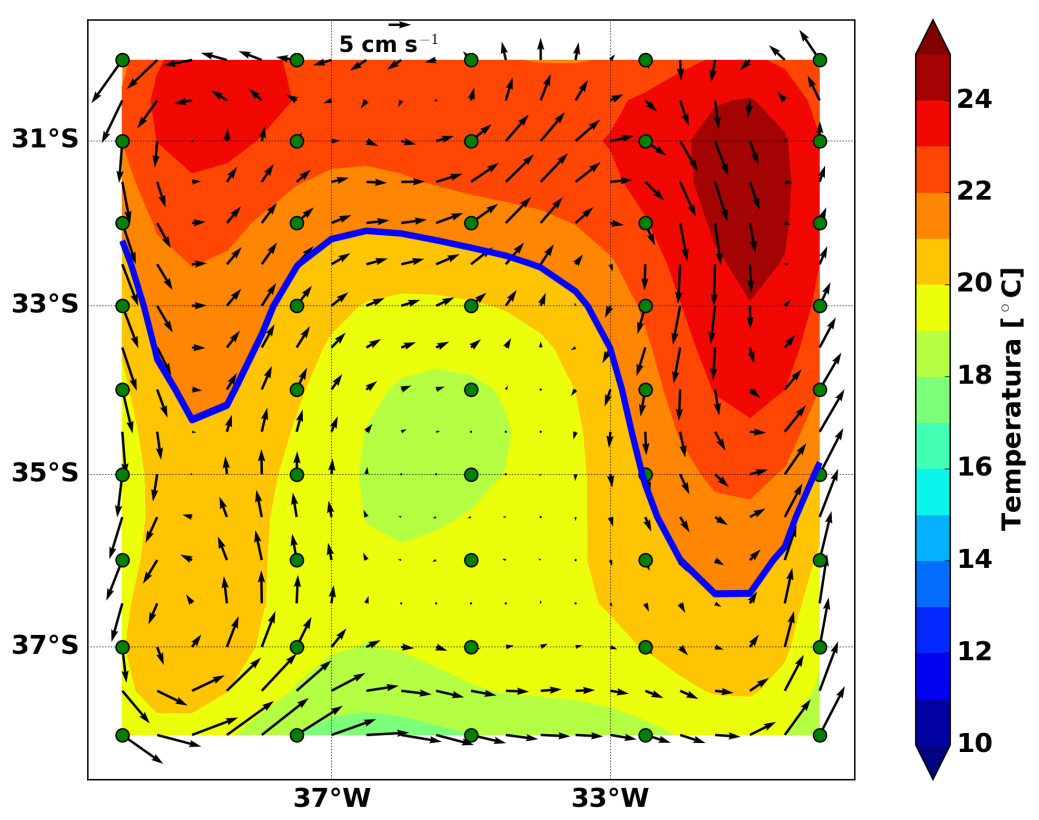

Figura 4.9: Mapa horizontal de temperatura na superfície com sobreposição dos vetores de velocidade geostrófica baroclínica relativa a $500 \mathrm{~m}\left(\vec{V}_{g} \mathrm{em} \mathrm{cm} \mathrm{s}^{-1}\right)$. A linha contínua azul indica a isoterma de $21,0^{\circ} \mathrm{C}$, característica da FCB.

\subsubsection{Dados de perfiladores Argo}

A análise dos dados de temperatura oriundos dos perfiladores Argo lançados durante a OCSUL (painéis superiores das Figuras 4.10 e 4.11) permitiu verificar a existência de duas séries temporais de AMSTAS distintas, caracterizadas possivelmente pelas posições assumidas pelos perfiladores ao longo da deriva. Ambos perfiladores permaneceram no interior da área de estudo e deslocaram-se apenas algumas centenas de quilômetros a partir das posições de lançamento durante todo período estudado.

O perfilador Argo A (ID 5903130), lançado em 28/04/2015 na posição 35 S/ $35^{\circ} \mathrm{W}$ detectou a formação típica de água modal denotada pela presença da isoterma de $15,9^{\circ} \mathrm{C}$ na superfície desde o dia $31 / 08 / 2015$ na posição $35,40^{\circ} \mathrm{S} / 34,06^{\circ} \mathrm{W}$ até o início da reestratificação da camada superior. $\mathrm{O}$ aquecimento a partir da segunda quinzena de outubro de 2015 provocou o afundamento dessa isoterma conforme pode ser visto no painel superior da Figura 4.10. O referido perfilador encontrava-se entre as latitudes de $35^{\circ} \mathrm{S}$ e $36^{\circ} \mathrm{S}$ no período de formação. 


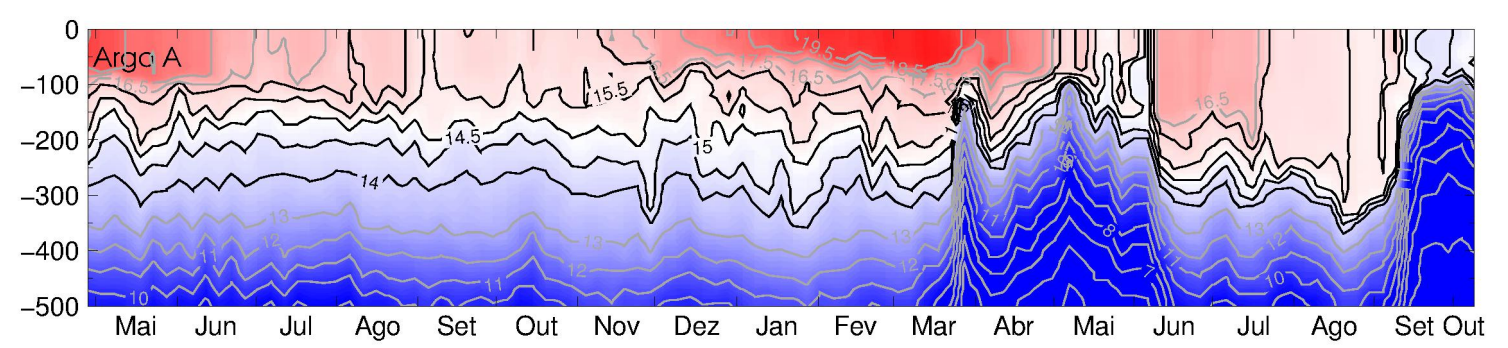

${ }^{\circ} \mathrm{C}$

Mai Jun Jul Ago Set Out Nov Dez Jan Fev Mar Abr Mai Jun Jul Ago Set Out
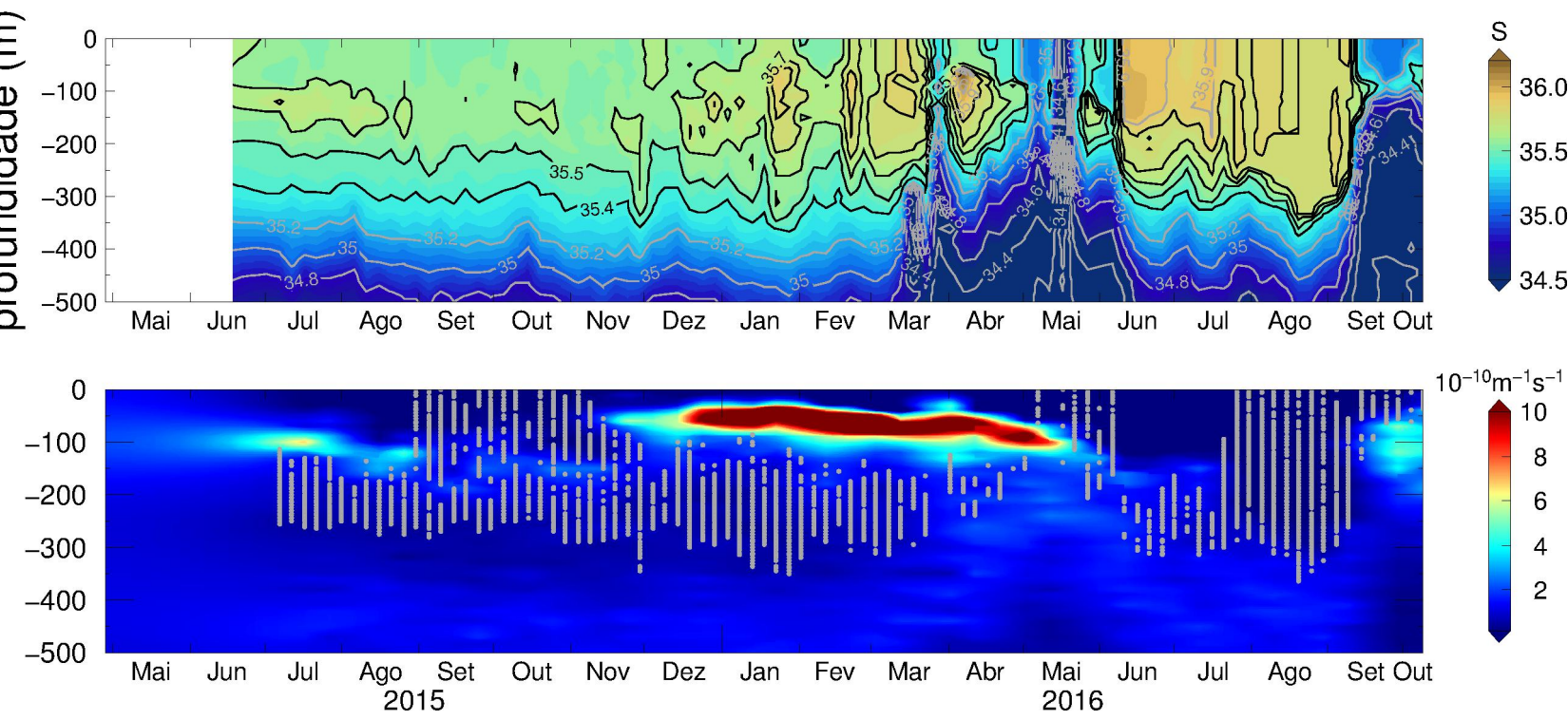

Figura 4.10: Diagrama profundidade-tempo da temperatura (em ${ }^{\circ} \mathrm{C}$ no painel superior), salinidade (intermediário) e vorticidade potencial $\left(Q \mathrm{em} \mathrm{m}^{-1} \mathrm{~s}^{-1}\right.$, inferior) do perfilador Argo A. Os contornos destacados indicam as isotermas e isohalinas dentro da camada de AMSTAS. As barras verticais em cinza no painel inferior são formadas pela união dos pontos que contém as posições do perfil onde foi detectada AMSTAS.

O deslocamento do perfilador Argo A em direção ao sul (Figura 2.2), atingindo latitudes maiores que $38^{\circ} \mathrm{S}$ no mês de abril de 2016, fez com que o mesmo deixasse de detectar a presença de AMSTAS em seus perfis, sendo possível observar que as isotermas e isohalinas destacadas na figura se aproximam abruptamente ao final de março de 2016 (painéis superior e intermediário da Figura 4.10). Entretanto, a partir do dia 22/05/2016 o perfilador Argo A começou a se deslocar na direção norte e voltou a detectar a presença de AMSTAS, a partir desse dia, na posição $39,84^{\circ} \mathrm{S} / 37,32^{\circ} \mathrm{W}$. Merece destaque a detecção de AMSTAS em formação no mês de maio de 2016.

Já o perfilador Argo B (ID 5903131), lançado em 10/05/2015 na posição 30S/ $40^{\circ} \mathrm{W}$ detectou apenas água modal afundada, denotada pelo posicionamento da isoterma de $15,9^{\circ} \mathrm{C}$ apenas em profundidades superiores a $200 \mathrm{~m}$. Nessa região essa isoterma não atingiu a superfície no período típico de formação da AMSTAS (julho a outubro), 
conforme pode ser observado no painel superior da Figura 4.11. O referido perfilador encontrava-se ao norte da latitude $34^{\circ} \mathrm{S}$ no período típico de formação tanto em 2015 quanto em 2016, o que denota que na região ao norte dessa latitude (porção norte da área de estudo) não ocorreu formação de água modal em ambos invernos.

É possível observar que com o deslocamento do perfilador Argo B em direção ao sul (Figura 2.2), atingindo latitudes maiores que $34^{\circ} \mathrm{S}$ nos meses de março e abril de 2016 , gradativamente a isoterma de $15,9^{\circ} \mathrm{C}$ se aproxima da superfície, posicionando-se em profundidades de cerca de 120m (painel superior da Figura 4.11). Tais dados coletados confirmam a observação da anisotropia da camada de água modal, previamente verificada por meio dos dados de CTD coletados durante a OCSUL realizada entre abril e maio de 2015. O perfilador Argo B detectou apenas a presença de AMSTAS afundada ao longo de sua trajetória em toda a série temporal.
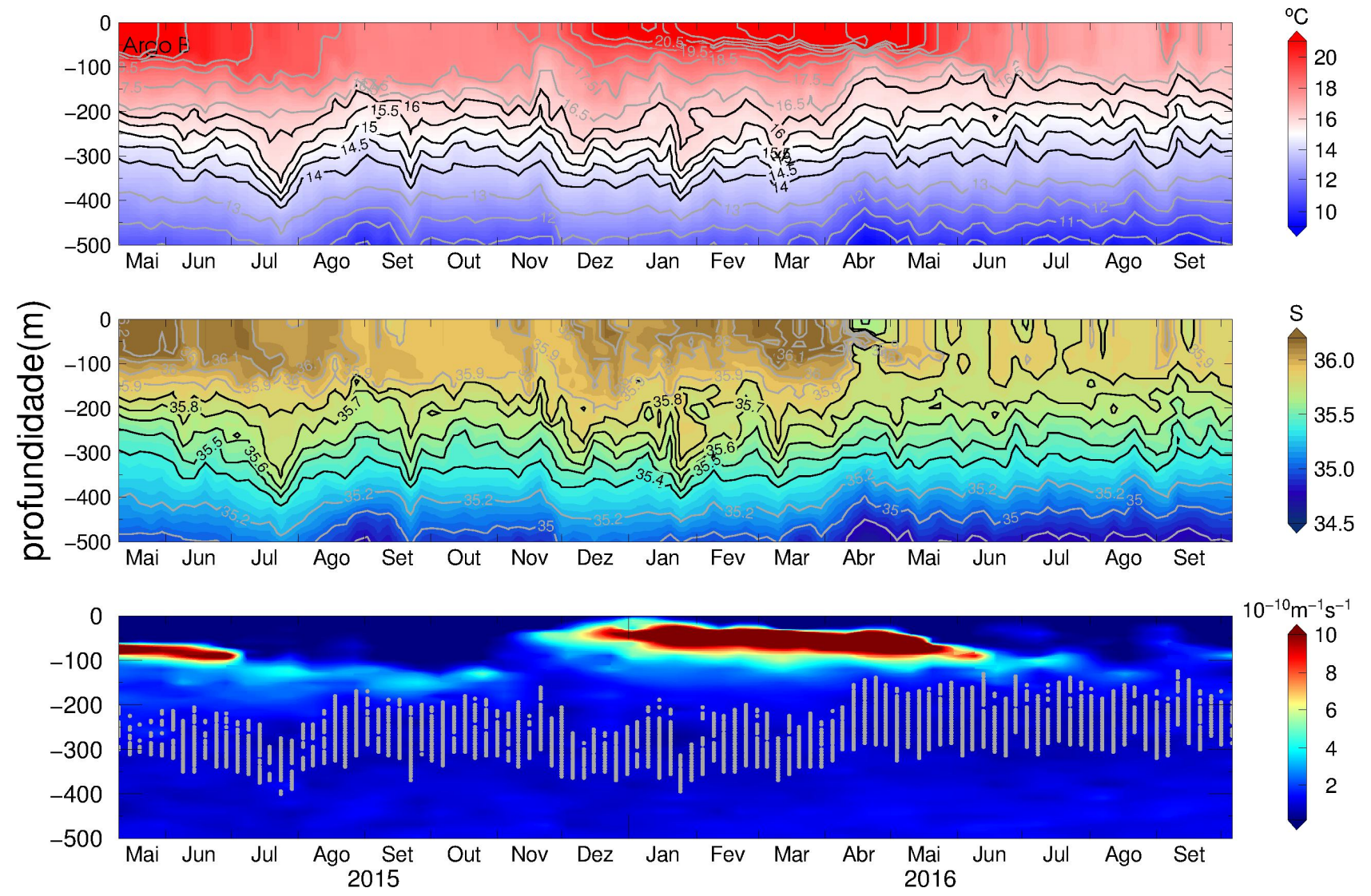

Figura 4.11: Similar à Figura 4.10 para o perfilador Argo B. 
Os painéis inferiores das Figuras 4.10 e 4.11) permitem confirmar que a vorticidade potencial $(Q)$ mínima é condição necessária para a caracterização das águas modais subtropicais, entretanto não é suficiente para identificação das mesmas. Somente a análise combinada dos parâmetros físicos da amostra com os valores mínimos de $Q$ permitem a correta detecção das AMSTAS. A Figura 4.10 em particular, apresenta no seu painel inferior durante o período de formação uma clara distinção entre a AMSTAS detectada próximo da superfície, com menores valores de $Q$ (em média 2,0 $\times 10^{-11} \mathrm{~m}^{-1} \mathrm{~s}^{-1}$ e alcançando menos de $\left.2,0 \times 10^{-12} \mathrm{~m}^{-1} \mathrm{~s}^{-1}\right)$, e a AMSTAS que jazia afundada, com valores maiores de $Q$ quando comparados à AMSTAS recém formada. É possível notar, ainda, maior descontinuidade vertical dos pontos que continham as posições do perfil onde foi detectada AMSTAS, marcados em cinza, entre as profundidades de 150 e 200m durante o período de formação, demonstrando a presença de uma tênue região de transição e separação entre as AMSTAS recém formada e afundada.

O presente estudo confirmou a validade do emprego de valores uma ordem de grandeza menores que os utilizados para detectar a AMSTAS afundada com o objetivo de diferenciar a AMSTAS recém formada por meio de dados in situ. Essa observação corrobora o critério admitido por Forget et al.]2011] ao utilizarem um modelo numérico para investigação da AM18 e diferenciação de volumes recém formados.

Os resultados obtidos dos dados de CTD e dos perfiladores Argo lançados permitiram confirmar a presença de água modal afundada e também a existência de um claro ciclo de formação na área de estudo, com denotada variabilidade espaço-temporal. Foi possível observar ainda que a dinâmica na área de estudo, identificada por meio do cálculo da componente baroclínica da velocidade geostrófica, exerce papel preponderante no afundamento e advecção da água modal subtropical, nos meses subsequentes ao período de formação.

\subsection{Estudo dos Dados de Modelos Numéricos}

A análise dos dados obtidos por meio do emprego de três configurações distintas de um mesmo modelo numérico para detecção de amostras de água modal subtropical permitiu verificar a existência de respostas diferentes devidas, possivelmente, 
às peculiaridades inerentes a cada uma das configurações do modelo utilizado. No intuito de reproduzir os resultados obtidos por meio dos dados in situ com o emprego de modelo oceânico, foi empregado o modelo numérico HYCOM.

\subsubsection{HYCOM-SAMOC}

Inicialmente, a configuração utilizada foi aquela proposta pelo Projeto SAMOC [Campos et al., em fase de elaboração] e descrita na Seção 2.3. Desta forma, pode-se estender a série temporal de dados para um período longo o suficiente que permitisse avaliar a variabilidade da AMSTAS.

Após aplicados os critérios de seleção de AMSTAS, citados na subseção 3.4.2. aos dados do modelo HYCOM-SAMOC foi possível observar que o mesmo não foi capaz de detectar amostras de AMSTAS na área de estudo nos meses de abril e maio de 2015.

A Figura 4.12 apresenta a média das profundidades das isotermas de 14,1 e $15,9^{\circ} \mathrm{C}$ para o mesmo período da OCSUL nos pontos de grade do modelo HYCOMSAMOC em que a vorticidade potencial $(Q)$ foi inferior a $2,0 \times 10^{-10} \mathrm{~m}^{-1} \mathrm{~s}^{-1}$. Além das referidas isotermas estarem extramente próximas na vertical, quando comparado ao observado nos dados da OCSUL, a isoterma de $15,9^{\circ} \mathrm{C}$ encontrava-se na profundidade de $50 \mathrm{~m}$ na área do cruzeiro ocenográfico, cerca de $100 \mathrm{~m}$ acima da profundidade observada para essa isoterma nos dados in situ.

Embora o modelo HYCOM-SAMOC possuísse 33 níveis isopicnais, apenas quatro deles encontravam-se dentro dos limites de 25,6 a $26,8 \mathrm{~kg} \mathrm{~m}^{-3}$ para os valores de $\sigma_{\theta}$ observados por Sato $\mathcal{E}$ Polito [2014] para as águas modais subtropicais do Atlântico Sul. Desta forma, esse modelo não foi utilizado para estudarmos a água modal. 


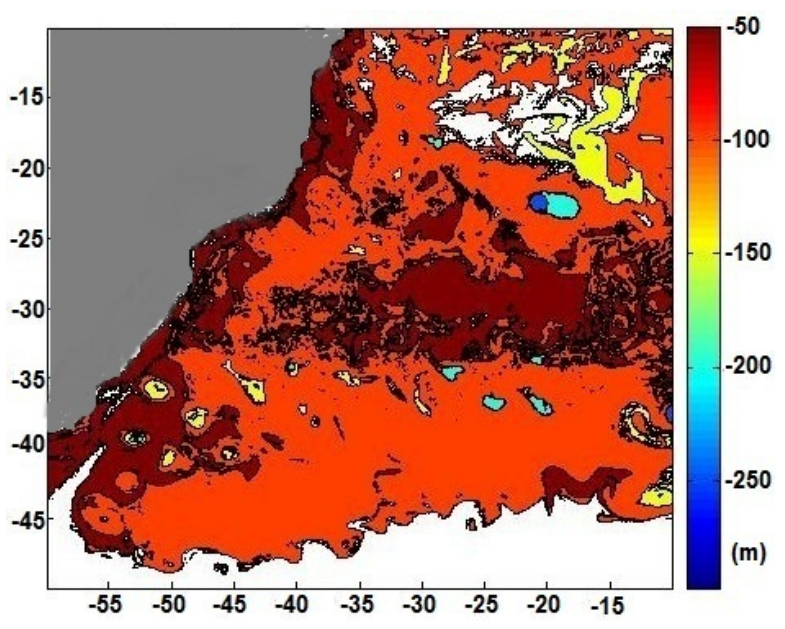

(a)

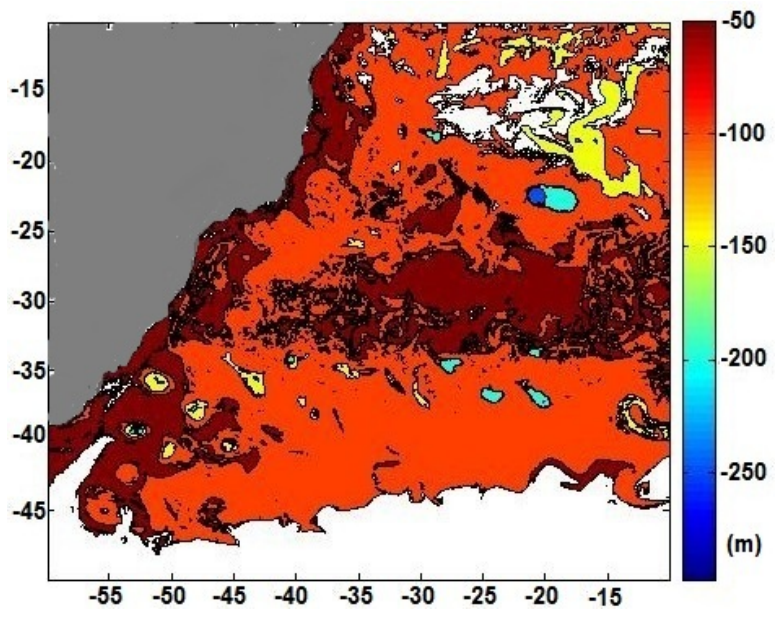

(b)

Figura 4.12: Profundidade média (em metros) das isotermas de $14,1^{\circ} \mathrm{C}$ (painel "a") e $15,9^{\circ} \mathrm{C}$ (painel " $\mathrm{b}$ ") para o período da OCSUL nos pontos de grade do modelo HYCOM-SAMOC em que a vorticidade potencial $(Q)$ foi inferior a $2,0 \times 10^{-10} \mathrm{~m}^{-1} \mathrm{~s}^{-1}$.

\subsubsection{HYCOM 1}

Prosseguindo na tentativa de reproduzir os resultados da OCSUL, foi montada a configuração HYCOM 1 descrita na Seção 2.3. Tal configuração era mais simples do que o HYCOM-SAMOC (rodada livre e com climatologia repetida anualmente) e devido a restrições computacionais teve sua simulação realizada por apenas 4 anos. Entretanto, possuía 14 dos 33 níveis isopicnais distribuídos entre os valores de densidade potencial de 25,6 a $26,8 \mathrm{~kg} \mathrm{~m}^{-3}$, com diferença de $0,1 \mathrm{~kg} \mathrm{~m}^{-3}$ entre cada nível.

\section{Estimativa de Volume da AMSTAS}

O cálculo do volume de AMSTAS detectada em cada ponto de grade do modelo foi realizado por meio da multiplicação da área quadrada centrada em cada um dos pontos de grade $\left(\sim 9 \mathrm{~km}^{2}\right)$ pela espessura da camada de AMSTAS detectada em cada ponto de grade, obtida após aplicados todos os critérios de seleção citados na subseção 3.4 .2 .

O volume formado foi obtido a partir da aplicação do critério utilizado por Forget et al. [2011], segundo o qual considera-se a amostra de água modal subtropical recém formada aquela que possui vorticidade potencial $(Q)$ inferior a $2,0 \times 10^{-11}$ 
$\mathrm{m}^{-1} \mathrm{~s}^{-1}$, ou seja, uma ordem de grandeza menor que o valor de $Q$ admitido para a detecção de amostras afundadas.

A série temporal do volume de AMSTAS selecionada a partir dos dados do HYCOM 1 apresentou o valor de $(3,49 \pm 0,12) \times 10^{14} \mathrm{~m}^{3}$ para o volume médio de água modal subtropical afundada, no mês de junho, imediatamente anterior ao período de formação, dos anos 2, 3 e 4 da simulação. Foi possível observar que esse volume no mês de junho não apresenta a mesma tendência de aumento observada para os valores máximos de volume da AMSTAS afundado e formado, após a conclusão do primeiro ciclo sazonal da simulação (Figura 4.13). Para o mesmo período, a diferença entre o volume máximo para a AMSTAS afundada (obtido em novembro) e o valor mínimo detectado no mês de junho anterior (conforme Tabela 4.1), considerando a taxa de redução média observada entre os meses de abril e junho do mesmo ano, correspondeu em média a $36,6 \%$ do volume total formado naquele ciclo, representado pela soma do volume formado nos meses de julho, agosto, setembro e outubro de um mesmo ciclo sazonal. Tal relação é semelhante ao observado no estudo de Kelly E Dong [2013] para a AM18, segundo o qual apenas 35\% do volume recém formado é advectado e alcança maiores profundidades na região de subducção, onde a AM18 não atinge a superfície durante o inverno.

Tabela 4.1: Valores do volume médio mensal $\left(\times 10^{14} \mathrm{~m}^{3}\right)$ total de AMSTAS detectado nos meses de junho e novembro de cada ano da simulação do HYCOM 1.

\begin{tabular}{ccc}
\hline \hline \multicolumn{2}{c}{ Média Mensal do Volume de AMSTAS Afundada $\left(\times 10^{14} \mathrm{~m}^{3}\right)$} \\
\hline \hline Ano da Simulação & Junho & Novembro \\
\hline 1 & 7,05 & 8,02 \\
2 & 3,61 & 9,52 \\
3 & 3,48 & 11,13 \\
4 & 3,39 & 11,72 \\
\hline \hline
\end{tabular}




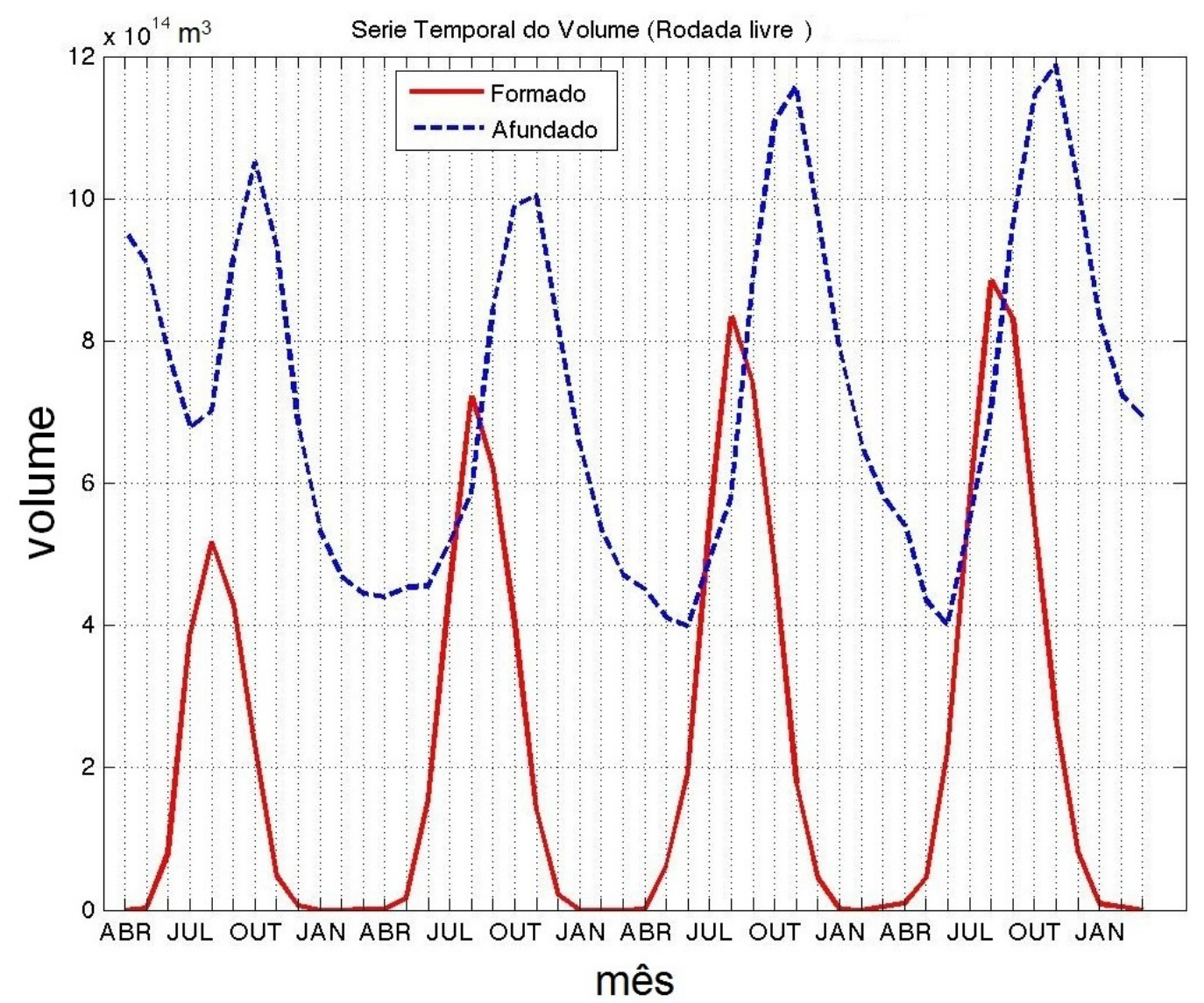

Figura 4.13: Série temporal do volume $\left(\mathrm{em} \mathrm{m}^{3}\right)$ de AMSTAS detectado a partir dos dados do modelo HYCOM 1. Em vermelho estão marcados os volumes de AMSTAS recém formados $\left(Q<2,0 \times 10^{-11} \mathrm{~m}^{-1} \mathrm{~s}^{-1}\right)$ e em azul os volumes de AMSTAS consolidada e afundada $(2,0 \times$ $\left.10^{-11} \mathrm{~m}^{-1} \mathrm{~s}^{-1}<=Q<=2,0 \times 10^{-10} \mathrm{~m}^{-1} \mathrm{~s}^{-1}\right)$.

O HYCOM 1 foi capaz de representar a AMSTAS e apresentou resultados para a série temporal do volume coerentes com os estudos de Maze et al. [2013] para o Atlântico Norte, com o ciclo sazonal bem representado e a preservação de um volume médio de água modal subtropical afundada entre os períodos de formação (Figura 4.13).

A taxa de variação foi calculada a partir da diferença entre o volume de AMSTAS afundado observado em um determinado mês e o mês imediatamente anterior. 


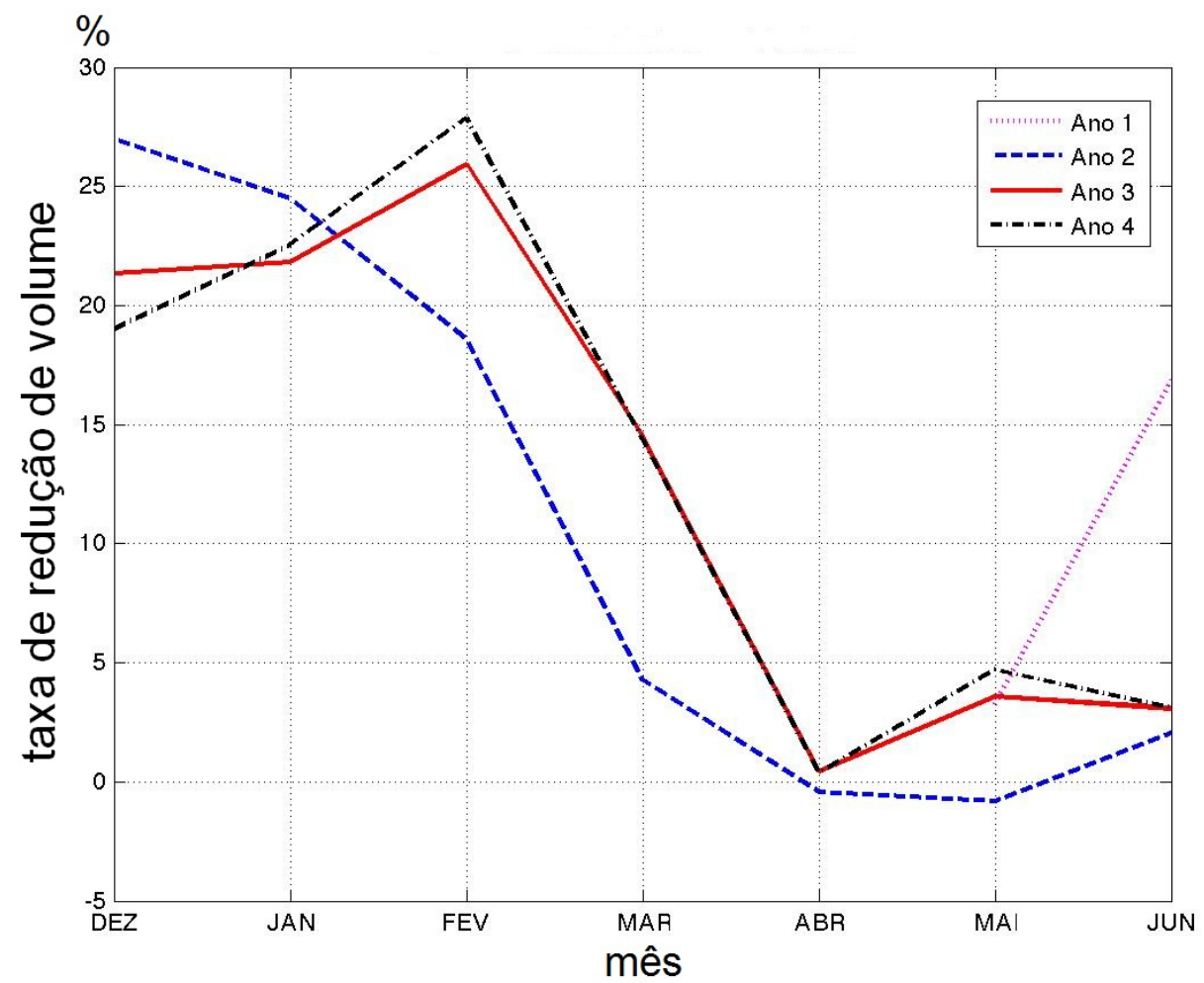

Figura 4.14: Taxa de variação mensal (em \%) do volume de AMSTAS afundado detectado a partir dos dados do modelo HYCOM 1.

No período de dezembro a junho de cada ciclo (excluindo-se o período típico de formação) essa taxa apresentou maiores valores durante o verão austral (janeiro a março) em todos os ciclos da simulação (Figura 4.14). Devido a isso, a média da taxa de redução empregada para o cálculo da relação entre o aumento do volume de AMSTAS afundado e o volume total recém formado foi construída apenas com os valores observados entre os meses de abril e junho de um mesmo ciclo.

\section{Distribuição Horizontal da AMSTAS}

Os mapas mensais de distribuição horizontal da camada de água modal subtropical detectada evidenciaram claramente o limite norte da área típica de formação $\left(\sim 34^{\circ} \mathrm{S}\right)$, conforme demonstrado nas Figuras $4.15 \mathrm{a} 4.18$. De uma forma geral, a formação se inicia no mês de julho ocupando regiões principalmente à oeste de $35^{\circ} \mathrm{W}$. Essas regiões se estendem para leste durante os meses de agosto e setembro. Ao longo do mês de outubro a formação é reduzida até que não mais ocorra em novembro. 

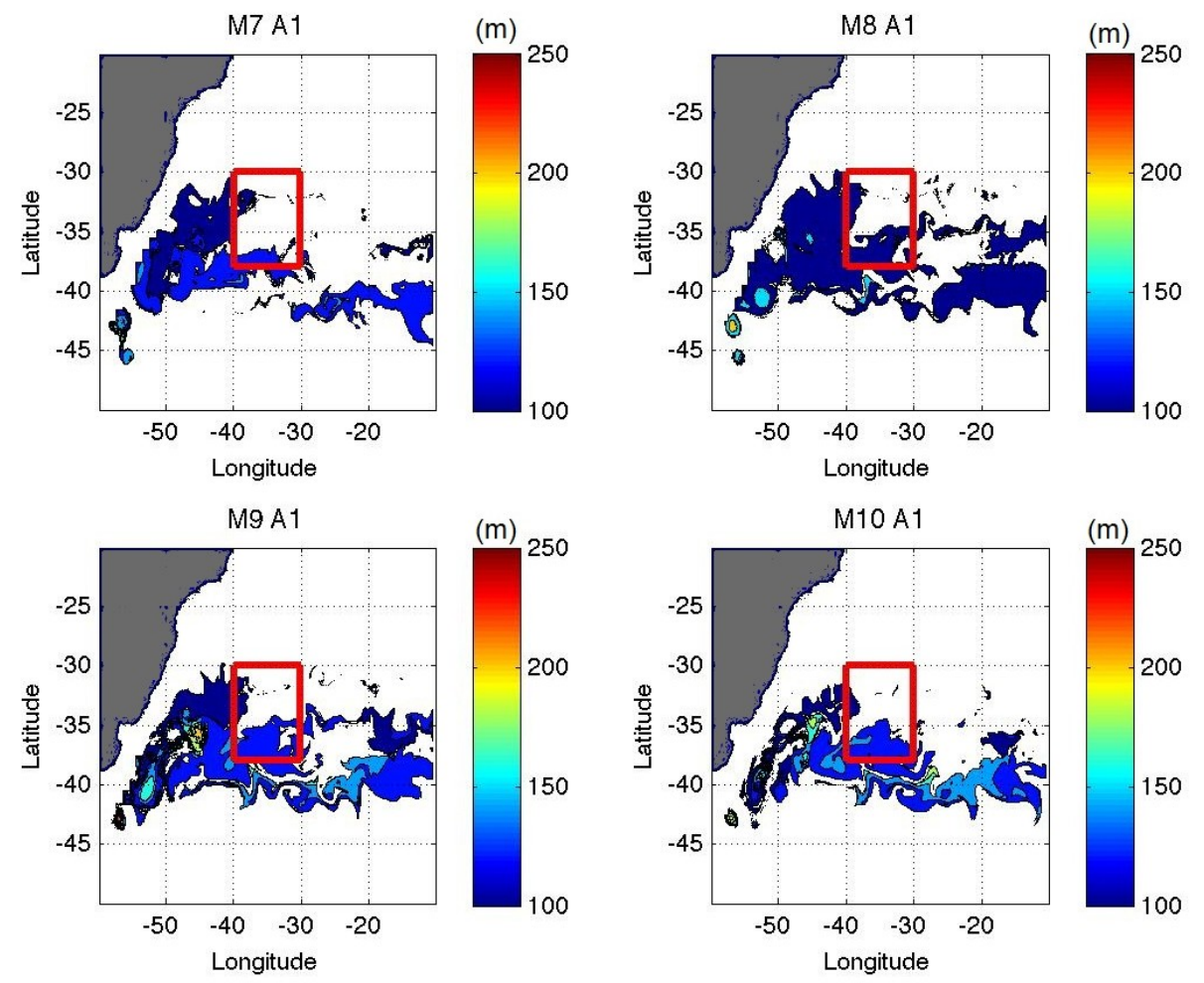

Figura 4.15: Mapa horizontal de espessura em metros da camada de AMSTAS formada, durante os quatro meses típicos do período de formação (JUL a OUT), no primeiro ano da simulação, detectada a partir dos dados do modelo HYCOM 1 em cada ponto da área de estudo. O retângulo vermelho indica os limites da área onde foi realizada a OCSUL.
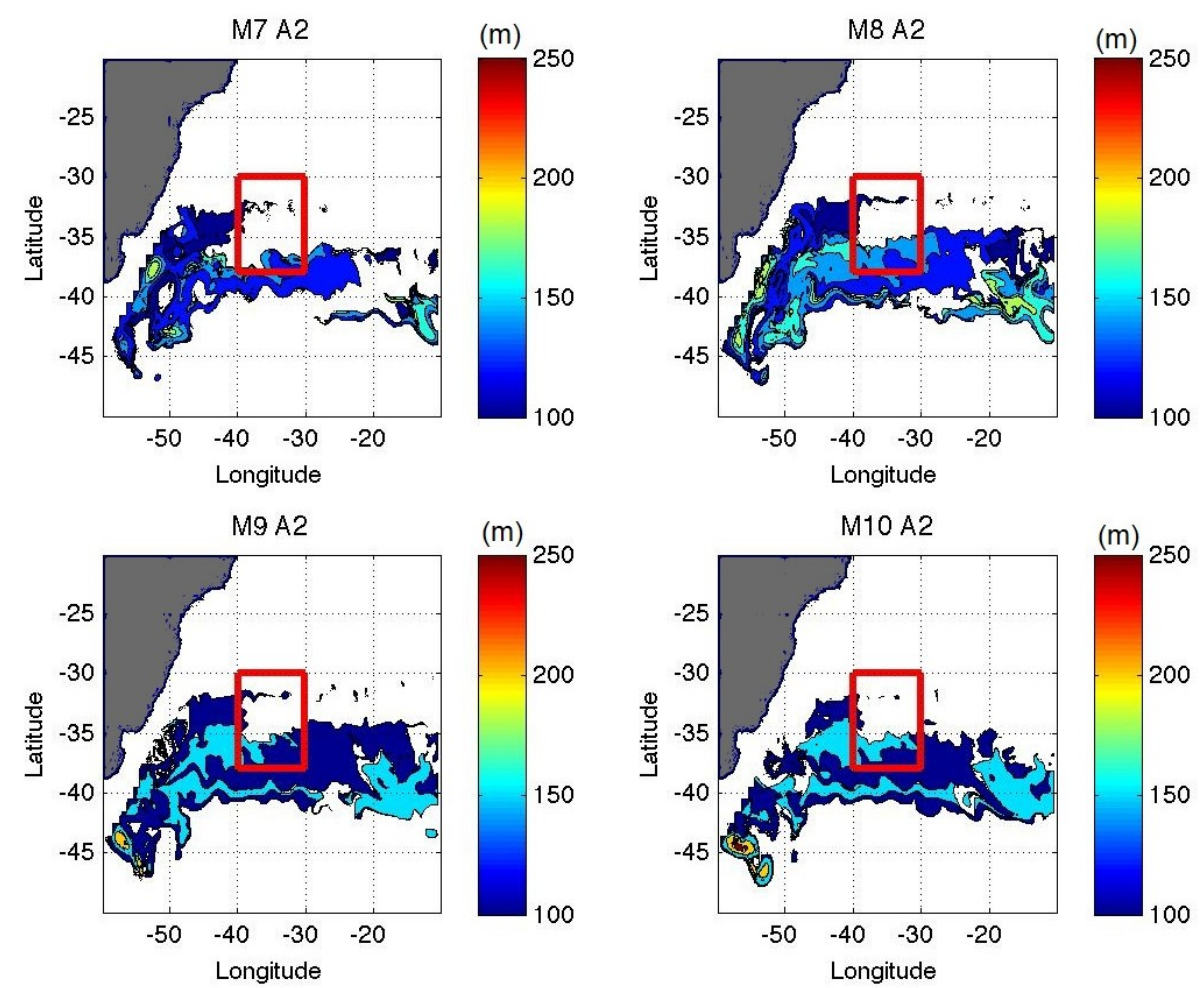

Figura 4.16: Semelhante à Figura 4.15 para o segundo ano da simulação. 

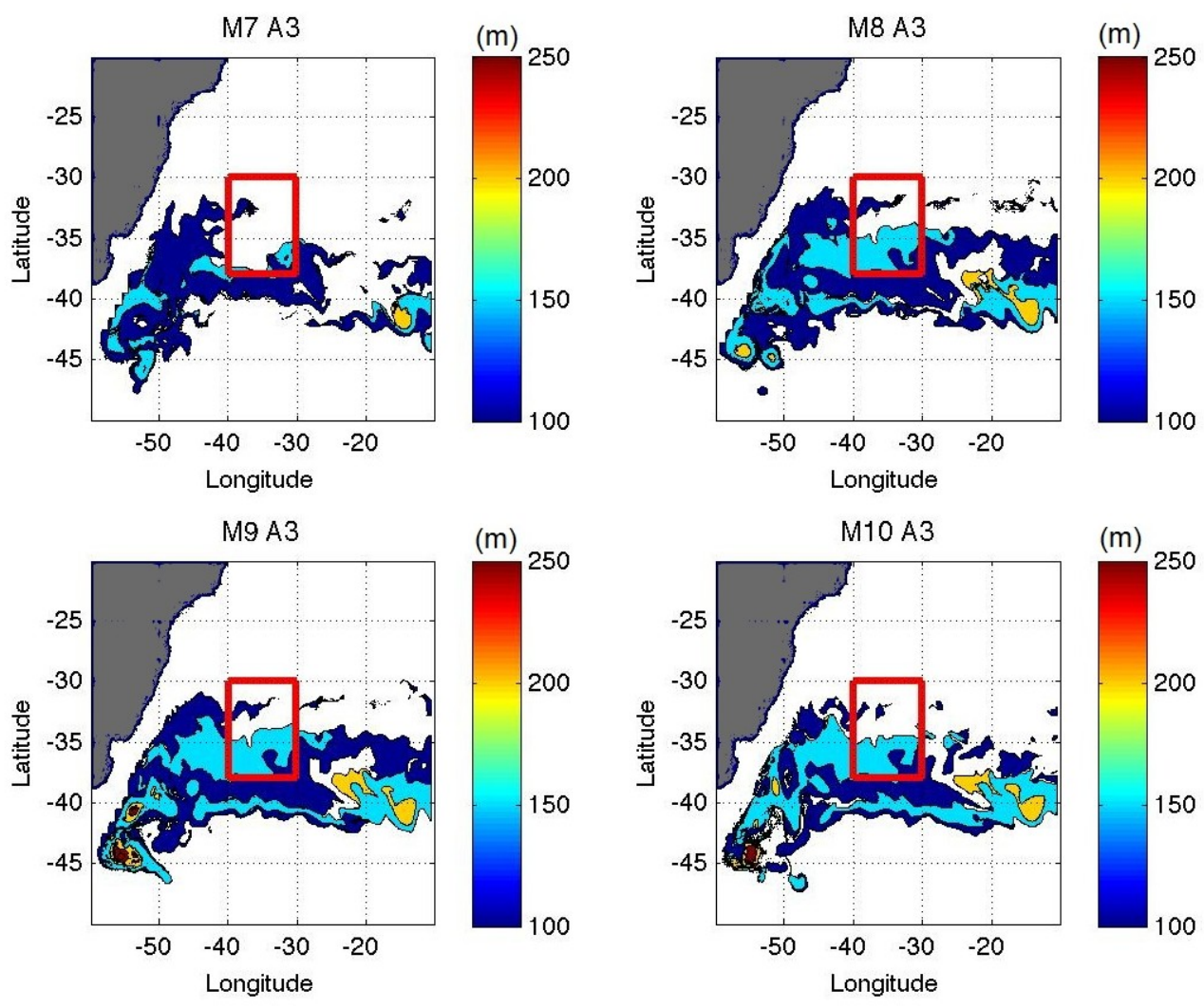

Figura 4.17: Semelhante à Figura 4.15 para o terceiro ano da simulação.
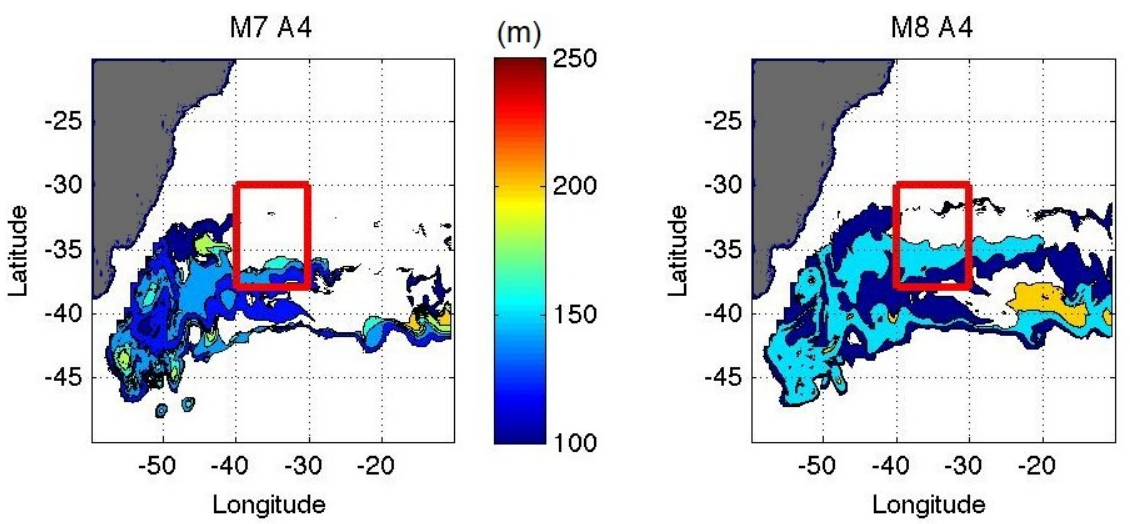

(m) 250

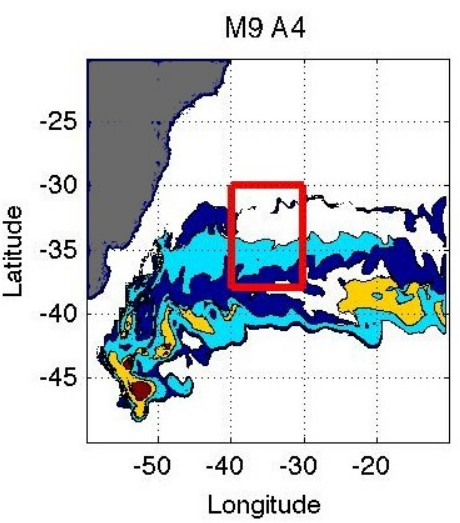

(m)

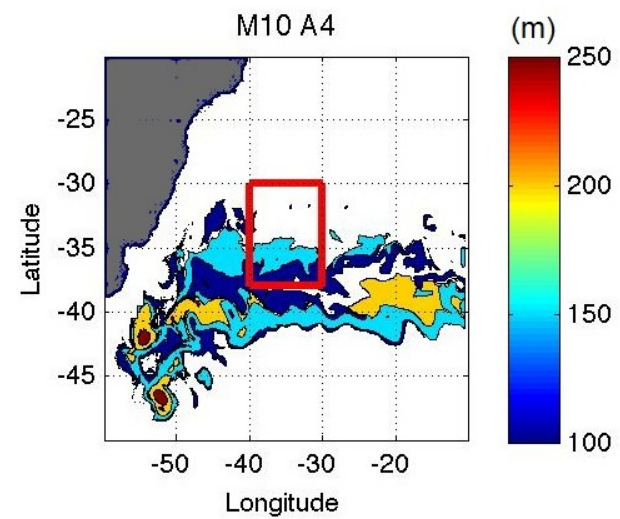

Figura 4.18: Semelhante à Figura 4.15 para o quarto ano da simulação. 
Da mesma forma, foi possível identificar a área ocupada pela AMSTAS consolidada e afundada após o período de formação (Figuras 4.19 e 4.20). A análise dos painéis do lado direito da Figura 4.19 para os meses de abril da simulação permitiu observar a dissipação e advecção dessa água modal afundada na direção norte a partir da área de formação. A área típica de formação alcançou $6,5 \times 10^{8} \mathrm{~m}^{2}$. A água modal subtropical em subsuperfície apresentou uma distribuição horizontal média mensal variando desde 9,0 $\times 10^{8} \mathrm{~m}^{2}$ em novembro, imediatamente após o período de formação, até $4,1 \times 10^{8} \mathrm{~m}^{2}$ em abril, após sofrer advecção na direção norte e dissipação.

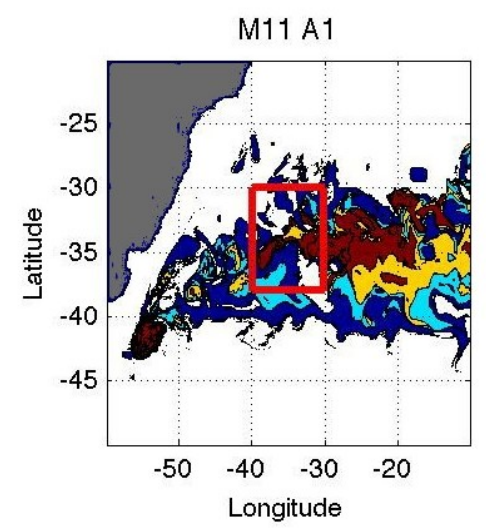

(m)
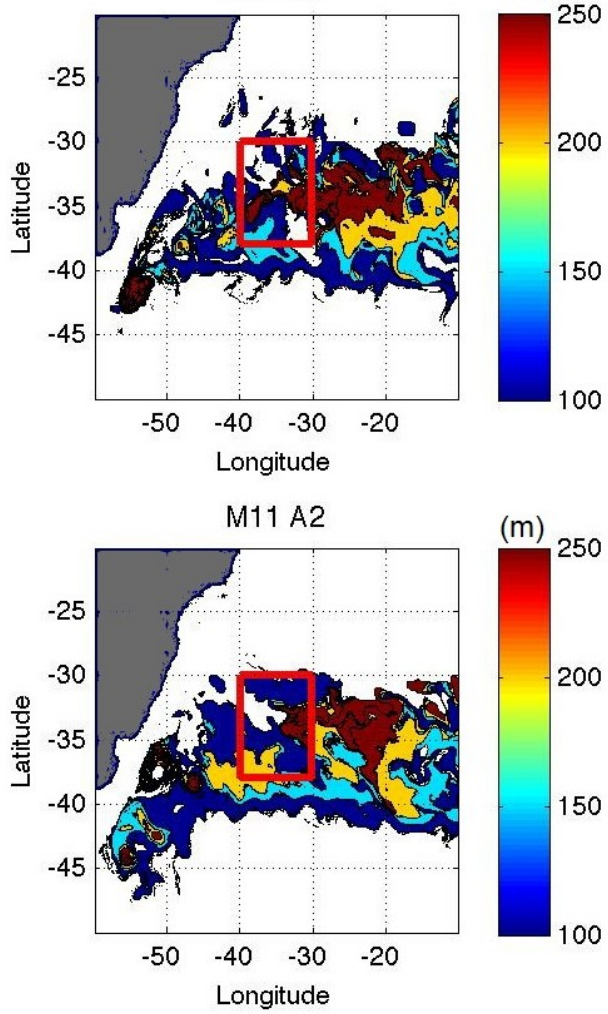

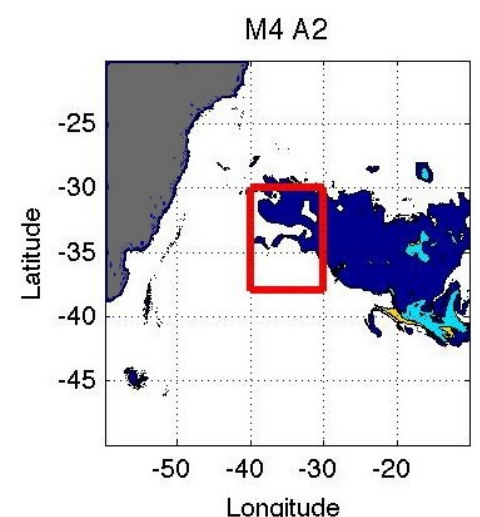

(m) 250
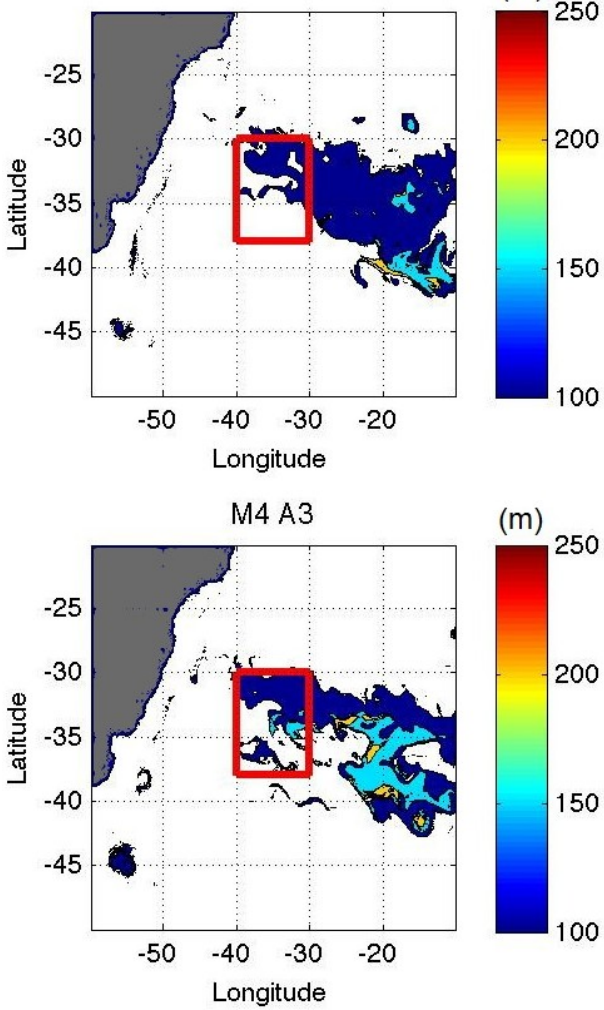
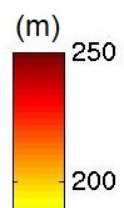

200

150

100

Figura 4.19: Mapa horizontal de espessura em metros da camada de AMSTAS afundada no mês de novembro do primeiro ano (painel superior esquerdo) e do segundo ano (painel inferior esquerdo) da simulação, e no mês de abril do segundo ano (painel superior direito) e do terceiro ano (painel inferior direito) da simulação, detectada a partir dos dados do modelo HYCOM 1. O retângulo vermelho indica os limites da área onde foi realizada a OCSUL. 

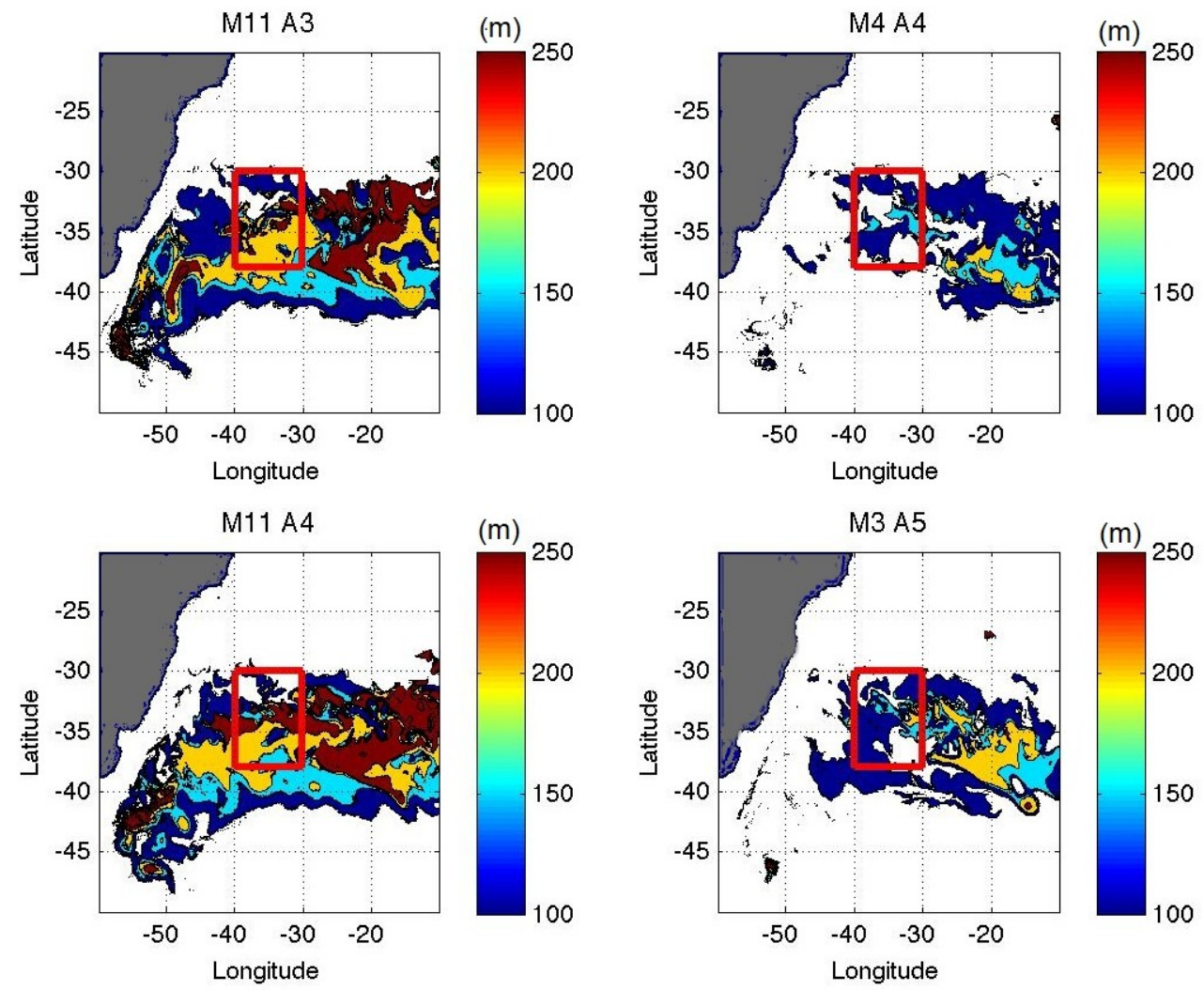

Figura 4.20: Similar à Figura 4.19 para os meses de novembro do terceiro (painel superior esquerdo) e do quarto ano (painel inferior esquerdo) da simulação, de abril do quarto ano (painel superior direito) e de março do quinto ano da simulação (painel inferior direito).

Foram observados os valores médios de $(13,78 \pm 0,26)^{\circ} \mathrm{C}$ para a temperatura da AMSTAS afundada detectada em toda a simulação e $(15,07 \pm 0,71)^{\circ} \mathrm{C}$ para o volume formado. Os valores de salinidade e densidade potencial dos pontos detectados como amostras de água modal subtropical foram, respectivamente, de 35,25 \pm 0,03 e $(26,45 \pm 0,06) \mathrm{kg} \mathrm{m}^{-3}$ para o volume afundado e 35,38 $\pm 0,08$ e $(26,27 \pm 0,12) \mathrm{kg} \mathrm{m}^{-3}$ para o volume formado. Além disso, foram observados gradientes de temperatura verticais médios de $0,0014^{\circ} \mathrm{C} / \mathrm{m}$ para o volume formado e $0,013^{\circ} \mathrm{C} / \mathrm{m}$ para o volume de AMSTAS afundado. Tais valores permitem constatar a robustez deste fenômeno na região da CBM. Mesmo com o emprego de parâmetros preliminares de detecção, que permitiam ao HYCOM 1 apresentar valores diferentes para temperatura, salinidade e densidade potencial daqueles apresentados nos resultados de Sato E Polito [2014], preservada no entanto a característica fundamental da baixa vorticidade potencial, os resultados extraídos da simulação convergiram para os valores observados anteriormente por outros autores [Provost et al., 1999, Sato E Polito, 2014, p. ex.] quando da 
identificação deste tipo de água modal no Atlântico Sudoeste.

Os mapas de incidência da AMSTAS detectada nos meses de formação (Figuras 4.21 a 4.23, notadamente a partir do segundo ano da simulação do HYCOM 1, permitiram observar a presença de três regiões distintas: uma região destacada na cor azul em que ocorre apenas a presença de AMSTAS afundada, mesmo nos meses típicos de formação; uma região assinalada pela cor verde em que ocorre formação de água modal na superfície concomitante com camadas de AMSTAS afundadas e uma região menor identificada pela cor vermelha que indica a existência de água modal apenas em superfície durante os meses de formação. Nessa última região, não ocorre afundamento da AMSTAS recém formada, sendo essa advectada para as outras regiões ou ainda dissipada durante o ciclo de formação vigente.
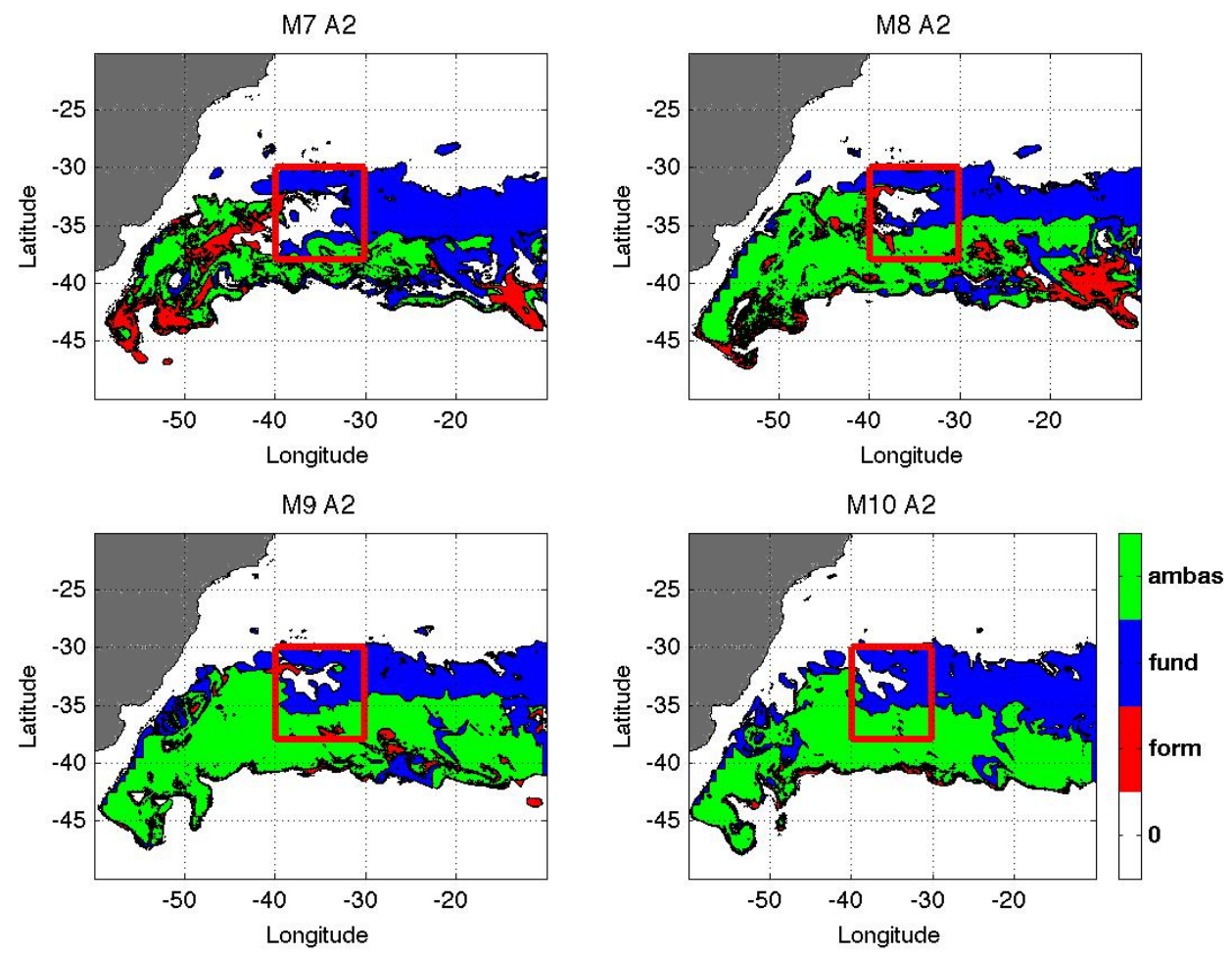

Figura 4.21: Mapa horizontal de incidência de AMSTAS afundada (azul), em formação na superfície (vermelho) e afundada concomitante com recém formada (verde) durante os meses de formação do segundo ano da simulação em cada ponto da área de estudo. O retângulo vermelho indica os limites da área onde foi realizada a OCSUL. 

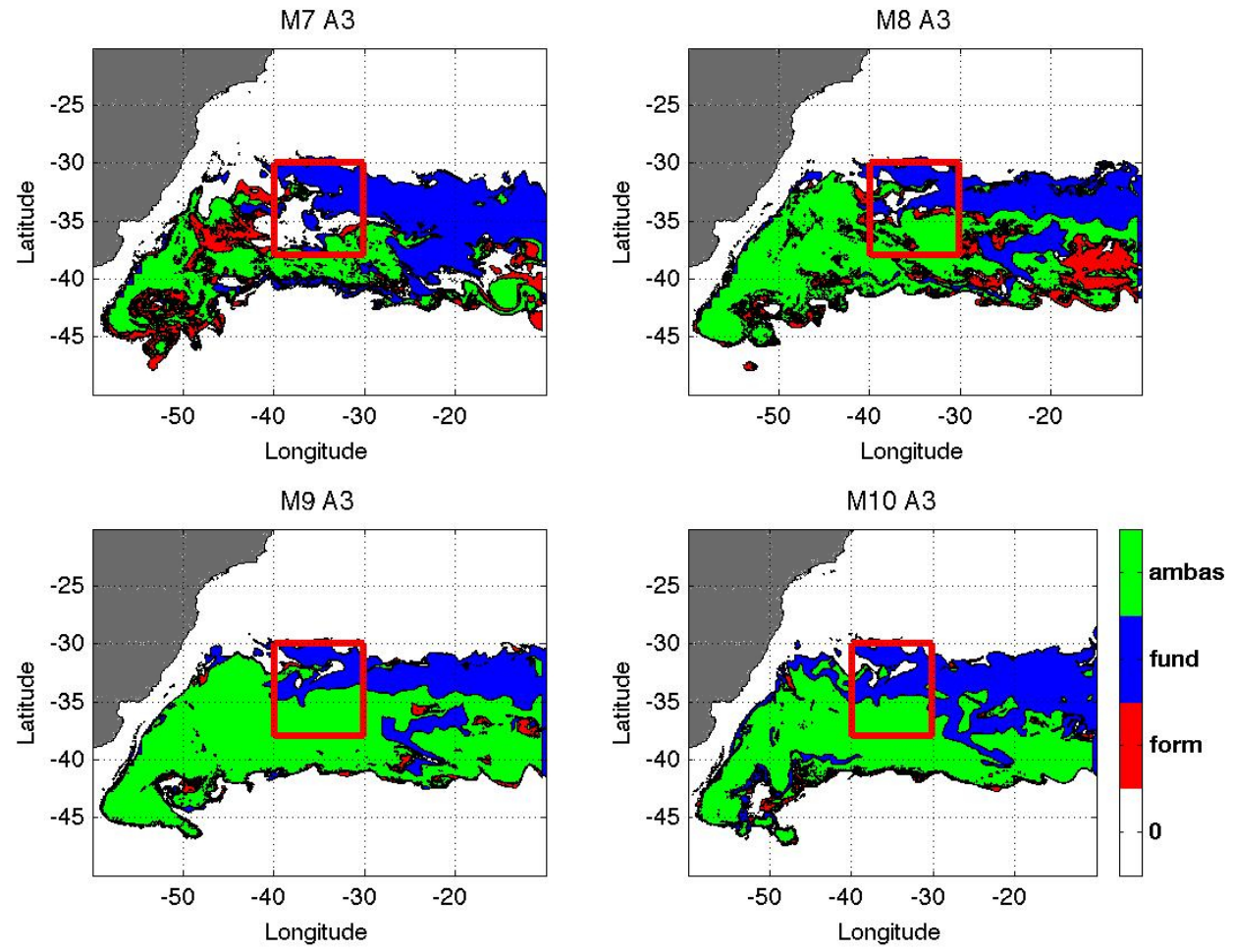

Figura 4.22: Similar à Figura 4.21 para o terceiro ano da simulação.
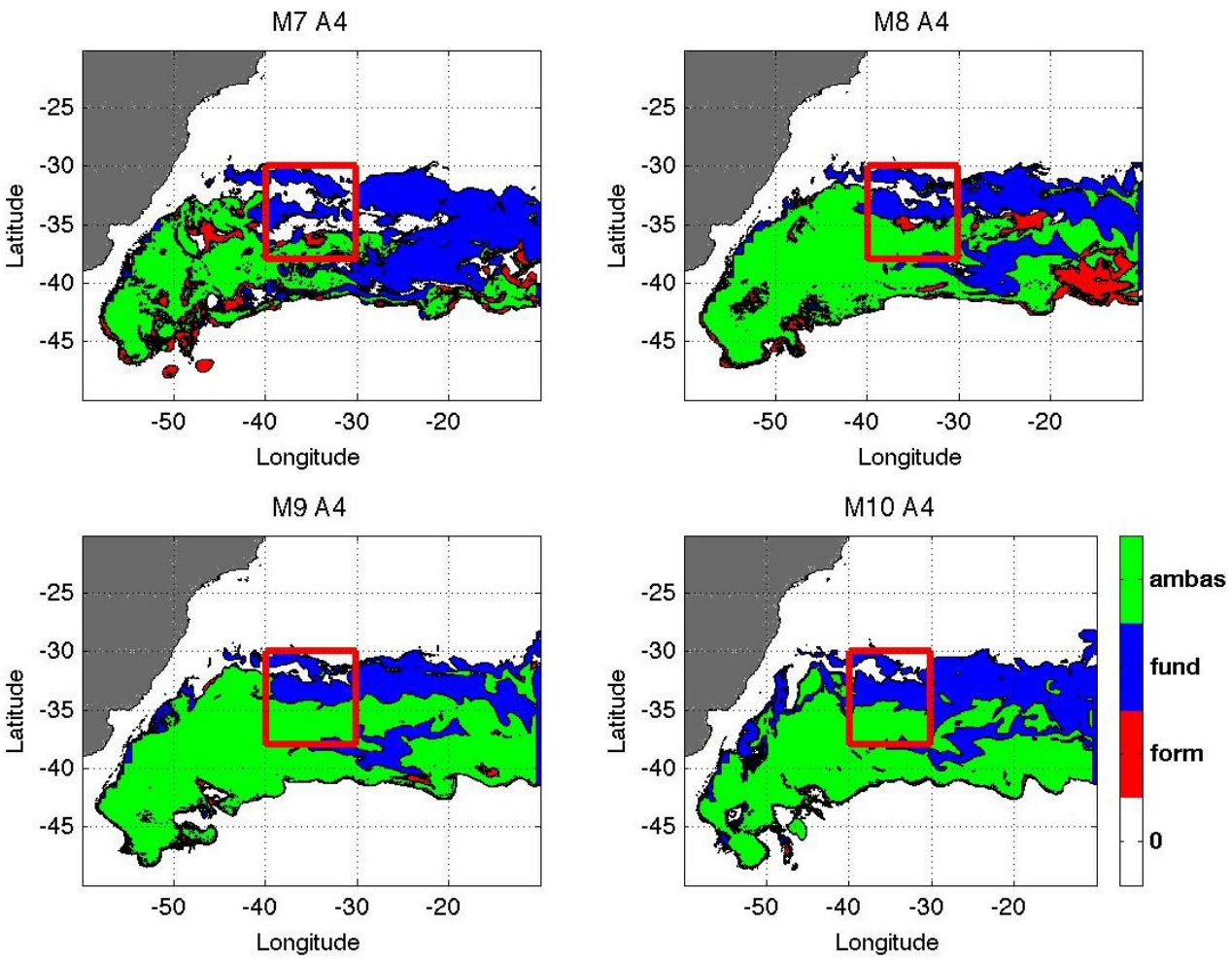

Figura 4.23: Similar à Figura 4.21 para o quarto ano da simulação. 
Os limites da área do cruzeiro oceanográfico, representados nas Figuras 4.21 a 4.23 pelo retângulo na cor vermelha, indicam que no interior da mesma ocorrem claramente dois tipos de incidência de AMSTAS: Ao sul de $34^{\circ} \mathrm{S}$ ocorre tanto formação de água modal quanto a existência da mesma previamente afundada; já ao norte dessa latitude, a AMSTAS ocorre apenas em subsuperfície e não é conectada com a atmosfera durante o inverno.

\subsubsection{HYCOM 2}

Após a detecção bem sucedida da água modal em um modelo não datado com forçante climatológica repetida (HYCOM 1), foi executado um experimento para verificar a viabilidade de realizar prognósticos da distribuição horizontal da AMSTAS por meio do emprego de um modelo datado e operacional. Dessa forma, foi empregado o modelo utilizado pelo CHM no âmbito da REMO (aqui designado por HYCOM 2), conforme detalhado no Capítulo2.

Os valores de volume observados na série temporal do HYCOM 2, obtidos após aplicados todos os critérios de seleção citados na subseção 3.4.2, foram semelhantes aos resultados obtidos com o HYCOM 1, ao início da simulação. Foi possível observar a clara presença de um ciclo sazonal, entretanto o que mais se destacou foi a redução do volume afundado desde o primeiro ano da simulação, que aumenta gradativamente desde 34,3\% até 81,7\% em relação ao ano anterior (Figura 4.24). O volume máximo formado para cada ano ocorreu nos meses de agosto/setembro e manteve uma média de $(1,23 \pm 0,07) \times 10^{14} \mathrm{~m}^{3}$ nos períodos de formação de 2012 a 2014 . O lapso de tempo entre os valores máximos de AMSTAS formada e afundada variou de 1 a 2 meses nos resultados do modelo HYCOM 2 não sendo possível estabelecer uma relação média entre o volume formado e o volume máximo afundado por ciclo, devido à grande variação desta provocada pela redução gradual do volume afundado. 


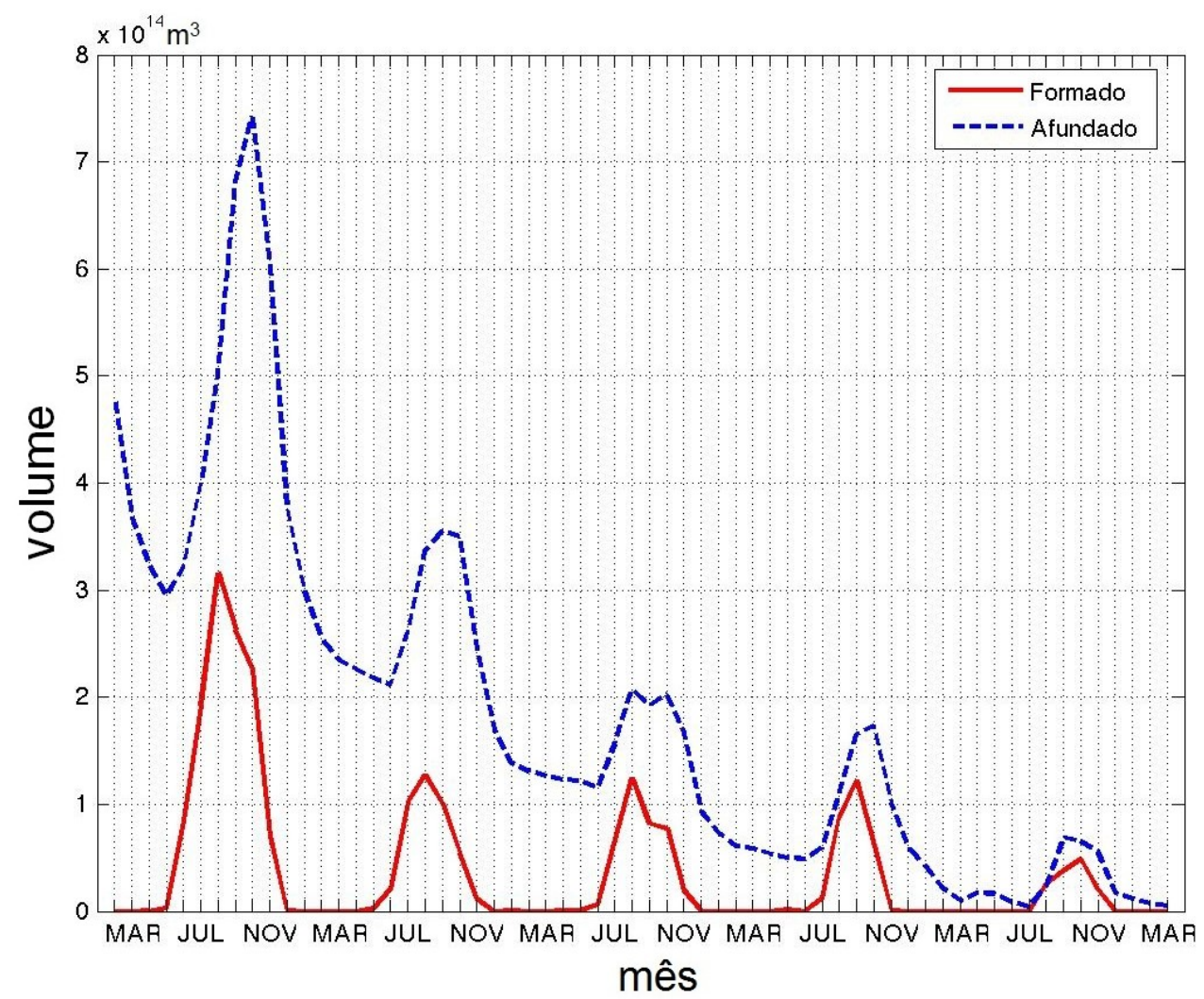

Figura 4.24: Série temporal do volume $\left(\mathrm{em} \mathrm{m}^{3}\right)$ de AMSTAS detectado a partir dos dados do modelo HYCOM 2. Em vermelho estão marcados os volumes de AMSTAS recém formados $\left(Q<2,0 \times 10^{-11} \mathrm{~m}^{-1} \mathrm{~s}^{-1}\right)$ e em azul os volumes de AMSTAS consolidada e afundada $(2,0 \times$ $\left.10^{-11} \mathrm{~m}^{-1} \mathrm{~s}^{-1}<=Q<=2,0 \times 10^{-10} \mathrm{~m}^{-1} \mathrm{~s}^{-1}\right)$.

As causas da severa dissipação da AMSTAS no modelo HYCOM 2 ainda carecem de investigação. Especulamos que as mesmas podem ser atribuídas ao menor número de níveis isopicnais empregados nessa configuração (21 níveis, sendo apenas 7 entre os limites de densidade da AMSTAS) e, principalmente ao fato da inicialização do modelo ser realizada por meio de dados com melhor resolução. O modelo HYCOM 2 inicialmente apresenta valores de volume da AMSTAS coerentes com os resultados do HYCOM 1 por ser inicializado com dados do HYCOM e NCODA, cuja resolução horizontal $\left(1 / 12^{\circ} \sim 9 \mathrm{~km}\right)$, é capaz de representar fenômenos de meso escala. Ao longo da simulação do HYCOM 2, entretanto, essa resolução horizontal é degradada para $1 / 4^{\circ}(\sim 27 \mathrm{~km})$ e as feições de meso escala deixam de ser representadas com o passar do tempo de integração.

Ao se observar a série temporal do volume com vorticidade potencial $(Q)$ inferior a $2,0 \times 10^{-10} \mathrm{~m}^{-1} \mathrm{~s}^{-1}$ e temperaturas típicas de águas modais subtropicais $(11,5$ 
a $\left.18,5^{\circ} \mathrm{C}\right)$, mostradas na Figura 4.25 , é possível constatar que as parcelas superficiais contendo os menores valores de $Q$ mantém o ciclo sazonal preservado, assim como um volume máximo em média superior a $2,0 \times 10^{14} \mathrm{~m}^{3}$. Ainda assim ocorre a redução do volume atinente às parcelas com maiores valores de $Q$ existentes em camadas mais profundas. Entretanto é notável que essa redução se dá de forma menos intensa evidenciando que o emprego do critério de baixos valores de gradiente vertical de temperatura para a detecção de AMSTAS no HYCOM 2 conduzirá a resultados distantes dos realísticos, principalmente no que tange ao volume de água modal subtropical afundada.

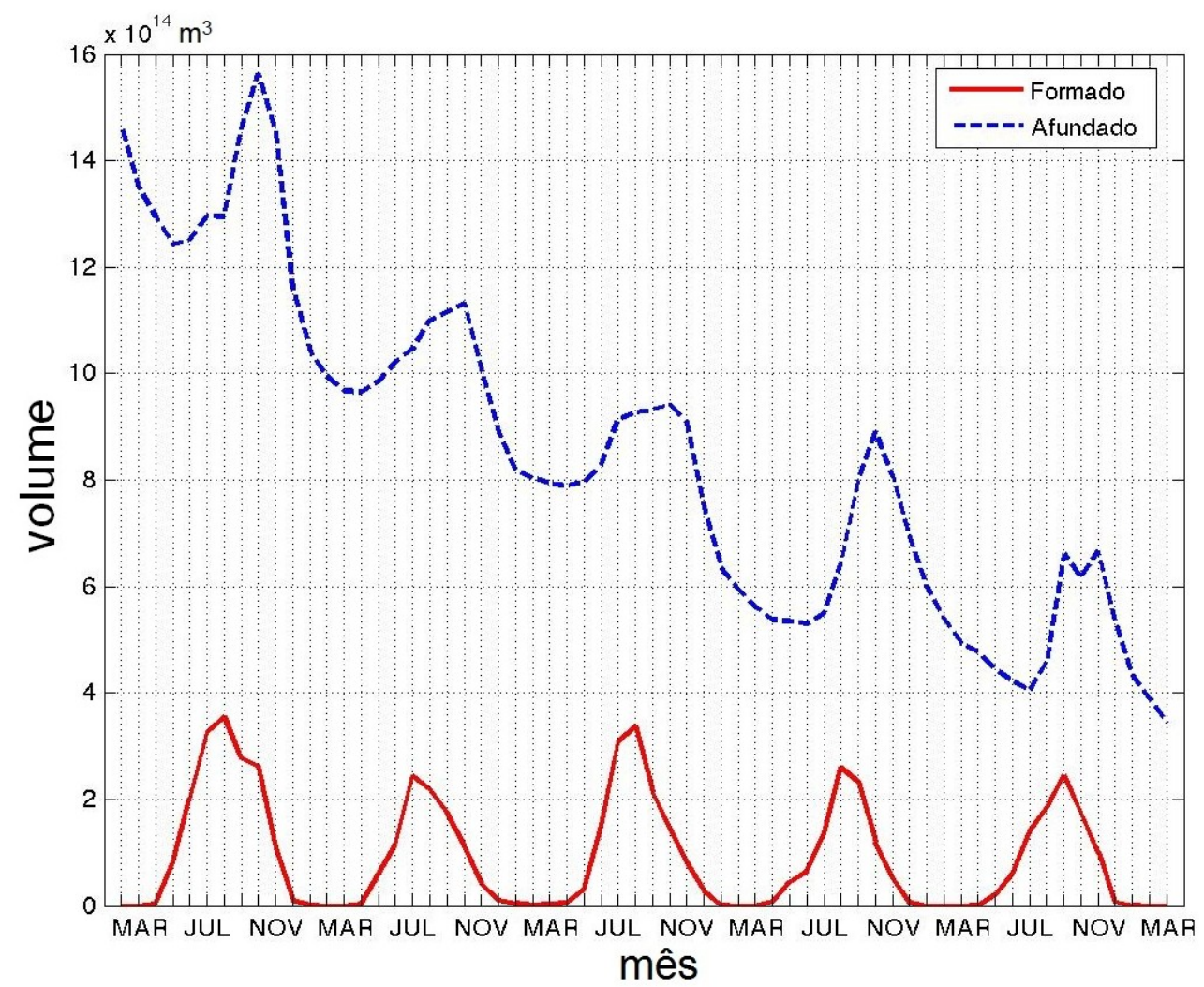

Figura 4.25: Série temporal do volume $\left(\mathrm{em} \mathrm{m}^{3}\right)$ de parcelas de água com vorticidade potencial $(Q)$ inferior a $2,0 \times 10^{-10} \mathrm{~m}^{-1} \mathrm{~s}^{-1}$ detectado a partir dos dados do modelo HYCOM 2, e temperaturas típicas da AMSTAS. Em vermelho estão marcados os volumes $\operatorname{com} Q<2,0 \times$ $10^{-11} \mathrm{~m}^{-1} \mathrm{~s}^{-1}$ e em azul os volumes $\operatorname{com} Q>=2,0 \times 10^{-11} \mathrm{~m}^{-1} \mathrm{~s}^{-1}$. 


\subsubsection{Calor Armazenado}

A existência de regiões contendo processos distintos relacionados com a formação, advecção e afundamento da AMSTAS na área de estudo indica a pertinência de realizar a análise do calor armazenado $\left(C_{A}\right)$. Para tanto, escolhemos duas subareas em separado, ambas apresentadas na Figura 4.26 sobre o mapa da temperatura média da superfície do mar dos quatro anos de simulação do modelo HYCOM 1. O campo de temperatura médio para cada nível de profundidade do modelo foi utilizado como referência para o cálculo de $C_{A}$. Das duas subareas escolhidas, uma delas é coincidente com os limites da área do cruzeiro oceanográfico. A outra, de mesma dimensão, delimita a região de encontro da CB com a CM [Brandini et al. 2000; Piola et al., 2008; Bouali et al. 2016. No prelo] e tem como limites as latitudes de $36^{\circ} \mathrm{S}$ e $44^{\circ} \mathrm{S}$ e as longitudes de $46^{\circ} \mathrm{W}$ e $56^{\circ} \mathrm{W}$.

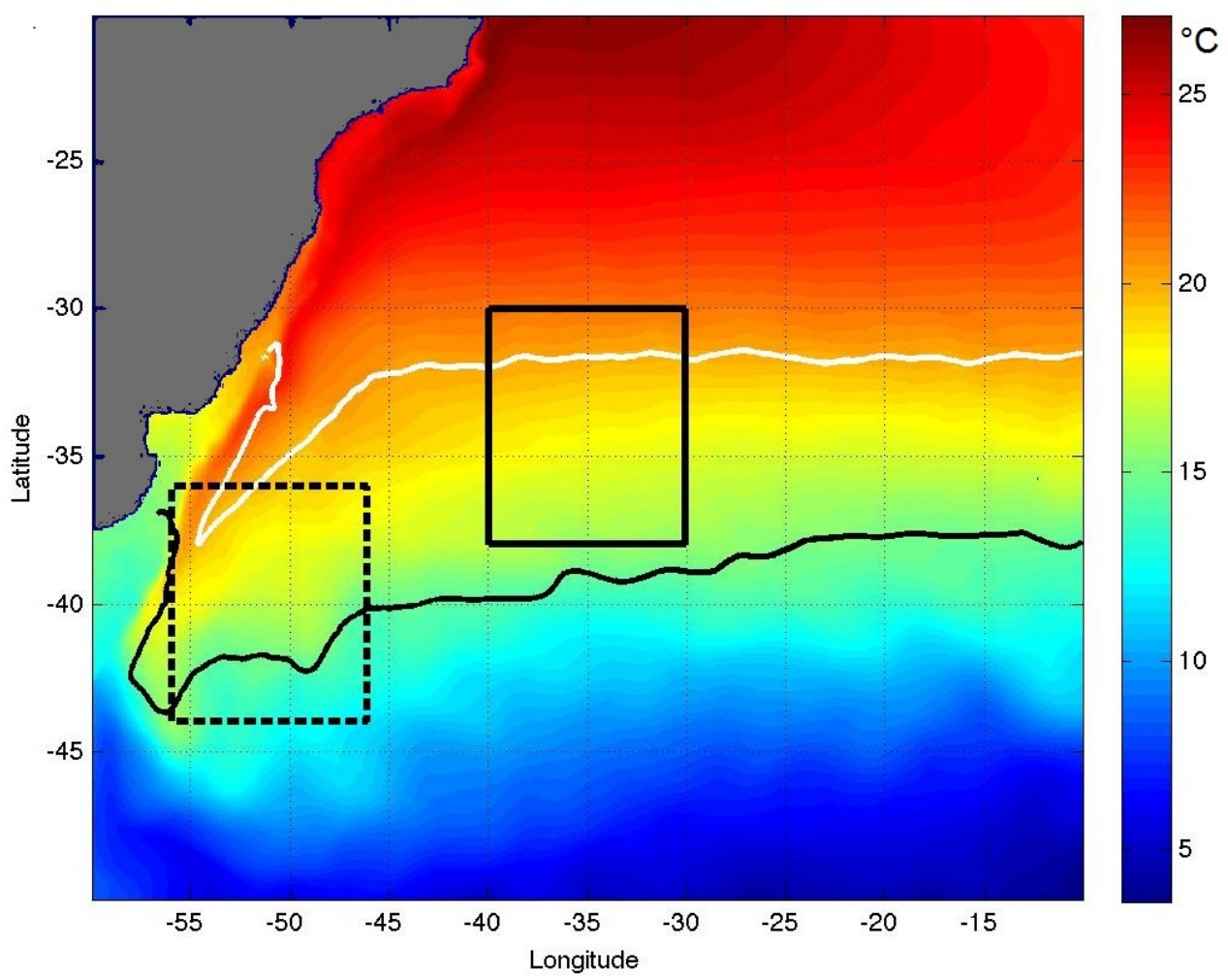

Figura 4.26: Mapa da temperatura média na superfície $\left(\mathrm{em}^{\circ} \mathrm{C}\right)$ dos quatro anos da simulação. As isotermas de $21^{\circ} \mathrm{C}$ (característica da Frente da Corrente do Brasil - FCB) e de $16^{\circ} \mathrm{C}$ (limite máximo da AMSTAS detectada nos dados in situ) são destacadas nas cores branca e preta, respectivamente. A subarea retangular demarcada pela linha sólida indica os limites da área do cruzeiro oceanográfico (OCSUL) e a identificada pela linha tracejada delimita a região de encontro da Corrente do Brasil (CB) com a Corrente das Malvinas (CM). 
O cálculo do calor armazenado $\left(C_{A}\right)$ por meio dos dados do modelo HYCOM 1 foi realizado para toda a área de estudo, empregando inicialmente a mesma metodologia utilizada por Kwon E Riser [2004] em que $T_{r e f}=0^{\circ} \mathrm{C}$. Foi calculado o $C_{A}$ apenas na camada de AMSTAS detectada e o $C_{A}$ total na coluna d'água até $500 \mathrm{~m}$. A variação do $C_{A}$ ao longo do tempo foi dominada pelo aumento do volume de AMSTAS ocorrido durante os períodos de formação, não sendo determinante a diferença de temperatura das amostras de água modal detectadas em superfície e afundadas (Figura 4.27). Tal resultado foi coerente com o observado por meio da mesma análise conduzida por Kwon E Riser [2004] no estudo dos processos de formação da AM18.

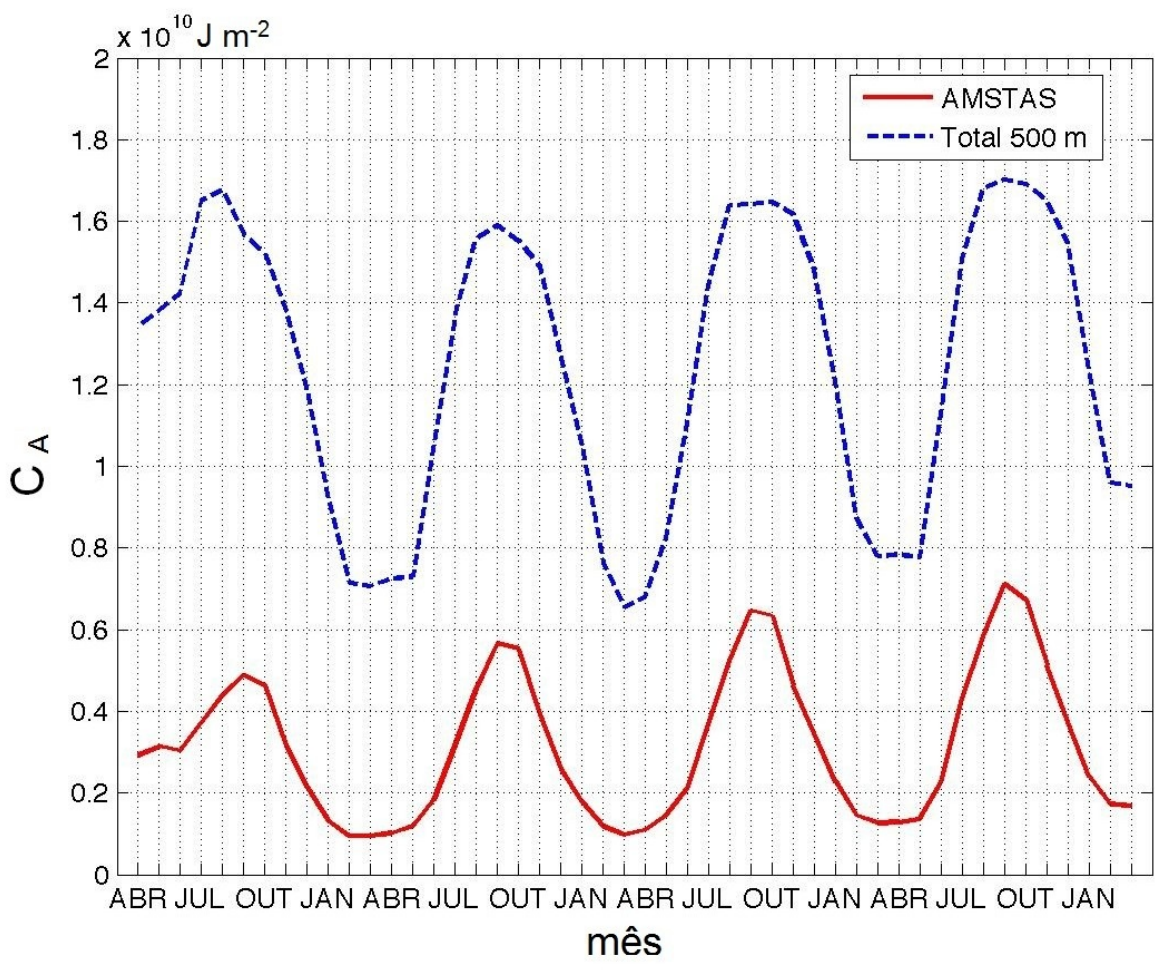

Figura 4.27: Série temporal do calor armazenado $\left(C_{A}\right)$ para toda a área de estudo, apresentada em $\mathrm{J} \mathrm{m}^{-2}$ integrado até $500 \mathrm{~m}$ de profundidade (cor azul) e apenas no interior da camada de AMSTAS (cor vermelha).

A análise em separado da série temporal do calor armazenado, empregando como $T_{\text {ref }}$ na equação (3.28) os valores de temperatura média para todo o período da simulação do estudo em cada um dos pontos de grade para a região da OCSUL (Figura 4.28 indicou um aspecto periódico e sazonal, com a ocorrência de valores negativos durante os períodos de formação. Os máximos e mínimos dos valores de $C_{A}$ integrado na coluna d'água até 500m e apenas confinado na camada de AMSTAS apresentaram- 
se em fase, não sendo possível observar qualquer tendência de aumento na curta série temporal de quatro anos de simulação.

Na região da OCSUL a camada de AMSTAS não apresenta qualquer alteração significativa do calor armazenado nos períodos fora da época de formação. Nesses períodos, o aumento de calor do oceano se dá apenas nas camadas superiores com a reestratificação (conforme é possível observar no gráfico de $C_{A}$ total até $500 \mathrm{~m}$ na Figura 4.28). Já nos períodos de formação, em que a AMSTAS se apresenta mais superficial, a perda de calor ocorre também no interior dessa camada homogênea.

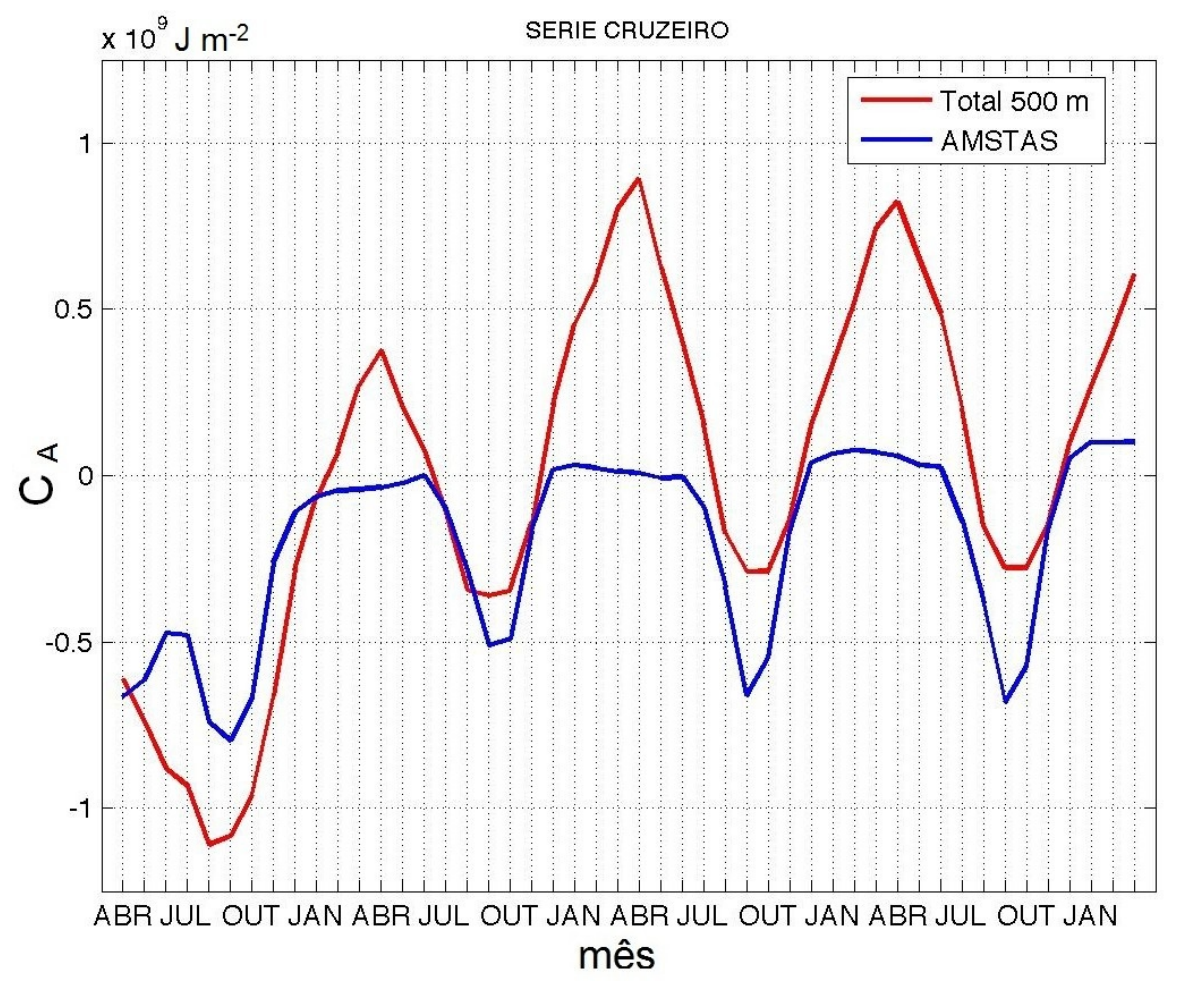

Figura 4.28: Série temporal do calor armazenado $\left(C_{A}\right)$, apresentada em $\mathrm{J} \mathrm{m}^{-2}$, na região da OCSUL, integrado até $500 \mathrm{~m}$ (cor vermelha) e integrado somente na camada de AMSTAS (cor azul).

A série temporal do calor armazenado para a região da CBM (Figura 4.29) apresentou os máximos e mínimos dos valores de $C_{A}$ integrado na coluna d'água até 500m e apenas confinado na camada de AMSTAS fora de fase. Isso provavelmente se deve à maior participação de processos advectivos na região. Dessa forma, a formação de água modal subtropical no inverno ocorre nessa região mesmo na inexistência de perda do calor armazenado, o que provavelmente indica que o movimento convectivo na região da CBM não é dominante para a formação de AMSTAS. O contrário pode ser 
verificado na região da OCSUL.

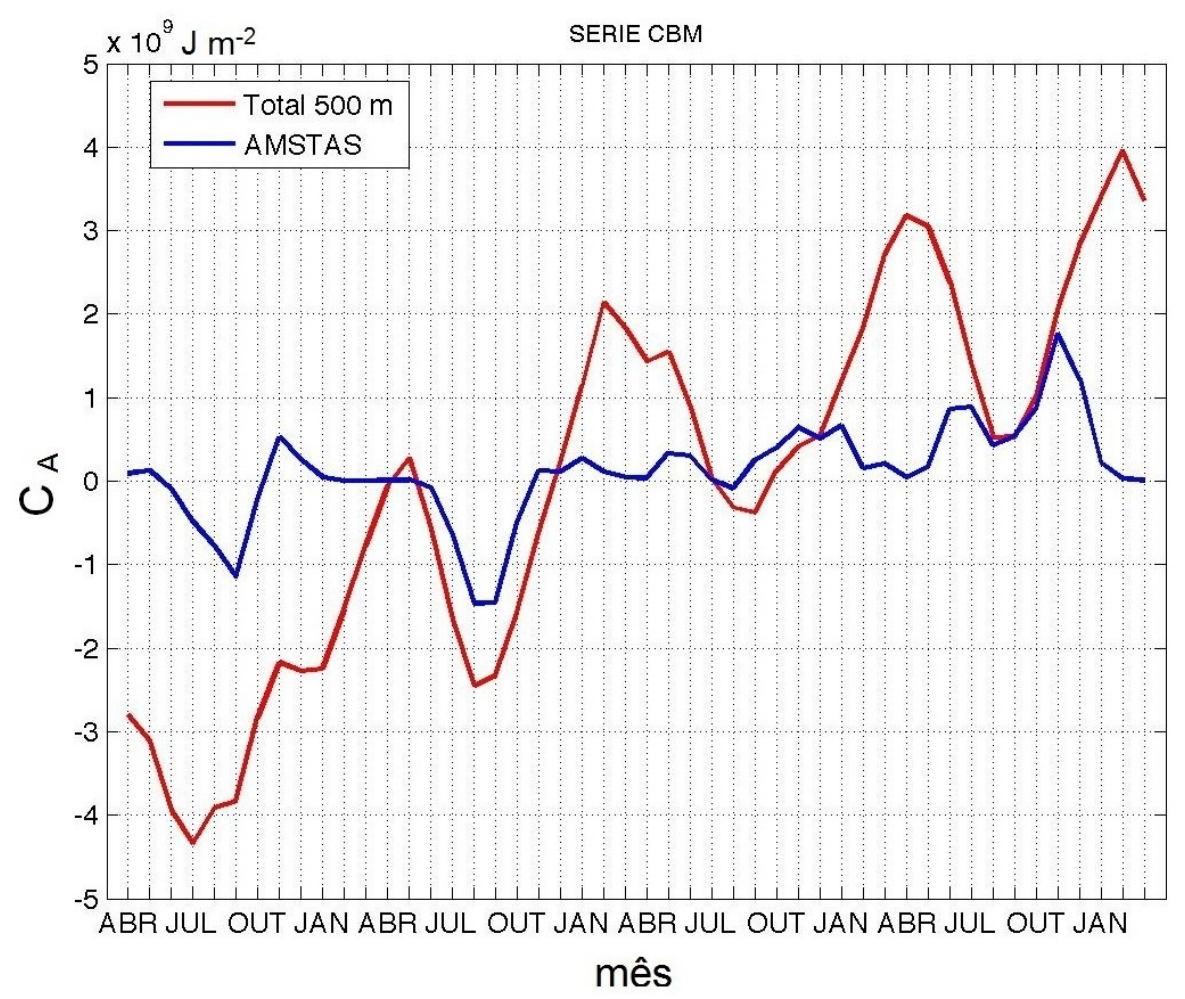

Figura 4.29: Similar à Figura 4.28 para a subarea referente à CBM.

Os mapas horizontais do calor armazenado integrado até $500 \mathrm{~m}$ para a região do cruzeiro oceanográfico apresentaram valores positivos (em média $8 \times 10^{8} \mathrm{~J} \mathrm{~m}^{-2}$ ) preponderantemente no período pré-formação (meses de março a junho) e nos meses de dezembro a fevereiro (Figuras $4.30 \mathrm{e} 4.31$ ). Em todos o meses supracitados ocorre a presença da isoterma de $21^{\circ} \mathrm{C}$ (característica da Frente da Corrente do Brasil - FCB) interceptando a área da OCSUL. Dessa forma, a existência de temperaturas na superfície maiores que $15,9^{\circ} \mathrm{C}$ ao norte dessa isoterma na área da OCSUL contribui para impedir a formação de água modal nesses meses. 

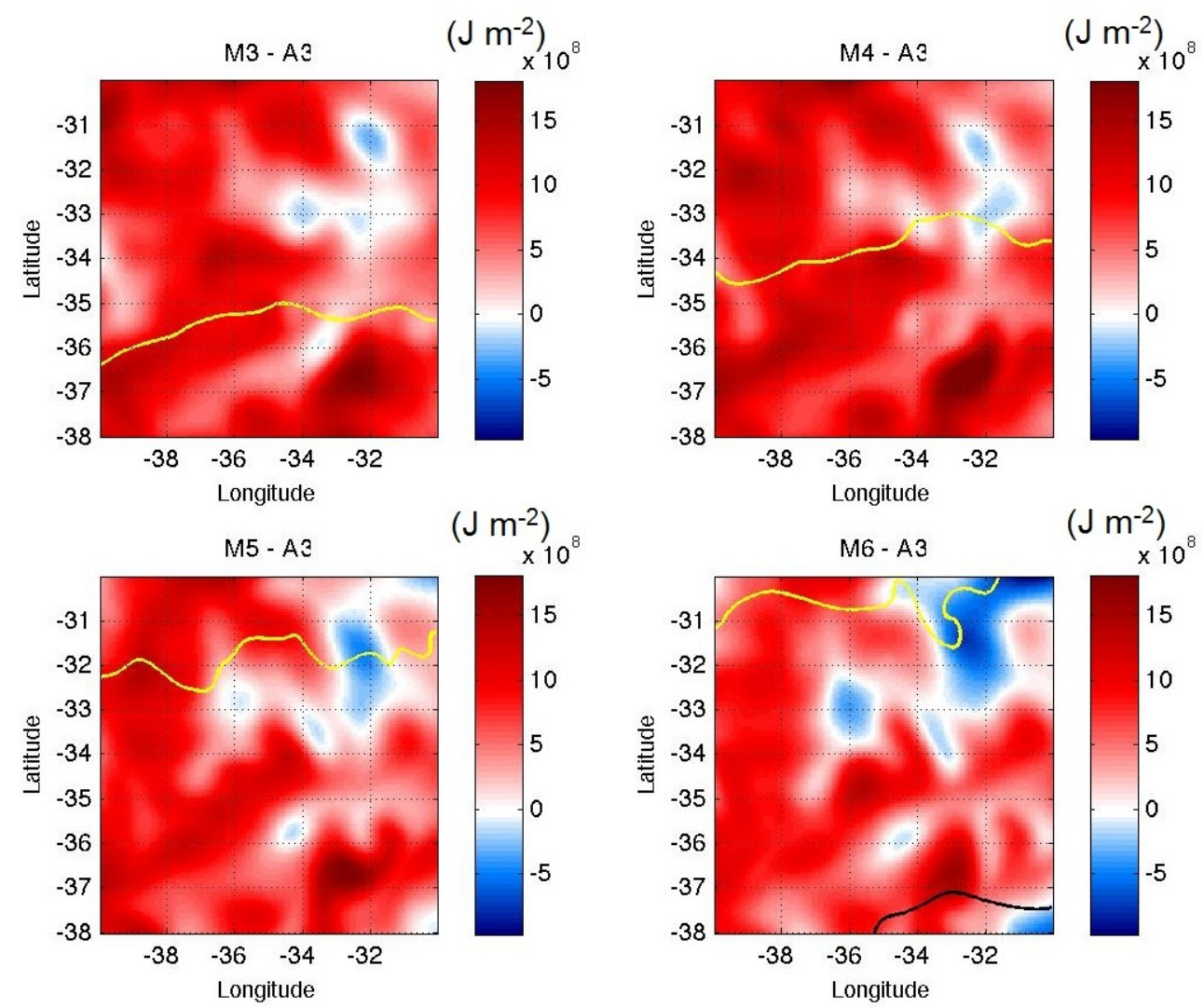

Figura 4.30: Calor armazenado $\left(C_{A}\right)$ integrado até $500 \mathrm{~m}\left(\mathrm{em} \mathrm{J} \mathrm{m}^{-2}\right)$ na subarea referente ao cruzeiro nos meses do período de pré-formação (março a junho) do terceiro ano da simulação do HYCOM 1. Os contornos das isotermas de $21^{\circ} \mathrm{C}$ (característica da FCB, amarelo) e $16^{\circ} \mathrm{C}$ (limite máximo da AMSTAS, preto) estão sobrepostos.

Embora cerca de metade da área da OCSUL tenha apresentado valores negativos de $C_{A}$ no mês de novembro (Figura 4.31), não ocorreu formação de água modal no conjunto de dados do modelo HYCOM 1 durante o referido período. A presença da isoterma de $16^{\circ} \mathrm{C}$ apenas no limite sudeste da área (painel superior esquerdo da Figura 4.31) indica que a possível causa da ausência de formação se deve à temperatura na superfície na área do cruzeiro apresentar-se superior ao valor dessa isoterma, limite máximo típico de formação da AMSTAS. 

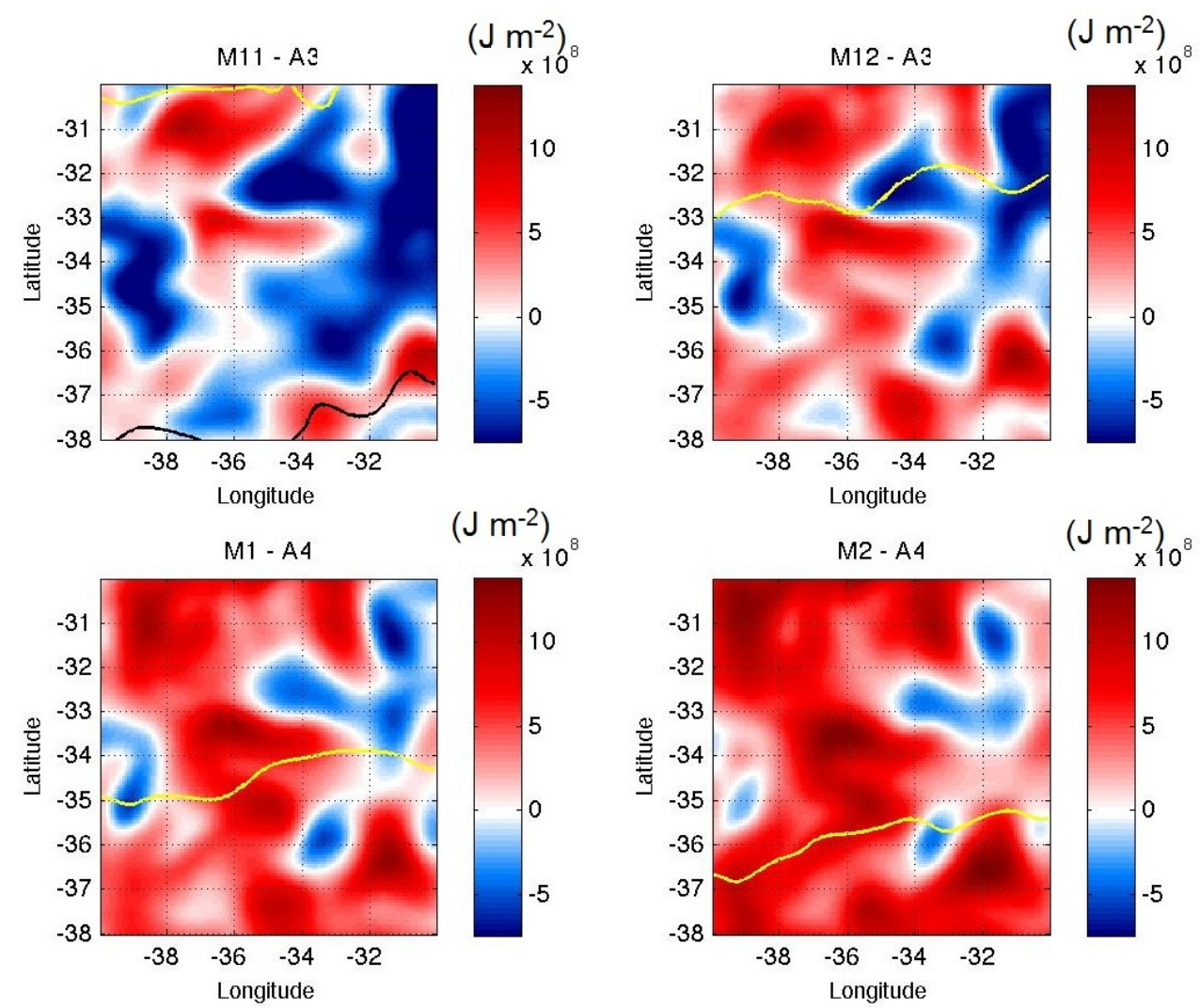

Figura 4.31: Similar à Figura 4.30 para os meses do período de pós-formação (novembro dezembro) do terceiro e (janeiro - fevereiro) quarto ano da simulação.

Durante o período de formação (julho a outubro) foi possível observar que a área ocupada por valores negativos de $C_{A}$ aumentou gradativamente, com máximo em setembro (Figura 4.32). Da mesma forma ocorreram as variações na região delimitada ao norte pela isoterma de $16^{\circ} \mathrm{C}$ no interior da subarea referente ao cruzeiro oceanográfico. Essa isoterma se fez presente interceptando a subarea da OCSUL no referido período de todos os anos da simulação, ao sul de $34^{\circ} \mathrm{S}$. 

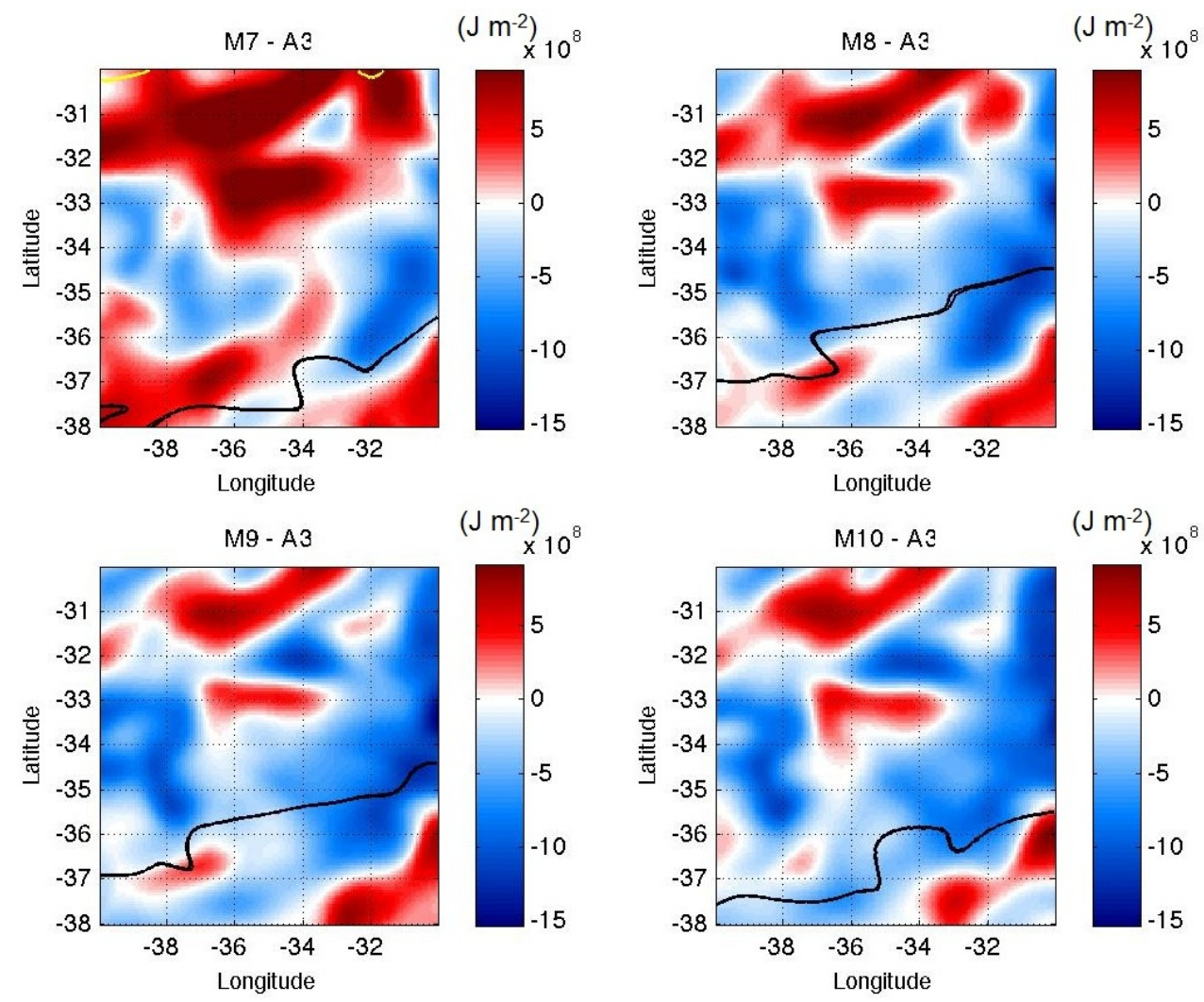

Figura 4.32: Similar à Figura 4.30 para os meses do período de formação (julho a outubro) do terceiro ano da simulação.

O calor armazenado integrado até $500 \mathrm{~m}$, no interior da subarea referente à CBM é apresentado nas Figuras 4.34 a 4.36. Foi possível verificar que os máximos e mínimos de $C_{A}$ apresentaram magnitudes em média uma ordem de grandeza maiores que os valores obtidos na subarea correspondente ao cruzeiro oceanográfico. Além disso, nenhum padrão espacial de ocorrência das áreas de $C_{A}$ negativo ou positivo pôde ser estabelecido. As isotermas de $16^{\circ} \mathrm{C}$ e de $21^{\circ} \mathrm{C}$ interceptaram a região da $\mathrm{CBM}$ em todos os meses da simulação, apresentando-se mais próximas do que na região da OCSUL e denotando os maiores valores de gradiente horizontal de temperatura típicos da região da CBM [Olson et al., 1988]. A maior variabilidade de $C_{A}$ na região da CBM é evidenciada nas Figuras 4.34 a 4.36 e se deve, principalmente, à alta energia cinética turbulenta (ECT) no interior dessa subarea conforme é possível observar na Figura 4.33 e também foi mencionado por Sato \& Polito [2014]. A ECT indica que nessa região ocorrem velocidades com maior magnitude que agiriam na introdução de vorticidade relativa, o que dificulta a existência e manutenção dos baixos valores de $Q$ característicos da AMSTAS. 

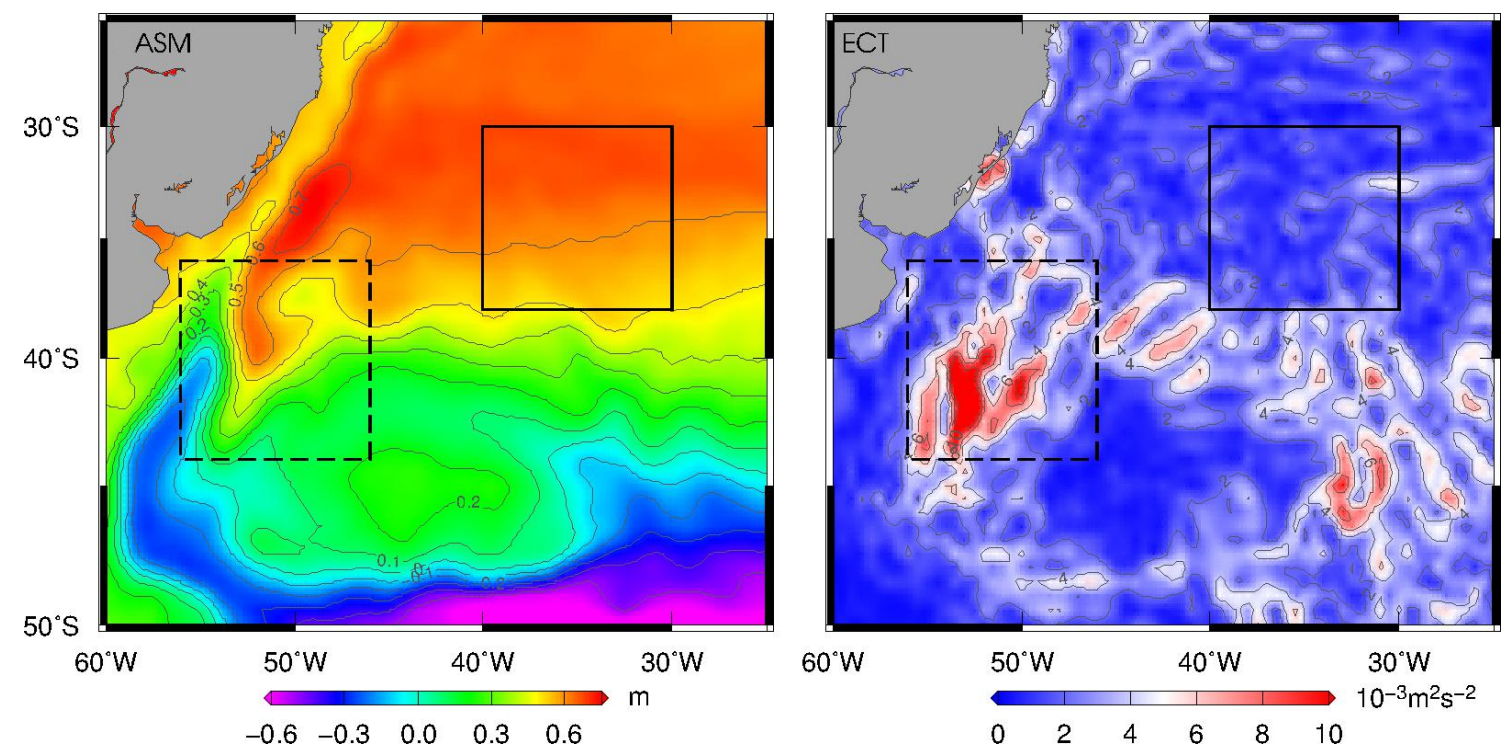

Figura 4.33: Altura da superfície do mar (ASM) média do período de 1993 a 2013 obtida da AVISO (painel da esquerda) e energia cinética turbulenta (ECT - painel da direita) indicando a reduzida dinâmica de meso escala da área da OCSUL (contorno sólido) quando comparada à região da CBM (contorno tracejado).
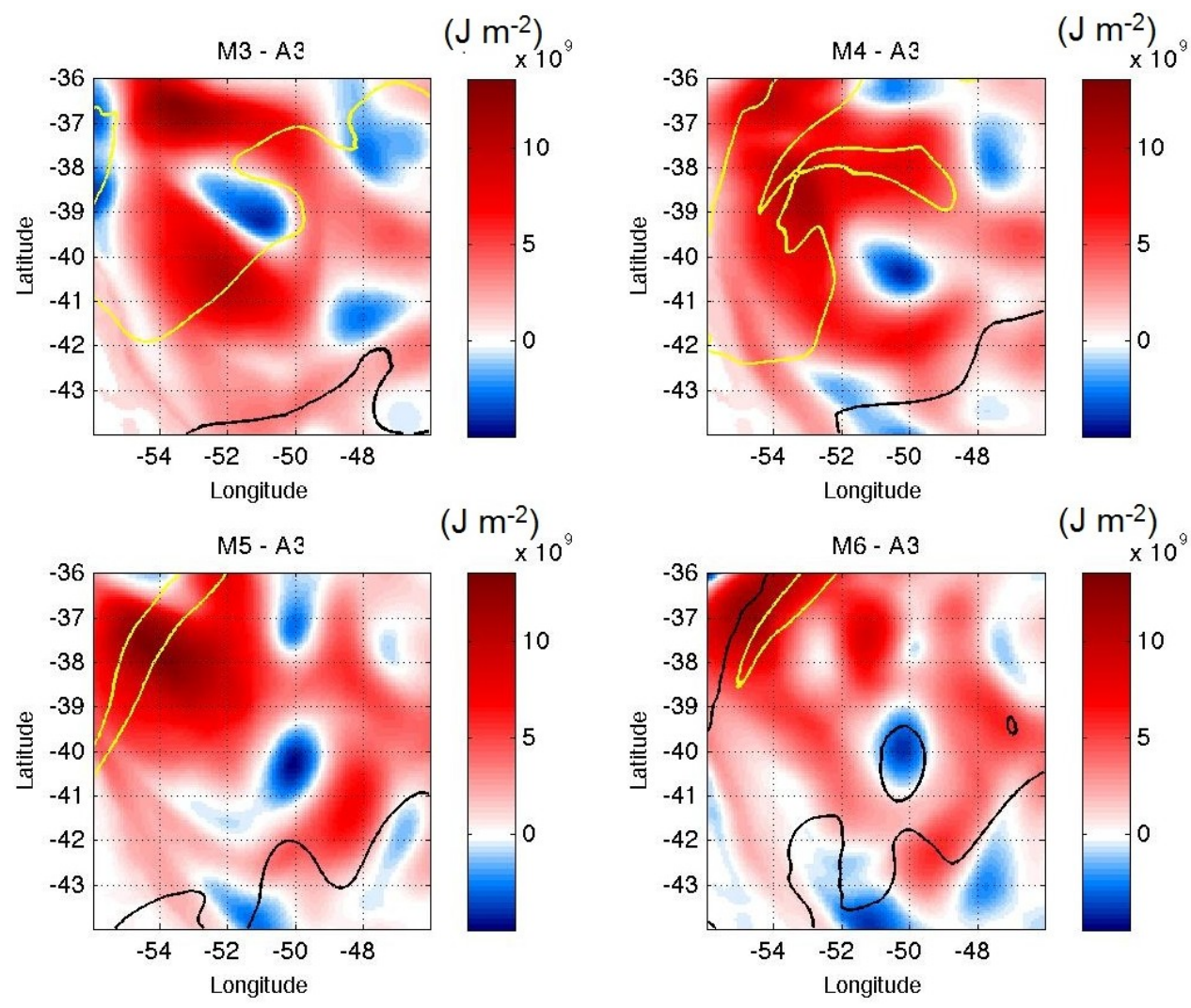

Figura 4.34: Calor armazenado $\left(C_{A}\right)$ integrado até $500 \mathrm{~m}\left(\mathrm{em} \mathrm{J} \mathrm{m}^{-2}\right)$ na subarea referente à CBM nos meses do período de pré-formação (março a junho) do terceiro ano da simulação. Os contornos das isotermas de $21^{\circ} \mathrm{C}$ (característica da FCB, amarelo) e $16^{\circ} \mathrm{C}$ (limite máximo da AMSTAS, preto) estão sobrepostos. 


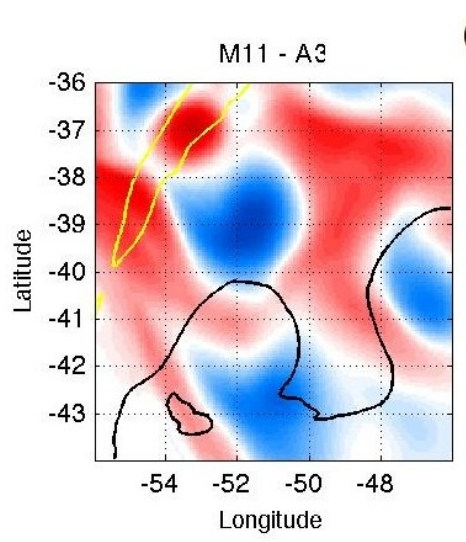

$\left(\mathrm{J} \mathrm{m}^{-2}\right) \underset{10^{10}}{ }$

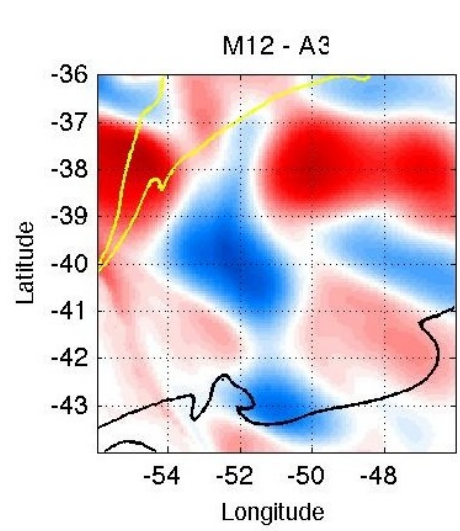

$\left(\mathrm{J} \mathrm{m}^{-2}\right)_{10}$
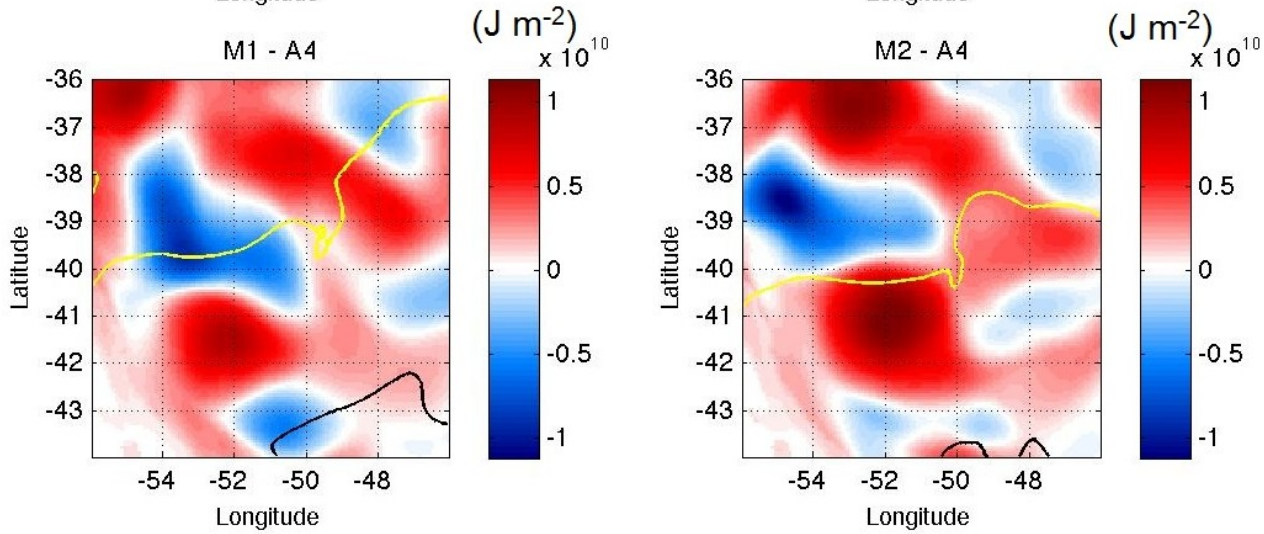

Figura 4.35: Similar à Figura 4.34 para os meses do período de pós-formação (novembro dezembro) do terceiro e (janeiro - fevereiro) quarto ano da simulação.

A ausência de um claro padrão na distribuição das áreas com valores negativos de $C_{A}$ e da isoterma de $16^{\circ} \mathrm{C}$ na região da CBM (Figura 4.36), embora essa seja uma região típica de formação de águas modais (conforme o observado nos mapas de incidência das Figuras 4.21 a 4.23 pode indicar que, nessa região para os dados de modelo, a participação de processos advectivos ou da dinâmica de Ekman na formação de AMSTAS é maior do que o observado na região do cruzeiro ao sul de $34^{\circ} \mathrm{S}$. Esses processos atuam na redistribuição do campo de temperatura da região. 

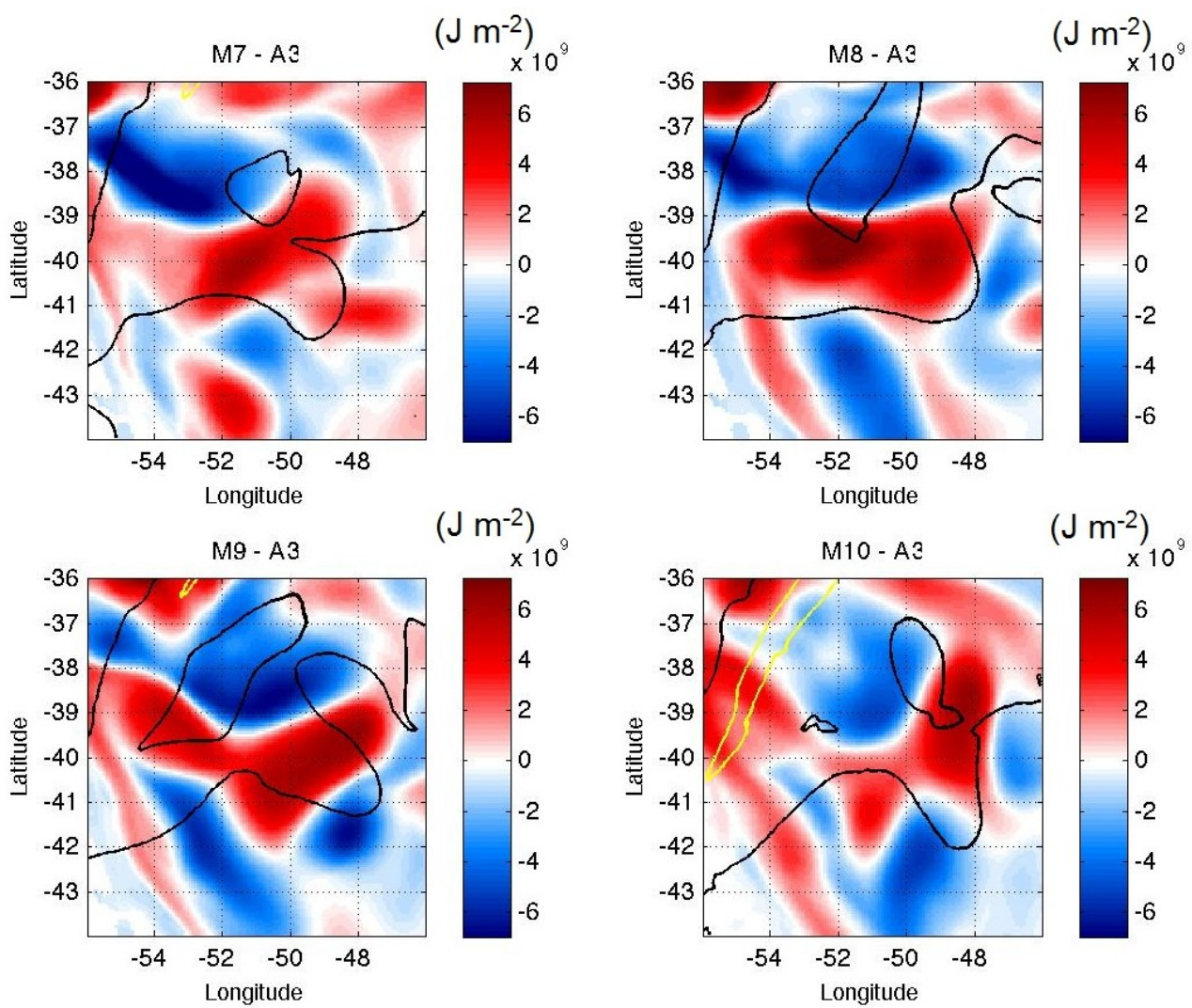

Figura 4.36: Similar à Figura 4.34 para os meses do período de formação (julho a outubro) do terceiro ano da simulação.

\subsection{Estudo dos Dados de Altímetro}

Para o estudo do calor armazenado $\left(C_{A}\right)$ foi empregada a mesma análise em duas subareas distintas utilizada na Seção 4.3 uma delas coincidente com os limites da área do cruzeiro (OCSUL) e adjacente à retroflexão da CB e a outra, de mesma dimensão, contendo a região de encontro da CB com a CM. Entretanto, foi utilizada a equação 3.29 para o cálculo de $C_{A}$ a partir dos dados de altímetro.

A série temporal da média mensal do calor armazenado para as duas subareas distintas (Figura 4.37), obtida dos dados do Projeto ATOBA, tem curta duração (de novembro de 2013 a novembro de 2015), entretanto apresentou claramente os diferentes aspectos das regiões analisadas. Os dados permitiram a análise inclusive de regiões com batimetria inferior a $1000 \mathrm{~m}$, possibilitando a observação de $C_{A}$ até mesmo sobre a Elevação do Rio Grande, contida na área do cruzeiro oceanográfico. 


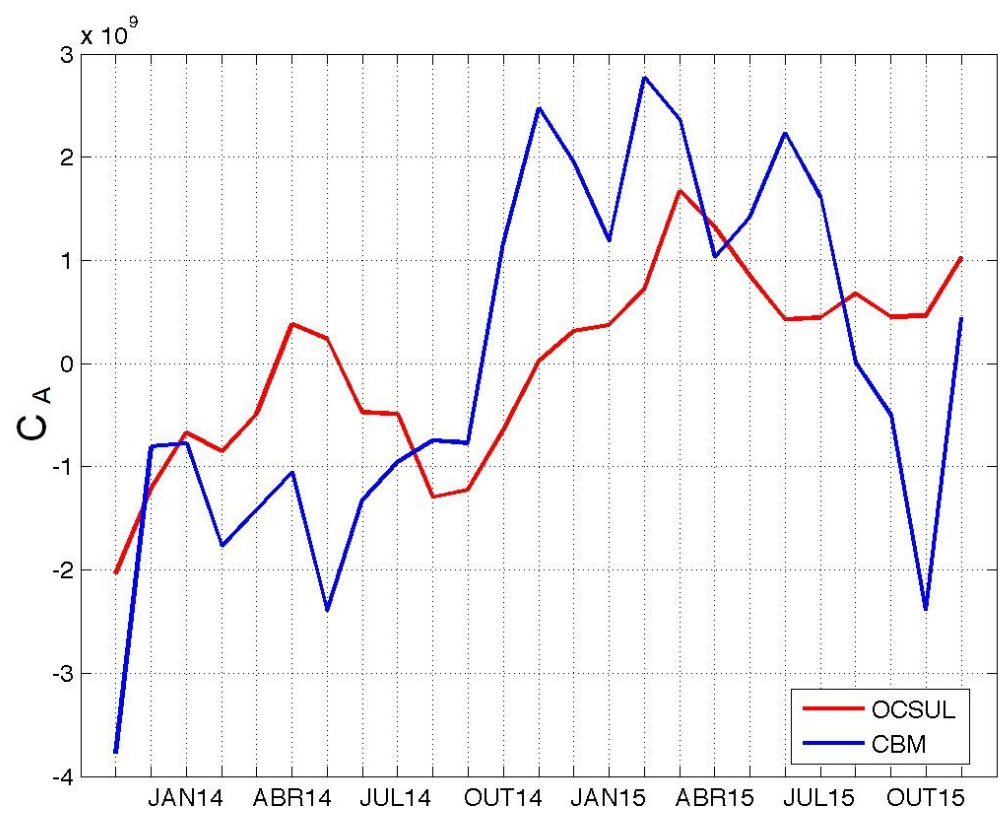

Figura 4.37: Calor armazenado $\left(C_{A}-\mathrm{J} \mathrm{m}^{-2}\right)$ dos dados de altímetro na subarea referente à CBM (azul) e para a região da OCSUL (vermelha).

A variabilidade da média mensal de $C_{A}$ é maior na região da $\mathrm{CBM}$, onde o ciclo sazonal não foi tão perceptível quanto na região da OCSUL. A mesma variabilidade foi observada na série temporal do $C_{A}$ calculado por meio dos dados de modelo oceânico para a região da CBM, conforme demonstrado na Figura 4.29. Nessa figura foi possível observar a ocorrência apenas de valores positivos de calor armazenado integrado até $500 \mathrm{~m}$ a partir do terceiro ano da simulação do modelo HYCOM 1, mesmo durante os períodos de formação de AMSTAS (julho a outubro), com magnitudes semelhantes às observadas nos dados de altímetro (Figura 4.37). O ciclo sazonal observado na Figura 4.37 para a região da OCSUL também foi constatado por meio dos dados do modelo HYCOM 1 (Figura 4.28). Entretanto, em todos os períodos de formação de AMSTAS da simulação do modelo HYCOM 1 foram verificados valores negativos de $C_{A}$ na região da OCSUL, o que não ocorreu entre os meses de julho e outubro de 2015 na série temporal da média mensal de $C_{A}$ calculada por meio dos dados de altímetro. Os mapas horizontais do calor armazenado para a região do cruzeiro oceanográfico apresentaram valores positivos (em média $30 \times 10^{8} \mathrm{~J} \mathrm{~m}^{-2}$ ) preponderantemente no período de préformação (meses de março a junho) e nos meses de dezembro a fevereiro (Figuras 4.38 e 4.39. 

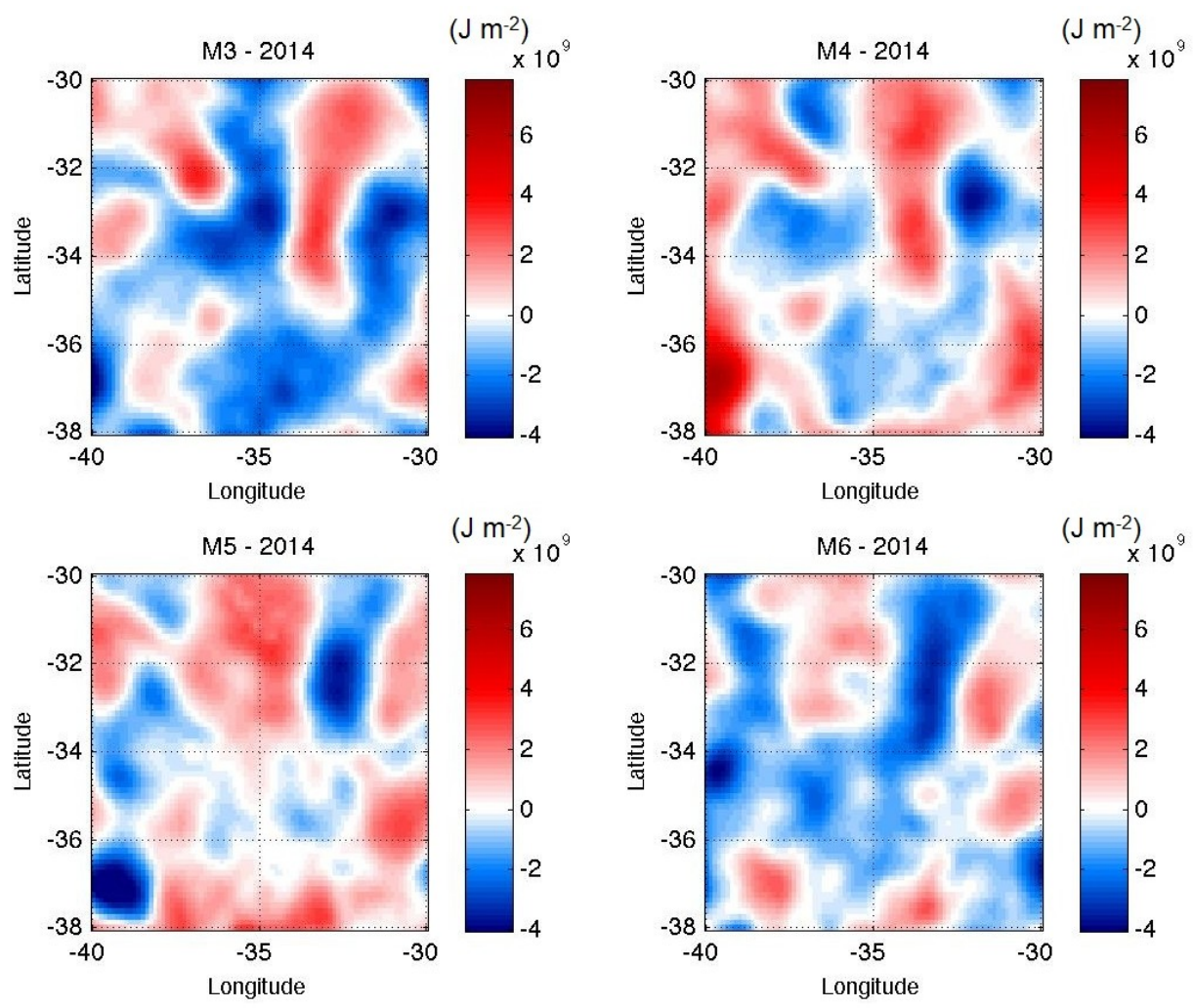

Figura 4.38: Calor armazenado $\left(C_{A}\right) \mathrm{em} \mathrm{J} \mathrm{m}^{-2}$, oriundo dos dados do Projeto ATOBA, para subarea referente ao cruzeiro oceanográfico nos meses do período de pré-formação (março a junho) de 2014.
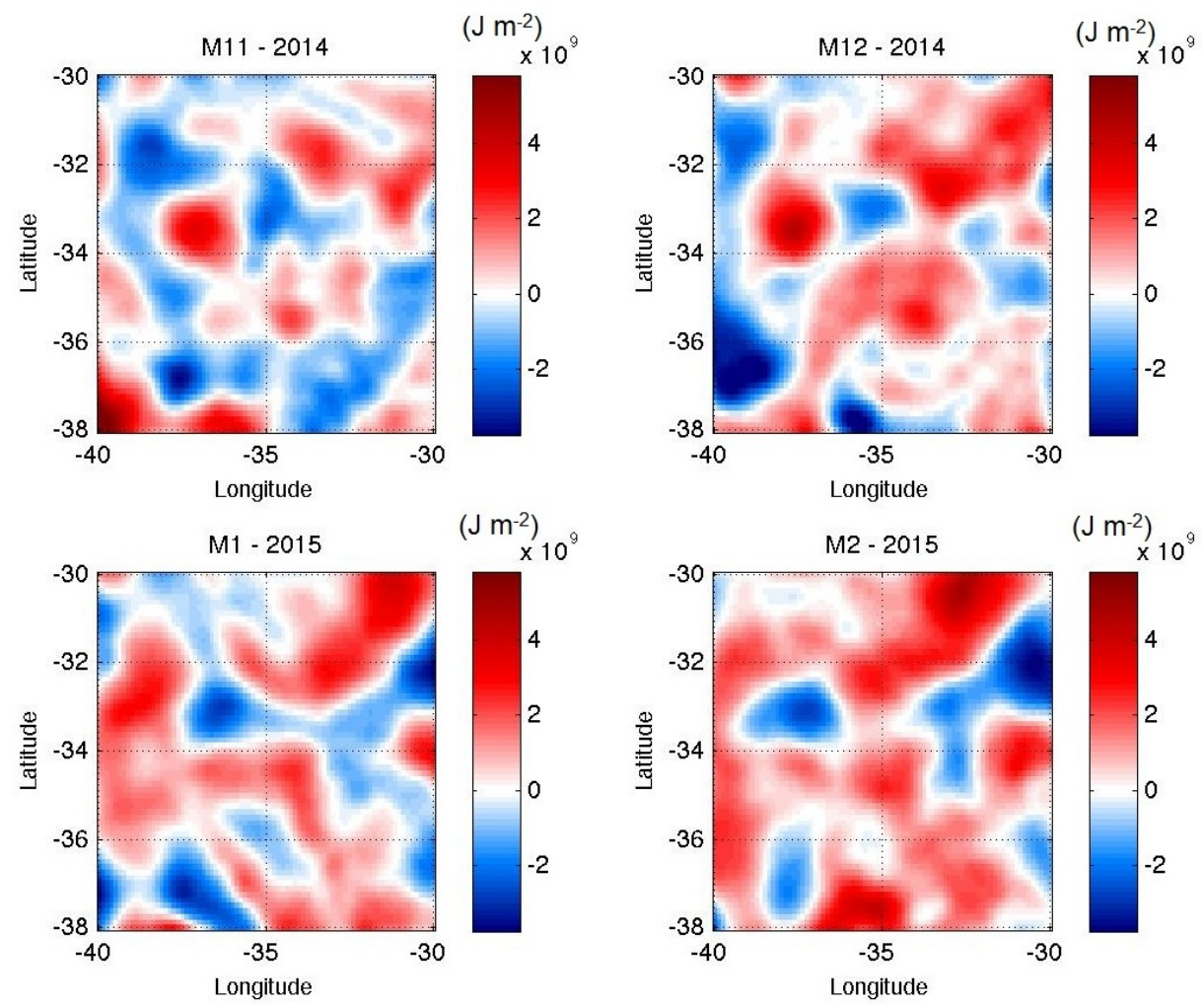

Figura 4.39: Similar à Figura 4.38 nos meses do período de pós-formação (novembro - dezembro) de 2014 e (janeiro - fevereiro) 2015. 
Durante o período de formação (julho a outubro) foi possível observar que a área ocupada por valores negativos de $C_{A}$ aumentou gradativamente, com máximo em setembro (Figura 4.40). Essa área denota aspecto favorável à formação de águas modais por processos convectivos e, semelhante aos dados de modelo oceânico descritos na Seção 4.3 , teve como limite norte a latitude de $\sim 34^{\circ} \mathrm{S}$.
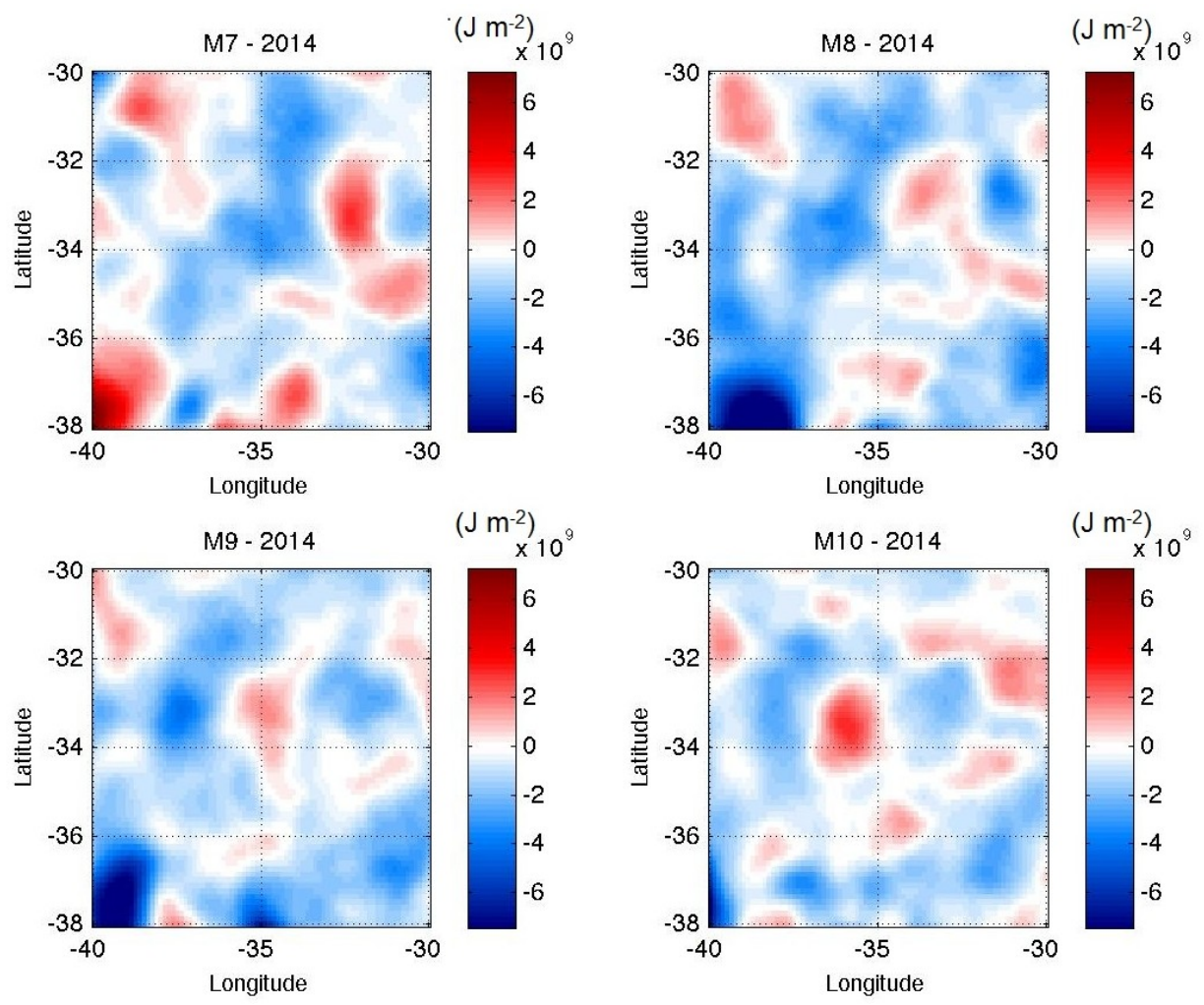

Figura 4.40: Similar à Figura 4.38 nos meses do período de formação (julho a outubro) de 2014.

Para a região da CBM, foi possível observar que o calor armazenado para os dados de altímetro apresentou máximos e mínimos com magnitudes em média duas vezes maiores que os valores obtidos na subarea correspondente ao cruzeiro oceanográfico. Da mesma forma que o verificado nos dados de modelo oceânico, nenhum padrão espacial de ocorrência das áreas com valores de $C_{A}$ negativos ou positivos pôde ser estabelecido. 

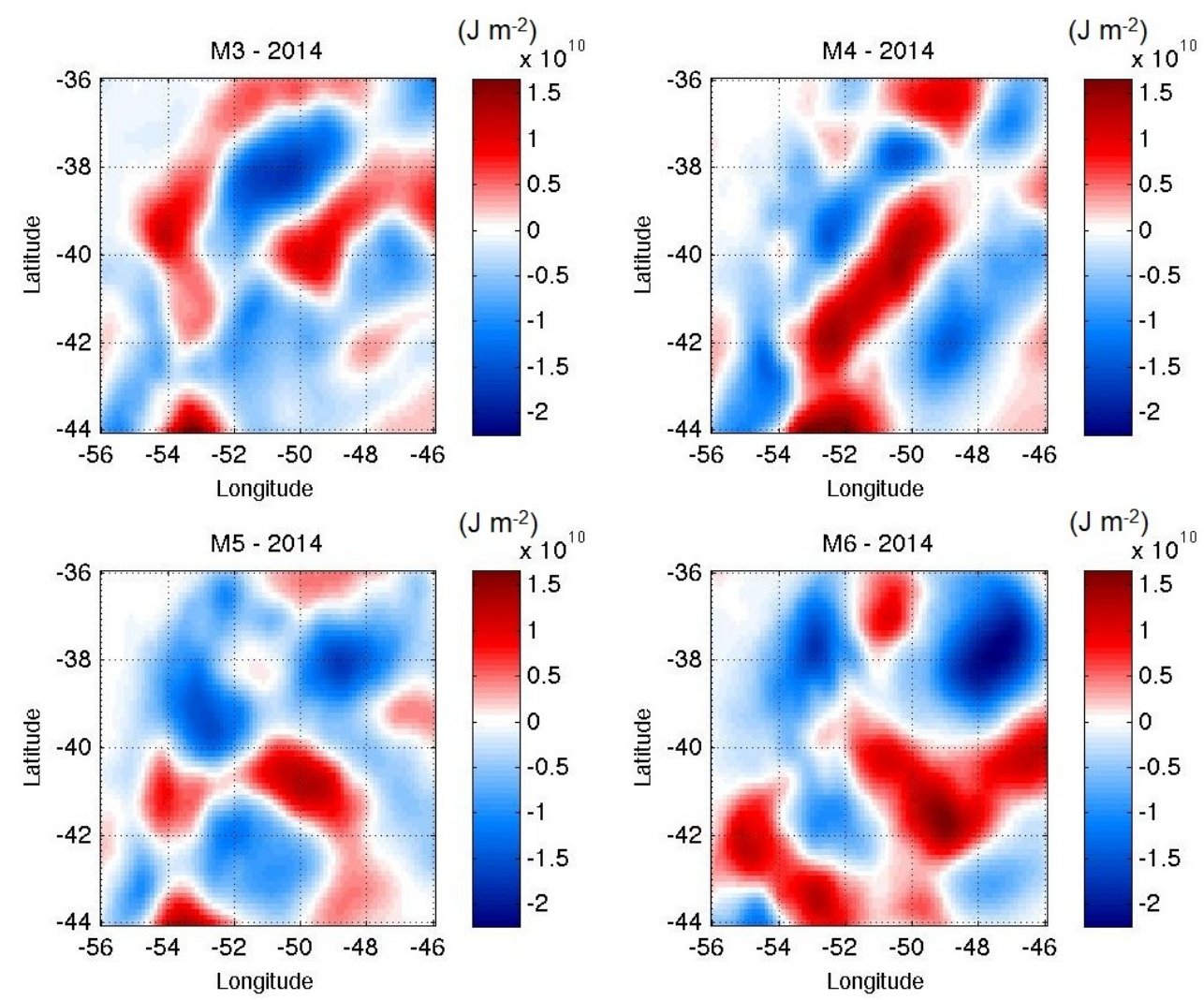

Figura 4.41: Calor armazenado $\left(C_{A}\right)$ em $\mathrm{J} \mathrm{m}^{-2}$, oriundo dos dados do Projeto ATOBA, para subarea referente à CBM nos meses do período de pré-formação (março a junho) de 2014.

Assim como fora observado nos dados de modelo oceânico, a maior variabilidade de $C_{A}$ na região da CBM é evidenciada nas Figuras 4.41 a 4.43 . A alta energia cinética turbulenta observada por Sato \& Polito [2014] no interior dessa subarea, e demonstrada na Figura 4.33, pode estar diretamente ligada com esse aspecto da região.

A ausência de um claro padrão na distribuição das áreas com valores negativos de $C_{A}$ na região da CBM (Figura 4.43) corrobora as observações advindas de modelo oceânico (Figura 4.36). 

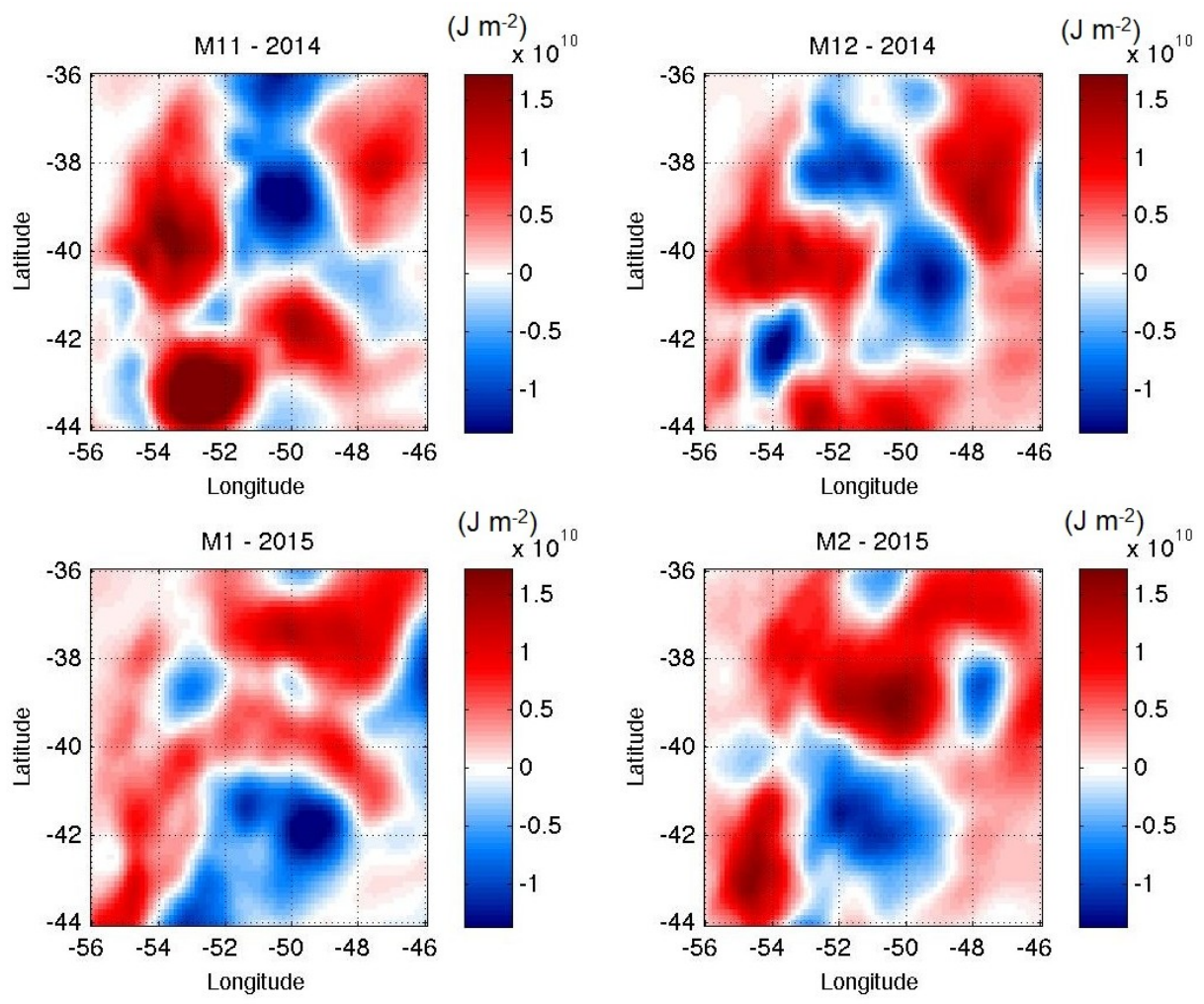

Figura 4.42: Similar à Figura 4.41 nos meses do período de pós-formação (novembro - dezembro) de 2014 e (janeiro - fevereiro) 2015.
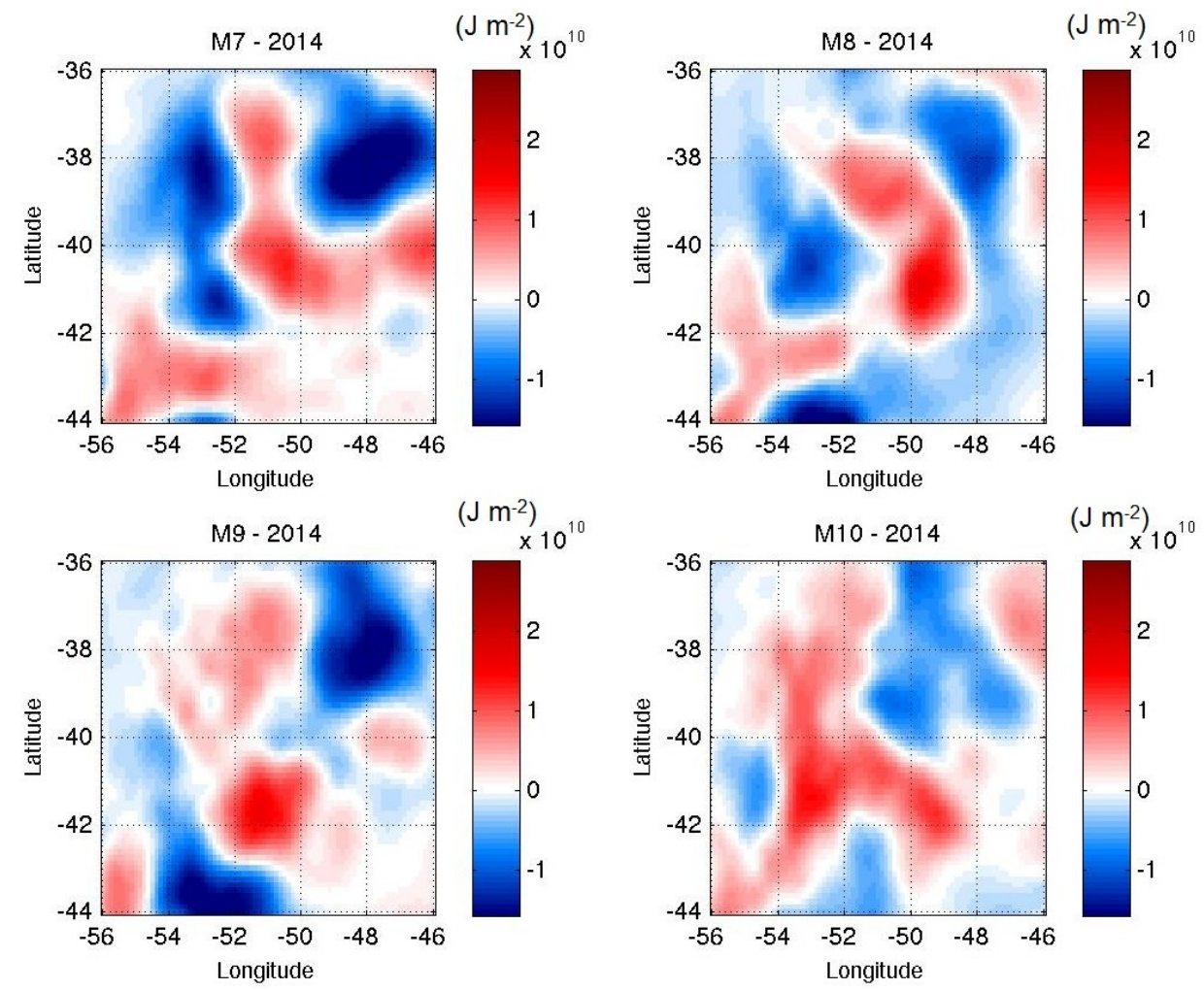

Figura 4.43: Similar à Figura 4.41 nos meses do período de formação (julho a outubro) de 2014. 


\section{Capítulo 5}

\section{Considerações Finais}

\subsection{Síntese e Conclusões}

O entendimento do ciclo de formação e dissipação das águas modais é fundamental devido ao importante papel que esse volume de água exerce como mediador das trocas de calor entre o oceano e a atmosfera. Tais trocas interferem diretamente no fortalecimento ou enfraquecimento de sistemas frontais atmosféricos [Rogers, 1995], além de evidenciarem as variações climáticas ocorridas tanto no oceano quanto na atmosfera ao longo do tempo [Hanawa \& Talley, 2001].

A região da Confluência Brasil-Malvinas (CBM) e da retroflexão da Corrente do Brasil (CB) apresenta intensa interação oceano-atmosfera devido principalmente a três fatores: o forte gradiente de temperatura que caracteriza a região, os ventos intensos de oeste e a frequente incidência de sistemas frontais sobretudo no inverno [Gordon. 1989]. É fundamental o conhecimento de sua variabilidade para a compreensão dos fenômenos oceânicos e atmosféricos no Atlântico Sudoeste. Pesquisas sobre essa região viabilizariam o aumento da acurácia dos modelos numéricos de previsão, como por exemplo, aqueles empregados pelo Centro de Hidrografia da Marinha (CHM).

Todavia, qualquer estudo de variabilidade é inócuo sem antes caracterizar de forma consistente as águas modais subtropicais, estabelecendo estimativas iniciais de distribuição espacial destas em área de caráter dinâmico e termodinâmico tão importante para o Atlântico Sudoeste, como a região da CBM e da retroflexão da CB.

De acordo com os objetivos estabelecidos, foi realizado o primeiro cruzeiro ocea- 
nográfico conduzido exclusivamente para o estudo de águas modais no Atlântico Sudoeste. Tal comissão permitiu avaliar a variação meridional da espessura da AMSTAS, por meio de mapas de distribuição horizontal dessa água modal e o acompanhamento da mesma com o emprego de séries temporais de dois perfiladores Argo lançados para este fim durante o cruzeiro oceanográfico. O emprego de modelos oceânicos permitiu realizar uma primeira estimativa de volume da AMSTAS na região da CBM e retroflexão da $\mathrm{CB}$, por meio de campos mensais de distribuição horizontal da espessura dessa água modal. No intuito de incrementar a análise dos padrões observados nos mapas mensais oriundos de modelo oceanográfico, foram construídos campos mensais de calor armazenado estimado por meio de dados de altímetro.

Sato \& Polito [2014] não observaram tendência significativa de alteração da densidade potencial da águas modais subtropicais no Atlântico Sul ao longo do período de 2002 a 2013. Tal fato denota a manutenção de estáveis parâmetros hidrográficos destas águas por longo tempo. Os autores observaram que a máxima espessura da camada de AMSTAS ocorre 80 dias antes da máxima energia cinética turbulenta (ECT). Com isso, um aumento da ECT poderia redundar na redução do volume de AMSTAS. No estudo aqui descrito, observamos que a maior dissipação do volume de AMSTAS recém formado ocorreu durante o verão austral (Figuras 4.19 e 4.20) na região coincidente com áreas de maior ECT (Figura 4.33). Os dados empregados no presente estudo permitiram ainda verificar que a AMSTAS detectada apresentou densidade potencial de $(26,45 \pm 0,06) \mathrm{kg} \mathrm{m}^{-3}$ para o volume afundado, ligeiramente maior que o valor de $(26,27 \pm 0,12) \mathrm{kg} \mathrm{m}^{-3}$ observado para o volume formado, corroborando portanto as observações anteriores de Sato \& Polito [2014].

Citamos, como principais observações advindas de nossos resultados:

- O ciclo sazonal da AMSTAS foi claramente observado em todos os conjuntos de dados empregados no presente estudo, com a formação de águas modais subtropicais ocorrendo em média de julho a outubro (inverno e ínicio da primavera austral);

- Os dados de CTD do cruzeiro oceanográfico permitiram observar a anisotropia da AMSTAS, com variação das profundidades mínima, máxima e espessura da camada variando com a latitude, conforme evidenciado nos mapas da Figura 4.2 . 
- A dominância da temperatura para detecção da camada de AMSTAS em relação à salinidade nos dados in situ indicam que os processos convectivos são dominantes para a formação de águas modais subtropicais na região do cruzeiro oceanográfico (retroflexão da CB);

- A data e a posição geográfica dos perfiladores Argo durante os períodos de formação de AMSTAS detectada sugerem que a formação de águas modais subtropicais no Atlântico Sudoeste se dá inicialmente à sudoeste da retroflexão da $\mathrm{CB}$, na região da $\mathrm{CBM}$, ocorrendo posteriormente em latitudes menores em direção ao interior da bacia, com limite norte da região de formação na latitude de $\sim 34^{\circ} \mathrm{S}$;

- A detecção eficaz de águas modais subtropicais por meio de modelos oceânicos só ocorre com a maior concentração de níveis isopicnais entre os limites de densidade potencial típicos das AMSTAS, não sendo determinante a realização de assimilação de dados ou o incremento da resolução horizontal e vertical dos modelos empregados;

- Os dados de modelo oceanográfico permitiram estimar um volume médio de AMSTAS na região da CBM e retroflexão da CB de $(3,49 \pm 0,12) \times 10^{14} \mathrm{~m}^{3}$ distribuído por uma área de $4,1 \times 10^{8} \mathrm{~m}^{2}$. Apenas $36,6 \%$ do volume total formado anualmente é afundado e adicionado à camada de AMSTAS que jazia afundada antes do período de formação, nos resultados do modelo oceanográfico do estudo;

- A maior dissipação da AMSTAS recém formada ocorre na região da CBM, à sudoeste da área de estudo, com maior intensidade nos meses de verão austral. Sugere-se que isso se deva a presença da CB nessa região e à ocorrência de vórtices e grande atividade de mesoescala.

- A tendência de aumento de volume de AMSTAS observada no modelo oceânico se deve à instabilidades na região da CBM, sendo possível observar a mesma tendência no calor armazenado para a referida região. Tal tendência não influencia o volume médio de AMSTAS afundada detectado no modelo e perpetuado a 
cada ciclo da água modal subtropical. Da mesma forma, o calor armazenado na região do cruzeiro oceanográfico, distante da CBM e adjacente à retroflexão da $\mathrm{CB}$, não apresenta essa tendência e sim um ciclo sazonal bem definido;

- Os mapas de incidência da AMSTAS detectada no modelo durante o período de formação indicam que na região do cruzeiro a formação se dá limitada ao norte pela latitude de $\sim 34^{\circ} \mathrm{S}$. Ao norte dessa latitude ocorre a presença apenas de AMSTAS afundada e formada em ciclos anteriores;

Por fim, podemos afirmar que o presente estudo permitiu verificar o aprofundamento da camada de AMSTAS e a variação de sua espessura na direção meridional a partir da área de formação, conforme proposto em nossa hipótese. Da mesma forma, foi possível observar que as áreas de formação detectadas por meio do modelo oceânico estavam associadas com regiões que apresentaram perda de calor armazenado calculado a partir dos dados de altímetro na região da OCSUL (proximidades da retroflexão da CB). Todavia, na região da CBM não foi possível identificar áreas com perda de calor armazenado associadas com as áreas de formação, tanto nos dados de altímetro quanto nos resultados do modelo oceânico.

\subsection{Sugestões para Trabalhos Futuros}

Os resultados apresentados no presente trabalho evidenciaram a intensa dinâmica de mesoescala inerente à região da $\mathrm{CBM}$ provocada, principalmente, pela instabilidade gerada pelo encontro de correntes de contorno oeste (CCO) tão díspares quanto a suas estruturas termohalinas.

O emprego de dados de modelo incrementa sobremaneira o estudo de áreas em que a distribuição espaço-temporal de dados in situ seja rarefeita, como a região do presente estudo. Entretanto, a coleta de dados in situ é essencial para o estudo acurado de regiões com intensa atividade de mesoescala, tais como a CBM. Dessa forma, a fim de associar com maior precisão os padrões dinâmicos aos padrões termodinâmicos observados nos resultados deste trabalho, apresentamos como sugestões para trabalhos futuros: 
- Realizar um número maior de coletas de dados de temperatura e salinidade in situ com emprego de equipamentos CTD, perfiladores lagrangeanos Argo e glidders na região da CBM, por meio de cruzeiros oceanográficos períodicos com coleta de dados meteorológicos simultânea durante os invernos a fim de permitir o estudo da contribuição da advecção de propriedades da CB para o processo de formação de AMSTAS nessa região;

- Empregar dados de modelo oceânico, com configuração específica que permita maior concentração de níveis isopicnais nos limites de densidade potencial típicos das águas modais subtropicais, por meio de recursos computacionais capazes de realizar simulações de longo tempo a fim de verificar a ocorrência de tendência de aumento do volume de AMSTAS e realizar o adequado estudo de variabilidade das mesmas;

- Adequar modelos oceanográficos operacionais já existentes, com adensamento de níveis isopicnais nos limites de densidade potencial específicos das águas modais subtropicais, a fim de permitir a realização de prognósticos da advecção e dissipação da AMSTAS detectada e auxiliar o emprego otimizado de sensores acústicos oceanográficos, tais como perfiladores de corrente por doppler acústico (ADCP) fundeados e ecobatímetros invertidos. 


\section{Referências Bibliográficas}

Anderson, D. L. T. \& A. E. Gill, 1975: Spin-up of a stratified ocean, with applications to upwelling. Deep-Sea Research, 22, 583-596.

Andersson, A. J., L. A. Krug, N. R. Bates, \& S. C. Doney, 2013: Sea-air $\mathrm{CO}_{2}$ flux in the North Atlantic subtropical gyre: Role and influence of Sub-Tropical Mode Water formation. Deep-Sea Research II, 91, 57-70.

Assireu, A., M. Stevenson, \& J. Stech, 2003: Surface circulation and kinetic energy in the SW Atlantic obtained by drifters. Continental Shelf Research, 23(2), 145-157.

Bates, N., A. C. Pequignet, R. J. Johnson, \& N. Gruber, 2002: A short-term sink for atmospheric $\mathrm{CO}_{2}$ in subtropical mode water of the North Atlantic Ocean. Nature, (420), 489-493.

Bleck, R., 2002: An Oceanic general circulation model framed in hybrid isopycnicCartesian coordinates. Ocean Modelling, 4, 55-88.

Böebel, O., R. E. Davis, M. Ollitraut, R. G. Peterson, P. L. Richard, C. Schmid, \& W. Zenk, 1999: The intermediate depth circulation of the Western South Atlantic. Geophysical Research Letters, 26(21), 3329-3332.

Bouali, M., O. T. Sato, \& P. S. Polito, 2016. No prelo: Temporal trends in sea surface temperature gradients in the South Atlantic Ocean. Remote Sensing of Environment.

Brandini, F. P., D. Boltovskoy, A. Piola, S. Kocmur, R. Röttgers, P. C. Abreu, \& R. M. Lopes, 2000: Multiannual trends in fronts and distribution of nutrients and chlorophyll in the southwestern Atlantic (30-62 ${ }^{\circ}$ S). Deep-Sea Research I, 47, 1015-1033. 
Campos, E. J. D., I. Ansoge, S. Dong, S. L. Garzoli, G. J. Goni, S. Majumder, C. S. Menen, A. R. Piola, C. Schmid, \& S. Speich, em fase de elaboração: Meridional Fluxes Across SAMBA from Model and Observations. Journal of Climate.

Campos, E. J. D. \& D. B. Olson, 1991: Stationary Rossby Waves in Western Boundary Current Extensions. Journal of Physical Oceanography, 21(8), 1202-1224.

Carrère, L., F. Lyard, M. Cancet, A. Guillot, \& L. Roblou, 2012: Fes2012: A new global tidal model taking advantage of nearly 20 years of altimetry. In: Proceedings of meeting, volume 20 .

Chambers, D. P., B. D. Tapley, \& R. H. Stewart, 1997: Long-period ocean heat storage rates and basin-scale heat fluxes from TOPEX. Journal of Geophysical Research, 102(10), $10,525-10,533$.

Chassignet, E. P., H. E. Hurlburt, O. M. Smedstad, G. R. Halliwell, P. J. Hogan, A. J. Wallcraft, R. Baraille, \& R. Bleck, 2007: The HYCOM (HYbrid Coordinate Ocean Model) data assimilative system. Journal of Marine Systems, 65, 60-83.

Chassignet, E. P., L. T. Smith, G. R. Halliwell, \& R. Bleck, 2003: North Atlantic simulations with the HYbrid Coordinate Ocean Model (HYCOM): impact of the vertical coordinate choice, reference density, and thermobaricity. Journal of Physical Oceanography, 33, 2504-2526.

Chelton, D. B., M. G. Schlax, \& R. M. Samelson, 2011: Global observations of nonlinear mesoscale eddies. Progress in Oceanography, 91(2), 167-216.

Chelton, D. B., M. G. Schlax, D. L. Witter, \& J. G. Richman, 1990: Geosat Altimeter Observations of the Surface Circulation of the Southern Ocean. Journal of Geophysical Research, 95, 17.877-17.903.

Conkright, M. E., R. A. Locarnini, H. E. Garcia, T. D. OB́rien, T. P. Boyer, C. Stephens, \& J. I. Antonov, 2002: World Ocean Atlas 2001: Objective Analyses, Data Statistics, and Figures. National Oceanographic Data Center, Silver Spring, cd-rom documentation edição, 17 pp. 
Cooper, M. \& K. Haines, 1996: Altimetric assimilation with water property conservation. Journal of Geophysical Research: Oceans, 101(C1), 1059-1077.

Cushman-Roisin, B., 1994: Introduction to Geophysical Fluid Dynamics. Prentice-Hall Inc., New Jersey, 320 pp.

Davis, X. J., F. Straneo, Y.-O. Kwon, K. A. Kelly, \& J. M. Toole, 2013: Evolution and formation of North Atlantic Eighteen Degree Water in the Sargasso Sea from moored data. Deep-Sea Research II, 91, 11-24.

de Boyer Montegut, C., J. Mignot, A. Lazar, \& S. Cravatte, 2007: Control of salinity on the mixed layer depth in the world ocean: 1. General description. Journal of Geophysical Research, 112, C06.011.

Douglass, E. M., S. R. Jayne, S. Peacock, F. O. Bryan, \& M. E. Maltrud, 2012: Subtropical Mode Water Variability in a Climatologically Forced Model in the Northwestern Pacific Ocean. Journal of Physical Oceanography, 42, 126-140.

Douglass, E. M., Y.-O. Kwon, \& S. R. Jayne, 2013: A comparison of North Pacific and North Atlantic subtropical mode waters in a climatologically-forced model. Deep-Sea Research II, 91, 139-151.

Ducet, N., P. Y. L. Traon, \& G. Reverdin, 2000: Global high resolution mapping of ocean circulation from the combination of TOPEX/Poseidon and ERS-1/2. Journal of Geophysical Research, 105(C8), 19.477-19.498.

Emery, W. J. \& R. E. Thomson, 1998: Data analysis methods in physical oceanography. Pergamon, Great Britain, 634 pp.

Ferreira, M. B., V. J. Barroso, O. T. Sato, C. E. P. Ribeiro, P. S. Bernardo, \& P. S. Polito, 2015: Propagação Acústica na Água Modal Subtropical do Atlântico Sul. Anais Hidrográficos, LXXII, 126-140.

Fofonoff, N. P. \& R. C. J. Millard, 1983: Algorithms for Computation of Fundamental Properties of Seawater. Endorsed by Unesco/SCOR/ICES/IAPSO Joint Panel on Oceanographic Tables and Standards and SCOR Working Group 51. UNESCO technical papers in marine science, (44), 58. 
Forget, G., G. Maze, M. Buckley, \& J. Marshall, 2011: Estimated seasonal cycle of North Atlantic Eighteen Degree Water Volume. Journal of Physical Oceanography, 41(2), 269286.

Fox, D. N., W. J. Teague, C. N. Barron, M. R. Carnes, \& C. M. Lee, 2002: The Modular Ocean Data Assimilation System (MODAS). Journal of Atmospheric and Oceanic Technology, 19(2), 240-252.

Fratantoni, D. M., Y.-O. Kwon, \& B. A. Hodges, 2013: Direct observation of subtropical mode water circulation in the western North Atlantic Ocean. Deep-Sea Research II, $91,35-56$.

Gaillard, F., E. Brion, \& R. Charraudeau, 2009: ISAS-V5: Description of the Method and User Manual. Institut Français de Recherche pour L'exploitation de La Mer, Plouzané, rapport lpo 09-04 edição, 34 pp.

Garzoli, S. L. \& Z. Garrafo, 1989: Transports, frontal motions and eddies at the Brazil Malvinas currents confluence. Deep-Sea Research, 36(5), 681-703.

Gill, A. E. \& P. P. Niiler, 1973: The theory of the seasonal variability in the ocean. Deep Sea Research and Oceanographic Abstracts, 20(2), 141-177.

Gong, X. \& M. B. Richman, 1995: On the application of cluster analysis to growing season precipitation data in North America east of the Rockies. Journal of Climate, 8(4), 897-931.

Goni, G. J., F. Bringas, \& P. N. DiNezio, 2011: Observed low frequency variability of the Brazil Current front. Journal of Geophysical Research: Oceans, 116(C10037), doi:10.1029/2011JC007.198.

Goni, G. J., S. Kamholz, S. Garzoli, \& D. B. Olson, 1996: Dynamics of the Brazil - Malvinas Confluence based on inverted echo sounders and altimetry. Journal of Geophysical Research, 101(C7), 16.273-16.289.

Goni, G. J. \& I. Wainer, 2001: Investigation of the Brazil Current front variability from altimeter data. Journal of Geophysical Research, 106(C12), 31,117-31,128. 
Gordon, A. L., 1981: South Atlantic thermocline ventilation. Deep-Sea Research, 28, 1239-1264.

Gordon, A. L., 1989: Brazil-Malvinas Confluence - 1984. Deep-Sea Research, 36(3), 359384.

Gould, W. J., 2005: From Swallow floats to Argo - the development of neutrally buoyant floats. Deep-Sea Research II, 52, 529-543.

Gruber, N., C. D. Keeling, \& N. R. Bates, 2002: Interannual variability in the North Atlantic Ocean Carbon Sink. Science, 298, 2374-2378.

Halliwell, G., 2004: Evaluation of vertical coordinate and vertical mixing algorithms in the HYbrid Coordinate Ocean Model (HYCOM). Ocean Modelling, 7, 285-322.

Hanawa, K. \& L. Talley, 2001: Mode waters. In: Ocean Circulation and Climate: Observing and Modelling the Global Ocean, International Geophysics Series. Academic Press, London, 373-386.

Holte, J. \& L. Talley, 2009: A New Algorithm for Finding Mixed Layer Depths with Applications to Argo Data and Subantarctic Mode Water Formation. Journal of Atmospheric and Oceanic Technology, 26(9), 1920-1939.

Jenkins, W. J., 1987: ${ }^{3} \mathrm{H}$ and ${ }^{3} \mathrm{He}$ in the Beta Triangle: Observations of Gyre Ventilation and Oxygen Utilization Rates. Journal of Physical Oceanography, 17, 763-783.

Jenkins, W. J., 1998: Studying subtropical thermocline ventilation and circulation using tritium and ${ }^{3}$ He. Journal of Geophysical Research, 103, 15.817-15.831.

Kelly, K. A. \& S. Dong, 2013: The contributions of atmosphere and ocean to North Atlantic Subtropical Mode Water volume anomalies. Deep-Sea Research II, 91, 111127.

Kistler, R., E. Kalnay, W. Collins, S. Saha, G. White, J. Woollen, M. Chelliah, W. Ebisuzaki, M. Kanamitsu, V. Kousky, H. V. D. Dool, R. Jenne, \& M. Fiorino, 2001: The NCEP-NCAR 50-Year Reanalysis: Monthly means CD-ROM and documentation. Bulletin of the American Meteorological Society, 82, 247-267. 
Klein, B. \& N. Hogg, 1996: On the variability of 18 Degree Water formation as observed from moored instruments at 55 $5^{\circ}$. Deep-Sea Research I, 43(1-12), 1777-1806.

Kundu, P. K., 1990: Fluid Mechanics. Academic Press, Inc., San Diego, California, 638 pp.

Kwon, Y.-O. \& S. C. Riser, 2004: North Atlantic subtropical mode water: A history of ocean-atmosphere interaction 1961-2000. Geophysical Research Letters, 31, L19.307.

Large, W. G. \& S. G. Yeager, 2009: The global climatology of an interannually varying air-sea flux data set. Climate Dynamics, 33, 341-364.

Lentini, C. A. D., G. J. Goni, \& D. B. Olson, 2006: Investigation of Brazil Current rings in the confluence region. Journal of Geophysical Research: Oceans, 111(C06013), doi:10.1029/2005JC002.988.

Levine, N., S. C. Doney, I. Lima, R. Wanninkhof, N. R. Bates, \& R. A. Feely, 2011: The impact of the North Atlantic Oscillation on the uptake and accumulation of anthropogenic $\mathrm{CO}_{2}$ by North Atlantic ocean mode waters. Global Biogeochemical Cycles, 25(3), GB3022.

Levitus, S., J. I. Antonov, T. P. Boyer, O. K. Baranova, H. E. Garcia, R. A. Locarnini, A. V. Mishonov, J. R. Reagan, D. Seidov, E. S. Yarosh, \& M. M. Zweng, 2012: World ocean heat content and thermosteric sea level change (0-2000 m), 1955-2010. Geophysical Research Letters, 39(L10603), doi:10.1029/2012GL051.106.

Locarnini, R. A., A. V. Mishonov, J. I. Antonov, T. P. Boyer, H. E. Garcia, O. K. Baranova, M. M. Zweng, C. R. Paver, J. R. Reagan, D. R. Johnson, M. Hamilton, \& D. Seidov, 2013: World Ocean Atlas 2013, Volume 1: Temperature. NOAA Atlas NESDIS 73, Silver Spring, $40 \mathrm{pp}$.

Lévy, M., 2005: Nutrients in remote mode. Nature, 437, 628-631.

Marshall, J., A. Andersson, N. Bates, W. Dewar, S. Doney, J. Edson, R. Ferrari, G. Forget, D. Fratantoni, M. Gregg, J. T., K. Kelly, S. Lozier, R. Lumpkin, G. Maze, J. Palter, R. Samelson, K. Silverthorne, E. Skyllingstad, F. Straneo, L. Talley, L.Thomas, J. Toole, \& R. Weller, 2009: The CLIMODE field campaign: observing the cycle of convection 
and restratification over the Gulf Stream. Bulletin of the American Meteorological Society, 90, 1337-1350.

Masuzawa, J., 1969: Subtropical Mode Water. Deep-Sea Research, 16, 463-472.

Maze, G., J. Deshayes, J. Marshall, A.-M. Tréguier, A. Chronis, \& L. Vollmer, 2013: Surface vertical PV fluxes and subtropical mode water formation in an eddy-resolving numerical simulation. Deep-Sea Research II, 91, 128-138.

Maze, G., G. Forget, M. Buckley, J. Marshall, \& I. Cerovecki, 2009: Using transformation and formation maps to study the role of air-sea heat fluxes in north atlantic eighteen degree water formation. Journal of Physical Oceanography, 39(8), 1818-1835.

McCartney, M. S., 1982: The subtropical recirculation of Mode Waters. Journal of Marine Research, 40(Supplement), 427-464.

McGillicuddy, D. J., L. A. Anderson, N. R. Bates, T. Bibby, K. O. Buesseler, C. A. Carlson, C. S. Davis, C. Ewart, P. G. Falkowski, S. A. Goldthwait, D. A. Hansell, W. J. Jenkins, R. Johnson, V. K. Kosnyrev, J. R. Ledwell, Q. P. Li, D. A. Siegel, \& D. K. Steinberg, 2007: Eddy/Wind Interactions Stimulate Extraordinary Mid-Ocean Plankton Blooms. Science, 316, 1021-1026.

Miranda, L. B., B. M. Castro, \& B. Kjerfve, 2002: Princípios de Oceanografia Física de Estuários. Editora da Universidade de São Paulo, São Paulo, 424 pp.

Molinari, R., 1982: Observations of eastward currents in the tropical South Atlantic Ocean: 1978-1980. Journal of Geophysical Research, 87, 9707-9714.

Müller, P., 1995: Ertel's potential vorticity theorem in physical oceanography. Reviews of Geophysics, 33(1), 67-97.

Olsina, O., N. Wienders, \& W. K. Dewar, 2013: An estimate of the climatology and variability of Eighteen Degree Water potential vorticity forcing. Deep-Sea Research II, 91, 84-95.

Olson, D. B., G. P. Podesta, R. H. Evans, \& O. B. Brown, 1988: Temporal variations in the separation of Brazil and Malvinas Currents. Deep-Sea Research, 35(12), 1971-1990. 
Palter, J., M. S. Lozier, \& R. T. Barber, 2005: The effect of advection on the nutrient reservoir in the North Atlantic subtropical gyre. Nature, 437, 687-692.

Pedlosky, J., 1987: Geophysical Fluid Dynamics. Springer, Berlin, 2 edição, 710 pp.

Peterson, R. G. \& L. Stramma, 1991: Upper-level Circulation in the South Atlantic Ocean. Progress In Oceanography, 26, 1-73.

Piola, A. R. \& R. P. Matano, 2001: Brazil and falklands (malvinas) currents. In: Encyclopedia of Ocean Sciences, J. H. Steele (editor). Academic Press, Oxford, 340-349.

Piola, A. R., O. O. Möller, R. A. Guerrero, \& E. J. D. Campos, 2008: Variability of the subtropical shelf front off eastern South America: Winter 2003 and summer 2004. Continental Shelf Research, 28, 1639-1648.

Polito, P. S., O. T. Sato, \& W. T. Liu, 2000: Characterization and validation of the heat storage variability from TOPEX/Poseidon at four oceanographic sites. Journal of Geophysical Research, 105(C7), 16.911-16.921.

Pond, S. \& G. L. Pickard, 1991: Introductory dynamical oceanography. Oxford, 2 edição, 349 pp.

Provost, C., C. Escoffier, K. Maamaatauiahutapu, A. Kartavtseff, \& V. Garçon, 1999: Subtropical mode waters in the South Atlantic Ocean. Journal of Geophysical Research, 104(C9), 21.033-21.049.

Provost, C., S. Gana, V. Garçon, K. Maamaatauiahutapu, \& M. England, 1995: Hydrographic conditions in the Brazil-Malvinas Confluence during austral summer 1990. Journal of Geophysical Research, 100(C6), 10,655-10,678.

Provost, C., O. Garcia, \& V. Garçon, 1992: Analysis of Satellite Sea Surface Temperature Time Series in the Brazil - Malvinas Current Confluence Region: Dominance of the Annual and Semiannual Periods. Journal of Geophysical Research, 97(C11), 17.84117.858.

Qiu, B. \& S. Chen, 2006: Decadal Variability in the Formation of the North Pacific Subtropical Mode Water: Oceanic versus Atmospheric Control. Journal of Physical Oceanography, 36, 1365-1380. 
Qiu, B., P. Hacker, S. Chen, K. A. Donohue, D. R. Watts, H. Mitsudera, N. G. Hogg, \& S. R. Jayne, 2006: Observations of the Subtropical Mode Water Evolution from the Kuroshio Extension System Study. Journal of Physical Oceanography, 36, 457-473.

Qiu, B. \& W. Miao, 2000: Kuroshio Path Variations South of Japan: Bimodality as a Self-Sustained Internal Oscillation. Journal of Physical Oceanography, 30, 2124-2137.

Rainville, L., S. Jayne, J. McClean, \& M. Maltrud, 2007: Formation of subtropical mode water in a high-resolution ocean simulation of the Kuroshio Extension region. Ocean Modelling, 17, 338-356.

Robinson, I. S., 2004: Measuring the Oceans from Space: The Principles and Methods of Satellite Oceanography. Springer, Chichester, 669 pp.

Roden, G. I., 1986: Thermohaline fronts and baroclinic flow in the Argentine Basin during the austral spring of 1984. Journal of Geophysical Research, 91, 5075-5093.

Roden, G. I., 1989: The vertical thermohaline structure in the Argentine Basin. Journal of Geophysical Research, 94, 877-896.

Rodríguez, O. C., 2011: The TRACEO Ray Tracing Program. SiPLAB/FCT/Universidade do Algarve, $69 \mathrm{pp}$.

Rogers, D. P., 1995: Air sea Interation: Connecting the Ocean and Atmosphere. Reviews of Geophysics, 33, 1377-1383.

Sato, O. T., 2009: Fluxo de calor oceânico medido por satélites. In: Oceanografia por Satélites, R. B. Souza (editor). Oficina de Textos, São Paulo, 2 edição, 165-184.

Sato, O. T. \& P. S. Polito, 2014: Observation of South Atlantic subtropical mode waters with Argo profiling float data. Journal of Geophysical Research, 119, doi:10.1002/ 2013JC009.438.

Schubert, W., E. Ruprecht, R. Hertenstein, R. N. Ferreira, R. Taft, C. Rozoff, P. Ciesielski, \& H.-C. Kuo, 2004: English translations of twenty-one of Ertel's papers on geophysical fluid dynamics. Meteorologische Zeitschrift, 13(6), 527-576. 
Silveira, I. C. A., G. R. Flierl, \& W. S. Brown, 1999: Dynamics of Separating Western Boundary Currents. Journal of Physical Oceanography, 29(2), 119-144.

Silverthorne, K. E. \& J. M. Toole, 2013: Quasi-Lagrangian observations of the upper ocean response to wintertime forcing in the Gulf Stream. Deep-Sea Research II, 91, 25-34.

Smith, L. T., E. P. Chassignet, \& D. B. Olson, 1994: Wind-forced variations in the Brazil - Malvinas confluence region as simulated in a coarse resolution numerical model of the South Atlantic. Journal of Geophysical Research, 99(C3), 5095-5117.

Smith, W. H. F. \& D. T. Sandwell, 1997: Global sea floor topography from satellite altimetry and ship depth soundings. Science, 277, 1956-1962.

Stommel, H., 1948: The westward intensification of wind-driven ocean currents. Transactions American Geophysical Union, 29, 202-206.

Stramma, L., 1991: Geostrophic Transport of the South Equatorial Current in the Atlantic. Journal of Marine Research, 49(2), 281 - 294.

Stramma, L. \& M. England, 1999: On the water masses and mean circulation of the South Atlantic Ocean. Journal of Geophysical Research, 104(C9), 20.863-20.883.

Stramma, L. \& R. G. Peterson, 1990: The South Atlantic Current. Journal of Physical Oceanography, 20, 846-859.

Suga, T., Y. Aoki, H. Saito, \& K. Hanawa, 2008: Ventilation of the North Pacific subtropical pycnocline and mode water formation. Progress in Oceanography, 77, 285-297.

Suga, T. \& K. Hanawa, 1995: The Subtropical Mode Water Circulation in the North Pacific. Journal of Physical Oceanography, 25, 958-970.

Suga, T., K. Hanawa, \& Y. Toba, 1989: Subtropical Mode Water in the $137^{\circ}$ E Section. Journal of Physical Oceanography, 19, 1605-1618.

Sverdrup, H. U., 1947: Wind-driven currents in a baroclinic ocean; with application to the equatorial currents off the eastern Pacific. Proceedings of the National Academy of Sciences of the United States of America, 33, 318-336. 
Talley, L., 1988: Potential Vorticity Distribution in the North Pacific. Journal of Physical Oceanography, 18, 89-106.

Talley, L. D. \& M. E. Raymet, 1982: Eighteen Degree Water variability. Journal of Marine Research, 40(Supplement), 757-775.

Tomczak, M. \& J. S. Godfrey, 1994: Regional oceanography: an introduction. Pergamon, Great Britain, 422 pp.

Tsuchiya, M., L. D. Talley, \& M. S. McCartney, 1994: Water-mass distributions in the western South Atlantic; A section form South Georgia Island (54S) northward across the equator. Journal of Marine Research, 52(1), 55-81.

Vivier, F. \& C. Provost, 1999: Volume transport of the Malvinas Current: Can the flow be monitored by TOPEX/POSEIDON? Journal of Geophysical Research, 104(C9), 21.105-21.122.

Whitworth, T. \& W. D. Nowlin, 1987: Water masses and currents of the Southern Ocean at the Greenwich Meridian. Journal of Geophysical Research: Oceans, 92(C6), 2156-2202.

Worthington, L. V., 1959: The $18^{\circ} \mathrm{C}$ water in the Sargasso Sea. Deep-Sea Research, 5, 297-305.

Worthington, L. V., 1972: Negative Oceanic Heat Flux as a Cause of Water-Mass Formation. Journal of Physical Oceanography, 2(3), 205-211.

Yan, X.-H., P. P. Niiler, S. K. Nadiga, R. H. Stewart, \& D. R. Cayan, 1995: Seasonal heat storage in the North Pacific: 1976-1989. Journal of Geophysical Research: Oceans, 100(C4), 6899-6926.

Yu, L., X. Jin, \& R. A. Weller, 2008: Multidecade Global Flux Datasets from the Objectively Analyzed Air-sea Fluxes (OAFlux) Project: Latent and sensible heat fluxes, ocean evaporation, and related surface meteorological variables. Vol. OA-2008-01, Woods Hole Oceanographic Institution, Massachusetts, 64 pp.

Zweng, M. M., J. R. Reagan, J. I. Antonov, R. A. Locarnini, T. P. Boyer, H. E. Garcia, O. K. Baranova, D. R. Johnson, D. Seidov, \& M. M. Biddle, 2013: World Ocean Atlas 2013, Volume 2: Salinity. NOAA Atlas NESDIS 74, Silver Spring, 39 pp. 